Florida International University FIU Digital Commons

FIU Electronic Theses and Dissertations

University Graduate School

10-10-2014

\title{
Optimization of Cooling Protocols for Hearts Destined for Transplantation
}

\author{
Abas Abdoli \\ aabdo004@fiu.edu
}

DOI: $10.25148 /$ etd.FI14110707

Follow this and additional works at: https://digitalcommons.fiu.edu/etd

Part of the Biochemical Phenomena, Metabolism, and Nutrition Commons, Biomedical Engineering and Bioengineering Commons, Computational Engineering Commons, and the Heat Transfer, Combustion Commons

\section{Recommended Citation}

Abdoli, Abas, "Optimization of Cooling Protocols for Hearts Destined for Transplantation" (2014). FIU Electronic Theses and Dissertations. 1579.

https://digitalcommons.fiu.edu/etd/1579

This work is brought to you for free and open access by the University Graduate School at FIU Digital Commons. It has been accepted for inclusion in FIU Electronic Theses and Dissertations by an authorized administrator of FIU Digital Commons. For more information, please contact dcc@fiu.edu. 


\title{
FLORIDA INTERNATIONAL UNIVERSITY
}

Miami, Florida

\section{OPTIMIZATION OF COOLING PROTOCOLS FOR HEARTS DESTINED FOR TRANSPLANTATION}

\author{
A dissertation submitted in partial fulfillment of the \\ requirements for the degree of \\ DOCTOR OF PHILOSOPHY \\ in \\ MECHANICAL ENGINEERING \\ by
}

Abas Abdoli

2014 
To: Dean Amir Mirmiran

College of Engineering and Computing

This dissertation, written by Abas Abdoli, and entitled Optimization of Cooling Protocols for Hearts Destined for Transplantation, having been approved in respect to style and intellectual content, is referred to you for judgment.

We have read this dissertation and recommend that it be approved.

$\begin{array}{r}\hline \text { Chandrajit L. Bajaj } \\ \hline \text { Brian H. Dennis } \\ \hline \text { Cheng-Xian (Charlie) Lin } \\ \hline \text { David F. Stowe } \\ \hline \text { Nikolaos Tsoukias } \\ \hline \text { Igor Tsukanov } \\ \hline \text { S. Dulikravich, Major Professor }\end{array}$

George S. Dulikravich, Major Professor

Date of Defense: October 20, 2014

The dissertation of Abas Abdoli is approved.

\begin{tabular}{r}
\hline $\begin{array}{r}\text { Dean Amir Mirmiran } \\
\text { College of Engineering and Computing }\end{array}$ \\
$\qquad \begin{array}{r}\text { Dean Lakshmi N. Reddi } \\
\text { University Graduate School }\end{array}$
\end{tabular}

Florida International University, 2014 
(C) Copyright 2014 by Abas Abdoli All rights reserved. 


\section{DEDICATION}

To my wife Betty, my family and Belfi 


\section{ACKNOWLEDGMENTS}

First and foremost, I would like to express my sincere gratitude to my advisor, Prof. George S. Dulikravich, for his continuous support of my Ph.D. study and research, for his patience, motivation, enthusiasm, and immense knowledge. The joy and enthusiasm he has for his research was contagious, and inspired me to work on multiple, diverse, exciting projects.

My thesis committee guided me through my Ph.D. research. I would like to thank Prof. Chandrajit L. Bajaj for his support, encouragement and insightful comments. He provided a detailed human heart geometry, which was crucial for this numerical research. My sincere thanks also goes to Prof. David F. Stowe for his detailed reviews, insightful comments and questions. I also thank Prof. M. Salik Jahania for his invaluable comments and suggestions.

I thank the rest of my committee members: Prof. Cheng-Xian (Charlie) Lin, Prof. Igor Tsukanov, Prof. Brian H. Dennis and Prof. Nikolaos Tsoukias for their encouragement and helpful comments.

I gratefully acknowledge the FIU Instructional and Research Computing Center for providing HPC resources to perform calculations for this project. I thank Mr. Mike Kirgan and Dr. Mengxing Cheng for their help with using FIU's HPC.

I thank my friends and fellow labmates in MAIDOC: Siavash Rastkar, Rajesh Jha, Sohail Reddy, Gianni Jimenez and Genesis Vasquez, for their stimulating discussions and assistance. 


\section{ABSTRACT OF THE DISSERTATION \\ OPTIMIZATION OF COOLING PROTOCOLS FOR HEARTS DESTINED FOR \\ TRANSPLANTATION \\ by}

Abas Abdoli

Florida International University, 2014

Miami, Florida

\section{Professor George S. Dulikravich, Major Professor}

Design and analysis of conceptually different cooling systems for the human heart preservation are numerically investigated. A heart cooling container with required connections was designed for a normal size human heart. A three-dimensional, high resolution human heart geometric model obtained from CT-angio data was used for simulations. Nine different cooling designs are introduced in this research. The first cooling design (Case 1) used a cooling gelatin only outside of the heart. In the second cooling design (Case 2), the internal parts of the heart were cooled via pumping a cooling liquid inside both the heart's pulmonary and systemic circulation systems. An unsteady conjugate heat transfer analysis is performed to simulate the temperature field variations within the heart during the cooling process. Case 3 simulated the currently used cooling method in which the coolant is stagnant. Case 4 was a combination of Case 1 and Case 2. A linear thermoelasticity analysis was performed to assess the stresses applied on the heart during the cooling process.

In Cases 5 through 9, the coolant solution was used for both internal and external cooling. For external circulation in Case 5 and Case 6, two inlets and two outlets were 
designed on the walls of the cooling container. Case 5 used laminar flows for coolant circulations inside and outside of the heart. Effects of turbulent flow on cooling of the heart were studied in Case 6. In Case 7, an additional inlet was designed on the cooling container wall to create a jet impinging the hot region of the heart's wall. Unsteady periodic inlet velocities were applied in Case 8 and Case 9. The average temperature of the heart in Case 5 was $+5.0^{\circ} \mathrm{C}$ after $1500 \mathrm{~s}$ of cooling.

Multi-objective constrained optimization was performed for Case 5. Inlet velocities for two internal and one external coolant circulations were the three design variables for optimization. Minimizing the average temperature of the heart, wall shear stress and total volumetric flow rates were the three objectives. The only constraint was to keep von Mises stress below the ultimate tensile stress of the heart's tissue. 


\section{TABLE OF CONTENTS}

CHAPTER

PAGE

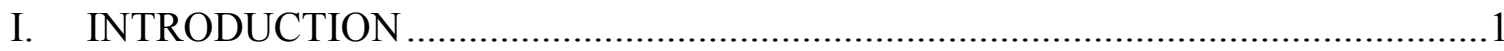

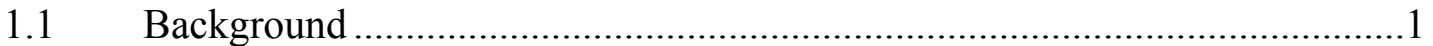

$1.2 \quad$ Organ Preservation Methods.....................................................................

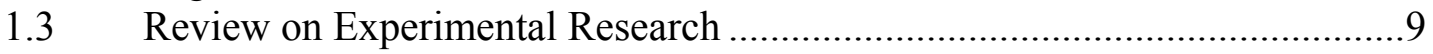

$1.4 \quad$ Review on Cooling Solutions .............................................................10

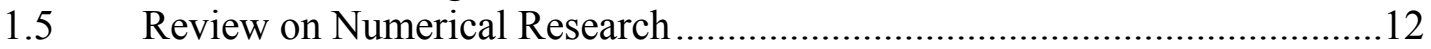

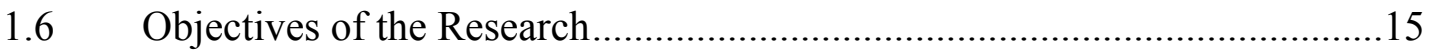

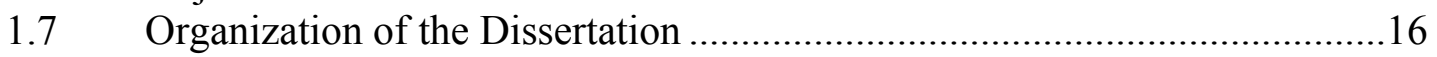

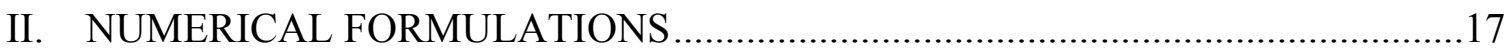

2.1 Conjugate Heat Transfer Formulations ……….........................................17

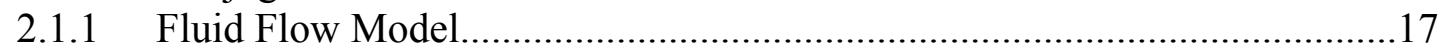

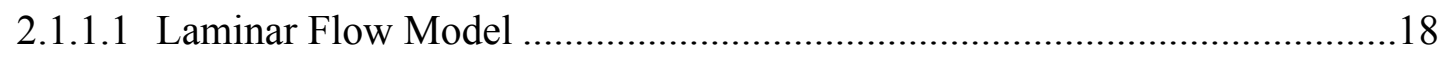

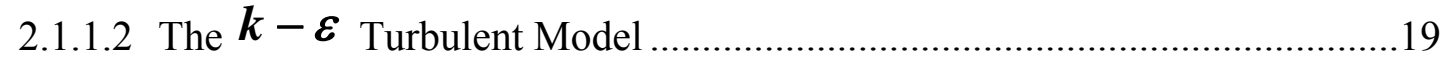

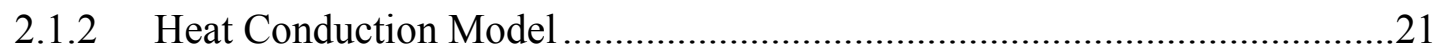

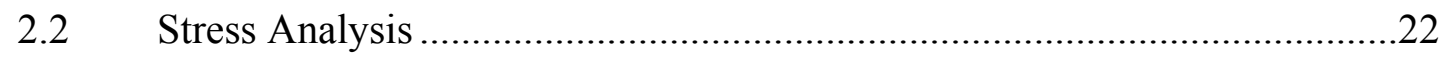

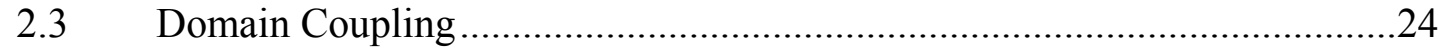

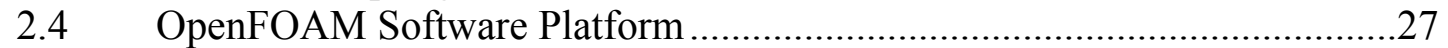

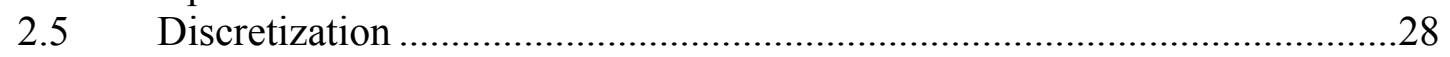

2.5.1 Solution Domain Discretization...............................................................29

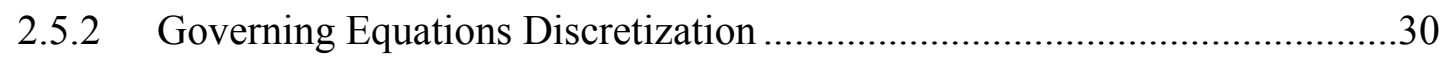

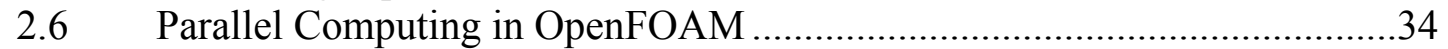

$2.7 \quad$ Domain Decomposition Methods .................................................................

III. SEMI-CONJUGATE AND CONJUGATE COOLING SYSTEMS ...........................39

3.1 Heart Geometric Model and Implementation ................................................39

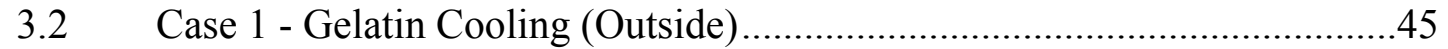

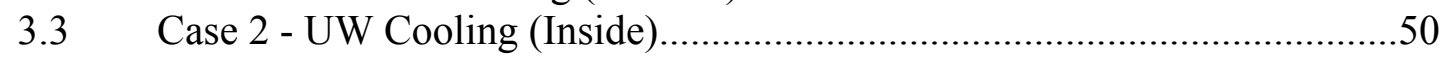

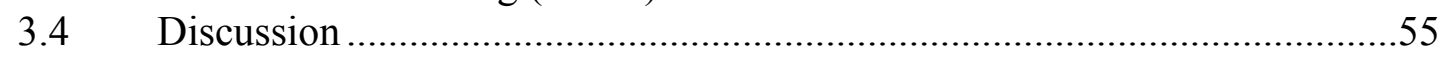

IV. FULLY-CONJUGATE COOLING WITH GELATIN ............................................57

4.1 Case 3 - Gelatin Cooling (Inside and Outside) .............................................57

4.1.1 Thermo-Fluid Analysis ...............................................................................58

4.2 Case 4 - Gelatin Cooling (Outside) and UW Cooling (Inside) ......................65

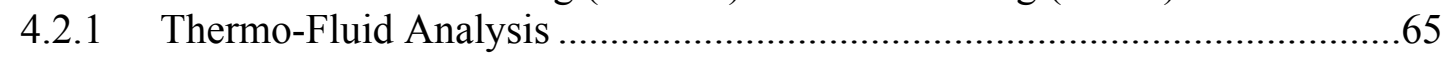

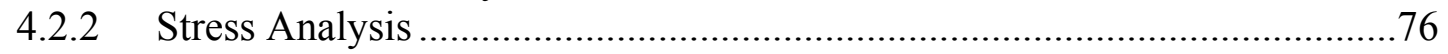

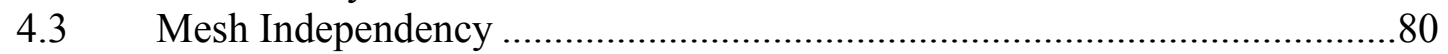

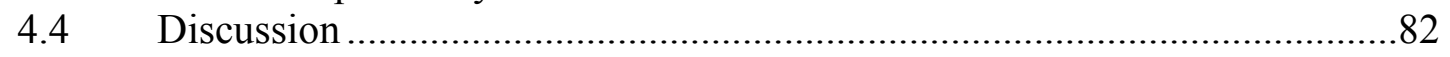

V. FULLY-CONJUGATE COOLING WITH TURBULENT FLOWS ………..............84

5.1 Case 5 - UW Cooling (Laminar Internal and External Flows) .......................84 
5.2 Case 6 - UW Cooling (Laminar Internal and Turbulent External Flows) ....96

5.3 Case 7 - UW Cooling (Laminar Internal and Turbulent External Flows) ..100

5.4 Unsteady Periodic Boundary Condition ....................................................105

5.5 Case 8 - UW Cooling (Turbulent Internal and External Flows) ..................108

5.6 Case 9 - UW Cooling (Turbulent Internal and External Flows) ..................111

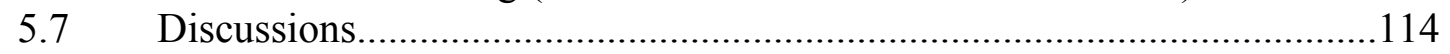

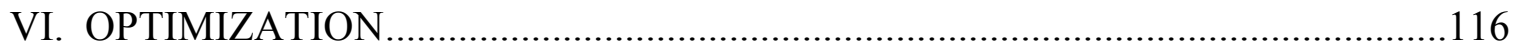

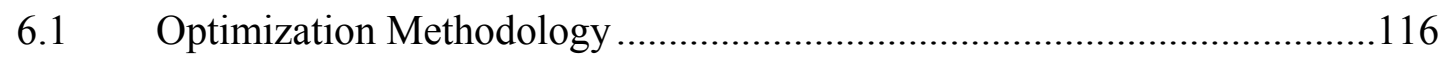

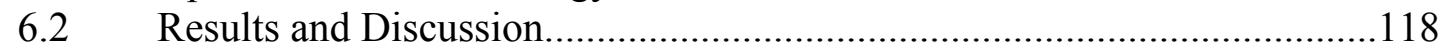

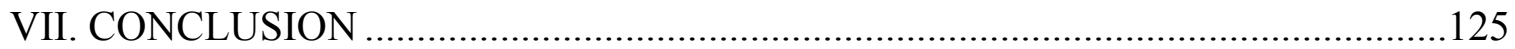

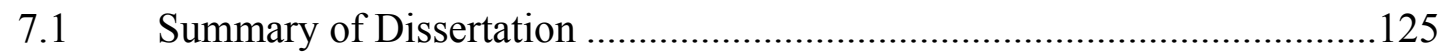

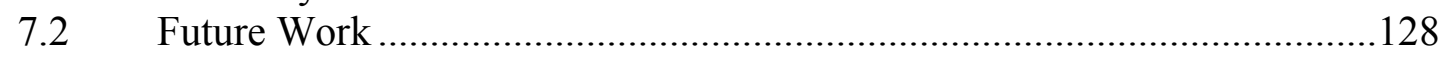

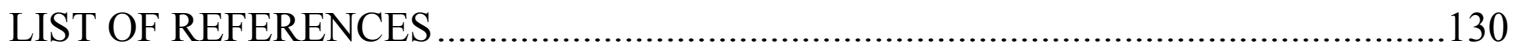

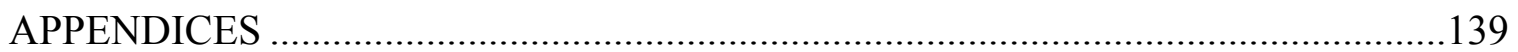

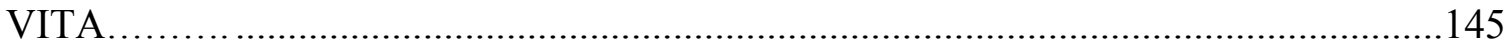




\section{LIST OF TABLES}

TABLE

PAGE

Table 1.1. Heart transplant waiting list activity among adult patients in the United States [3].

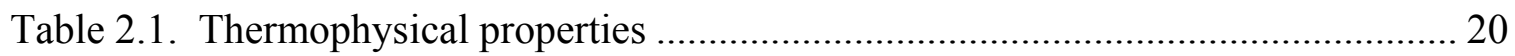

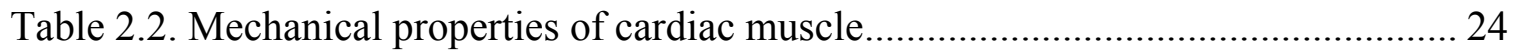

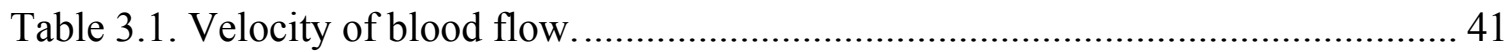

Table 3.2. Boundary conditions for cooling container walls.................................... 45

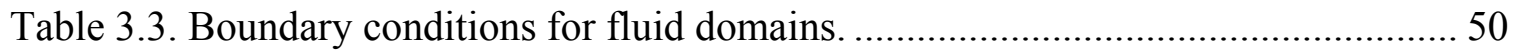

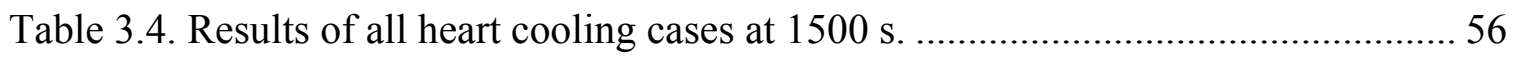

Table 4.1. Finer hexahedral grid cells for different computational domains ................... 81

Table 4.2. Comparison of simulation results for Case 4 and Case 4-fine at $20 \mathrm{~s}$............ 82

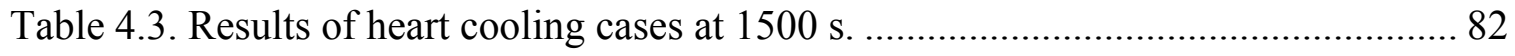

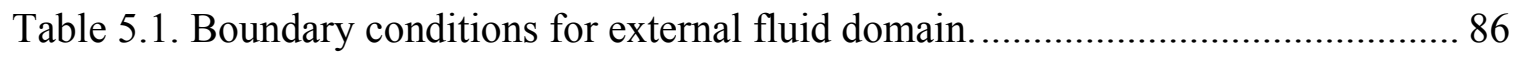

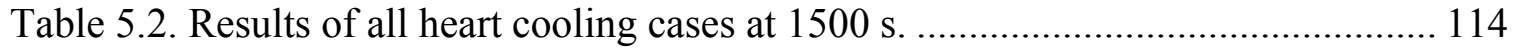

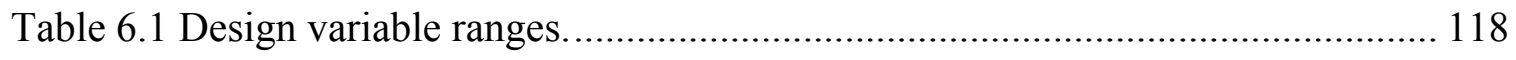

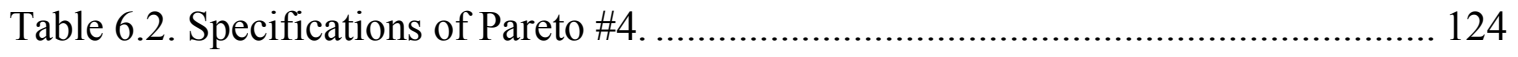

Table 6.3. Output parameters for Pareto \#4 ............................................................. 124

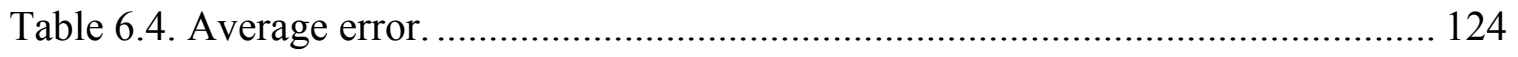




\section{LIST OF FIGURES}

FIGURE

PAGE

Figure 1.1. Percent of adult wait-listed patients in 2010 who received a deceased donor heart transplant within one year in the United States [3].

Figure 1.2. Cause of death among adult heart transplanted recipients [3]........................6

Figure 2.1. Schematic of coupling approaches for a one time step, a) monolithic coupling, and b) partitioned coupling. $\mathrm{S}_{\mathrm{f}}$ is fluid solution, $\mathrm{S}_{\mathrm{s}}$ is solid solution, and $\mathrm{S}_{\mathrm{fs}}$

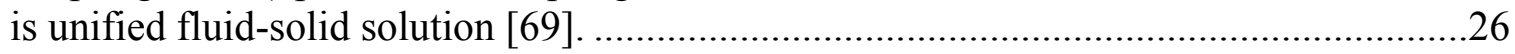

Figure 2.2. Partitioned coupling with separate variables and separate meshes. ...............26

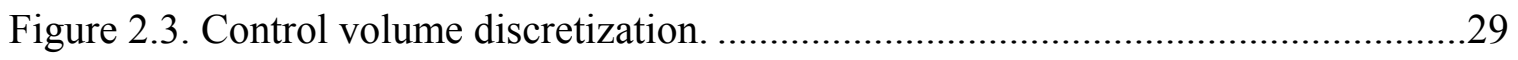

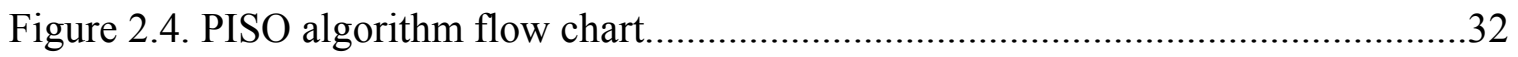

Figure 2.5. Zero-halo layer approach for domain decomposition. .................................35

Figure 3.1. Heart anatomy, a) blood flow circulation, and b) typical values of circulatory pressures (SP is the Systolic Pressure, DP is the Diastolic Pressure, and $\mathrm{MP}$ is the Mean Pressure) [95]....

Figure 3.2. Heart model, a) whole heart $[55,58]$, and b) innermost (blood contact) and outermost surfaces.

Figure 3.3. Heart surfaces: a) all surfaces, b) outermost surfaces, c) heart pulmonary circulation domain surfaces, and d) heart systemic circulation domain surfaces.

Figure 3.4. Cooling system: a) cooling container, b) connections and caps, c) circulation directions for the right (pulmonic) heart, and d) circulation directions for the left (systemic) heart.

Figure 3.5. Temperature distribution (sagittal view): a) $0 \mathrm{~s}$, b) $300 \mathrm{~s}, \mathrm{c}$ ) $600 \mathrm{~s}$, d) 900 $\mathrm{s}, \mathrm{e}) 1200 \mathrm{~s}$, and f) $1500 \mathrm{~s}$.

Figure 3.6. a) Temperature variations (maximum, minimum and average volumetric temperatures of the heart) $v s$. time.

Figure 3.7. Coefficient of variation of average temperature vs. time.

Figure 3.8. Temperature distribution (cut-away view): a) $0 \mathrm{~s}$, b) $300 \mathrm{~s}$, c) $600 \mathrm{~s}$, d) $900 \mathrm{~s}$, e) $1200 \mathrm{~s}$, and f) $1500 \mathrm{~s}$. 
Figure 3.9. a) Temperature variations (maximum, minimum and average volumetric temperatures of the heart) $v s$. time.

Figure 3.10. Coefficient of variation of average temperature $v s$. time.

Figure 3.11. UW streamlines of the internal circulation with, a) temperature distribution, and b) velocity distribution.

Figure 4.1. Temperature distribution (volumetric view) of the heart tissue with constant color legend: a) $0 \mathrm{~s}$, b) $300 \mathrm{~s}$, c) $600 \mathrm{~s}$, d) $900 \mathrm{~s}$, e) $1500 \mathrm{~s}$, and f) $3600 \mathrm{~s}$.

Figure 4.2. Temperature distribution (sagittal view): a) $0 \mathrm{~s}$, b) $300 \mathrm{~s}$, c) $600 \mathrm{~s}$, d) 900 s, e) $1200 \mathrm{~s}$, and f) $1500 \mathrm{~s}$.

Figure 4.3. Metabolic rate (cut-away view): a) $0 \mathrm{~s}$, b) $300 \mathrm{~s}$, c) $600 \mathrm{~s}$, d) $900 \mathrm{~s}$, e) $1200 \mathrm{~s}$, and f) $1500 \mathrm{~s}$.

Figure 4.4. Temperature variations (maximum, minimum and average volumetric temperatures of the heart $v s$. time).

Figure 4.5. Cooling rate vs. time (logarithmic scale)

Figure 4.6. Coefficient of variation of volumetric temperature $v s$. time.

Figure 4.7. Temperature distribution (volumetric view) of the heart tissue with constant color legend: a) $0 \mathrm{~s}$, b) $300 \mathrm{~s}$, c) $600 \mathrm{~s}$, d) $900 \mathrm{~s}$, e) $1200 \mathrm{~s}$, and f) $1500 \mathrm{~s}$.

Figure 4.8. Temperature distribution at $300 \mathrm{~s}$ : a) first cut-away view, b) second cutaway view.

Figure 4.9. Temperature distribution (sagittal view): a) $0 \mathrm{~s}$, b) $300 \mathrm{~s}$, c) $600 \mathrm{~s}$, d) 900 s, e) $1200 \mathrm{~s}$, and f) $1500 \mathrm{~s}$.

Figure 4.10. Temperature variations (maximum, minimum and average volumetric

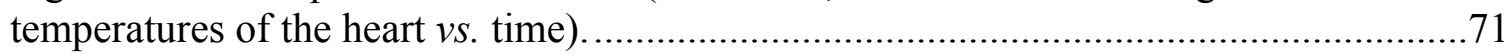

Figure 4.11. Cooling rates $v s$. time (logarithmic scale), ................................................72

Figure 4.12. Coefficient of variation of volumetric temperature $v s$. time. ........................72

Figure 4.13. Velocity distribution at $300 \mathrm{~s}$ : a) coolant inside the ventricles with temperature distribution inside the heart tissue and gelatin (cut-away view), and b) coolant average speeds within the pulmonary and systemic circulatory domains.............73

Figure 4.14. Metabolic rate (cut-away view): a) $0 \mathrm{~s}$, b) $300 \mathrm{~s}$, c) $600 \mathrm{~s}$, d) $900 \mathrm{~s}$, e) $1200 \mathrm{~s}$, and f) $1500 \mathrm{~s}$. 
Figure 4.15. Maximum von Mises stress inside the heart and ultimate tensile stresses vs. time.

Figure 4.16. Maximum coolant pressure inside the pulmonary domain (PD) and systemic domain $(\mathrm{SD})$.

Figure 4.17. WSS magnitude; a) entire fluid contact surfaces, and b) cut-away enlarged view of higher shear stresses region.

Figure 4.18. Heart hexahedral mesh; a) used for simulations presented in this research, and b) finer mesh used for simulation until $20 \mathrm{~s}$.

Figure 5.1. Cooling system: a) cooling container, b) connections and caps, c) inlet 1 and outlet 1 for external cooling, d) inlet 2 and outlet 2 for external cooling coolant. .....85

Figure 5.2. UW solution streamlines (external circulation), a) temperature distribution, and b) velocity distribution at $300 \mathrm{~s}$.

Figure 5.3. UW solution streamlines (internal circulations), a) temperature distribution, and b) velocity distribution.

Figure 5.4. Temperature distribution of the heart tissue with constant color legend: a) $0 \mathrm{~s}$, b) $300 \mathrm{~s}$, c) $600 \mathrm{~s}$, d) $900 \mathrm{~s}$, e) $1500 \mathrm{~s}$, and f) $3600 \mathrm{~s}$.

Figure 5.5. Temperature distribution at $300 \mathrm{~s}$ : a) 1st cut-away view, b) 2nd cut-away view

Figure 5.6. Temperature variations (maximum, minimum and average volumetric temperatures of the heart $v s$. time)......

Figure 5.7. Cooling rate vs. time (logarithmic scale)............................................93

Figure 5.8. Coefficient of variation of volumetric temperature $v s$. time. ........................94

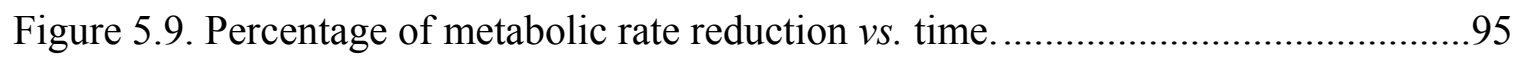

Figure 5.10. UW solution streamlines (external circulation), a) temperature distribution, and b) velocity distribution at $300 \mathrm{~s}$.

Figure 5.11. UW solution streamlines (internal circulations), a) temperature distribution, and $b$ ) velocity distribution.

Figure 5.12. Temperature variations (maximum, minimum and average volumetric temperatures of the heart $v s$. time) .98

Figure 5.13. Cooling rate vs. time (logarithmic scale)........ .98 
Figure 5.14. Coefficient of variation of volumetric temperature vs. time.

Figure 5.15. Percentage of metabolic rate reduction $v s$. time.

Figure 5.16. Cooling system: a) inlet 1 and outlet 1, b) inlet 2, inlet 3 and outlet 2 for the external cooling circulation.

Figure 5.17. UW solution streamlines (external circulation), a) temperature distribution, and b) velocity distribution, c) cut-way view of temperature field, and d) cut-way view of velocity field at $300 \mathrm{~s}$

Figure 5.18. UW solution streamlines (internal circulations), a) temperature distribution, and b) velocity distribution..

Figure 5.19. Temperature variations (maximum, minimum and average volumetric temperatures of the heart $v s$. time).

Figure 5.20. Cooling rate vs. time (logarithmic scale).

Figure 5.21. Coefficient of variation of volumetric temperature vs. time.

Figure 5.22. Percentage of metabolic rate reduction vs. time.

Figure 5.23. External cooling system: a) inlet $1 \& 2$ and outlet $1 \& 2$, b) inlet $3 \& 4$ and outlet $3 \& 4$ for external cooling.

Figure 5.24. Inlet velocity profile for Case 8 and Case 9 ss. time (V0 $=1 \mathrm{~m} / \mathrm{s})$.

Figure 5.25. UW solution streamlines (external circulation), a) temperature distribution, and b) velocity distribution at $300 \mathrm{~s}$.

Figure 5.26. UW solution streamlines (internal circulations), a) temperature distribution, and b) velocity distribution.

Figure 5.27. Temperature variations (maximum, minimum and average volumetric temperatures of the heart $v s$. time).

Figure 5.28. Cooling rate vs. time (logarithmic scale).

Figure 5.29. UW solution streamlines (external circulation), a) temperature distribution, and b) velocity distribution at $300 \mathrm{~s}$.

Figure 5.30. UW solution streamlines (internal circulations), a) temperature distribution, and $b$ ) velocity distribution.

Figure 5.31. Temperature variations (maximum, minimum and average volumetric temperatures of the heart vs. time). 
Figure 5.32. Cooling rate vs. time (logarithmic scale).

Figure 6.1. Flow chart showing how different software modules were linked together to generate virtual and real Pareto frontiers

Figure 6.2. Optimization work flow in modeFRONTIER.

Figure 6.3. Average temperature vs. WSS for initial population, virtual Pareto, and real Pareto optimal designs.

Figure 6.4. Average temperature vs. total volumetric flow rate for initial population, virtual Pareto, and real Pareto optimal designs.

Figure 6.5. WSS vs. volumetric flow rate for initial population, virtual Pareto, and real Pareto optimal designs.

Figure 6.6. Average temperature vs.WSS vs. volumetric flow rate for initial population, virtual Pareto, and real Pareto optimal designs. 


\section{CHAPTER I}

\section{INTRODUCTION}

In the first section of this chapter (section 1.1), a brief review on heart transplant history, its past and current challenges, is presented. Section 1.2 reviews heart cooling preservation methods. Then, in section 1.3, some of the experimental research on heart cooling preservation is presented. A brief review on different types of cooling solutions is introduced in section 1.4. In section 1.5, numerical studies on this field are reviewed. Objectives of this research and organization of the dissertation are presented in section 1.6 and 1.7 , respectively.

\subsection{Background}

The first heart transplant in the world to a human was performed by James Hardy on January 23, 1964, at the University of Mississippi Medical Center in Jackson [1]. The recipient was a 68-year-old man, but the donor was a chimpanzee. The patient died 1 hour later of acute rejection [1]. The first human-to-human heart transplant was performed on December 3, 1967 by Christian Barnard at the Groote Schuur Hospital Cape Town, South Africa [1]. The heart of a 25-year-old woman was transplanted into a 54-year-old man. The patient lived for only 18 days after transplantation. This was considered a transient success. Three days later, on December 6, 1967, Adrian Kantrowitz performed the first heart transplant in the United States at Maimonides Medical Center in Brooklyn, New York [1]. The recipient was an 18-day-old male infant who received the heart of a 2 -day-old anencephalic male. The patient died $6 \frac{1}{2}$ hours after 
surgery [1]. Soon after, heart transplantation became a very interesting subject for researchers, and many surgeons quickly co-opted the procedure. However, due to the earlier death of recipients, the number of reported heart transplants decreased from 100 in 1968 , to just 18 in 1970. The major problem was the rejection of new tissues by the recipient's body.

The developments in tissue typing and immunosuppressant drugs helped to increase the number of transplants and recipient's survival rate. In mid-1970s, Jean Borel discovered a very promising immunosuppressant drug called cyclosporine [2].

Most heart recipients receive the heart from deceased donors. However, there are cases in which patients need a heart-lung combination transplant but his/her heart may be in good condition and it is possible to be transplanted into yet another patient. This is known as a "domino" heart transplant.

Among all organs, the heart is the most valuable and challenging organ for transplantation due to its vital role in blood circulation. Heart operates as a pump and circulates the blood in the entire body to deliver oxygen and nutrients to cells, and to remove metabolic by-products and toxins from cells. Thus, unlike other organs, the transplanted heart must function at its highest capacity right after transplantation.

Table 1 shows the heart transplant activities for the year 2009, 2010 and 2011 in the United States [3] reported by the United States Organ Procurement and Transplantation Network (USOPTN). As this table shows, 1,931 heart transplants were performed in 2011. One of the important pieces of information in this table is the number of patients who were removed from the waiting list. Considering the removal reasons listed in this table, it can be observed that 441 patients died in 2011 before receiving a 
heart transplant. This indicates that approximately $18 \%$ of patients died due to lack of matching hearts.

Table 1.1. Heart transplant waiting list activity among adult patients in the United States [3].

\begin{tabular}{lrrr} 
Activity & $\mathbf{2 0 0 9}$ & $\mathbf{2 0 1 0}$ & $\mathbf{2 0 1 1}$ \\
\hline Patients at start of year & 2,409 & 2,668 & 2,867 \\
Patients added during year & 2,890 & 2,916 & 2,783 \\
Patients removed during year & 2,625 & 2,710 & 2,837 \\
Patients at end of year & 2,674 & 2,874 & 2,813 \\
& & & \\
Removal reason: & & & \\
& 1,840 & 1,965 & 1,931 \\
Deceased donor transplant & 435.0 & 400.0 & 441.0 \\
Patient died & 14 & 12 & 18 \\
Patient refused transplant & 193 & 164 & 166 \\
Condition improved, transplant not needed & 55 & 61 & 92 \\
Too sick to transplant & 88 & 108 & 189 \\
Other & &
\end{tabular}

Figure 1 shows the demographic distribution of the percentage of adult wait-listed patients in the year 2010 who received a deceased donor heart transplant within one year, as reported by USOPTN [3]. As this figure shows the maximum percentage which is shown in dark blue color was $72.7 \%$. The light blue color ravels the minimum percentage which was $34.3 \%$. In can be observed that only in a few states the maximum of adult wait-listed patients received a heart transplant within one year. 


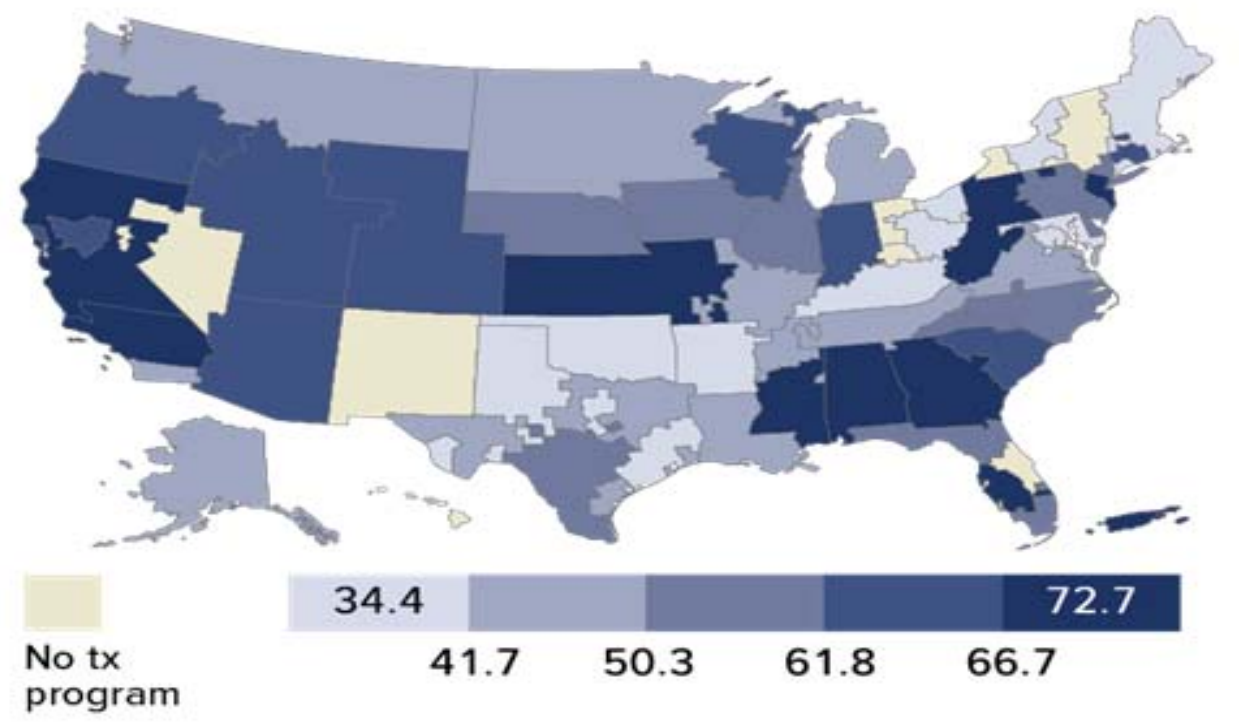

Figure 1.1. Percent of adult wait-listed patients in 2010 who received a deceased donor heart transplant within one year in the United States [3].

The Organ Procurement and Transplantation Network (OPTN) in its policies, prioritizes organ allocation to the most critically ill-heart matching candidates. As part of this policy, OPTN defines five concentric geographical zones for the heart allocation [4, 5]. These five zones prioritize the heart allocation as follow

1. Zone A: Includes all transplant hospitals within 500 nautical miles of the donor hospital but outside of the donor hospital's DSA ${ }^{1}$.

2. Zone B: All transplant hospitals within 1,000 nautical miles of the donor hospital but outside of Zone A and the donor hospital's DSA.

\footnotetext{
${ }^{1}$ Donation Service Area (DSA): The geographic area designated by the Centers for Medicare and Medicaid Services (CMS) that is served by one organ procurement organization (OPO), one or more transplant hospitals, and one or more donor hospitals.
} 
3. Zone C: All transplant hospitals within 1,500 nautical miles of the donor hospital but outside of Zone B and the donor hospital's DSA.

4. Zone D: All transplant hospitals within 2,500 nautical miles of the donor hospital but outside of Zone C.

5. Zone E: All transplant hospitals more than 2,500 nautical miles from the donor hospital.

The above zones were implemented to facilitate transplant coordination and to minimize ischemic time [6]. More information about prioritized match candidates based on the level of urgency for transplantation can be found in OPTN policies [4]. In most cases, the donor and the recipient of the compatible heart are at vastly different geographic locations. Therefore, the preservation of a deceased heart has gained a crucial role in the transplantation process. An optimal preservation protocol will enable transplantation despite geographical differences between the donor and the matching recipient.

The main problem in the heart preservation is the relatively short time that the heart can survive from the moment of their harvesting to the moment of its surgical transplantation into the recipient's body. Currently, the time limit for an explanted human heart to remain viable is only 4.5 hours when the heart is kept submerged in a saline solution at a temperature close to that of freezing water. As it was mentioned, in most cases, the donor and the recipient of the compatible heart are at vastly different geographic locations. This means that the current 4.5 hours limitation must cover transportation from the site of harvesting to the nearest airport, flight time to the airport nearest to the recipient's location, and travel time from that airport to the hospital where 
the recipient is located. In practice, this leaves at most two hours for air transportation of the heart, which is insufficient to cover even half of the territory of the United States. An optimal preservation protocol is key in extending the current preservation time, thereby expanding the transplant geographical zones and increasing the number of heart transplants to the most critically ill-heart matched recipients.

The USOPTN's 2011 annual report [3] reveals major causes for the death of patients who had received a heart transplant. Based on this report, organ failure, cardiovascular failure, malignancy and infection are the major known causes of death among adult heart transplanted recipients. A proper cooling preservation protocol will help to minimize or eliminate some of these causes of death such as organ infection.

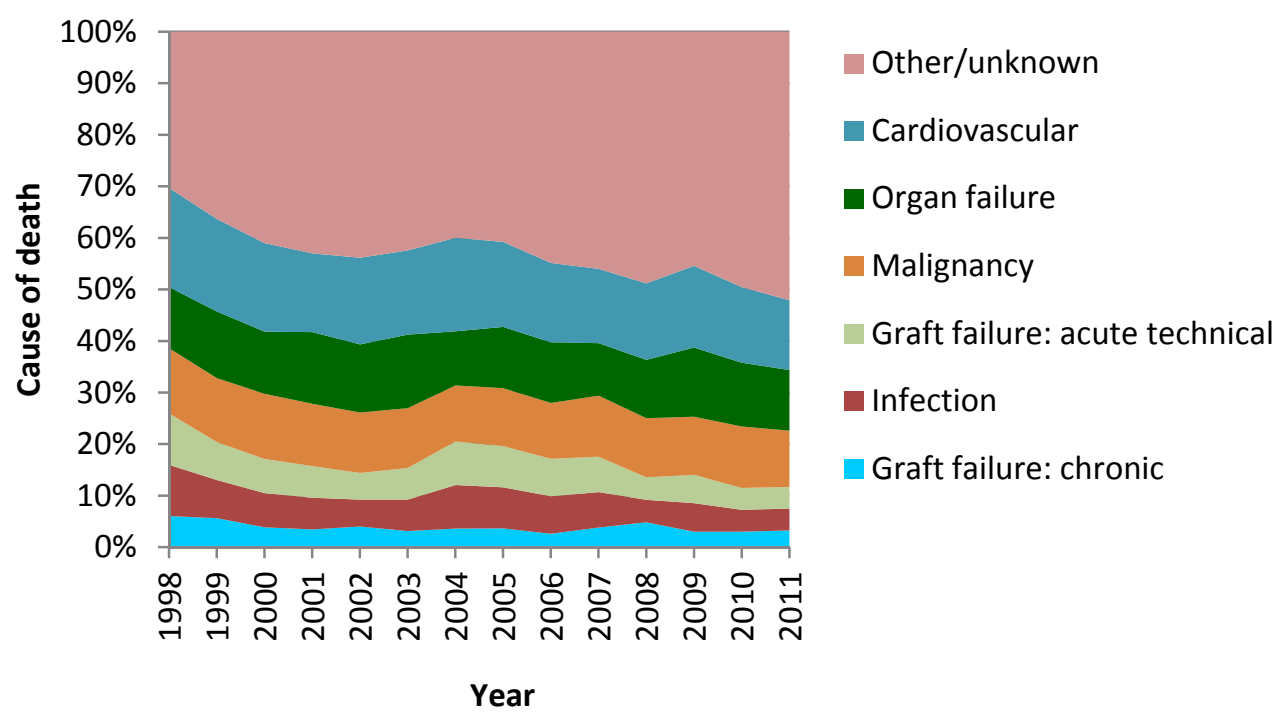

Figure 1.2. Cause of death among adult heart transplanted recipients [3]. 


\subsection{Organ Preservation Methods}

From the heat transfer point of view, organ preservation approaches can be classified into two methods: cold preservation and warm preservation.

The underlying principle of warm (normothermic) preservation is to maintain cellular metabolism, to allow cell functions to continue, and to avoid ischemia. The challenges in warm perfusion are to provide oxygen to cells and remove waste products by using a good perfusate (blood or blood components), while preventing thrombus formation, vascular damage and infection [7]. Recently, this concept has been revisited with considerable success $[8,9,10]$. Normothermic preservation also has more technical challenges compared to the cold preservation. This method requires specialist skills and complex apparatus.

Cold preservation on the contrary takes advantage of the profound effect of decreasing cell temperature to decrease the cell metabolic rate to avert cell death $[11,12]$. The well-known "Q10 law" states that for every $10^{\circ} \mathrm{C}$ reduction in tissue temperature there is a corresponding reduction in cell metabolism equal to the constant Q10. The law is written as

$$
\frac{q_{m}}{q_{m 0}}=\left(\mathrm{Q}_{10}\right)^{\left[\left(T-T_{0}\right) / 10\right]}
$$

where $T$ is temperature in degrees Celsius and $q_{m}$ is the cell metabolic rate. Values for $\mathrm{Q}_{10}$ range from 2.0 to 3.0 and are cited in the physiology literature [13]. For example, 
assuming a mid-range value, say $\mathrm{Q}_{10}=2.5$, it can be observed that reducing temperature from $+37^{\circ} \mathrm{C}$ to $+27^{\circ} \mathrm{C}$ reduces the metabolic rate by a factor of 2.5 . Reducing temperature to $+4^{\circ} \mathrm{C}$ reduces the metabolic rate by $95 \%$. As a result of reducing the cell metabolic rate, oxygen and glucose consumption and carbon dioxide production are decreased as well [11]. Thus, the cell damage due to lack of oxygen will be decreased [12]. Cold preservation is also less expensive and less complicated than warm preservation. This method is a simple, relatively inexpensive technique that allows the convenient transportation of any organ.

Cold preservation approaches can be classified into three major methods: static cold storage, hypothermic machine perfusion and persufflation [14]. In the static cold method, the organ is cooled only from outside by using a cooling solution. The static cold preservation is the cheapest and simplest preservation method. However, this method is not able to deliver nutrient and oxygen to cells. Moreover, lack of internal cooling in this method causes more ischemic damages to the organ.

The hypothermic machine perfusion applies both external and internal cooling. For internal cooling, a cooling liquid is perfused or pumped within the organ. This enables the delivery of nutrients and oxygen into the core of the organ, and removes waste products under appropriate conditions. This method has a higher risk of damage to the vascular structures due to perfusion pressures compared to the static cold preservation. In terms of technical complexity and cost, this method is moderately complicated and relatively inexpensive $[14,15]$.

The third method is persufflation or gaseous oxygen perfusion. In this method gaseous oxygen is pumped within the organ. The Persufflation method has higher 
capacity to deliver more oxygen to cells and prevent edema within the organ compared to the methods explained above. But at the same time, this method causes more vascular damages compared to other methods. It should also be mentioned that using gaseous oxygen requires longer cooling time compared to the hypothermic machine perfusion. This is because of the smaller heat capacity of gas compared to liquid. This method is expected to be as complex and expensive as the hypothermic machine perfusion $[14,16]$.

\subsection{Review on Experimental Research}

Currently the static cold preservation is the most commonly used method for heart preservation. By keeping the heart submerged in a cold saline solution, it can currently be preserved up to 4 hours. The primary graft failure rate in this method is less than two percent [17].

One of the challenges in the heart cooling preservation is the highly sensitive cardiac muscles [18]. Second rinsing or leucocyte depleted in-situ reperfusion can help to increase ischemic tolerance up to 6 hours [17] suggesting that continuous cold perfusion is a viable method of extending the useful life of an organ destined for transplantation. Jahania et al. [19] described the protective strategy and principles for using hypothermia in heart preservation. Collins et al. $[6,20]$ reported cases in which hearts were successfully resuscitated by hypothermic machine perfusion with full recovery of function. They could also resuscitate one of the two hearts which belonged to Non Beating Heart Donors (NBHDs). 
Stowe et al. [21] showed that stopping tissue perfusion and cooling isolated guinea pig hearts to $+3.4^{\circ} \mathrm{C}$ for 6 hours resulted in a return of left ventricular pressure of up to $81 \%$ of that before cooling. As a result of heart temperature reduction during cooling process, heart rate decreases which led to depressed mitochondrial (m) bioenergetics, excess reactive oxygen species (ROS) generation, and $\mathrm{mCa}^{2+}$ loading [22]. These are the major factors underlying ischemia and reperfusion (IR) injury. Stowe and his colleagues conducted several researches to address this issue $[23,24,25,26]$.

White et al. tried to minimize myocardial injury and improve short-term posttransplant function by using initial reperfusion with a tepid adenosine-lidocaine cardioplegia and continuous myocardial perfusion [27]. Many of the experimental research studies in this field have been focused on the cooling solution. Therefore a review on cooling solutions is presented separately in the following section.

\subsection{Review on Cooling Solutions}

In the late 1980s Folkert Belzer and James Southard developed the first thoughtfully designed solution for pancreas preservation. This solution is known as University of Wisconsin solution [28]. Soon after, this solution became the first intracellular-like medium and displaced EuroCollins solution as the preferred medium for cold storage of the pancreas, liver and kidney [29, 30]. The UW solution has also been used in preservation of the heart and other organs [31,32].

The UW solution is based on a typical intracellular principal with a very high potassium $(\mathrm{K}+)$ and low sodium $\left(\mathrm{Na}^{+}\right)$ion composition [12]. It contains impermeants 
lacto bionate and raffinose to prevent cell swelling. It also includes a colloidal agent with the rationale, called pentastarch to prevent interstitial edema formation. Antioxidants such as glutathione, adenine nucleotide precursors, radical scavengers, dexametasone and phosphate buffer are also included in this solution [17].

Another often used solution is Histidine-tryptophan-ketoglutarate, or Custodiol HTK solution. HTK is a low $\mathrm{K}+$ preservation solution, which works based on the principle of inactivating organ function by removing extracellular sodium and calcium, with intensive buffering of the extracellular space by using histidine / histidine hydrochloride [33, 34]. HTK solution is used for in-vivo and ex-vivo perfusion in different organs such as pancreas, heart, liver and lung.

In other research, both solutions have been tested and compared for different organs [35, 36, 37]. Reichenspurner et al. [38] compared UW versus HTK solution for myocardial protection in heart transplantation. They reported a satisfactory myocardial preservation with HTK solution as long as the ischaemic time did not exceed $4 \mathrm{~h}$. Their results showed that UW graft protection gave excellent early functional results, even with ischaemic times longer than $4 \mathrm{~h}$.

Celsior Solution (CS) is another solution which has also been used for organ preservation. $\mathrm{CS}$ is a high $\mathrm{Na}^{+}$, low $\mathrm{K}+$, low-viscosity extracellular solution used in heart cooling $[17,39]$. Despite developments of different cooling solutions which are better than UW solution in some aspects [40], the UW solution remains as the standard solution for organ preservation [41]. 


\subsection{Review on Numerical Research}

Numerical studies in this field are very challenging due to geometric complexity and lack of certain experimental data.

As it was mentioned in the previous section, one of the main objectives in the cold preservation is to cool organs faster in order to maximize metabolic decay of the organ tissue. This requires applying higher cooling rates. Another important objective is to keep thermal and hydraulic stresses below the maximum tolerable stresses of the organ cells. This will limit the maximum allowable cooling rate. For controlling cooling rate in the organ, knowing the temperature distribution in the entire organ is required.

Dulikravich [42] demonstrated, in the case of two dimensions, that it is possible to maintain specified cooling rates at any point of the cooled object by varying container wall temperature distribution. Dulikravich and Hayes [43] applied boundary element method because of its simplicity for studying temperature field in arbitrary geometrical shapes. They demonstrated the accuracy of their simulation with known analytical solutions. Dennis and Dulikravich [44] used 3-D spectral finite elements to simulate unsteady temperature field and thermal stress field during freezing of an idealized canine kidney submerged in a gel without perfusion. They also for the first time demonstrated the optimized time-varying thermal boundary conditions use on the surface of a spherical freezing container and suggested use of optimized internal perfusion of the organ during the cooling process. They used sixth order Chebyshev polynomial [44] in terms of the 
circumferential angle to represent the variable boundary temperature on the surface of the container.

Dennis et al. [45] applied finite element method to study cooling rate of realistic 3-D human head and neck. They reported that to reach the target temperature in a reasonable period of time, it is necessary to use a pre-cooled blood in addition to a cold "ski cap", because of very low conduction heat transfer coefficient of the cranium on one side, and the brain structure which is fully composed of blood vessels on the other side. Moore et al. [11] reported different experimental methods for brain cooling such as infusion of ice-cold fluids into the blood. Neimark et al. [46] in their research tried to simulate effects of intracarotid cold saline infusion by using 1-D assumption to get the blood temperature mixture and 2-D assumption to get the temperature field.

Trunk et al. [47, 48] applied an explicit finite difference method to solve temperature diffusion equation in order to simulate the temperature changes in the heart during Topical Cooling (TC). TC is a myocardial protection technique which is often used in cardiac surgery as an adjunct to cardioplegia. They used a 3-D heart model, derived from Visible Human Data set from National Library of Medicine [49], with spatial resolution of $1 \mathrm{~mm}$. However, their thermal analysis coolant flow was not included.

Sterk and Trobec [50] simulated the 3-D heart model submerged inside the water cooling liquid without perfusion. They used an explicit finite difference method to solve Navier-Stokes equations to account for thermal buoyancy flow inside the cooling liquid bath. They used the same 3-D heart model, derived from Visible Human Data set [41]. 
Trayanova [51] reviewed the whole heart modeling for cardiac electrophysiology and electromechanics applications.

The complex geometry of the human heart is one of the major challenges for numerical simulations. Researchers have developed different methods for extracting and meshing 3-D high resolution heart geometric models from computer tomography (CT) for different applications. Parssl et al. [52] generated computational meshes for cardiac electrophysiology problems by using their method which applies the dual mesh of an octree. An octree is a hierarchical data structure. Their mesh generator can be applied directly to segmented image data stacks.

Carson et al. [53] developed automated meshing algorithms to generate adaptive anisotropic hybrid meshes for arbitrary biological geometries. By applying their meshing algorithms, they were able to generate efficient and accurate meshes, which can equilibrate the relative error over the whole mesh in fluid-structure interaction computations $[53,54]$.

Zhang and Bajaj [55] applied a finite element method for meshing the 3-D human heart modeled from MRI scan data. They extracted adaptive tetrahedral meshes from a volumetric gridded database of signed distance function with a resolution of $257^{3}$. In 2006, Bajaj et al. [56] constructed patient specific heart models using high resolution computer tomography (CT) data. Additionally Bajaj and Goswami [57, 58] performed multi-component heart reconstruction, segmentation and meshing from volumetric imaging. They applied a distant function technique in geometry modeling to generate a 3D finite-element and boundary element human heart mesh model from high resolution CT-angio imaging data. 
Based on the available literature, it appears that fully 3-D conjugate heat transfer analysis and thermal stress analysis of a heart during cooling from body temperature to water freezing temperature has not been performed. Also, optimization of a fully 3-D time-accurate cooling protocol of a heart has not been performed.

\subsection{Objectives of the Research}

The ultimate objective of this research is to extend the viability of the heart to at least 8 hours. This would provide up to 5.5 hours for air transport, thus enabling heart transplantations anywhere in the United States. As part of achieving this goal, the just explanted heart should be brought to a just-above tissue freezing temperature as uniformly and as quickly as possible. At the same time, prevent all possible damages to the heart tissue due to thermal and hydraulic stresses during preservation process. The following items will be the objectives of this numerical research:

$>$ Using detailed 3-D heart geometry with includes the major vessels.

$>$ Designing a cooling container including required inlets/outlets and connections for coolant circulations.

$>$ Performing 3-D unsteady conjugate heat transfer analyses for the heart during different cooling process.

$>$ Performing thermal stress analysis for the entire organ during different cooling processes. 
$>$ Performing optimization to find the optimal cooling design to cool the heart as fast as possible and at the same time reduce stresses applied on the heart during cooling process.

\subsection{Organization of the Dissertation}

The remaining chapters are organized as follow

In Chapter II, numerical procedures, governing equations and assumptions are discussed. Semi-conjugate and conjugate cooling designs are presented in Chapter III. In Chapter IV, two fully conjugate cooling designs were introduced. In Chapter V, turbulent flows and periodic unsteady boundary conditions were used for inlet velocities of internal and external cooling. Optimization of the cooling design to find the optimal inlet velocities are discussed in Chapter VI. Discussions and recommendations for future work are presented in Chapter VII. 


\section{CHAPTER II}

\section{NUMERICAL FORMULATIONS}

In this chapter, numerical formulations and schemes used for simulations are explained. Formulations were classified into two sections: conjugated heat transfer formulations (section 2.1), and stress analysis formulations (section 2.2). In section 2.3 and section 2.4 parallel computing methods and domain decommission algorithm are discussed, respectively.

\subsection{Conjugate Heat Transfer Formulations}

Conjugated heat transfer formulations include the fluid flow model (section 2.1.1), the conduction heat transfer model (section 2.1.2) and the domain coupling method (section 2.1.3).

\subsubsection{Fluid Flow Model}

The UW solution was chosen as the cooling solution to pump through the major veins into the heart's chambers. This solution was considered as a Newtonian fluid. There is no available data for the critical Reynolds number inside the heart. Kisslo and Adams [59] demonstrated that the blood flow inside the heart, great vessels and most of the cardiovascular system is normally laminar. Stein and Sabbah [60] studied the turbulent blood flow in the ascending aorta of humans with normal and diseased aortic valves. 
They reported that the critical Reynolds number in smooth, straight pipes which is 2,300 is also an acceptable criterion for the blood flow pattern inside the aorta. They mentioned that for Reynolds numbers below 2,300, even strong disturbances do not cause the flow to become turbulent. The turbulent flow in the aorta is mainly due to the aortic valve opening and closing and the pulsatile flow by muscle contraction. However, in some of the cooling designs presented in this dissertation, the flow was uniform through open valves. For such cases, considering these very low Reynolds numbers, static-open position of valves and by taking into account Kisslo, Adams, Stein and Sabbah's observations, for Reynolds numbers less than 2,000, fluid flow was assumed to be laminar and for Reynolds numbers equal or greater than 2,000 fluid flow was assumed to be turbulent.

In section 2.1.1.1, Navier-Stokes equations used for laminar flow simulations are discussed. For turbulent cases, the $\boldsymbol{k}-\boldsymbol{\varepsilon}$ turbulent model was used which is presented in section 2.1.1.1. A brief introduction about OpenFOAM software platform used in this research is presented in section 2.1.1.3. Numerical discretizations are explained in section 2.1.1.4.

\subsubsection{Laminar Flow Model}

Laminar flow was modeled by using the Navier-Stokes equations for incompressible viscous fluid flow. The equations for conservation of mass and linear momentum for this case have the form

$$
\nabla \cdot \overrightarrow{\mathrm{V}}=0
$$




$$
\rho\left(\frac{\partial \overrightarrow{\mathrm{V}}}{\partial t}+\overrightarrow{\mathrm{V}} \cdot \nabla \overrightarrow{\mathrm{V}}\right)=-\nabla p+\mu \nabla^{2} \overrightarrow{\mathrm{V}}+\rho \vec{g}
$$

where, $\rho$ is density, $\overrightarrow{\mathrm{V}}$ is the velocity vector, $p$ is the static pressure, $\mu$ is the dynamic viscosity and $\vec{g}$ is the gravitational acceleration. The conservation of energy for incompressible flow in stagnation enthalpy form was used as

$$
\rho\left[\frac{\partial h_{o}}{\partial t}+(\overrightarrow{\mathrm{V}} \cdot \nabla) h_{o}\right]=\frac{\partial p}{\partial t}+\nabla \cdot\left(\underline{\underline{\tau}} \cdot \overrightarrow{\mathrm{V}}-\dot{\vec{q}}_{c}-\dot{\vec{q}}_{r}\right)+\rho \vec{g} \cdot \overrightarrow{\mathrm{V}}+\rho \dot{q}
$$

where, $h_{0}=h+\frac{\vec{V}^{2}}{2}$ is the stagnation enthalpy per unit mass, $\underline{\underline{\tau}}$ is the stress tensor, $\dot{\vec{q}}_{c}$ is the conduction heat flux, $\dot{\vec{q}}_{r}$ is the radiation heat flux, $\dot{q}$ is the heat source.

\subsubsection{The $\boldsymbol{k}-\boldsymbol{\varepsilon}$ Turbulent Model}

This model uses the Reynolds-averaged Navier-Stokes equations (RANS) to obtain approximate time-averaged solutions to the Navier-Stokes equations [61]. The idea behind the RANS equations is to decompose an instantaneous quantity, into its timeaveraged and fluctuating quantities.

$$
\rho\left(\frac{\partial \overrightarrow{\mathrm{V}}}{\partial t}+\overrightarrow{\mathrm{V}} \cdot \nabla \overrightarrow{\mathrm{V}}\right)=-\nabla p+\nabla \cdot\left(\left(\mu+\mu_{T}\right)\left[\nabla \overrightarrow{\mathrm{V}}+\nabla \overrightarrow{\mathrm{V}}^{\mathrm{T}}\right]\right)
$$

Here, $\mu$ is the dynamics viscosity of fluid and $\mu_{T}$ is turbulent viscosity which includes the effect of velocity fluctuations that were calculated from the $k-\varepsilon$ turbulence model. The $k-\varepsilon$ model is based on the turbulent kinetic energy and the dissipation rate. 
In standard $k-\varepsilon$ model $v_{T}=C_{\mu} \frac{k^{2}}{\varepsilon_{T}}$, where $k$ is the turbulent kinetic energy and $\varepsilon_{T}$ is the dissipation rate. In formulations in this paper, the dissipation rate was shown with $\varepsilon_{T}$. This turbulent model includes two equations for $k$ and $\varepsilon$ which need to be added to governing equations. The $k$ and $\varepsilon_{T}$ equations for incompressible are

$$
\begin{aligned}
& \frac{\partial k}{\partial t}+\nabla \cdot\left(k \overrightarrow{\mathrm{V}}-\frac{v_{T}}{\sigma_{k}} \nabla k\right)=P-\varepsilon_{T} \\
& \frac{\partial \varepsilon_{T}}{\partial t}+\nabla .\left(\varepsilon_{T} \overrightarrow{\mathrm{V}}-\frac{v_{T}}{\sigma_{\varepsilon}} \nabla \varepsilon_{T}\right)=\frac{\varepsilon_{T}}{k}\left(C_{1} P-C_{2} \varepsilon_{T}\right)
\end{aligned}
$$

where $P=\frac{\nu_{T}}{2}\left|\nabla \overrightarrow{\mathrm{V}}+\nabla \overrightarrow{\mathrm{V}}^{\mathrm{T}}\right|^{2}$ and represents the production of turbulence kinetic energy.

The following are the standard values of the $k-\varepsilon$ model constants

$$
C_{1}=1.44 \quad C_{2}=1.92 \quad C_{\mu}=0.09 \quad \sigma_{k}=1 \quad \sigma_{\varepsilon}=1.3
$$

The thermophysical properties of the UW solution and the heart are shown in table 2. The thermophysical properties of the gelatin were assumed to be the same as UW solution. As this table shows, thermophysical properties of the UW solution are very close to thermophysical properties of water.

Table 2.1. Thermophysical properties

\begin{tabular}{|l|c|c|c|c|}
\hline Material & $\begin{array}{c}\text { Density, } \boldsymbol{\rho} \\
\left(\mathbf{k g ~ m}^{-3}\right)\end{array}$ & $\begin{array}{c}\text { Specific Heat, C } \\
\left(\mathbf{J ~ k g ~}^{-1} \mathbf{K}^{-1}\right)\end{array}$ & $\begin{array}{c}\text { Heat Conductivity, } \mathbf{k} \\
\left(\mathbf{W ~ m}^{-1} \mathbf{K}^{-1}\right)\end{array}$ & $\begin{array}{c}\text { Viscosity, } \boldsymbol{\mu} \\
\left(\mathbf{k g ~ m}^{-1} \mathbf{~ s}^{-1}\right)\end{array}$ \\
\hline UW solution [4] & 1025 & 4180 & 0.6 & 0.0037 \\
\hline Heart tissue [5] & 1060 & 3716.98 & 0.586 & - \\
\hline
\end{tabular}




\subsubsection{Heat Conduction Model}

Heart tissue and cooling gelatin were considered as isotropic solid materials [63]. For the solid domains, only energy balance was applied. The updated version of equation 2.3 for solid domains, which is mostly known as the transient heat conduction equation, is

$$
\frac{\partial T}{\partial t}=\alpha \nabla^{2} T
$$

where $\alpha$ is thermal diffusivity. The average volumetric temperature and coefficient of variation of volumetric temperature were used to further investigate the distribution of temperatures during the cooling process. Coefficient of variation (CV) was used to indicate temperature non-uniformity inside the heart tissue and was defined as follows

$$
\mathrm{CV}=\frac{\mathrm{SD}}{T_{\text {ave }}}
$$

Here,

$$
\begin{aligned}
& \mathrm{SD}=\sqrt{\frac{1}{N} \sum_{i=1}^{N}\left(T_{i}-T_{\text {ave }}\right)^{2}} \\
& T_{\text {ave }}=\frac{1}{N}\left(T_{1}+T_{2}+\ldots+T_{N}\right)
\end{aligned}
$$

where, $T_{\text {ave }}$ average temperature, $T_{i}$ is the temperature and $N$ is the number of grid cells inside the heart tissue. In this computational study, average volumetric temperature refers to the average temperature of all computational cells by considering their volumes. 


\subsection{Stress Analysis}

Stress analysis was performed for the simulated heart during the cooling process. It was assumed that heart tissue is a homogenous and isotropic material. The main objectives of stress analysis were to investigate thermal stresses and internal shear stresses applied by pumping the cold solution from the vessels to the chambers as the internal cooling process. The pressure inside the resting heart during cooling is less than the diastolic pressure of the beating heart. Because the heart will not be beating and the cooling process will be continuous (constant flow), it is acceptable to assume there would be little deformation of the heart chambers or vessels during the cooling process. The conservation of momentum for a homogeneous solid body element [64] can be written as

$$
\rho \frac{\partial^{2} \vec{u}}{\partial t^{2}}-\nabla \cdot \sigma-\vec{f}_{b}=0
$$

where $\vec{u}$ is the solid displacement vector, $\sigma$ is the stress tensor and $\vec{f}_{b}$ is the body force.

For a linear elastic solid body, stress tensor, $\sigma$, is written as

$$
\sigma=2 G \varepsilon+\lambda \operatorname{tr}(\varepsilon) \mathrm{I}
$$

where $\lambda$ and $G$ are the Lamé's first and second (shear modulus) parameters respectively, $\varepsilon$ is the strain tensor and $\mathrm{I}$ is the unit tensor. $\lambda$ and $G$ can be determined by using the following formulas

$$
\lambda=\frac{E v}{(1+v)(1-2 v)} \quad G=\frac{E}{2(1+v)}
$$


Here, $E$ is the module of elasticity, $v$ Poisson's ratio. The combined strain tensor $\varepsilon$ is defined as

$$
\varepsilon=\frac{1}{2}\left[\nabla \vec{u}+(\nabla \vec{u})^{\mathrm{T}}\right]+\alpha_{\mathrm{v}} \Delta T \mathrm{I} \quad \Delta T=T-T_{0}
$$

where $\alpha_{\mathrm{v}}$ is the coefficient of thermal expansion, $T_{0}$ is the reference temperature and the superscript $\mathbf{T}$ denotes the transpose. Combining equations $2.21,2.22$ and 2.24, the governing equation for an isotropic, homogenous, solid body with no motion and no external body forces, is

$$
\nabla \cdot\left[G\left(\nabla \vec{u}+(\nabla \vec{u})^{\mathrm{T}}+2 \alpha_{\mathrm{v}} \Delta T \mathrm{I}\right)+\lambda \operatorname{tr}\left(\nabla \vec{u}+\alpha_{\mathrm{v}} \Delta T \mathrm{I}\right)\right]=0
$$

The OpenFOAM stress analysis solver (solidDisplacementFoam) was applied for solving the above equation. This solver is a transient, segregated, finite-volume solver of linear-elastic, small-strain deformation. It also includes the thermal stresses.

The von Mises stress criteria was used to further study the stress field inside the heart during cooling. The von Mises stress is defined as

$$
\sigma_{v}=\sqrt{\frac{3}{2} \sigma^{\prime}: \sigma^{\prime}}
$$

where

$$
\sigma^{\prime}=\sigma-\frac{\operatorname{tr}(\sigma)}{3} I
$$

where $\sigma^{\prime}$ is the deviatoric stress tensor. Maximum stresses in all directions are also considered in stress analysis. The objective was to keep the maximum von Mises stress and the maximum of all stresses in different direction below the ultimate tensile stress of 
the heart tissue. Mechanical properties of the heart tissue were assumed to be the same as the cardiac muscle. The required data for mechanical properties of cardiac muscles are demonstrated in table 2.2. As this table shows, cardiac muscle has a very small thermal expansion coefficient.

Table 2.2. Mechanical properties of cardiac muscle

\begin{tabular}{|c|c|c|c|c|}
\hline Material & $\begin{array}{c}\text { Young's Elastic } \\
\text { Modulus (kPa) }\end{array}$ & $\begin{array}{c}\text { Ultimate Tensile } \\
\text { Stress }(\mathbf{k P a})\end{array}$ & $\begin{array}{c}\text { Poisson's } \\
\text { Ratio }\end{array}$ & $\begin{array}{c}\text { Thermal Expansion } \\
\text { Coefficient }\left({ }^{\circ} \mathbf{C}^{-1}\right)\end{array}$ \\
\hline Cardiac muscle & $80[65]$ & $110[65,66]$ & $0.4[67]$ & $0.0003[68]$ \\
\hline
\end{tabular}

\subsection{Domain Coupling}

The numerical procedures for coupling fluid and solid domains can be classified into two approaches: monolithic (implicit) and explicit (partitioned). In the monolithic method the governing equations for both the fluid and solid domains are derived based on the same primitive variables. This leads to one single solution matrix for the entire domain $[69,70]$. Figure 6 a illustrates a schematic view of the monolithic approach for a one time step. The major advantage of this method is its potential to attain higher accuracy and iteratively capture temperatures and heat fluxes at interfaces of heart tissue and coolant fluid and heart tissue and outside gelatin. The following are some of the major drawbacks of this method $[69,70]$.

- The single solution matrix requires a larger amount of memory to store all the primitive variables for both fluid and solid domains $[71,72]$. 
- There is a higher chance to obtain an ill-conditioned solution matrix due to differences in fluid and solid rigidity $[72,73]$.

- In cases with disparate time scales, the single time step for all domains can be inefficient [73].

- It is more difficult to generate a single mesh discretization that has the proper quality for each domain [74].

- More expertise is required to develop and maintain such a specialized, highly complex code $[75,76]$.

In contrast, the partitioned approach uses separate solution matrices, separate mesh discretizations, and separate numerical algorithms for fluid and solid domains. This method is the most useful for fluid-solid coupling. Figure 2.1 demonstrates the schema of partitioned coupling for a time step. As this figure shows, for each time step, fluid and solid solutions are coupled through their interface.

a)

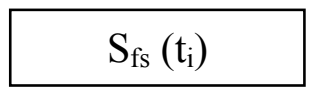

Time Step

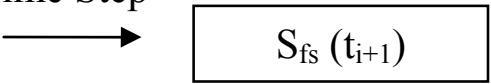

b)

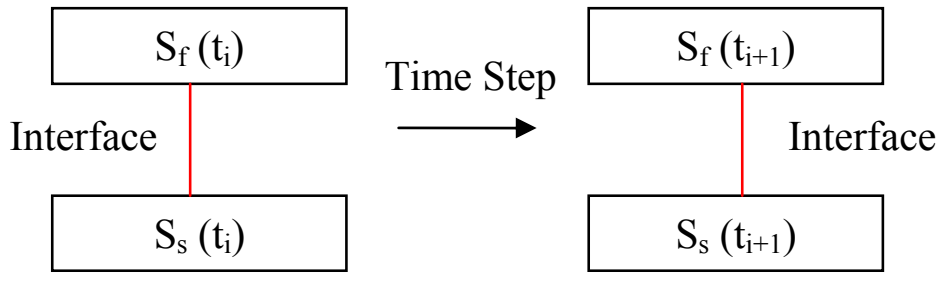


Figure 2.1. Schematic of coupling approaches for a one time step, a) monolithic coupling, and b) partitioned coupling. $\mathrm{S}_{\mathrm{f}}$ is fluid solution, $\mathrm{S}_{\mathrm{s}}$ is solid solution, and $\mathrm{S}_{\mathrm{fs}}$ is unified fluid-solid solution [69].

For this research the partitioned coupling method was used to couple solid and fluid domains. Figure 2.2 shows the coupled fluid and solid domains with their separate variables and separate meshes.

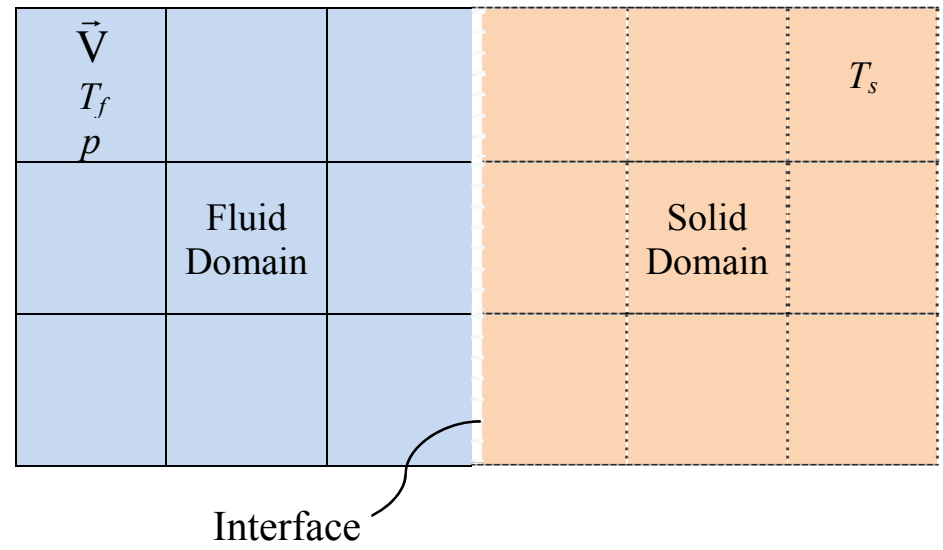

Figure 2.2. Partitioned coupling with separate variables and separate meshes.

Considering the governing equations for each domain as explained in previous sections, temperatures and heat fluxes should be equal at the interface, that is,

$$
T_{f}=T_{s} \quad \text { and } \quad K_{f} \nabla T_{f}=K_{s} \nabla T_{s}
$$

where, $T_{f}$ and $T_{s}$ are the temperatures of fluid and solid domains, respectively. Boundary conditions were applied on boundary patches. Each patch consisted of numerous surface triangles. Coupled boundary patches are updating at each global iteration as follow 
1. Solve the fluid flow and fluid temperature equation (find $\overrightarrow{\mathrm{V}}$ and $T_{f}$ in the entire fluid domain).

2. Apply the temperature on the fluid-solid interface $\left(T_{f}=T_{s}\right)$.

3. Solve for the temperature in the solid domain (find $T_{s}$ for the entire solid domain).

4. Update the fluid temperature at the fluid-solid interface using the new heat flux $\left(K_{f} \nabla T_{f}=K_{s} \nabla T_{s}\right)$.

Solvers for each domain were placed inside a loop to achieve the coupled convergence through a global iterative process. Multi-region, three-dimensional, unsteady conjugate heat transfer OpenFOAM solver (chtMultiRegionFoam) was applied for simulations. The chtMultiRegionFoam is a parallel solver that has been validated by different researchers [77]. In following sections, OpenFOAM software platform, numerical schemes and procedures are explained.

\subsection{OpenFOAM Software Platform}

The OpenFOAM® (Open Field Operation and Manipulation) software platform was used for simulations [78]. The OpenFOAM CFD Toolbox is a free, open source CFD software package with more than 80 solvers that simulate specific problems in engineering mechanics and more than 170 utility applications that perform pre- and postprocessing tasks such as meshing, data visualization, etc. By being an open access 
Toolbox, OpenFOAM offers users complete freedom to customize and extend its existing functionality, either by themselves or through support from OpenCFD [78]. The following are advantages of OpenFOAM compared to closed source softwares [78]

- It allows users to have total freedom to create or modify a solver.

- It allows users to reuse functionality that is pre-compiled into shared libraries.

- Solvers can be used by a specific need rather than "bolt-on" subroutines.

- All applications, including those for meshing, CFD simulations, preprocessing and post-processing are compiled using common functionality in the collection of libraries included in OpenFOAM. This ensures consistency in the entire OpenFOAM distribution, rather than having a suite of packages compiled from completely separate source code.

- It has transparent solution algorithms which can be viewed by the user to better understand the underlying physics.

OpenFOAM by using advanced level $\mathrm{C}++$ as the core programming language brings major benefits to users [78]

- Easier to debug codes and error checking at both compile and run time.

- Extremely robust solver and utility executable.

- High speed calculation with efficient memory management and fast linear equation solvers.

- Parallel processing with linear speed up with number of processors. 


\subsection{Discretization}

The discretization process in a numerical simulation can be divided into two parts: 1) discretization of the solution domain (section 2.5.1), and 2) discretization of governing equations $[79,80,81]$ (section 2.5.2).

\subsubsection{Solution Domain Discretization}

The aim of solution domain discretization is to generate a computational mesh for solving the governing equations. The solution domain discretization can also be divided in two parts: discretization of space and discretization of time (for transient simulations). For space discretization, the space is divided into a finite number of control volumes known as computational cells. Figure 2.3 shows two cells which are connected through their common face.

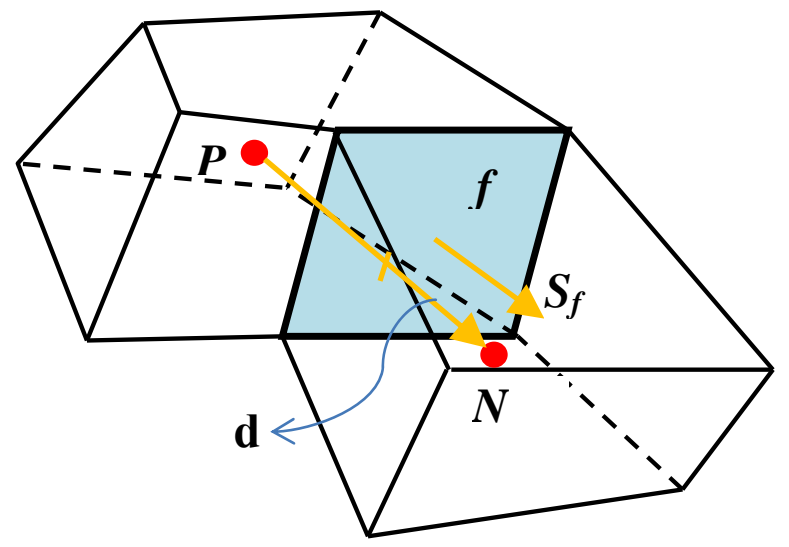

Figure 2.3. Control volume discretization. 
All dependent variables and properties are saved at the cell centroid $P$. They may also be stored on faces or vertices. Each cell is bounded by a set of flat faces $(f$ in figure 2.3). OpenFOAM does not have any limitation for the number of faces bounding each

cell, and for the alignment of each face. This kind of mesh is also known as "arbitrarily unstructured mesh" to differentiate it from meshes in which the cell faces have a prescribed alignment, typically by the coordinate axes [78]. $S_{f}$ is the face area vector is constructed for each face in such a way that it points outwards from the cell. This vector is normal to the face and has the magnitude equal to the area of the face. Figure 2.3 shows two types of faces for cells. One is the internal faces which connect two cells. One of the adjoining cells is considered as the internal face owner and the other one is considered as the internal face neighbor. $N$ is the center of the neighbor cell.

For time discretization in transient simulations, the time interval is broken into a finite number of time steps. The size of time step may vary by monitoring certain conditions calculated during the numerical simulation [81].

\subsubsection{Governing Equations Discretization}

There are two approaches for numerically solving a set of governing equations: simultaneous algorithm and segregated algorithm. In simultaneous algorithms [82, 83, 81] the Nervier-Stokes are solved simultaneously over the entire solution domain. These algorithms might be considered when the number of computational cells is small and the number of governing equations is not too large. The solution matrix for these algorithms includes the inter-equation coupling and is several times larger than the number of 
computational cells. Therefore, cost of a simultaneous solutions is high, both in the number of operations and memory requirements [81].

In another approach known as segregated approach $[84,85]$ the equations are solved in a specific sequence. Thus, a special treatment is required in order to establish the necessary inter-equation coupling in the pressure-velocity system. The two most popular schemes for the inter-equation couplings are PISO [85], SIMPLE [84] and their derivatives.

OpenFOAM fluid flow solver used in this project applies the PISO (Pressure Implicit with Splitting of Operators) algorithm [86, 81] for the pressure-velocity transient problems. Figure 2.4 demonstrates all numerical steps required in PISO algorithm in the flow chart format. This algorithm allows more than one pressure-velocity correction.

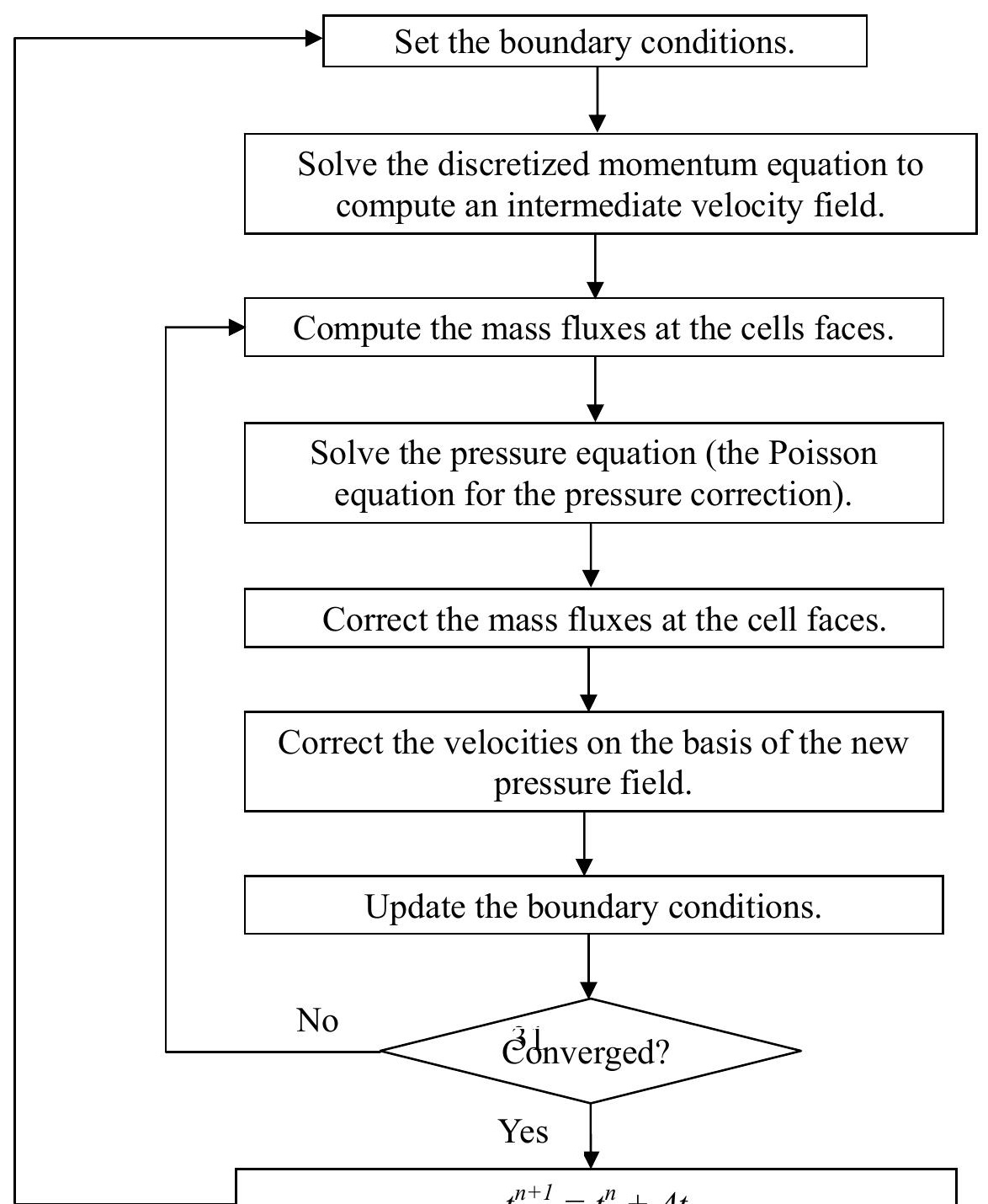


Figure 2.4. PISO algorithm flow chart.

The major advantages of PISO over SIMPLE algorithm are

$\checkmark$ It does not need under-relaxation factors

$\checkmark$ The momentum corrector step is performed more than once

$\checkmark \quad$ It is useful for irregular cells

Another correction can be applied to account for the non-orthogonality of the computational grid. Some of boundary conditions are defined based on the pressure and velocity of solution domain. Therefore, they should be updated after calculation of new velocity and pressure fields. For instance, OpenFOAM has a boundary condition (inletOutlet or outletInlet) which switches a Dirichlet boundary condition to a zero gradient boundary condition and vice versa, based on the information obtained from the fluid field.

For Navier-Stokes equation, a first order implicit Euler scheme was applied for discretization of first time derivatives [87]

$$
\frac{\partial}{\partial t} \int_{V} \rho \Phi d V=\frac{\left(\rho_{P} \Phi_{P} V\right)^{n}-\left(\rho_{P} \Phi_{P} V\right)^{o}}{\Delta t}
$$

in which superscript $n$ indicate new values and superscript $o$ indicate old values. $\Phi$ can represent any tensor field. Subscript $P$ indicates the center of the cell. $\Delta t$ is the time step.

The convection term is integrated over a control volume and linearized as follow

$$
\int_{V} \nabla(\rho \vec{V} \Phi) d V=\int_{S} d S \square(\rho \vec{V} \Phi)=\sum_{f} S_{f} \square(\rho \vec{V})_{f} \Phi_{f}=\sum_{f} F \Phi_{f}
$$

The face field value, $\Phi_{f}$, is determined by using one of the following schemes 
- Upwind differencing (UD) in which $\Phi_{f}$ is calculated based on the direction of flow

$$
\Phi_{f}=\left\{\begin{array}{lll}
\Phi_{P} & \text { for } & F \geq 0 \\
\Phi_{N} & \text { for } & F<0
\end{array}\right.
$$

Subscript $P$ indicates the center of a neighboring cell, $F$ is the convection mass flux $(\rho \overrightarrow{V A})$.

- Central differencing (CD) which is a second order bounded scheme

$\Phi_{f}=f_{x} \Phi_{P}+\left(1-f_{x}\right) \Phi_{N}$

where $f_{x}=\overline{f N} / \overline{P N} \cdot \overline{f N}$ is the distance between $f$ and cell center $N, \overline{P N}$ is the distance between cell centers $P$ and $N$.

- $\quad$ Blended differencing (BD) which is a combination of upwind and central differencing

$$
\Phi_{f}=(1-\gamma)\left(\Phi_{f}\right)_{U D}+\gamma\left(\Phi_{f}\right)_{C D}
$$

For selecting $\gamma$, OpenFOAM offers several schemes including the wellknown schemes such as van Leer, SUPERBEE, MINMOD [87].

Gauss integration method was used for discretization of gradient terms. The discretization is performed by applying the standard method of Gauss's theorem to the volume integral [87]

$$
\int_{V} \nabla \Phi d V=\int_{S} \Phi d S=\sum_{f} S_{f} \Phi_{f}
$$

The divergence term is linearized by integration over a control volume 


$$
\int_{V} \nabla \square \Phi d V=\int_{S} d S \llbracket \Phi=\sum_{f} S_{f} \square \Phi_{f}
$$

in which $\Phi_{f}$ either can be specified directly at surfaces, or can be determined by central differencing for a volume field.

\subsection{Parallel Computing in OpenFOAM}

OpenFOAM employs domain decomposition to perform a process level numerical parallelization of numerical algorithms $[88,89]$. The global computational domain is divided into separates computational subdomains. Then, each subdomain will be allocated to separate processors [90, 91]. Subdomains will have different meshes, and in case of a multi-physics simulation, they could have different governing equations as well. The mapping between processors and the subdomains is one-to-one. Therefore, it can be considered as a single program multiple data parallelism (SPMD). In this case, each processor executes its program based on its own set of data. To proceed calculations, each processor will need data that exists in other subdomains, thus, they have to be able to communicate with each other to synchronize their data. OpenFOAM's decomposition methods are presented separately in the next section.

OpenFOAM uses the standard message passing interface (MPI) for communications synchronization between the processors on each subdomain. There are two types of communication: communication with neighboring, and global communication with all the processors. 
One of the most common approaches for the communication scheme is the overlapping elements, which duplicates the cells next to subdomains common boundaries. This method is known as halo-layer approach [81, 88]. OpenFOAM applies the zero-halo layer approach for domain decomposition $[81,88]$. Figure 2.5 illustrates the zero-halo layer approach. The red lines are internal edges which will be treated as boundaries in this approach. These boundaries are known as inter-processor (or processor) boundaries which are updated implicitly through communications between processors.
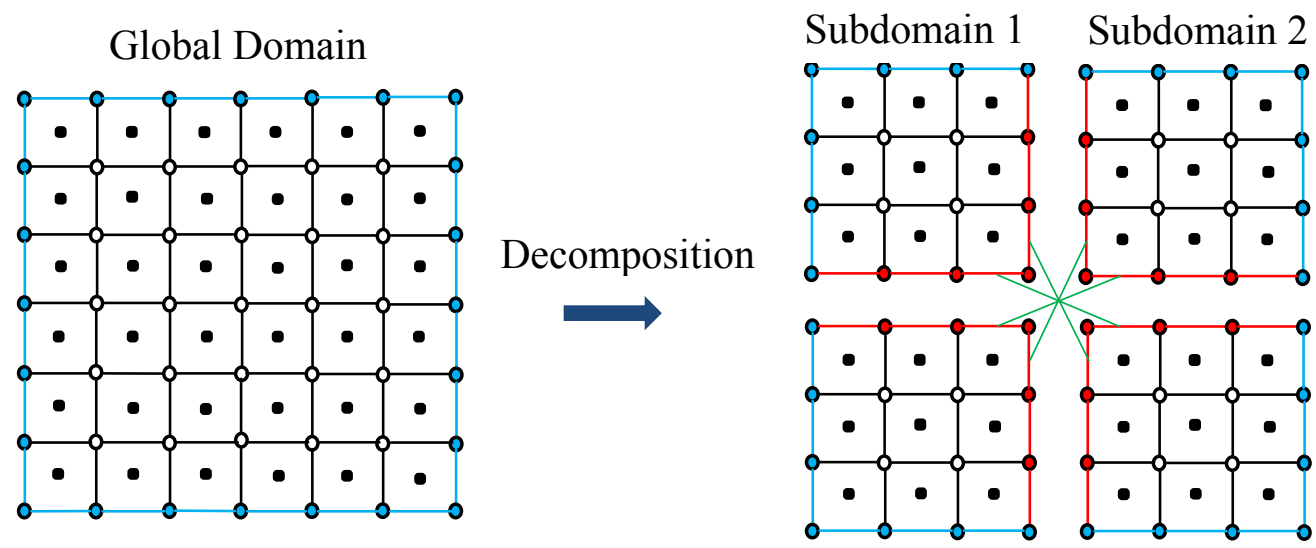

Subdomain 3 Subdomain 4

Figure 2.5. Zero-halo layer approach for domain decomposition.

Each inter-processor face only belongs to two subdomains. In the zero-halo layer approach, the faces can be categorized as $[89,92]$

1. Internal faces (within a single processor mesh)

2. Boundary faces 


\section{Inter-processor boundary faces}

The inter-processor boundary is the difference between the parallel and serial computational domains. The zero-halo layer approach has a major impact on the code design since it requires all cell and face loops to recognize and handle the halo layer.

From algorithm point of view, the zero-halo layer is an inconsistent approach. It has coupled boundary with out-of-core addressing in different places in the code [92]. It is similar to the cyclic or periodic boundary conditions. For instance, to calculate the gradient operator (using the Gauss's theorem), face values of the variable need to be evaluated. For internal faces, the evaluation is performed using an interpolation scheme such as the central interpolation, equation 2.12. In inter-processor boundary cells, $\Phi_{P}$

and $\Phi_{N}$ are on different processors. Assuming $\Phi_{P}$ is local, then $\Phi_{N}$ can be fetched through pairwise communication. The evaluation of face values between two domains can be done in three steps [92]

1. Collect internal cell values from local domain and send them to the neighboring processor

2. Receive internal cell values from neighboring processor

3. Evaluate inter-processor face value using interpolation

The parallel communications are wrapped in a Pstream module, which isolates the communications details from OpenFOAM solvers. Thus, similar patterns can be seen in 
local computations that require an interface influence to be included. The communication wrapper Pstream contains processor rank and size, and performs both point-to-point and collective communications [89].

\subsection{Domain Decomposition Methods}

OpenFOAM has four decomposition methods for dividing the solution domain into non-overlapping subdomains $[88,78]$. These methods are Simple, Hierarchical, METIS [93], and SCOTCH [94]:

- Simple decomposition:

The simple geometric decomposition splits the global domain into subdomains by coordinate in a tensor product fashion. The number of partitions per each coordinate should be specified.

- Hierarchical decomposition:

This method is similar to the simple decomposition method except the directions of splits which need to be specified by user. For instance first $n$ splits in the $\mathrm{x}$ direction and then $m$ splits in the y direction.

- METIS decomposition:

METIS is a powerful library for partitioning and ordering matrices and graphs. OpenFOAM uses this library to partition the computational domain. 
By default OpenFOAM minimizes the communication volume by using multilevel k-way partitioning. METIS decomposition has two partitioning methods: multilevel recursive bisections and multilevel k-way partitioning. Both of these methods try to minimize the communication volume between processors. Moreover, these methods enable users to specify weights for the different subdomains. There is also a parallel version for METIS which is called ParMETIS.

- SCOTCH decomposition:

SCOTCH is also a versatile partitioning and ordering library which is available in OpenFOAM. This decomposition method also attempts to minimize communication volume between processors by minimizing the number of internal boundaries. The main objective is to split the edges in a way to have the minimum internal boundaries for communications.

This library employs different partitioning methods such as the multilevel FM-like algorithms, k-way graph partitioning and recursive bi-partitioning. It is also possible to assign different weights for different processors. PtSCOTCH is the parallel version of this method. 


\section{CHAPTER III}

\section{SEMI-CONJUGATE AND CONJUGATE COOLING SYSTEMS}

Heat geometry and cooling container design are presented in section 3.1. The first semi-conjugated cooling system, in which only the cooling gelatin was used for the external cooling, is discussed in section 3.2. Section 3.5 presents the conjugated cooling system. In this cooling system, only the cooling liquid was used for the internal cooling.

\subsection{Heart Geometric Model and Implementation}

To better understand the details of human heart geometry, a simplified schematic model of the human heart is shown in figure 3.1a. This figure shows the direction of blood flow in the chambers and vessels of the heart. Figure $3.1 \mathrm{~b}$ demonstrates the circulatory pressure distributions inside the normally beating heart [95]. The blood circulatory system in the heart consists of the systemic (left) and pulmonary (right) circulations. The left heart systemic circulation system (depicted in red) pumps oxygenated blood to the body, and consists of left pulmonary veins, right pulmonary veins, left atrium, mitral valve, left ventricle, semilunar valve, and aorta, which normally has three cephalad branches, i.e., brachiocephalic artery, left common carotid artery and left subclavian artery. 
a)

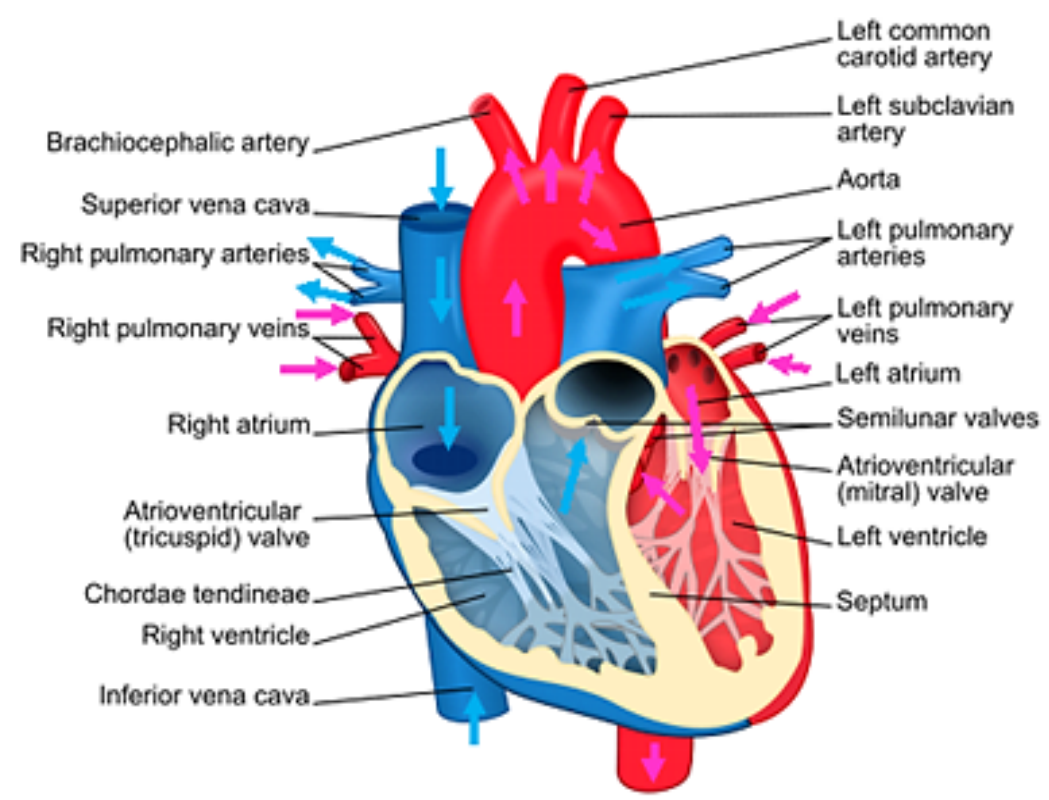

b)

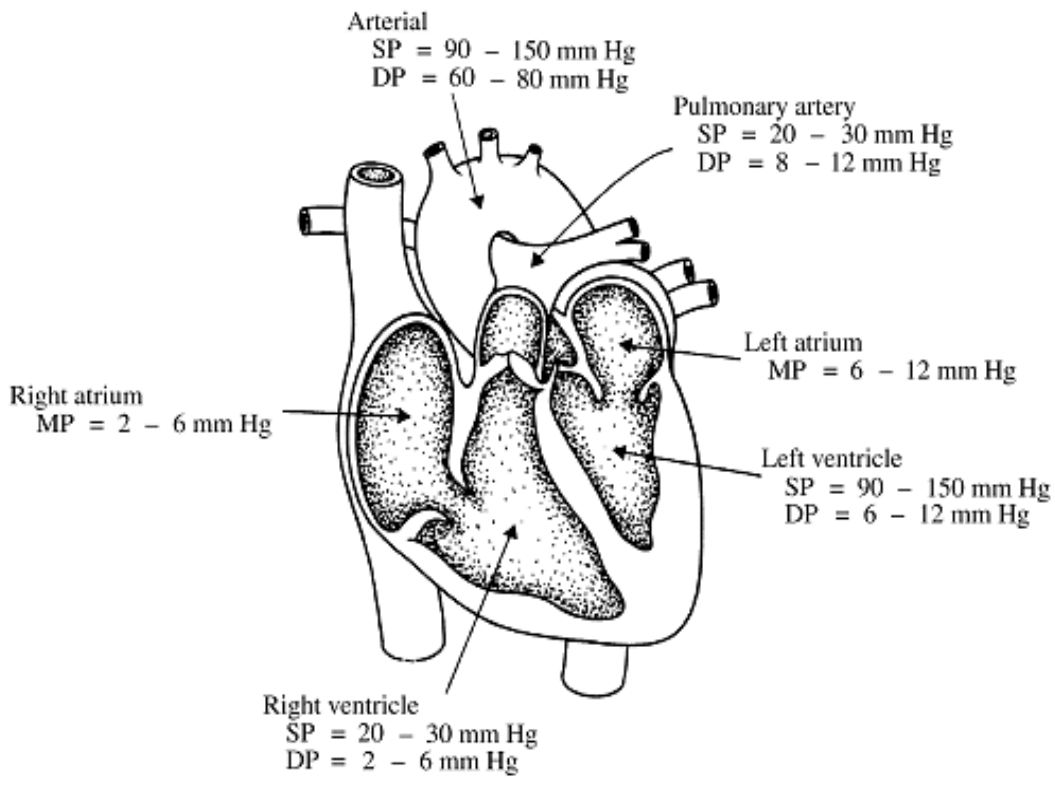

Figure 3.1. Heart anatomy, a) blood flow circulation, and b) typical values of circulatory pressures (SP is the Systolic Pressure, DP is the Diastolic Pressure, and MP is the Mean Pressure) [95]. 
The heart right pulmonary circulation system (depicted in blue) pumps deoxygenated blood to the lungs, and consists of the inferior vena cava, superior vena cava, right atrium, tricuspid valve, right ventricle, semilunar valve, and right and left pulmonary arteries.

Ranges in the velocity of blood flow in the major inflow and outflow vessels of the heart are shown in table 3.1. Maximal blood flow ejection velocity is in the aorta, whereas the superior vena cava has a minimal and smaller inlet velocity compared to the inferior vena cava.

Table 3.1. Velocity of blood flow.

\begin{tabular}{|l|c|c|}
\hline Major Vein & Inlet/Outlet & Velocity (cm/s) [reference] \\
\hline Aorta & Outlet & $108-120[96]$ \\
\hline Superior Vena Cava & Inlet & $10-35[97]$ \\
\hline Inferior Vena Cava & Inlet & $30-45[97]$ \\
\hline
\end{tabular}

The complex geometry of the human heart is a major challenge for undertaking this thermal fluid stress analysis. For the present analysis the human heart geometry model developed by Zhang, Bajaj and Goswami $[55,58]$ from CT-angio data was used for all simulations. This model (figure 3.2 a) does not include the coronary circulation; that is, this internal heart cooling system consisted of coolant pumped through the major vessels and heart chambers. The multi-physical components of this computational analysis requires having three separate domains; inside the heart (chambers), the heart tissue itself, and outside the heart. The first step in creating the required domains was to separate the innermost (blood contact) surfaces from outermost surfaces as shown in figure 3.2b. 
a)

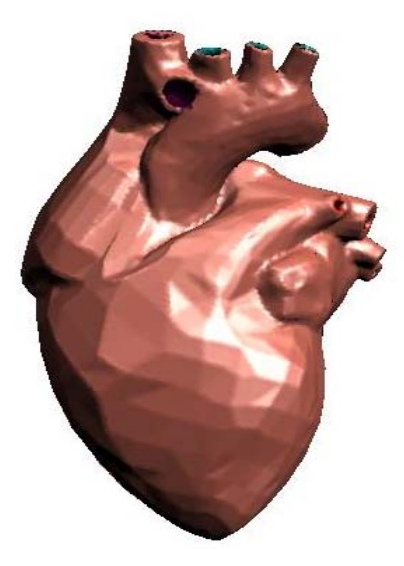

b)

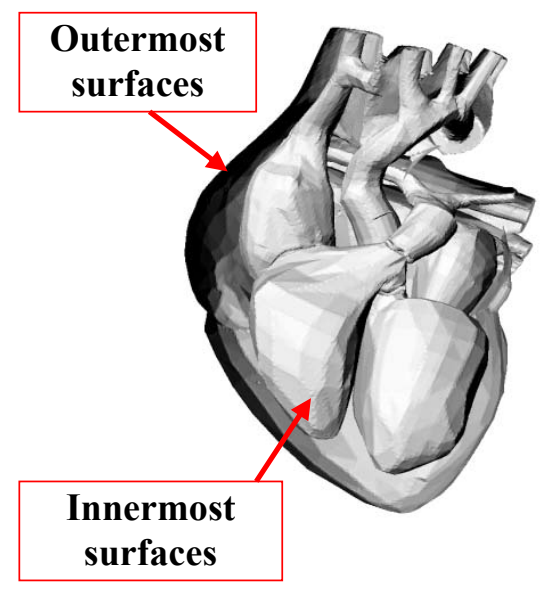

Figure 3.2. Heart model, a) whole heart $[55,58]$, and b) innermost (blood contact) and outermost surfaces.

Figure 3.3 demonstrates different domains surfaces in different colors. The blood contact surface which consists of the right (pulmonic) and left (systemic) heart circulations domains are shown in green and blue, respectively. Figures $3.3 \mathrm{a}$ and $3.3 \mathrm{~b}$ show the outermost surfaces in red.

a)

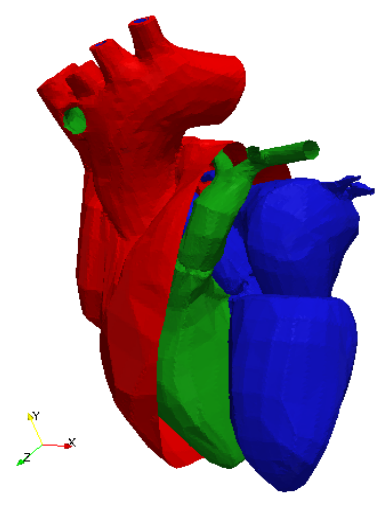

b)

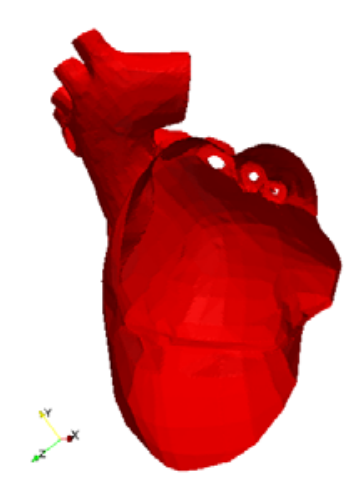


c)

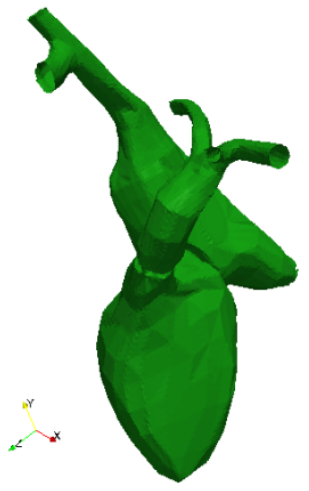

d)

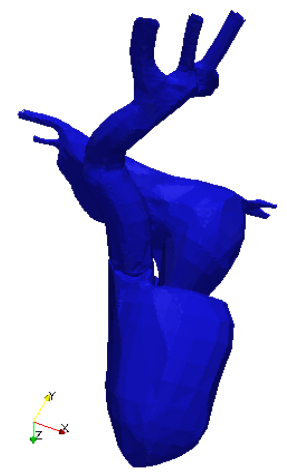

Figure 3.3. Heart surfaces: a) all surfaces, b) outermost surfaces, c) heart pulmonary circulation domain surfaces, and d) heart systemic circulation domain surfaces.

A hexahedra (figure $3.4 \mathrm{a}$ ) of $214 \mathrm{~mm}$ in length, $212 \mathrm{~mm}$ in width and $282 \mathrm{~mm}$ in height, with 4 inlets and 4 outlets was virtually designed as the heart-cooling container. These inlets/outlets which can be seen in figure 3.4, are specifically designed for internal cooling circulations. Figure $3.4 \mathrm{~b}$ shows the designed connections and caps for pumping coolant through the pulmonic and systemic vessels.
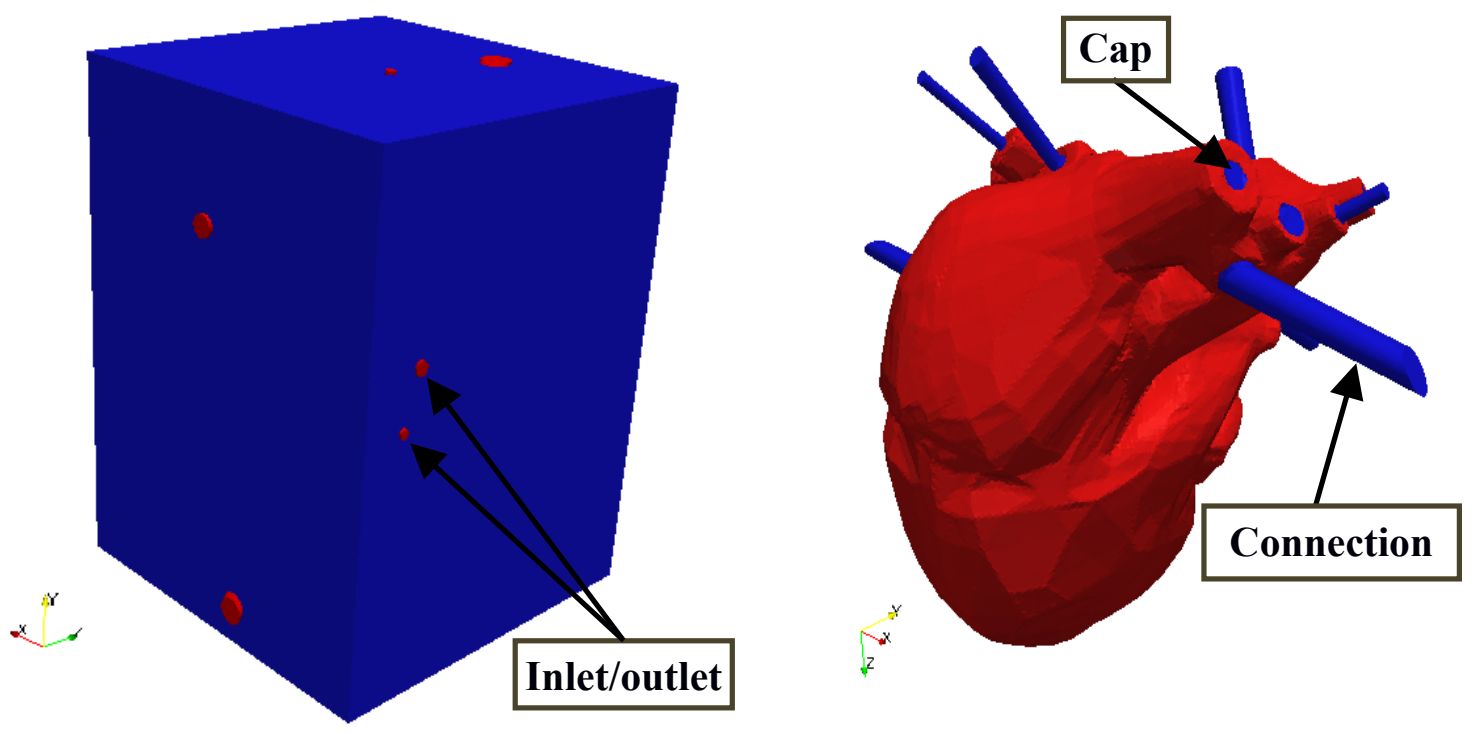
c)

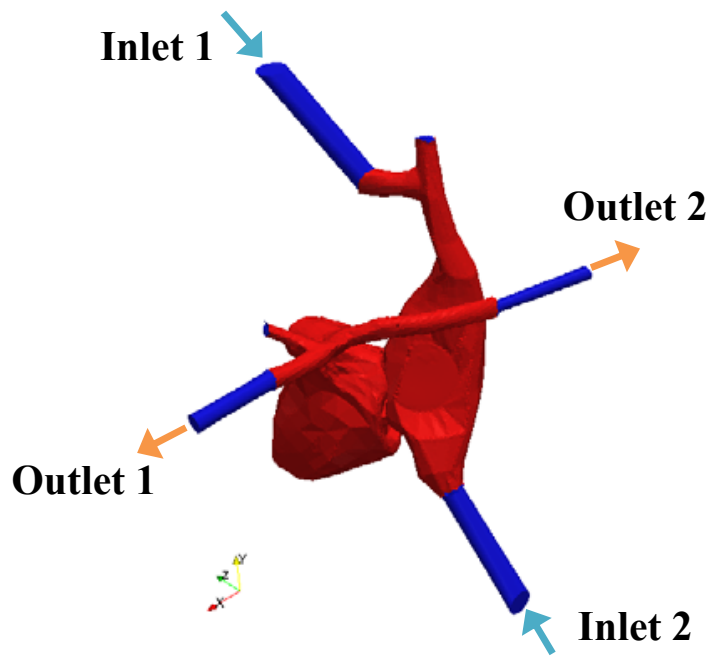

d)

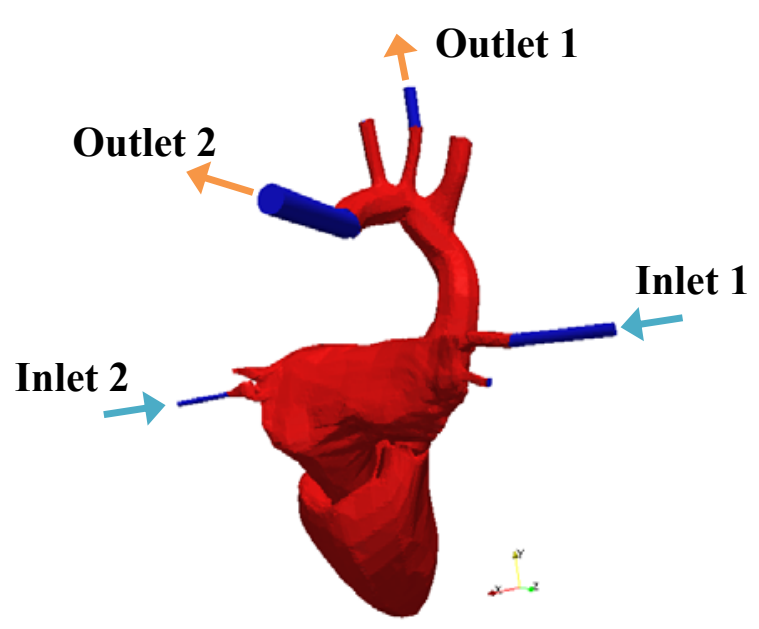

Figure 3.4. Cooling system: a) cooling container, b) connections and caps, c) circulation directions for the right (pulmonic) heart, and d) circulation directions for the left (systemic) heart.

For each of the two heart ventricles, two inlets and two outlets were incorporated to pump the coolant through the heart chambers as shown in figures $3.4 \mathrm{c}$ and $3.4 \mathrm{~d}$. For the right (pulmonic) heart circulation, the inferior vena cava and superior vena cava are the two flow inlets and one of the right pulmonary arteries and one of the left pulmonary arteries are the two flow outlets. For the left (systemic) heart circulation, one of the left pulmonary veins and one of the right pulmonary veins are the two flow inlets, and the aorta with one of its cephalad branches (left common carotid artery) are the two flow outlets. As these figures illustrate, the coolant will be pumped into the heart chambers in the same directions as that in an intact heart and circulatory system. This allows for the cooling solution to flow through chambers with the heart valves promoting forward flow and preventing backward flow, as occurs naturally. 


\subsection{Case 1 - Gelatin Cooling (Outside)}

In this cooling design, the heart is submersed inside gelatin cooling gel to apply external cooling. This cooling case was named "semi-conjugate" because the heart was cooled by using only one domain (outside of the heart). A multi-domain unsteady conduction heat transfer equation was solved for the heart tissue and its surrounding cooling gelatin. Temperature boundary conditions for the cooling container walls are given in table 3.2. Each wall had a constant value for temperature. The minimum and maximum wall temperatures were set at $-1{ }^{\circ} \mathrm{C}$ and $+1{ }^{\circ} \mathrm{C}$, respectively. The minimum wall temperature could be less than $-1{ }^{\circ} \mathrm{C}$, but the reason for choosing $-1{ }^{\circ} \mathrm{C}$ as the minimum temperature was to avoid cooling of the heart below $+4^{\circ} \mathrm{C}$, which might damage the heart cells if pure water domains were allowed to form ice crystals. Two wall temperatures, one set to $0^{\circ} \mathrm{C}$ and one set to $+1^{\circ} \mathrm{C}$ (table 3.2) were used to investigate the influence of different wall temperatures on differential cooling of the heart. The initial temperature of gelatin was assumed to be $+4^{\circ} \mathrm{C}$. The initial temperature of the heart was assumed to be $+37^{\circ} \mathrm{C}$.

Table 3.2. Boundary conditions for cooling container walls.

\begin{tabular}{|l|c|c|c|c|c|c|}
\hline Container Wall at & $\mathbf{X}_{\max }$ & $\mathbf{X}_{\min }$ & $\mathbf{Y}_{\max }$ & $\mathbf{Y}_{\min }$ & $\mathbf{Z}_{\max }$ & $\mathbf{Z}_{\min }$ \\
\hline Temperature & $0^{\circ} \mathrm{C}$ & $-1^{\circ} \mathrm{C}$ & $-1^{\circ} \mathrm{C}$ & $-1^{\circ} \mathrm{C}$ & $0^{\circ} \mathrm{C}$ & $+1^{\circ} \mathrm{C}$ \\
\hline
\end{tabular}

The initial temperature for the heart-gelatin interface was set as the average temperature of the heart and gelatin which was $+20.5^{\circ} \mathrm{C}$. 
Heat transfer analysis was performed for a cooling time of 1500 s. It was assumed that the major temperature reduction should occur within this interval. Therefore, $1500 \mathrm{~s}$ was chosen as the target time interval. A workstation computer with the Ubuntu 13.10 Linux OS was used for this simulation. Thermal simulation was run on 4 cores of an Intel Core i7, $3.4 \mathrm{GHz}$, Six Core with $64 \mathrm{~GB}$ memory. Total computing time was $2532 \mathrm{~s}$.

Figure 3.5 shows the temperature distributions in a sagittal view at $0 \mathrm{~s}, 300 \mathrm{~s}, 600 \mathrm{~s}$, $900 \mathrm{~s}, 1200 \mathrm{~s}$ and $1500 \mathrm{~s}$. A constant color legend from $+1^{\circ} \mathrm{C}$ to $+37^{\circ} \mathrm{C}$ was used to better illustrate the temperature variation of the heart tissue. Figure 3.5a illustrates the heart tissue's temperature distribution at the very beginning of the cooling process when the heart temperature was $+37^{\circ} \mathrm{C}$. The green color on the outermost surface of the heart in figure $3.5 \mathrm{a}$ is the initial coupled temperature between the warm heart and cold gelatin which was $+20.5^{\circ} \mathrm{C}$. The red color in figure 3.5 signifies the warmer spots (hot spots) within the heart tissue. As the cooling process continued, the red color turned to green, and then blue due to the temperature reduction of the heart tissue. Therefore, the minimum and maximum temperatures of the heart are not necessarily equal to the minimal to maximal range of the color legend. As this figure illustrates, there was a very large size higher temperature region remaining in the core of the heart after $1500 \mathrm{~s}$. This occurred due to lack of internal cooling. 
a)

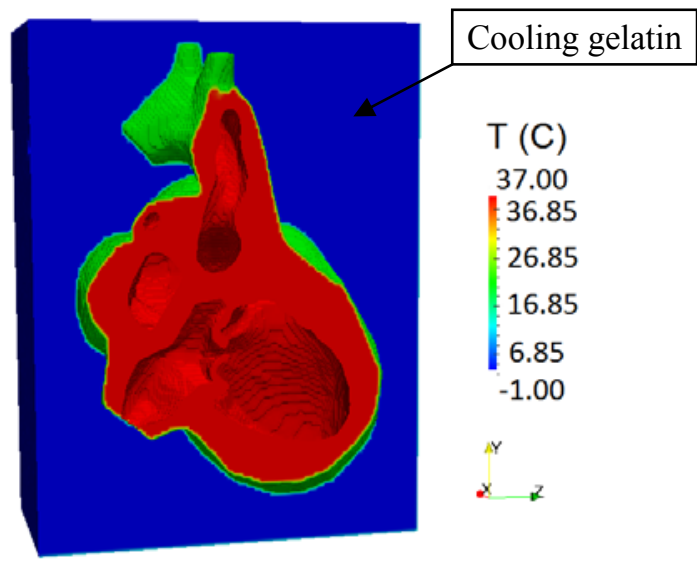

c)

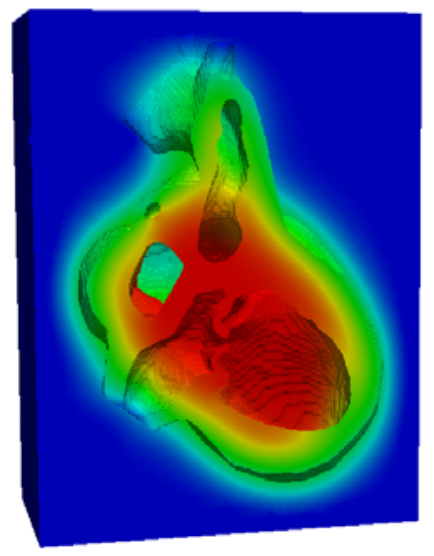

$\mathrm{T}(\mathrm{C})$

37.00

36.85

: 26.85

16.85

6.85

$-1.00$

iY

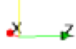

e)

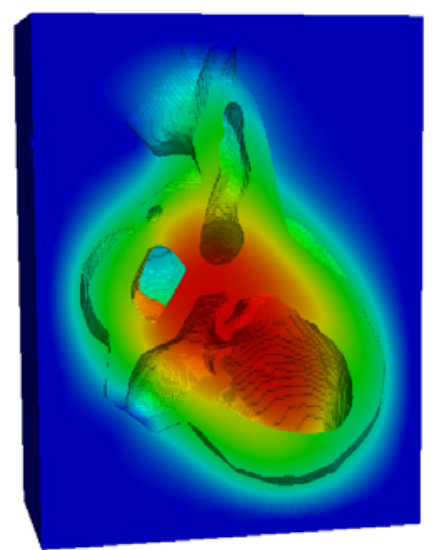

$T(C)$
37.00
36.85
26.85
16.85
6.85
-1.00
$\triangle Y$
$\times \quad Z$

b)

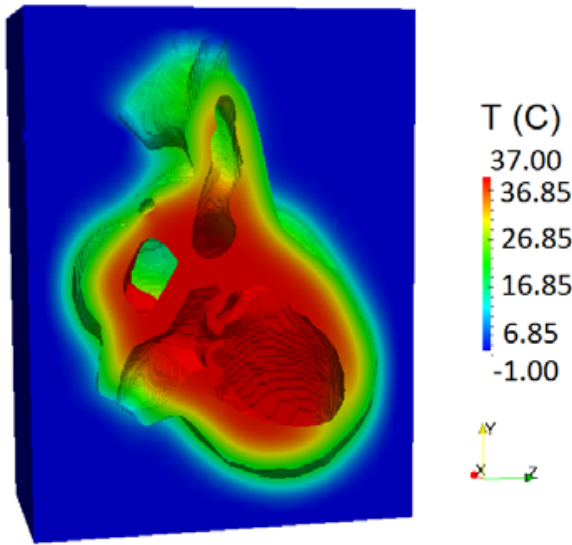

d)

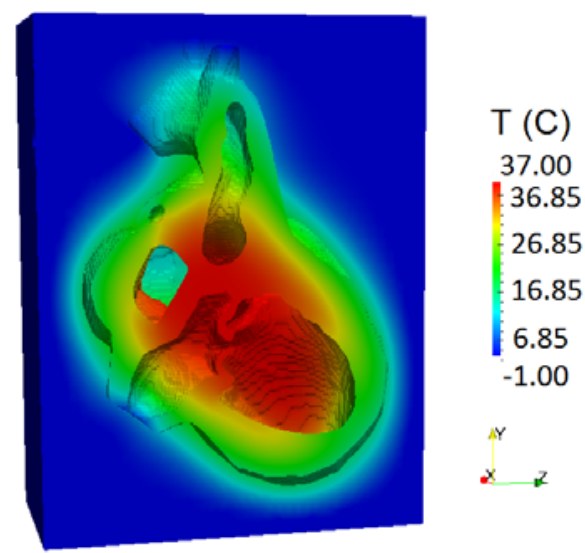

f)

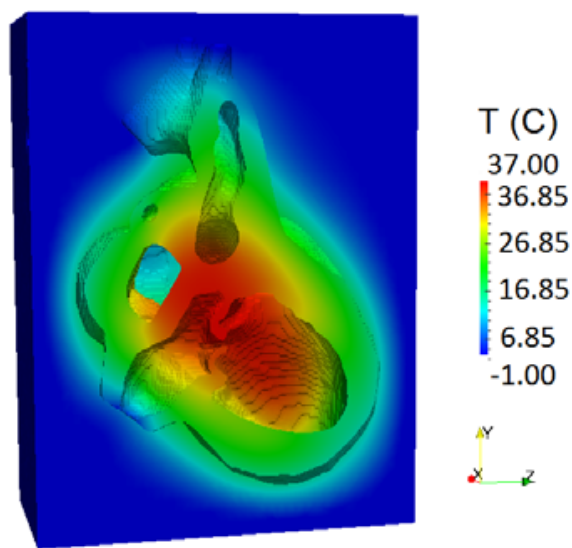

Figure 3.5. Temperature distribution (sagittal view): a) $0 \mathrm{~s}$, b) $300 \mathrm{~s}, \mathrm{c}) 600 \mathrm{~s}$, d) $900 \mathrm{~s}$, e) $1200 \mathrm{~s}$, and f) $1500 \mathrm{~s}$. 
To further reveal the temperature variations inside the heart during the cooling process, the maximum and minimum and average volumetric temperatures are shown in figure 3.6 demonstrating that variation of the minimum temperature is not significant. In this computational study, average volumetric temperature refers to the average temperature of all computational cells by considering their volumes.

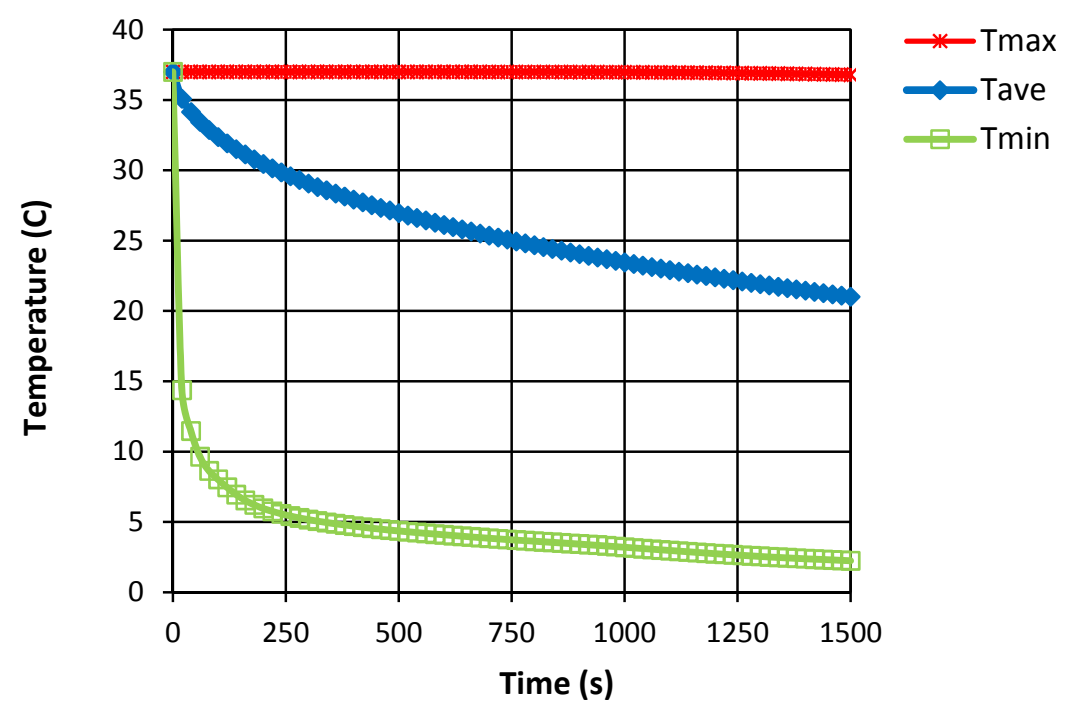

Figure 3.6. a) Temperature variations (maximum, minimum and average volumetric temperatures of the heart) $v s$. time.

The heart temperature will begin to decrease as soon as the coolant begins to flow. Since the gelatin has its minimum temperature at the beginning of cooling, the minimum temperature of the heart will drop noticeably at the beginning of cooling. The minimum temperature of the heart was $+2.2^{\circ} \mathrm{C}$ after $1500 \mathrm{~s}$ of cooling, which is less than the target of $+4^{\circ} \mathrm{C}$. This low temperature occurs on the very small part of outermost surfaces of the 
heart, which lie close to the container wall. The reason for this local low temperature is the small gap between the container wall, at $-1^{\circ} \mathrm{C}$, and the heart. Figure 3.6 shows a slight reduction in the maximum temperature of the heart to $+36.8^{\circ} \mathrm{C}$ after $1500 \mathrm{~s}$ of cooling with gelatin. The average volumetric temperature was reduced to $+21^{\circ} \mathrm{C}$ after $1500 \mathrm{~s}$.

$\mathrm{CV}$ of the average volumetric temperature (figure 3.7) demonstrates that nonuniformity of the average volumetric temperature increased until $500 \mathrm{~s}$ and then started to decrease with a very low slope. This is because of the slow pure conduction heat transfer from the outside of the heart. Therefore, the temperature non-uniformity was relatively small and was decreasing slowly.

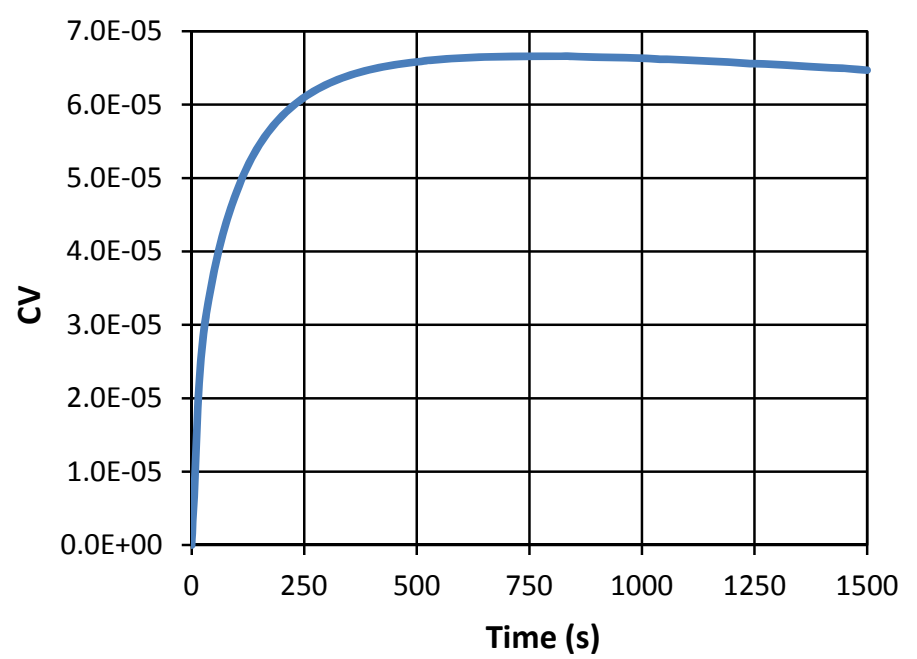

Figure 3.7. Coefficient of variation of average temperature $v s$. time.

The results suggest that pure heat conduction cooling with gelatin from the outside of the heart was not capable of removing sufficient amount of heat within the target time interval of $1500 \mathrm{~s}$. 


\subsection{Case 2 - UW Cooling (Inside)}

In this cooling design, the major heart vessels are connected to the cooling container via tubes to pump the UW solution within the heart. This design was named "conjugate" because it was cooling the heart using two internal circulation domains. For simulation of this cooling system, unsteady conjugate heat transfer equations presented in chapter II were solved using OpenFOAM software platform.

Table 3.3 shows the boundary conditions applied for these two domains. Considering the maximal averaged velocity of blood flow inside the beating heart given in table 3.1, and the diameter of each of the designated inlets, we chose the averaged inlet coolant velocities of $1 \mathrm{~m} / \mathrm{s}$ for the systemic circulation and $0.4 \mathrm{~m} / \mathrm{s}$ for the pulmonary circulation using the UW coolant as the fluid. The outlet pressure values were assumed to be the same and equal to $101 \mathrm{kPa}$ and constant. The temperature of the cooling fluid at the inlet was set as the minimal allowable temperature for the cooled organ, $+4^{\circ} \mathrm{C}$. Although the lowest allowed temperature was set at $+4^{\circ} \mathrm{C}$ in the simulations to avoid water ice crystals, some coolants with high osmolarities, such as UW solution, have a freezing point well below $+4^{\circ} \mathrm{C}$.

Table 3.3. Boundary conditions for fluid domains.

\begin{tabular}{|l|c|c|}
\hline Boundary Condition & $\begin{array}{c}\text { Heart Pulmonary } \\
\text { Circulation }\end{array}$ & $\begin{array}{c}\text { Heart Systemic } \\
\text { Circulation }\end{array}$ \\
\hline Inlet velocity magnitude & $0.4 \mathrm{~m} / \mathrm{s}$ & $1 \mathrm{~m} / \mathrm{s}$ \\
\hline Outlet pressure & $101 \mathrm{kPa}$ & $101 \mathrm{kPa}$ \\
\hline Inlet coolant temperature & $+4^{\circ} \mathrm{C}$ & $+4^{\circ} \mathrm{C}$ \\
\hline
\end{tabular}


A sub-zero temperature of the coolant would allow simulation of even faster cooling. However, it would likely not have a positive effect to enhance temperature uniformity in the heart wall, where temperature variation is governed by heat conduction. A parallel computer with the Red Hat Enterprise Linux Server 6.2 OS and LSF scheduler was used for simulations. Thermo-fluid simulation was run on 4 Intel Xeon CPU E52420 processors. Each processor has 6 physical cores, 12 threads and 48 GB memory. Total computing time was $108,751 \mathrm{~s}$.

Figure 3.8a illustrates the heart tissue's temperature distribution (cut-away view) during the cooling process. The green color on the innermost surface of the heart is the initial coupled temperature between the warm heart and cold gelatin. In this case, the initial interface temperature was also set as the average temperature of the heart and gelatin, which was $+20.5^{\circ} \mathrm{C}$. The constant color bar from $-1^{\circ} \mathrm{C}$ to $+37^{\circ} \mathrm{C}$ was used in this figure which is the same as the one in previous case (figure 3.5). As the cooling process proceeded, the color of the heart's tissue changes from red color to green, and then blue. It should be noted that the minimum and maximum temperatures of the heart are not necessarily equal to the minimal to maximal range of the color legend.

As figure 3.7 illustrates, after $1500 \mathrm{~s}$ of cooling almost all internal parts of the heart were cooled. However, lack of an external cooling led to having larger temperatures close to the outermost surfaces, specially where the heart wall is thicker. 
a)

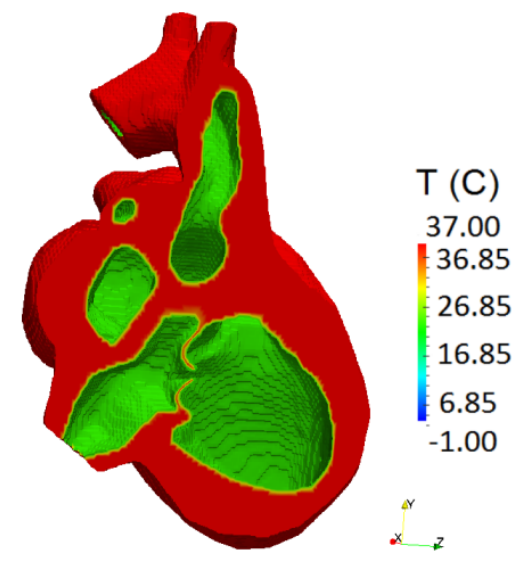

c)

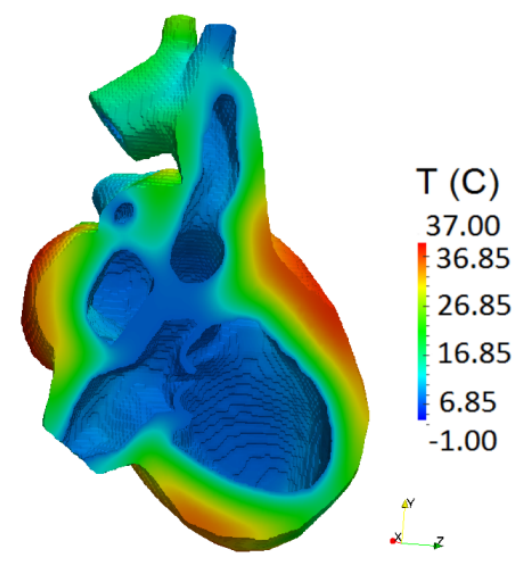

e)

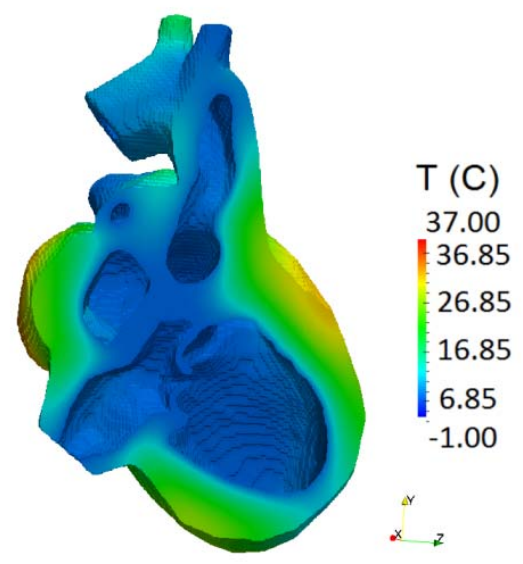

b)

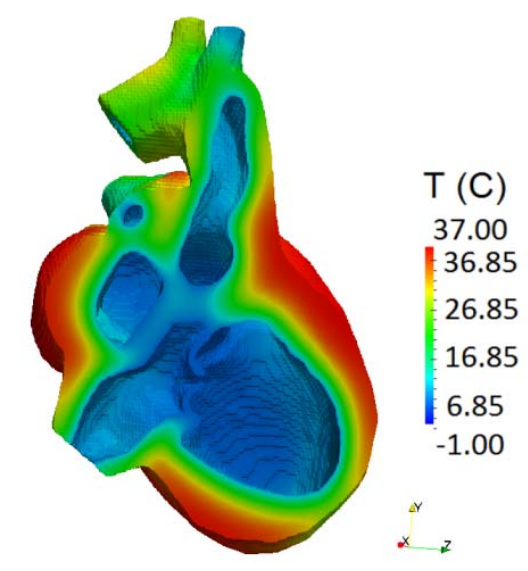

d)

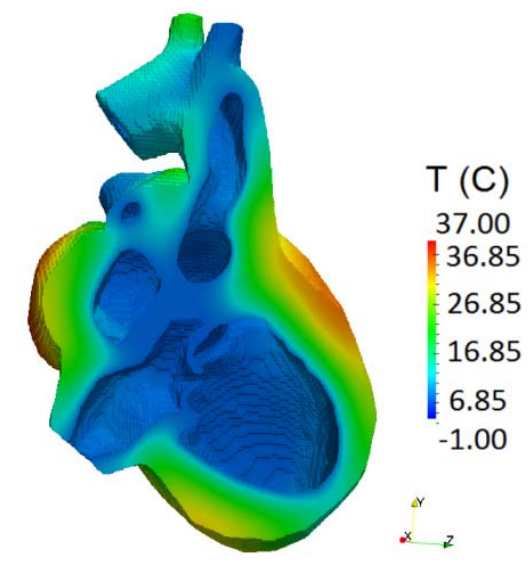

f)

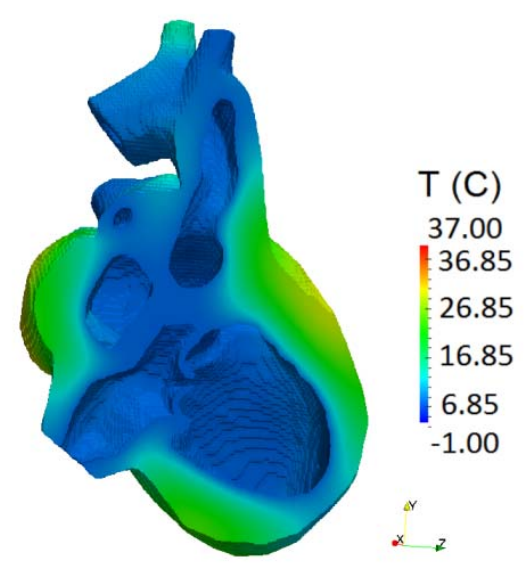

Figure 3.8. Temperature distribution (cut-away view): a) $0 \mathrm{~s}$, b) $300 \mathrm{~s}, \mathrm{c}) 600 \mathrm{~s}$, d) $900 \mathrm{~s}$, e) $1200 \mathrm{~s}$, and f) $1500 \mathrm{~s}$. 
In the next figure, the maximum and minimum and average volumetric temperatures of the heart are shown during cooling process. Figure 3.8 shows that the minimum temperature rapidly dropped to $+4^{\circ} \mathrm{C}$. The heart temperature will begin to decrease as soon as the coolant begins to flow. Since the cooling liquid has its minimum temperature at the beginning of cooling, the minimum temperature of the heart will drop noticeably at the beginning of cooling. Figure 3.6a shows that the maximum temperature was almost constant until $750 \mathrm{~s}$ of cooling. Then, it started decreasing and reached to its minimum of $32.5^{\circ} \mathrm{C}$ at $1500 \mathrm{~s}$. The average volumetric temperature was reduced to $+12.5^{\circ} \mathrm{C}$ after 1500 S.

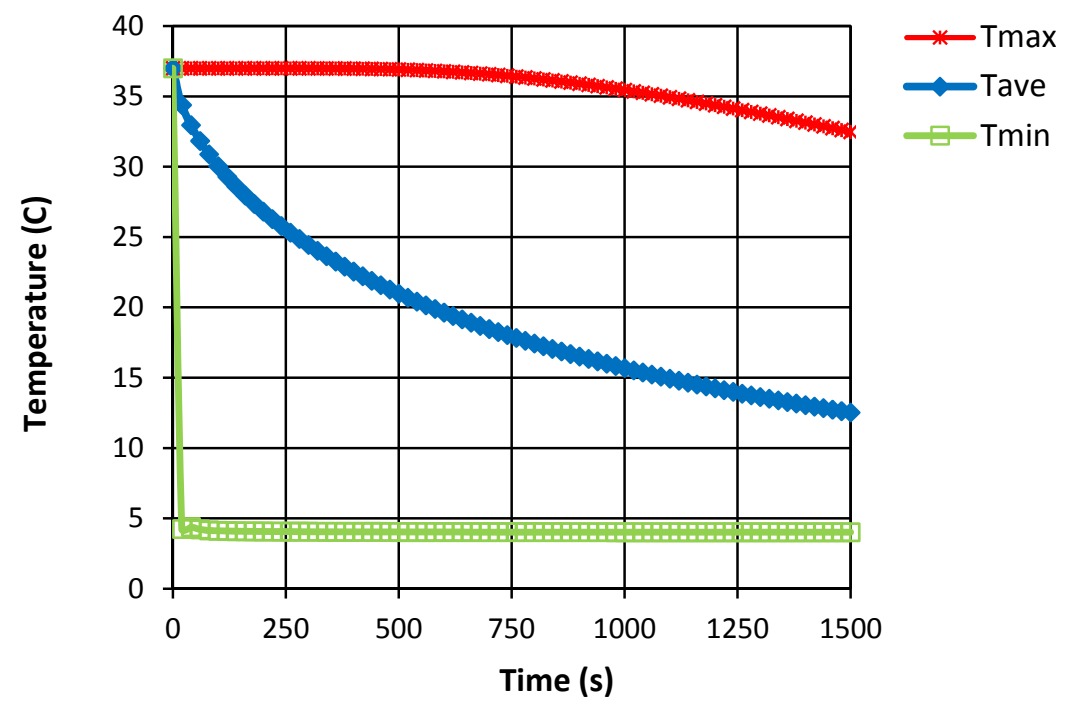

Figure 3.9. a) Temperature variations (maximum, minimum and average volumetric temperatures of the heart) vs. time. 


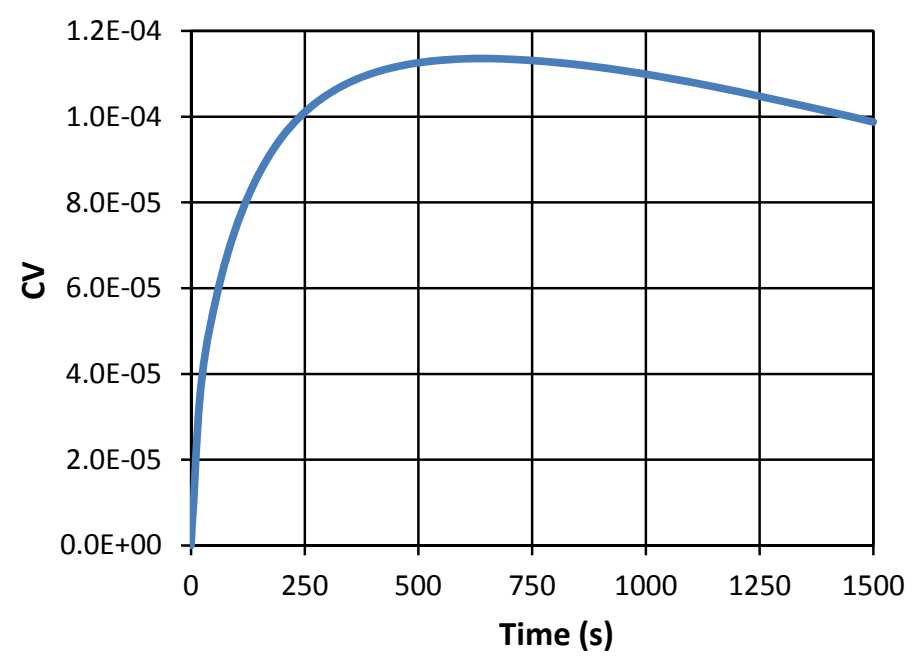

Figure 3.10. Coefficient of variation of average temperature $v s$. time.

$\mathrm{CV}$ of the average volumetric temperature is shown in figure 3.10. The maximum $\mathrm{CV}$ was $1.14 \mathrm{E}-6$ at $500 \mathrm{~s}$. It can be observed that non-uniformity of the average volumetric temperature increased until $500 \mathrm{~s}$ and then started to decrease with a moderate slope. The value of $\mathrm{CV}$ at $1500 \mathrm{~s}$ was $9.88 \mathrm{E}-5$ which is 0.87 times less than its maximum value.

Velocity and temperature distributions of the UW solution streamlines inside the heart pulmonary and systemic circulatory domains are shown in figure 3.9. Figure 3.9a illustrates that maximum velocity which is $2.30 \mathrm{~m} / \mathrm{s}$ occurred in the pulmonary circulatory domain, right after semilunar valve. Figure $3.9 \mathrm{~b}$ shows the maximum temperature variation of the UW solution is $+3.85^{\circ} \mathrm{C}$. It can also be seen that the UW temperature is higher near the outlets.

The coolant temperature in systemic circulatory domain is higher than the coolant temperature in the pulmonary circulatory domain. This is because of the lower velocity of the UW solution in the systemic circulatory domain than the pulmonary circulatory 
domain which can be observed in figure 3.9a. The lower coolant velocity will increase the heat transfer interval between the coolant and the heart and therefore will increase the coolant temperature. This can enhance the heat transfer process. However, having a lower velocity will decrease the rate of heat removed by the coolant. In this research, effects of inlet velocity on heat transfer from the heart were investigated for the external coolant flow.

a)

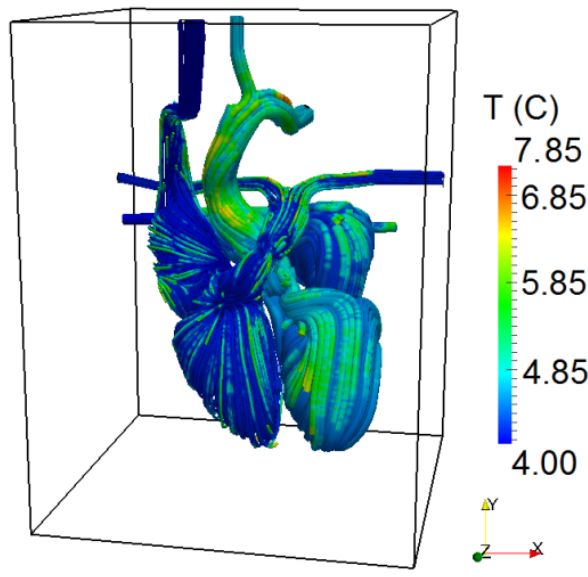

b)

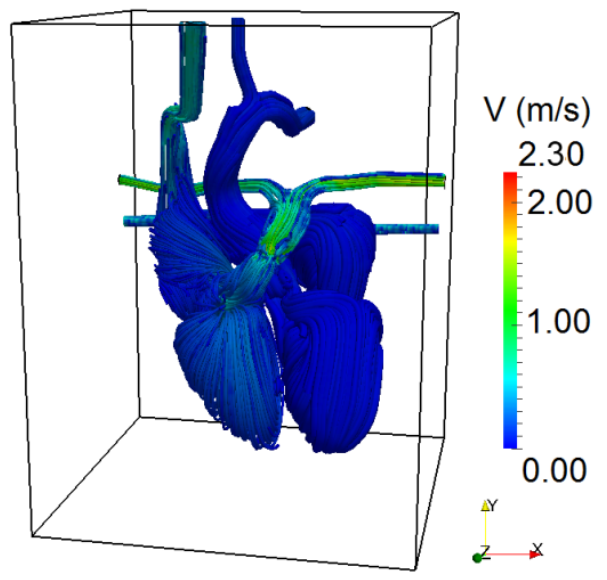

Figure 3.11. UW streamlines of the internal circulation with, a) temperature distribution, and b) velocity distribution.

\subsection{Discussion}

For further comparison, results of the both cases are shown in table 3.4 at $1500 \mathrm{~s}$. By comparing results of Case 1 (external gelatin cooling only, section 3.3) with results of the Case 2 (internal UW cooling only, section 3.4), a significant enhancement can be observed in terms of temperature reduction of the heart in Case 2. The minimum temperature in Case 1 was $+1.8^{\circ} \mathrm{C}$ less than the minimum temperature in Case 2. As it 
explained in section 3.3 this was because of the low wall temperature $\left(-1^{\circ} \mathrm{C}\right)$ in Case 1 . It is easier to maintain the minimum temperature at $+4^{\circ} \mathrm{C}$ using Case 2 , since the UW solution has the constant temperature equal to $+4^{\circ} \mathrm{C}$.

Table 3.4. Results of all heart cooling cases at $1500 \mathrm{~s}$.

\begin{tabular}{|l|c|c|}
\hline Parameter & Case 1* & Case 2 \\
\hline Minimum temperature $\left({ }^{\circ} \mathrm{C}\right)$ & +2.2 & +4.0 \\
\hline Maximum temperature $\left({ }^{\circ} \mathrm{C}\right)$ & +36.8 & +32.5 \\
\hline $\begin{array}{l}\text { Average volumetric } \\
\text { temperature }\left({ }^{\circ} \mathrm{C}\right)\end{array}$ & +21.0 & +12.5 \\
\hline $\mathrm{CV}$ & $6.4 \mathrm{E}-05$ & $9.88 \mathrm{E}-05$ \\
\hline Metabolic rate reduction $(\%)$ & 76.89 & 89.38 \\
\hline
\end{tabular}

* Cooling with gelatin from outside (semi-conjugate)

${ }^{\dagger}$ Cooling with UW solution from inside (conjugate)

The maximum temperature in Case 2 was $+4.3^{\circ} \mathrm{C}$ less than the Case 1 , which was due to the higher heat removal capacity of the cooling Case 1 compared to the one in Case 2. This will be more noticeable when the average volumetric temperatures of both cases are compared. The average volumetric temperature in Case 2 is $40.48 \%$ less than the one in Case 1. In terms of temperature uniformity, Case 1 showed a better result compared to Case 2. This can be explained by the slow, more uniform cooling conduction process in Case 1 compared to the fast, less uniform convection cooling process in Case 2. In other words, the fast convection heat transfer from inside resulted more nonuniformity (larger $\mathrm{CV}$ ) than the slow pure conduction heat transfer from the outside of the heart. 


\section{CHAPTER IV}

\section{FULLY-CONJUGATE COOLING WITH GELATIN}

In this chapter, two fully-conjugate cooling designs will be introduced and investigated numerically. In both of these cases cold gelatin was used in the cooling process. They were named "fully-conjugate" because all internal and external surfaces of the heart were cooled during cooling preservation. Section 4.1 presents the first fullyconjugate cooling system which applies gelatin cooling for both internal and external cooling. In section 4.2, the second fully-conjugate cooling case is presented. This fullyconjugate cooling case keeps the same external gelatin cooling as in Case 1, but it uses the UW solution for internal cooling. In the last section (section 4.3), a discussion about the proposed cooling systems is presented.

\subsection{Case 3 - Gelatin Cooling (Inside and Outside)}

The fully-conjugate cooling design in this chapter uses gelatin gel for both internal and external cooling. The cooling container for this case remained the same as the one in Case 1 and Case 2 presented in previous chapter (figure 3.4). All cooling container's walls were assumed to be thermally insulated. The reason for such assumption was to resemble the current cooling system. The initial and rest of boundary conditions for fluid domains in this fully-conjugate cooling case were kept the same as the initial and boundary conditions in semi-conjugate cooling Case 1. The initial boundary condition for internal gelatin cooling was set to $+4^{\circ} \mathrm{C}$ which is the same as 
external gelatin cooling. Thermo-fluid analysis results of this fully-conjugate case are presented in the following section.

\subsubsection{Thermo-Fluid Analysis}

Thermo-fluid simulation was performed for a 1500 s cooling period. A workstation computer with the Ubuntu 13.10 Linux OS was used for this simulation. Thermal simulation was run on 6 cores of an Intel Core i7, $3.4 \mathrm{GHz}$, Six Core with $64 \mathrm{~GB}$ memory. Total computing time was $4621 \mathrm{~s}$. Figure 4.1 shows the temperature variation of the heart at $0 \mathrm{~s}, 300 \mathrm{~s}, 600 \mathrm{~s}, 900 \mathrm{~s}, 1200 \mathrm{~s}$ and $1500 \mathrm{~s}$.

Figure $4.1 \mathrm{a}$ illustrates the heart tissue's temperature distribution at the very beginning of the cooling process when the heart temperature was $+37^{\circ} \mathrm{C}$. The translucent figure opacity level for lower temperatures was set to be smaller than higher temperatures. This way, high temperature regions within the heart tissue will be visible, as the temperature of their external regions decreases. As Figure 4.1 illustrates, heart tissue's temperature slowly decreased during the cooling period in this cooling concept that did not involve any external or internal convection. This simulated the most commonly used current method for heart cooling and transportation in which cooling liquid is stagnant. 
a)

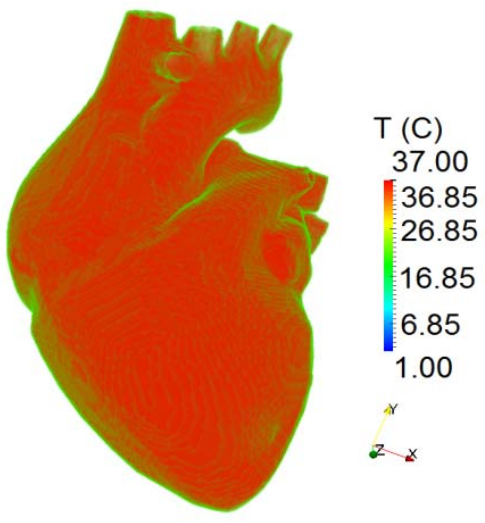

c)

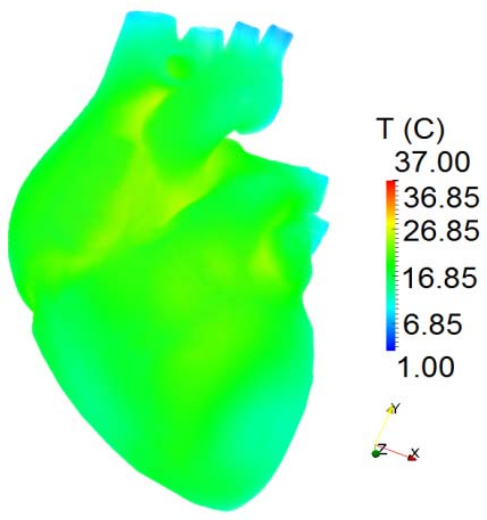

e)

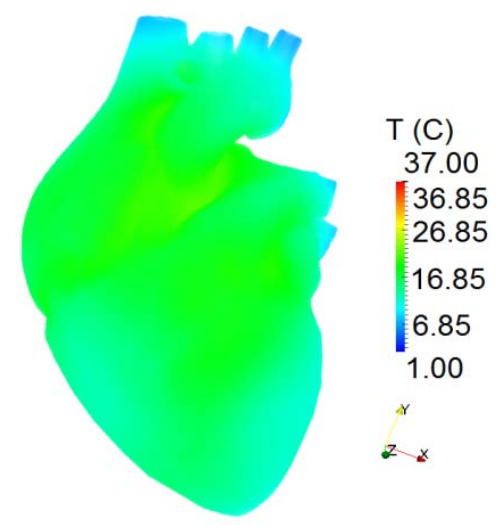

b)

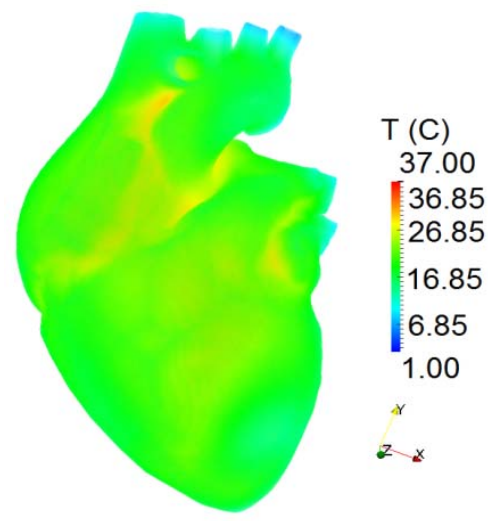

d)

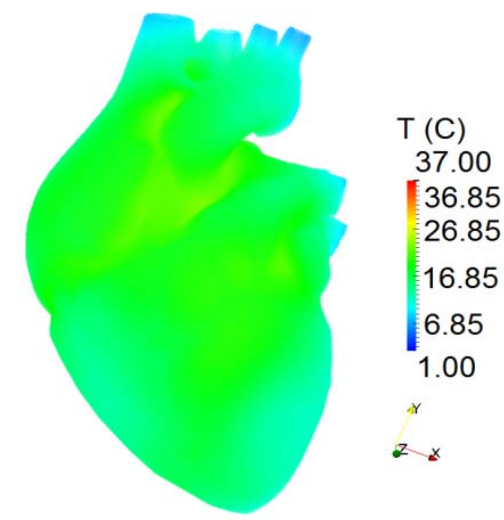

f)

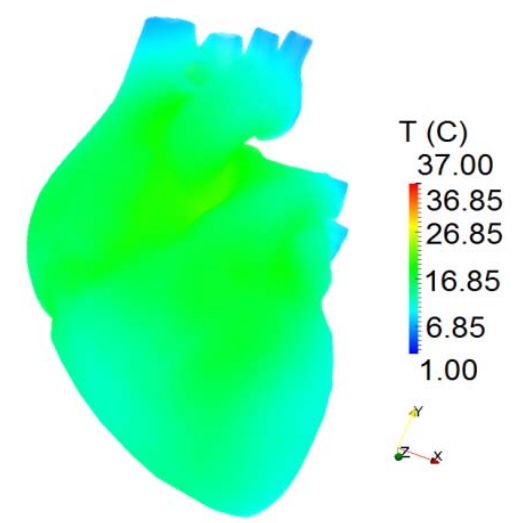

Figure 4.1. Temperature distribution (volumetric view) of the heart tissue with constant color legend: a) $0 \mathrm{~s}$, b) $300 \mathrm{~s}$, c) $600 \mathrm{~s}$, d) $900 \mathrm{~s}$, e) $1500 \mathrm{~s}$, and f) $3600 \mathrm{~s}$. 
Figure 4.2 shows sagittal views of heart and cooling gelatin inside and outside of the heart. A constant color bar from $+4^{\circ} \mathrm{C}$ to $37^{\circ} \mathrm{C}$ was used in this figure. It can be seen that the temperature of the gelatin inside the heart was increase after $300 \mathrm{~s}$. Figure $4.2 \mathrm{f}$ shows that the heart and gelatin have almost the same temperature (around $+17^{\circ} \mathrm{c}$ ) at $1500 \mathrm{~s}$.

a)

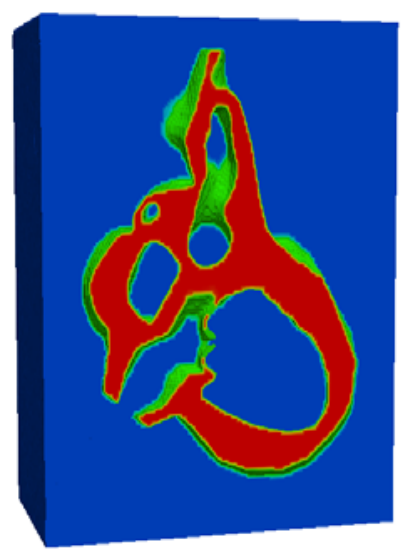

c)

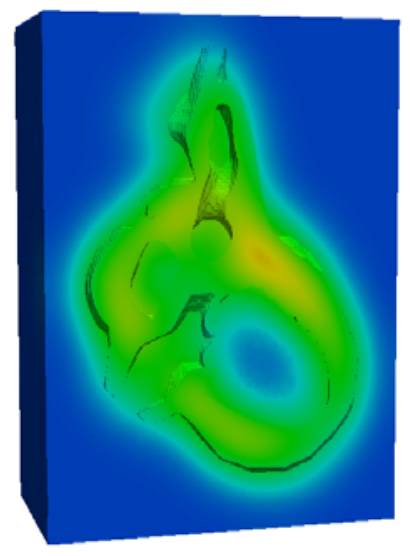

$\mathrm{T}(\mathrm{C})$

37.00

36.85

26.85

16.85

6.85

4.00

$\times$

$\mathrm{T}$ (C)

37.00

36.85

26.85

16.85

6.85

4.00

b)

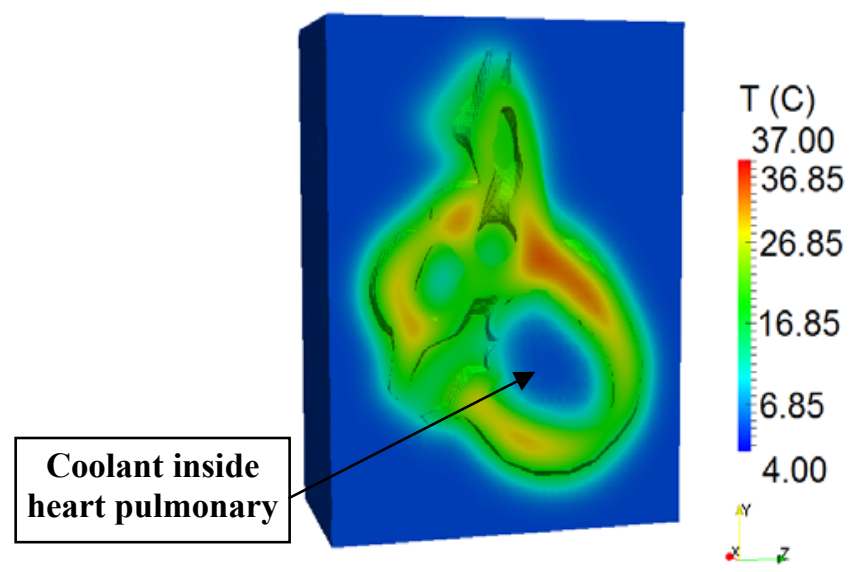

d)

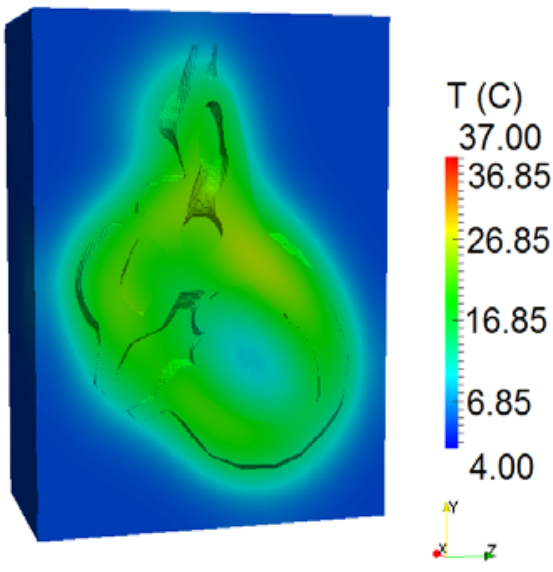


e)

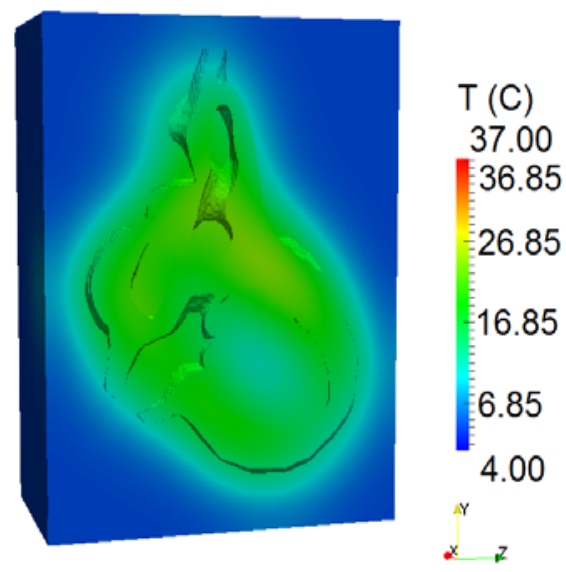

f)

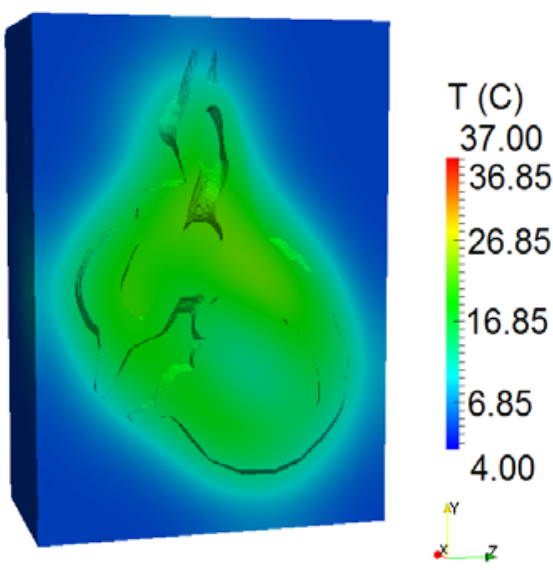

Figure 4.2. Temperature distribution (sagittal view): a) $0 \mathrm{~s}$, b) $300 \mathrm{~s}$, c) $600 \mathrm{~s}$, d) $900 \mathrm{~s}$, e) $1200 \mathrm{~s}$, and f) $1500 \mathrm{~s}$.

Metabolic rate variations were calculated using equation 1.1. Figure 4.3 shows cutaway views of heart's metabolic rate at $0 \mathrm{~s}, 300 \mathrm{~s}, 600 \mathrm{~s}, 900 \mathrm{~s}, 1200 \mathrm{~s}$ and $1500 \mathrm{~s}$. The color bars indicating metabolic rate ranges are changing in each of these figures. Thus, the maximum and minimum of color bars are indicating the maximum and minimum of metabolic rates in their figures. Figure 4.3.a shows $100 \%$ of metabolic rate for the heart at the beginning of cooling process. The minimum metabolic rate of $22.05 \%$ in this figure belongs to the heart-gelatin internal and external interfaces. After 300s, the maximum and minimum metabolic rate decreased to $85 \%$ and $6.35 \%$, respectively. It can be seen that after $300 \mathrm{~s}$, the temperature of gelatin inside the heart's major veins was increased. These values at $1500 \mathrm{~s}$ were $26.85 \%$ and $6.12 \%$ (figure $4.3 \mathrm{f}$ ). Also, it can be observed that the regions close to the heart's thick walls have higher metabolic rates after $1500 \mathrm{~s}$. 
a)

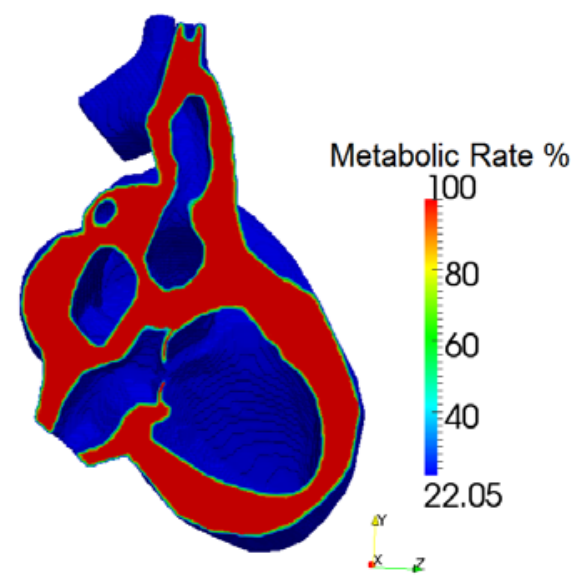

c)

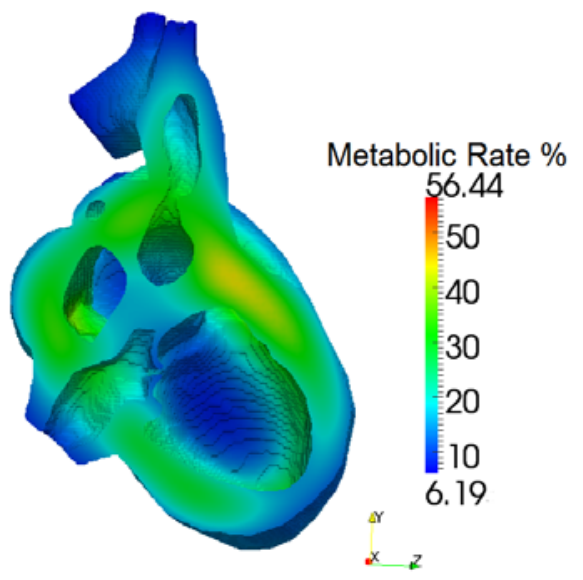

e)

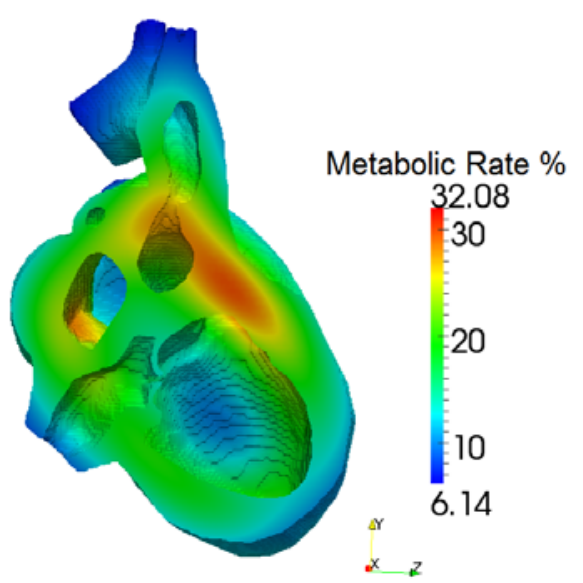

b)

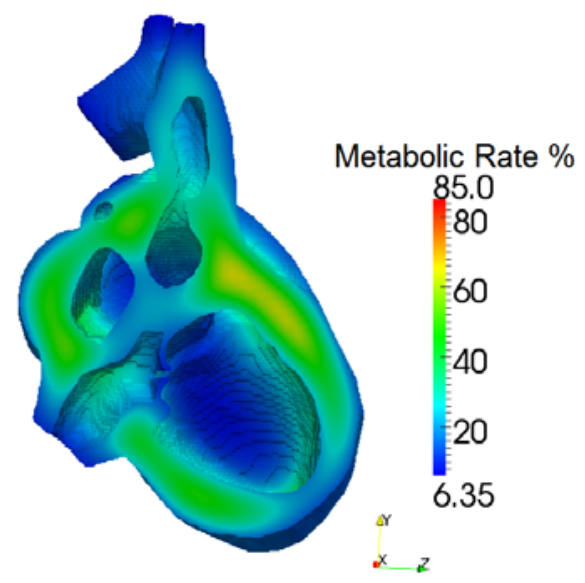

d)

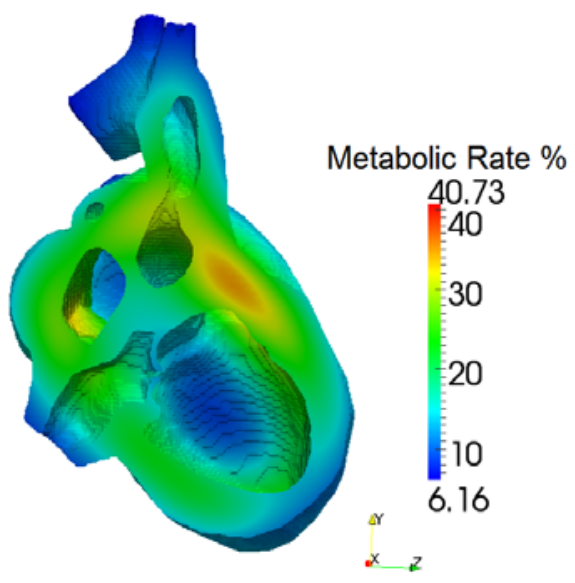

f)

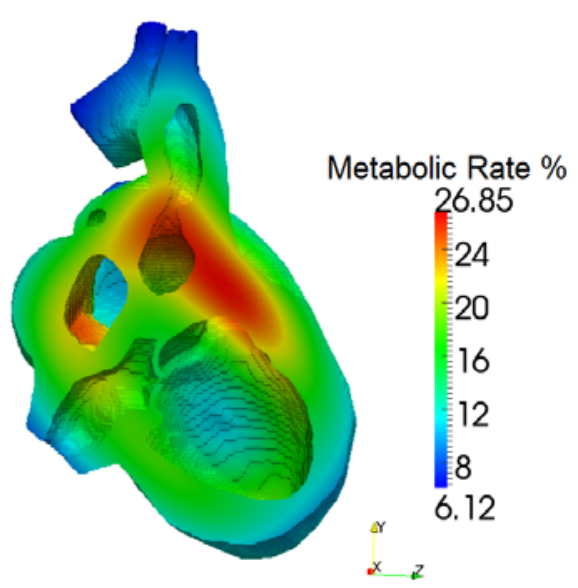

Figure 4.3. Metabolic rate (cut-away view): a) $0 \mathrm{~s}$, b) $300 \mathrm{~s}$, c) $600 \mathrm{~s}$, d) $900 \mathrm{~s}$, e) $1200 \mathrm{~s}$, and f) $1500 \mathrm{~s}$. 
Figure 4.4 shows the maximum, minimum and average volumetric temperatures of the heart. The maximum volumetric temperature decreased to $+23.8^{\circ} \mathrm{C}$ after $1500 \mathrm{~s}$. The average volumetric temperature of the heart was $+16.8^{\circ} \mathrm{C}$ at $1500 \mathrm{~s}$.

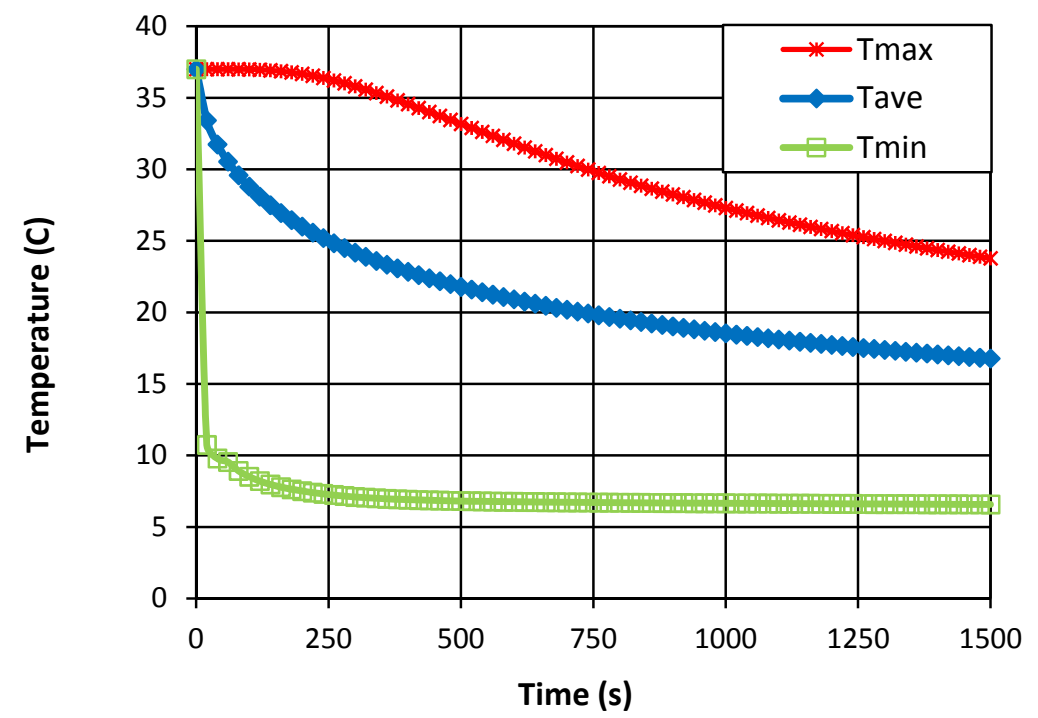

Figure 4.4. Temperature variations (maximum, minimum and average volumetric temperatures of the heart $v s$. time).

The cooling rates were calculated and shown in figure 4.5 on a logarithmic scale. The cooling rate of the average heart temperature had an almost linear slope, specially after $250 \mathrm{~s}$. The cooling rate of the maximum temperature reached to $1 \mathrm{e}-2$ after $1500 \mathrm{~s}$. 


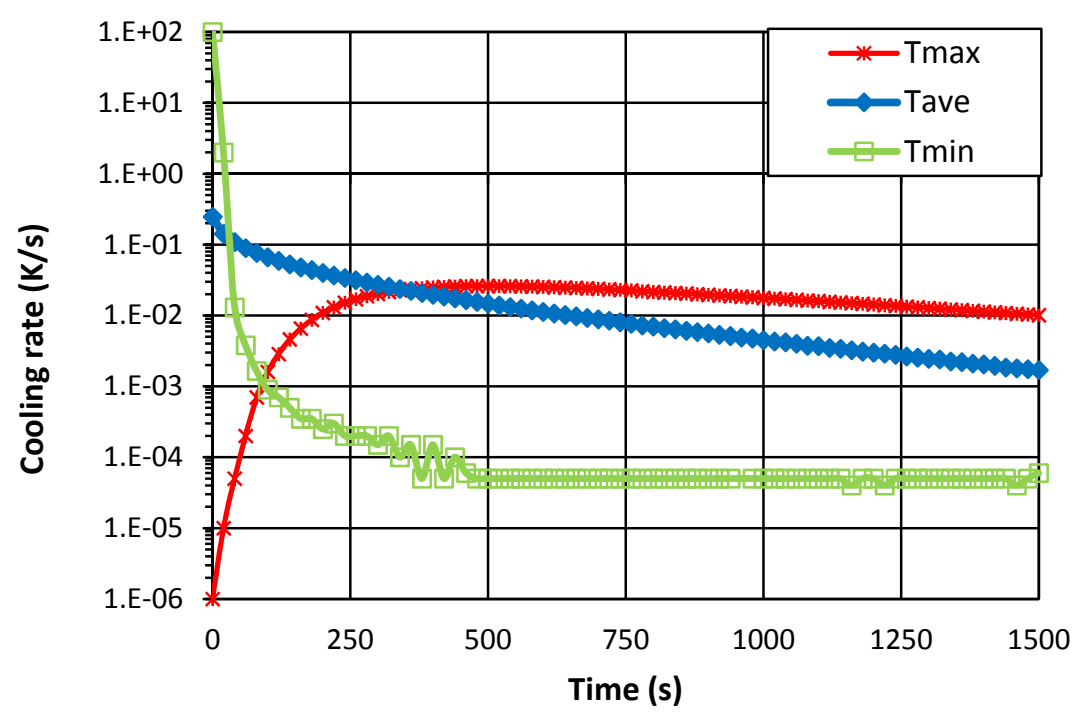

Figure 4.5. Cooling rate $v s$. time (logarithmic scale).

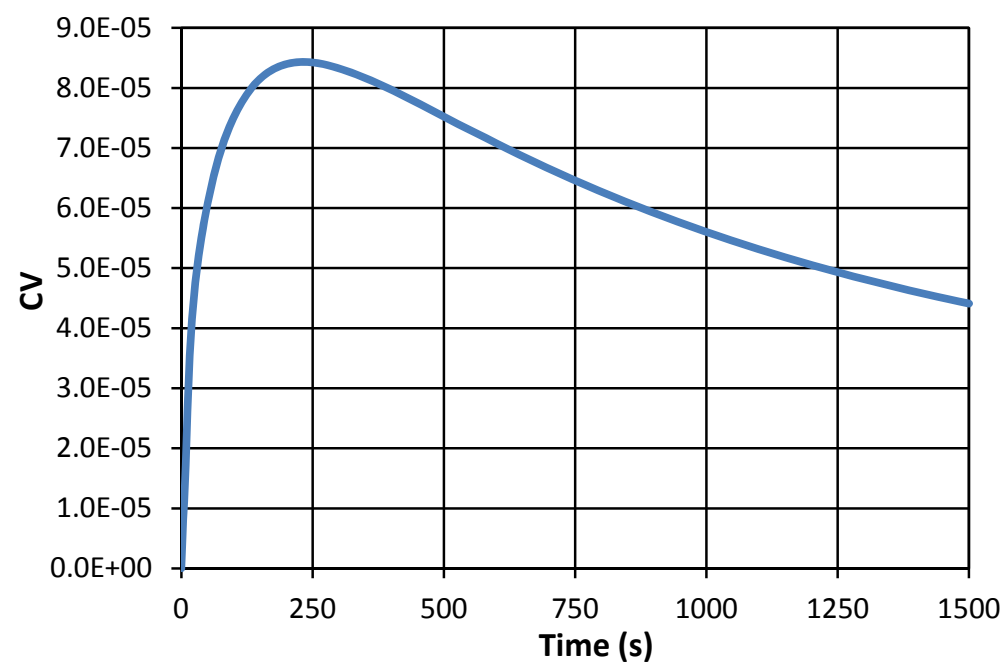

Figure 4.6. Coefficient of variation of volumetric temperature $v s$. time.

Variations of the $\mathrm{CV}$ of the average volumetric temperature of the heart versus time is shown in figure 4.6. The maximum value of $\mathrm{CV}$ was $8.43 \mathrm{E}-5$ at $240 \mathrm{~s}$. It can be observed that, the non-uniformity $(\mathrm{CV})$ of the average volumetric temperature increased until $240 \mathrm{~s}$ and then started to decrease and reached to $4.41 \mathrm{E}-5$ at $1500 \mathrm{~s}$. 


\subsection{Case 4 - Gelatin Cooling (Outside) and UW Cooling (Inside)}

The fully-conjugate cooling design in this chapter includes internal cooling via UW solution and external cooling via gelatin gel. Both cooling cases presented in chapter 3, were coupled to construct this fully-conjugate cooling design. Therefore, cooling container, connections and caps remained the same as those in previous cases (Figure 3.4). The internal circulations systems for the cooling liquid were also the same as those in Case 2. The main objective of the new cooling design was to study the cooling enhancement by coupling both semi-conjugate and conjugate cooling systems presented in chapter 3 . Therefore, initial and boundary conditions in this fully-conjugate cooling case were also kept the same as the initial and boundary conditions in semi-conjugate cooling Case 1 and conjugate cooling Case 2. Thermo-fluid analysis results are discussed in section 4.2.1. In section 4.2.2, stress analysis results are presented.

\subsubsection{Thermo-Fluid Analysis}

In this cooling case, there are two separate fluid domains, one for the right heart pulmonary circulation, and one for the left heart systemic circulation. The boundary conditions applied for the fluid flow simulation were the same as the boundary conditions used in the conjugate cooling Case 2 (table 3.4). Therefore, the averaged inlet velocities of coolant for the systemic circulation and the pulmonary circulation were $1 \mathrm{~m} / \mathrm{s}$ and 0.4 $\mathrm{m} / \mathrm{s}$, respectively. The outlet pressure values were assumed to be the same and equal to $101 \mathrm{kPa}$. The inlet temperature of the cooling fluid was set to $+4^{\circ} \mathrm{C}$. The temperature 
boundary conditions were also the same as the temperature boundary conditions applied in the semi-conjugate cooling Case 1 (table 3.2).

A parallel computer with the Red Hat Enterprise Linux Server 6.2 OS and LSF scheduler was used for simulations. Thermo-fluid simulation was run on 4 Intel Xeon CPU E5-2420 processors. Each processor has 6 physical cores, 12 threads and 48 GB memory. Total computing time was $114,018 \mathrm{~s}$.

Figure $4.7 \mathrm{a}$ illustrates the heart tissue's temperature distribution at the very beginning of the cooling process when the heart temperature was $+37^{\circ} \mathrm{C}$. The green color on the outermost surface of the heart is the initial coupled temperature between the warm heart and cold gelatin. This initial interface temperature was set as the average temperature of the heart and gelatin, which is $+20.5^{\circ} \mathrm{C}$. Figures $4.7 \mathrm{~b}$ to $4.7 \mathrm{f}$ demonstrate the heart cooling process at different time steps. A constant color legend from $+1^{\circ} \mathrm{C}$ to $+37^{\circ} \mathrm{C}$ was used to better illustrate the temperature variation of the heart tissue (figure 4.7). Therefore, the minimum and maximum temperatures of the heart are not necessarily equal to the minimal to maximal range of the color legend. The red color in figure $4.7 \mathrm{~b}$ signifies the initial hot spots within the heart tissue. As the cooling process continued, the red color turned to green, and then blue due to the temperature reduction of the heart tissue. 
a)

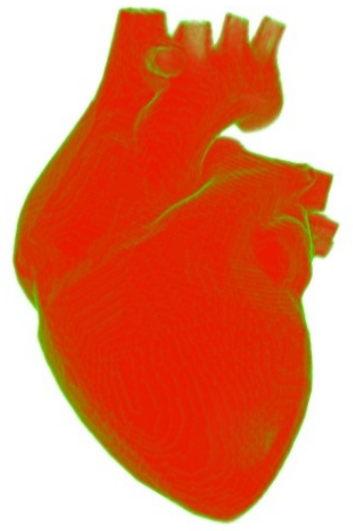

c)

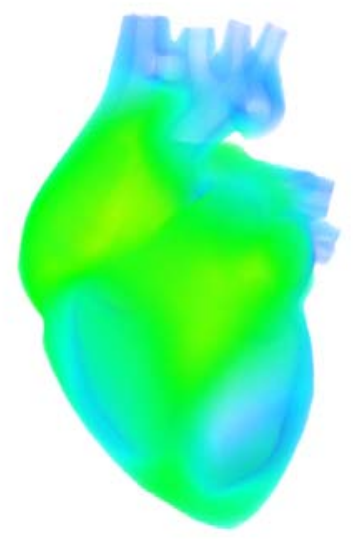

$\mathrm{T}$ (C)

37.00

36.85

26.85

16.85

6.85

1.00

$*$

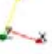

e)

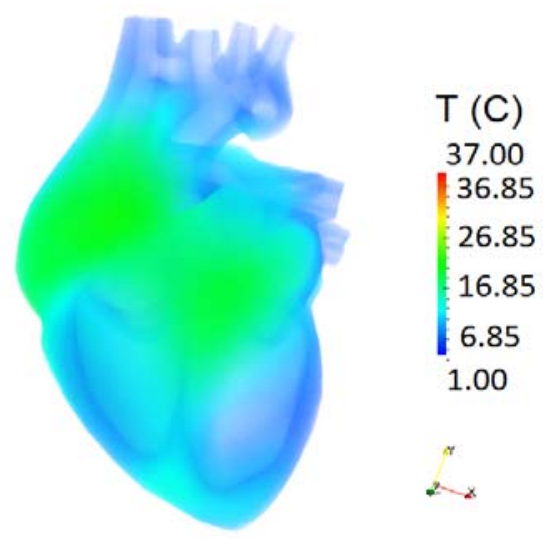

b)

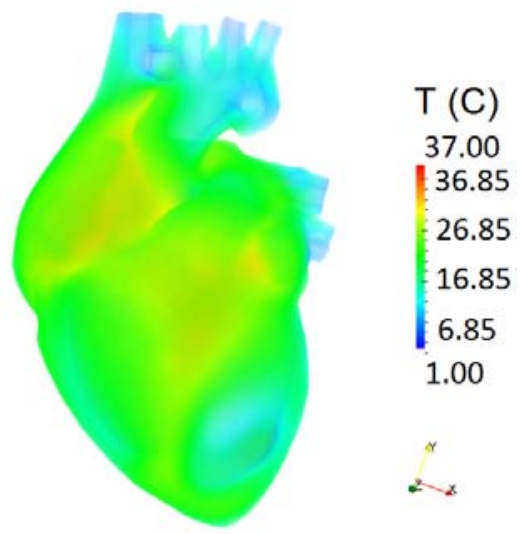

d)

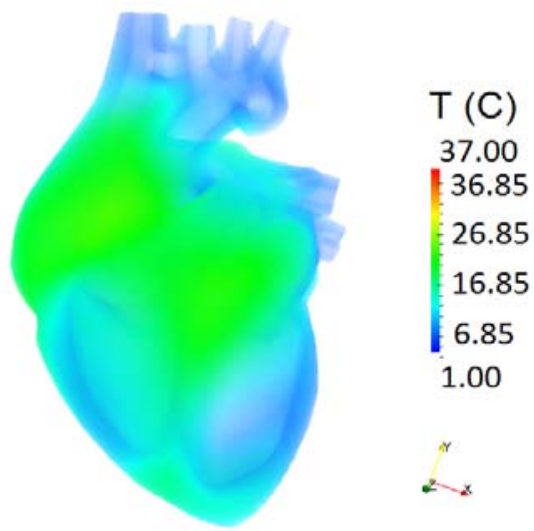

f)

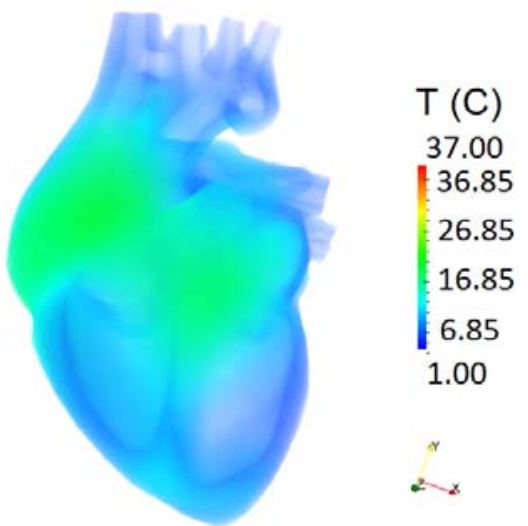

Figure 4.7. Temperature distribution (volumetric view) of the heart tissue with constant color legend: a) $0 \mathrm{~s}$, b) $300 \mathrm{~s}$, c) $600 \mathrm{~s}$, d) $900 \mathrm{~s}$, e) $1200 \mathrm{~s}$, and f) $1500 \mathrm{~s}$. 
To better illustrate the hot spot location inside the heart, cut-away views of heart are shown in figure 4.8 .

a)

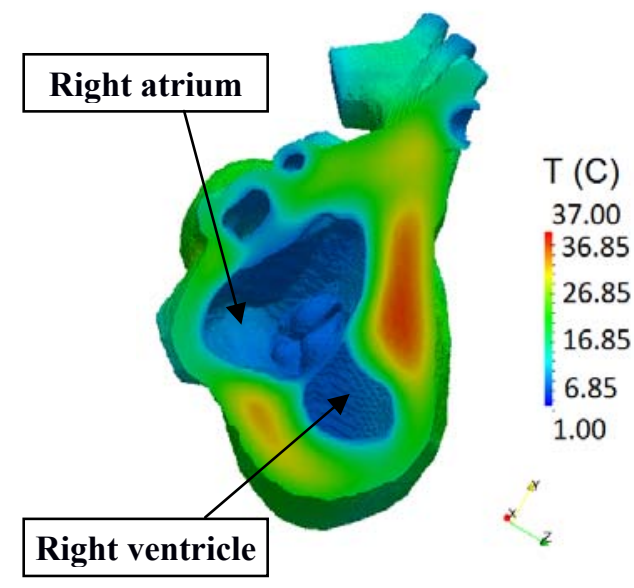

b)

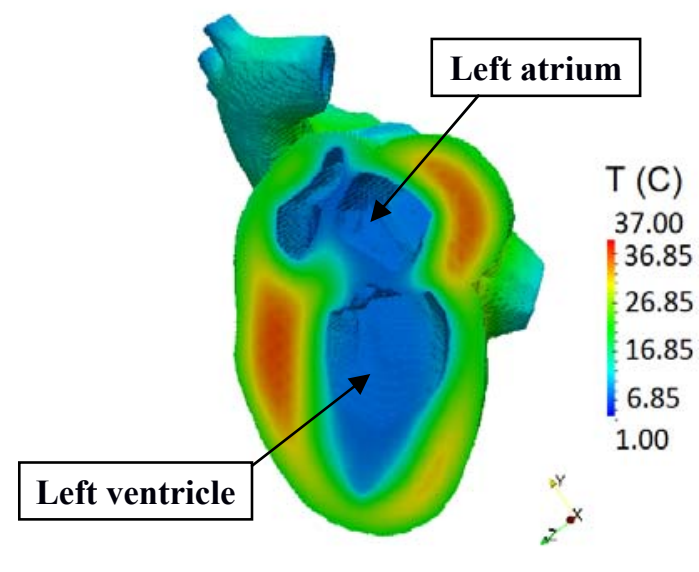

Figure 4.8. Temperature distribution at $300 \mathrm{~s}$ : a) first cut-away view, b) second cut-away view.

Figures $4.8 \mathrm{a}$ and $4.8 \mathrm{~b}$ demonstrate the distribution of heart tissue's temperature at $300 \mathrm{~s}$ for two different cut-away views. Figure 4.8a reveals a large hot spot located above the right ventricle and on the right side of the right atrium. Figure $4.8 \mathrm{~b}$ discloses two more hot spots; one is located on the left side of the left ventricle and the other is located on the right side of the left atrium. As this figure demonstrates, all hot spots were located in the regions where the heart walls were thicker. 
a)

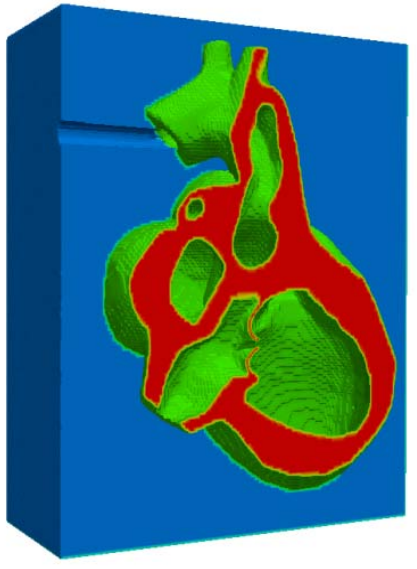

$\mathrm{T}$ (C)

37.00

36.85

26.85

16.85

6.85

$-1.00$

$x^{4}=$

c)

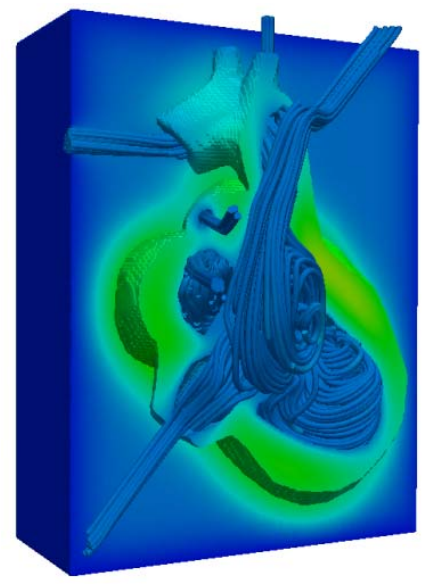

$\mathrm{T}$ (C)

37.00

36.85

26.85

16.85

6.85

$-1.00$

e)
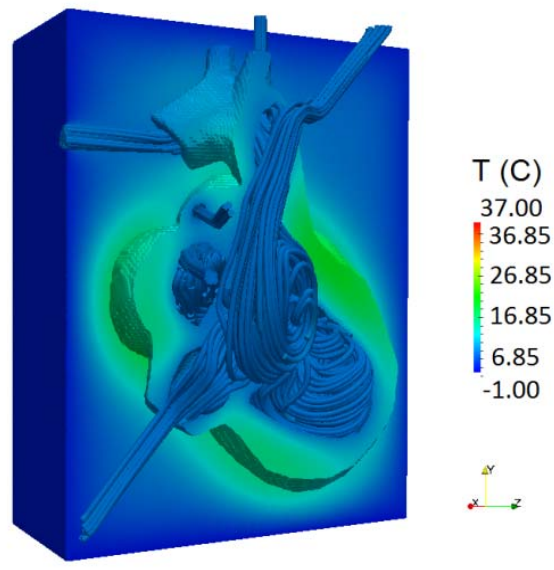

b)

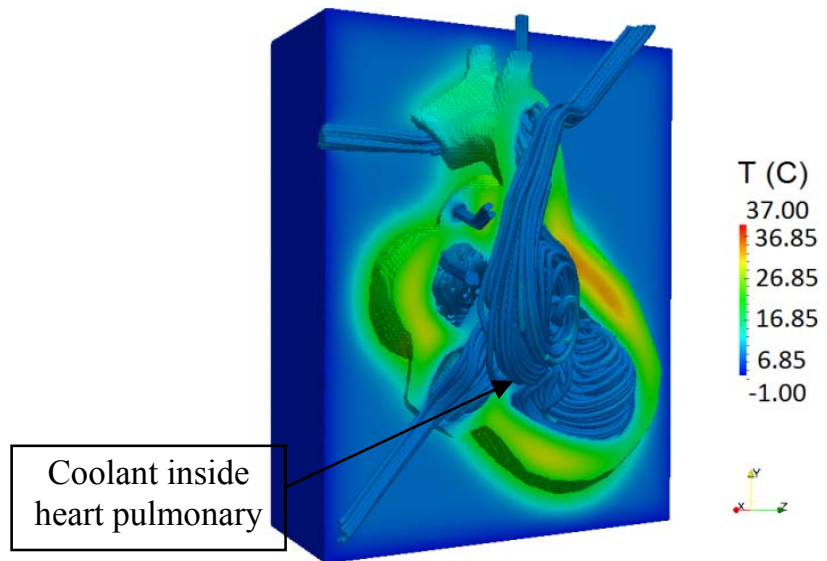

d)

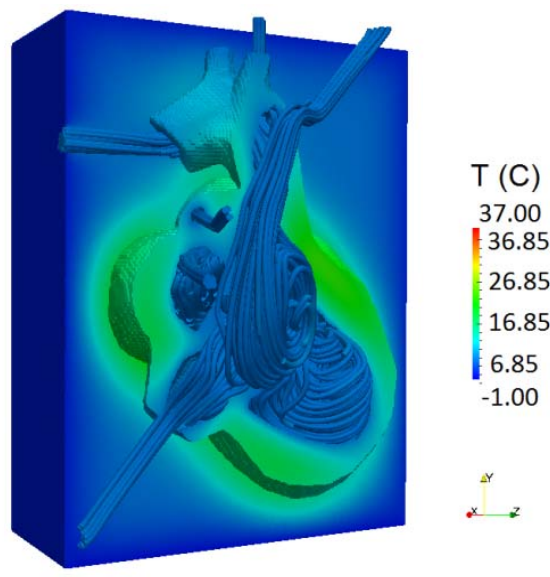

f)

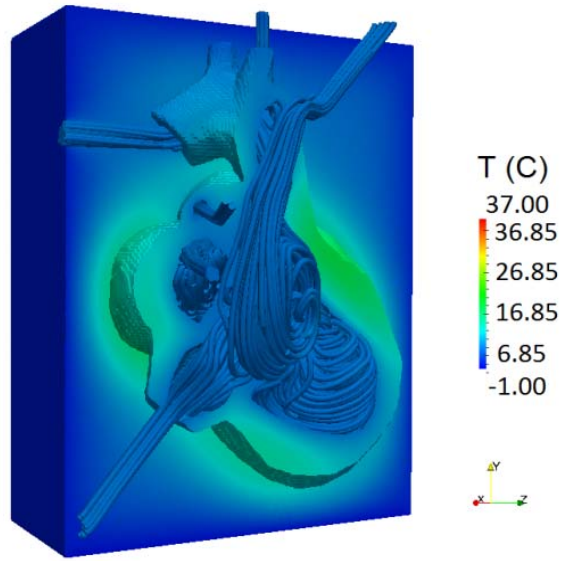

Figure 4.9. Temperature distribution (sagittal view): a) $0 \mathrm{~s}$, b) $300 \mathrm{~s}, \mathrm{c}) 600 \mathrm{~s}$, d) $900 \mathrm{~s}$, e) $1200 \mathrm{~s}$, and f) $1500 \mathrm{~s}$. 
Figure 4.9a shows the heart submersed in the cooling gelatin without coolant flow at the beginning of cooling. Figures $4.9 \mathrm{~b}$ to $4.9 \mathrm{f}$ illustrate the temperature distributions of the coolant flowing within the heart as well as temperature distributions within the heart tissue and the surrounding gelatin. The minimum temperature in figures $4.9 \mathrm{a}$ to figure 4.9f is $-1^{\circ} \mathrm{C}$, which is the minimum temperature of the cooling container walls. The temperature in this volume of the heart tissue was reduced from $+37.0^{\circ} \mathrm{C}$ to a minimum of $+15.8^{\circ} \mathrm{C}$ after $1500 \mathrm{~s}$. Figure 4.9 gives a better understanding of temperature fields in one particular sagittal cut of the cooling system. The temperature on the other side of the cut will be identical (please note the color bar temperature distribution is the same).

To further reveal the temperature variations inside the heart during the cooling process, the maximum and minimum and average volumetric temperatures are shown in figure 4.10 demonstrating that variation of the minimum temperature is not significant. The heart temperature will begin to decrease as soon as the coolant begins to flow. Since the coolant inlet temperature is constant and the gelatin has its minimum temperature at the beginning of cooling, the minimum temperature of the heart will not change noticeably over time. The minimum temperature of the heart was $+2.8^{\circ} \mathrm{C}$ after $1500 \mathrm{~s}$ of cooling, which is less than the target of $+4^{\circ} \mathrm{C}$. This low temperature occurs on the very small part of the outermost surfaces of the heart, which lie close to the container wall. The reason for this local low temperature is the small gap between the container wall, at $1^{\circ} \mathrm{C}$, and the heart. The minimum volumetric temperature in the semi-conjugate cooling Case 1 also occurred at the same location. At the same time, the maximum temperature was decreased by $18.9^{\circ} \mathrm{C}$, that is, from $+37.0^{\circ} \mathrm{C}$ to $+18.1^{\circ} \mathrm{C}$. The average volumetric temperature of the whole heart was calculated and is also shown in figure 4.10. The 
minimum average volumetric temperature was reduced by $29.0^{\circ} \mathrm{C}$, that is, from $+37.0^{\circ} \mathrm{C}$ to $+8.0^{\circ} \mathrm{C}$ after $1500 \mathrm{~s}$.

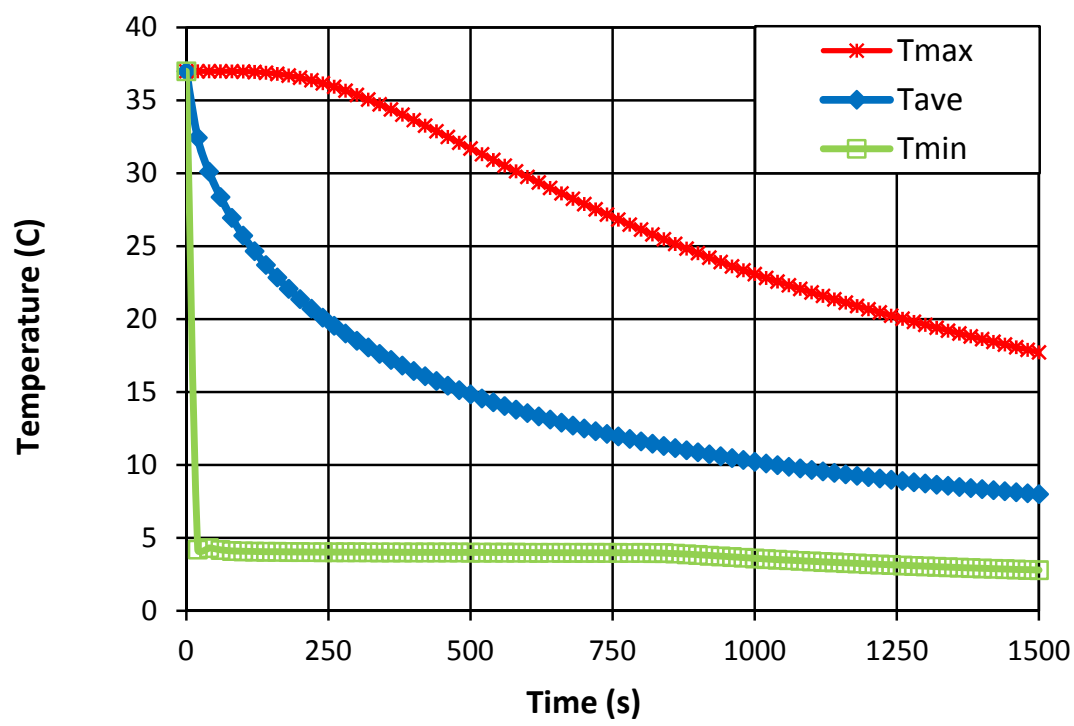

Figure 4.10. Temperature variations (maximum, minimum and average volumetric temperatures of the heart vs. time).

Figure 4.11 illustrates the variation in cooling rates by time for the maximum, minimum and the average volumetric temperatures of heart on a logarithmic scale. As this figure shows, the cooling rate for average volume temperature starts at $0.228^{\circ} \mathrm{C} / \mathrm{s}$ and gradually decreases to $0.0035^{\circ} \mathrm{C} / \mathrm{s}$ at $1500 \mathrm{~s}$. The cooling rate of the minimum temperature was very high initially $\left(32.8^{\circ} \mathrm{C} / \mathrm{s}\right)$, but decreased rapidly after a few seconds and became less than $0.005^{\circ} \mathrm{C} / \mathrm{s}$ after $20 \mathrm{~s}$. The maximum temperature started to decrease with an almost zero cooling rate, i.e., it did not cool at the beginning. Then, the maximum temperature started to decrease gradually and reached its maximum value $0.0198^{\circ} \mathrm{C} / \mathrm{s}$ at $480 \mathrm{~s}$. 


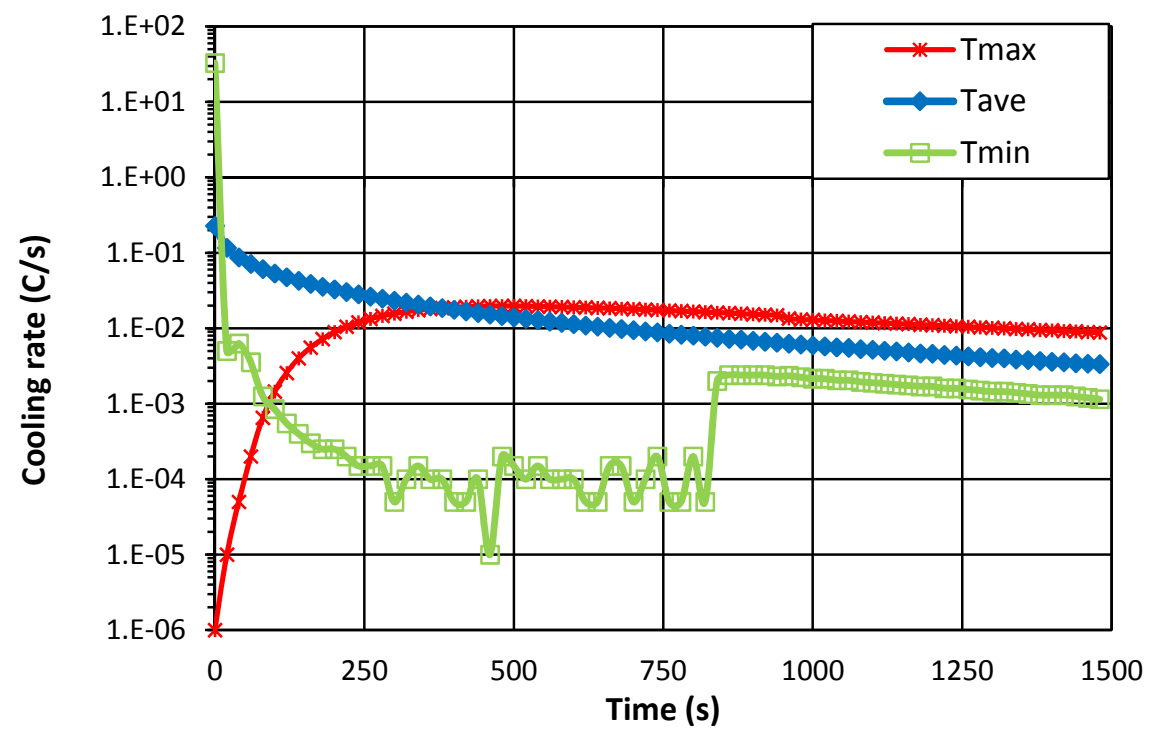

Figure 4.11. Cooling rates $v s$. time (logarithmic scale).

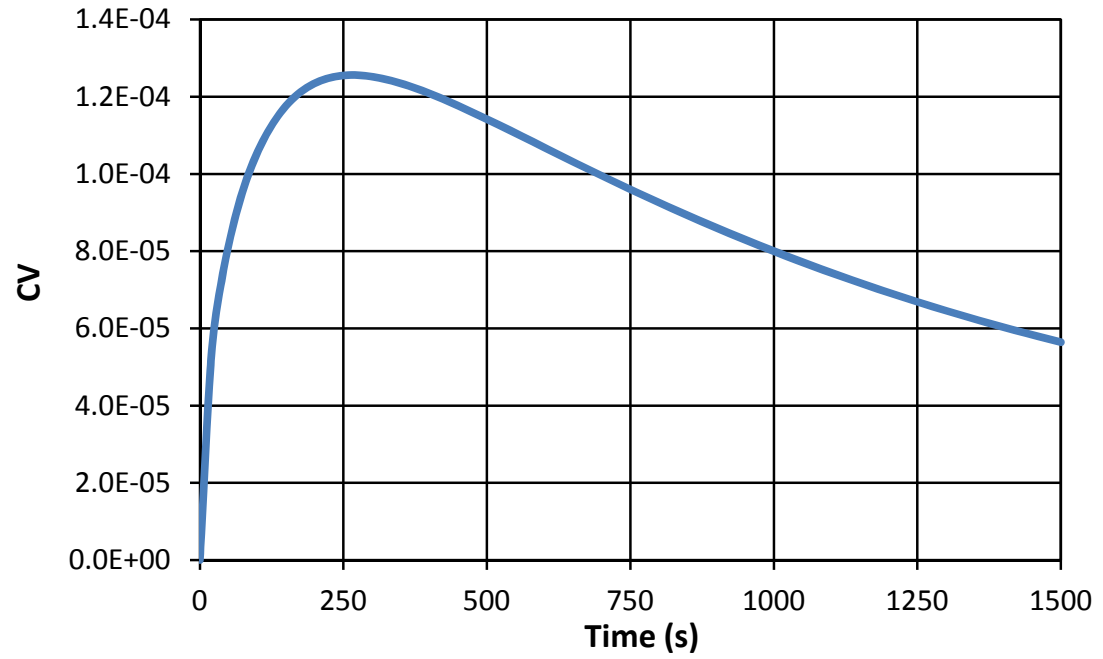

Figure 4.12. Coefficient of variation of volumetric temperature $v s$. time.

Figure 4.12 shows variations of the $\mathrm{CV}$ of the average volumetric temperature of the heart versus time. The maximum value of $\mathrm{CV}$ was $12.6 \mathrm{E}-5$ at $260 \mathrm{~s}$. It can be observed that, the non-uniformity $(\mathrm{CV})$ of the average volumetric temperature increased 
until $260 \mathrm{~s}$ and then started to decrease, thus reducing the non-uniformity 2.23 times at $1500 \mathrm{~s}$ compared to its maximum.

Figure 4.13 illustrates temperature fields and the flow streamlines inside the heart pulmonary and systemic circulatory domains at $300 \mathrm{~s}$.

a)

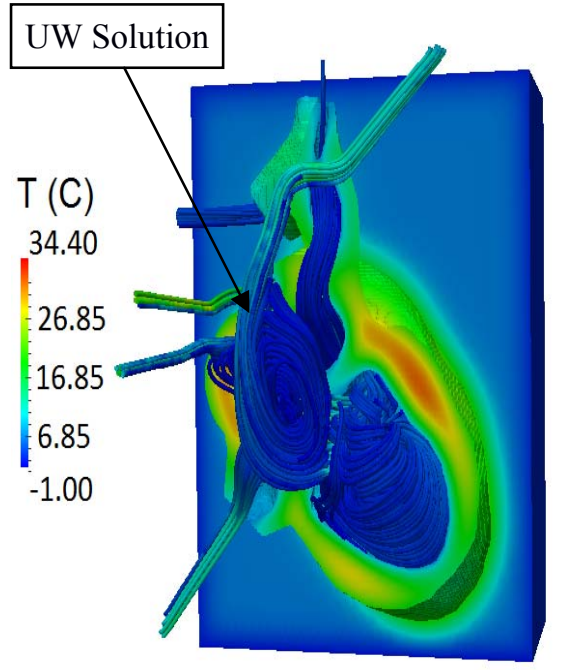

b)

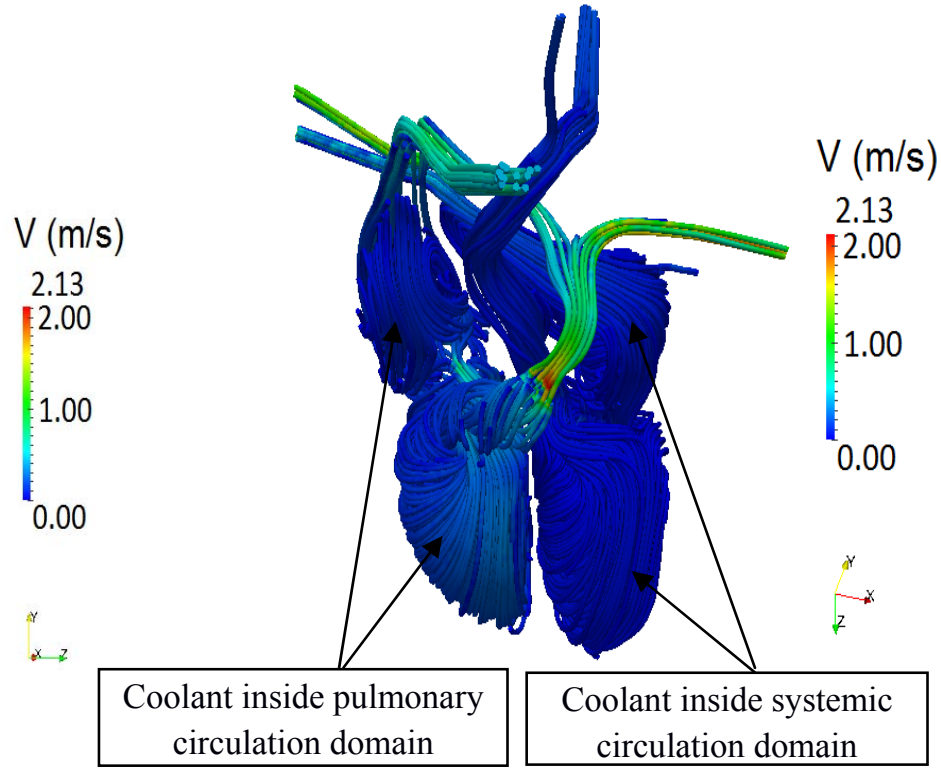

Figure 4.13. Velocity distribution at $300 \mathrm{~s}$ : a) coolant inside the ventricles with temperature distribution inside the heart tissue and gelatin (cut-away view), and b) coolant average speeds within the pulmonary and systemic circulatory domains.

The maximum averaged coolant velocity occurs in the pulmonary circulatory domain, just behind the semilunar valve, and is $2.13 \mathrm{~m} / \mathrm{s}$. Inlet flow rates can be determined from the averaged velocities at the inlets and diameters of the inlets. The flow rates for the two pulmonary circulatory inlets are calculated as $4826 \mathrm{ml} / \mathrm{min}$ and 4241 $\mathrm{ml} / \mathrm{min}$; for the two systemic circulatory inlets the values are $1086 \mathrm{ml} / \mathrm{min}$ and 271 $\mathrm{ml} / \mathrm{min}$. Figure 4.14 shows cut-away views of metabolic rate variations within the heart 
for six time steps. It can be observed that color bars are changing in each of these figures (4.14a to $4.14 \mathrm{f}$ ) based on their maximum and minimum values. As this figure shows the maximum metabolic rate was located at the top side of the right ventricle where the heart wall is thicker. It can also be observed that gelatin was not capable of cooling this region effectively.

a)

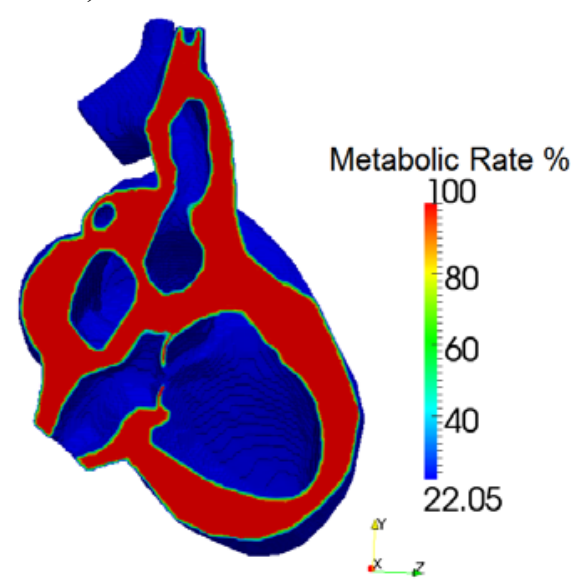

c)

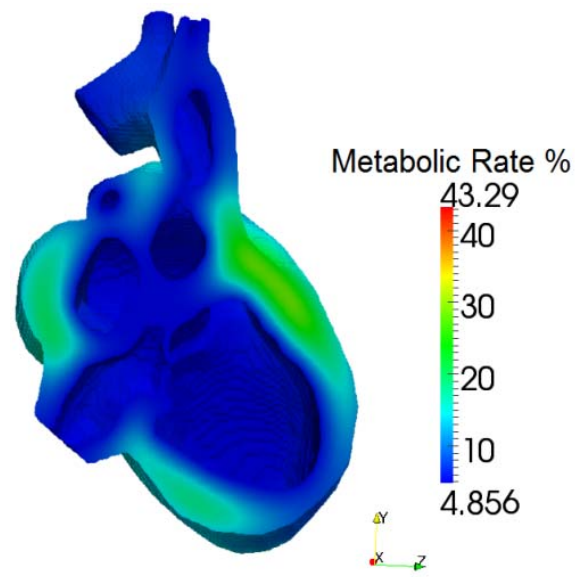

b)

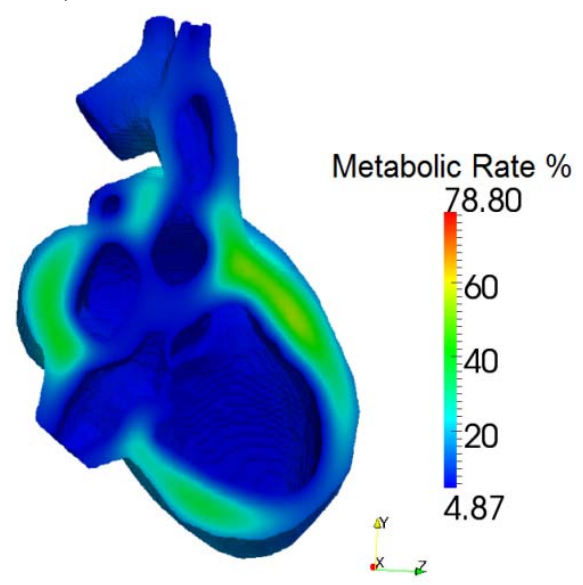

d)

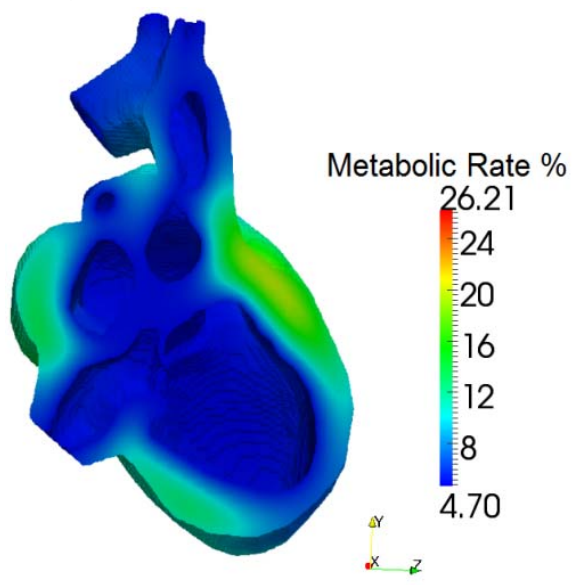



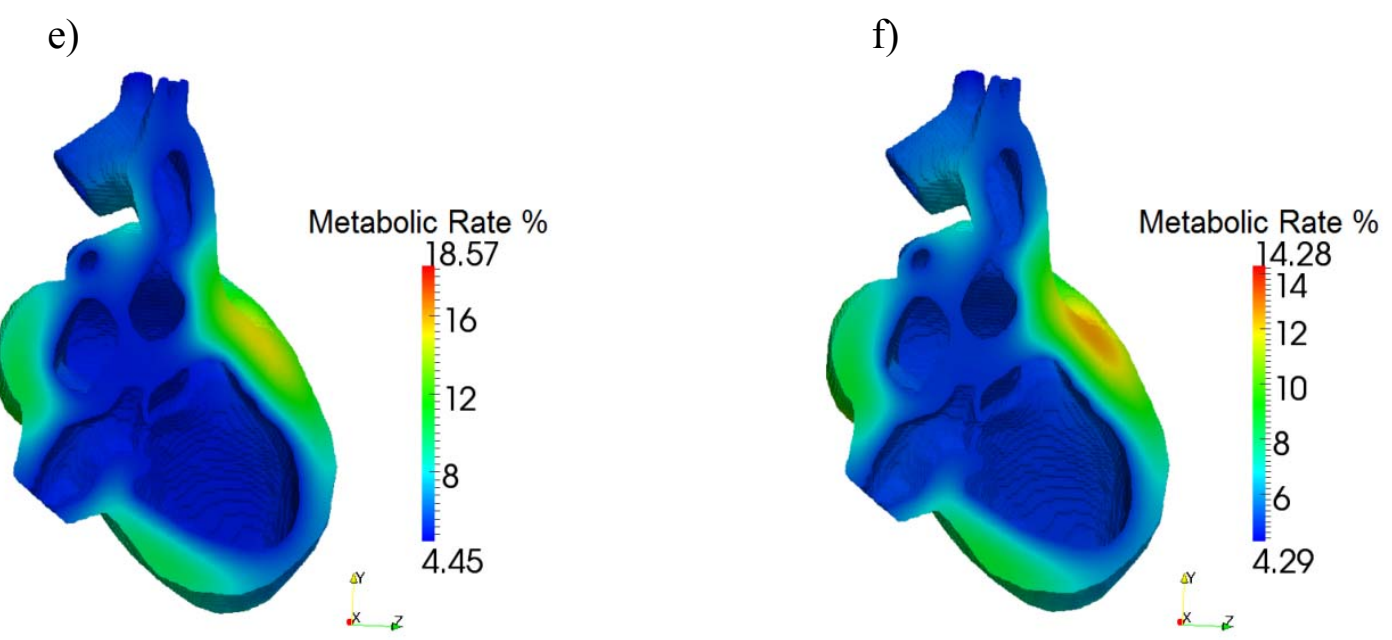

Figure 4.14. Metabolic rate (cut-away view): a) $0 \mathrm{~s}$, b) $300 \mathrm{~s}, \mathrm{c}) 600 \mathrm{~s}$, d) $900 \mathrm{~s}$, e) 1200 s, and f) $1500 \mathrm{~s}$.

As figure 4.9 shows, the temperature difference between the coolant and heart surfaces which are in contact with it, is almost zero. The heat convection law is given as

$q_{\text {conv }}=h_{\text {conv }} A\left(T_{s}-T_{f}\right)$

where $h_{c o n v}$ is the convection heat transfer coefficient, $A$ is the contact surface area between fluid and solid. By increasing the flow rates (velocities), $h_{c o n v}$ will increase. However, since $\left(T_{s}-T_{f}\right)$ tends to zero, the $h_{\text {conv }}$ effects will be almost negligible. Thus, increasing the coolant flow rates (velocities), would not only be ineffective in increasing the cooling rate, but would also increase the shear stresses on the heart tissue coolant interface and possibly cause endothelial tissue damage. 


\subsubsection{Stress Analysis}

For this cooling design, the stress analysis was performed by using the data obtained by the thermo-fluid analysis results. A zero displacement assumption was applied for the heart's outermost surfaces. Normal and shear forces applied by the coolant flowing to the innermost surfaces were used as the boundary condition of these surfaces. These values were updated for each time step. The heart temperature field was used to obtain the thermal stresses during the cooling process.

As table 2.2 shows, the ultimate tensile stress of cardiac muscle is $110 \mathrm{kPa}$. After obtaining the stress field measurement inside the heart, the maximum von Mises stress was calculated and is shown in figure 4.15. As this figure demonstrates, the maximum value of von Mises stress is almost constant ( $96 \mathrm{kPa})$. Therefore, the effect of thermal stresses is not significant due to the very small Young's elastic modulus and thermal expansion coefficient of the heart tissue. Thus, only the forces caused by the flowing coolant play a major role in the stress field. 


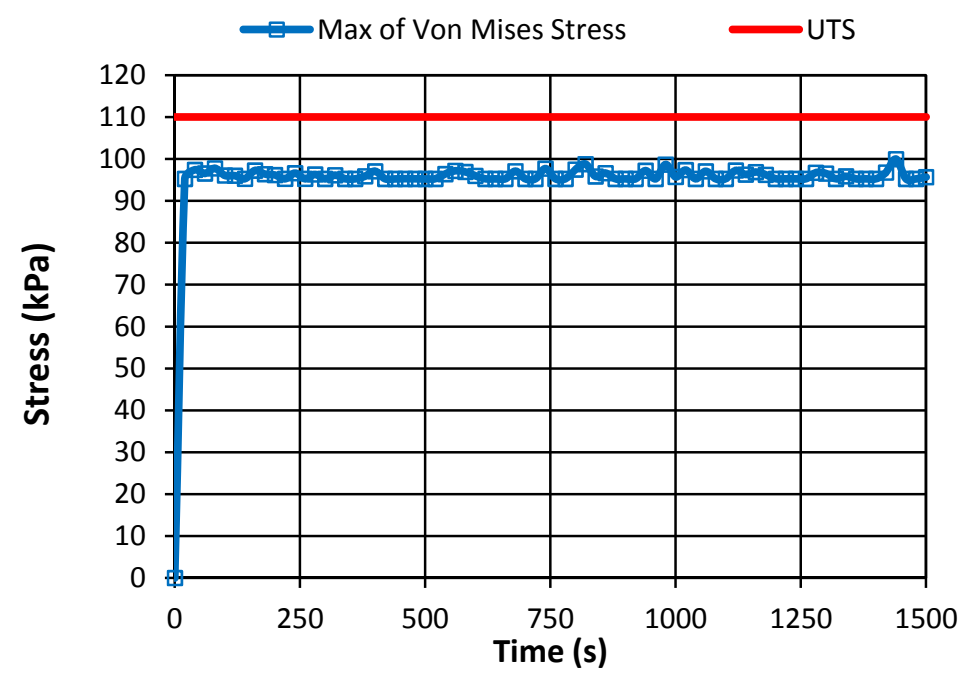

Figure 4.15. Maximum von Mises stress inside the heart and ultimate tensile stresses vs. time.

Figure 4.16 shows the maximum pressures of the coolant flowing within the pulmonary and systemic circulatory domains, including the heart chambers and major inlet and outlet vessels at every $20 \mathrm{~s}$. Pressure distributions within the pulmonary and systemic circulatory domains are related to the velocity fields within these domains. In this model, the fluid flow was considered and simulated as an unsteady flow mainly because of the unsteady temperature field. Therefore, the velocity field (flow pattern) will change with time even though the inlet velocity is a constant value. This causes variations in the pressure field with time. Inside the pulmonary circulatory domain, the maximum pressure fluctuated with time, but inside the systemic circulatory domain the maximum pressure was almost a constant $(\sim 102 \mathrm{kPa})$. This is because within the pulmonary circulatory domain the velocity field variation with time is negligible. As a result, the pressure field variation with time is also negligible. However, as figure 4.13b shows, the coolant velocity field within the pulmonary circulatory domain has larger values and 
larger variations. Therefore, this leads to fluctuations in the pressure field as shown in figure $4.13 \mathrm{~b}$. The purpose of this analysis was to estimate the maximum pressure that could occur within the heart during the cooling process. The importance of these simulations was to show that maximum pressures within the pulmonary and systemic circulatory domains remained less than $112 \mathrm{kPa}(\sim 80 \mathrm{mmHg})$.

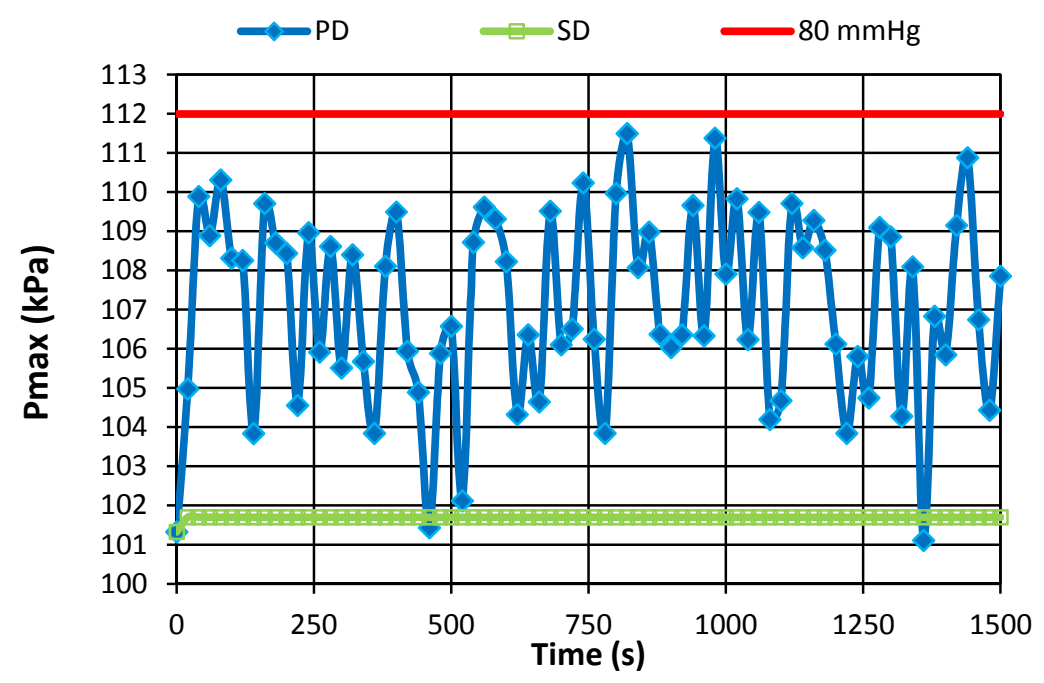

Figure 4.16. Maximum coolant pressure inside the pulmonary domain (PD) and systemic domain (SD).

It should be also mentioned that $80 \mathrm{mmHg}$ which is the safe valve pressure for the systemic circulation is actually the total pressure behind the valve. This is usually considered the pressure within the right ventricle. The results show that for systemic circulation the maximum pressure is much less than the $80 \mathrm{mmHg}$, so as the average pressure behind the valve. The total pressure in the pulmonary circulation was approximately $35 \mathrm{mmHg}$. 
To further investigate shear stresses caused by the UW solution flows, heart wall shear stresses (WSS) on the coolant-heart contact surfaces is plotted in figure 4.17.

a)

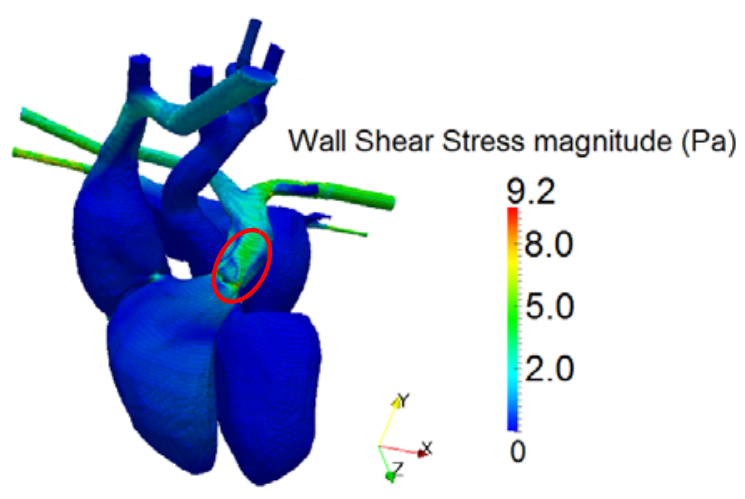

b)

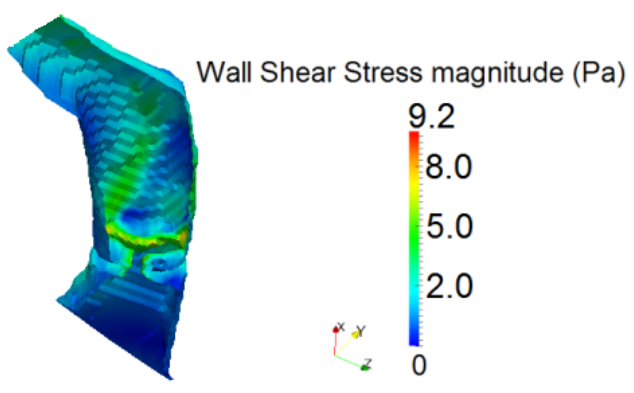

Figure 4.17. WSS magnitude; a) entire fluid contact surfaces, and b) cut-away enlarged view of higher shear stresses region.

Figure $4.17 \mathrm{a}$ demonstrates that on most of the coolant-heart contact surfaces, WSS was very small due to very small velocity gradients. The maximum WSS was $9.2 \mathrm{~Pa}$ which occurred in the pulmonary circulation domain at the pulmonary valve tip. The red oval in figure 4.17 a depicts the high WSS region. Figure $4.17 \mathrm{~b}$ shows an enlarged cutaway view of the WSS distribution in this region. Higher WSS can also be observed at the inlet and outlet connections.

Accurate measurement of WSS applied on the entire liquid contact surfaces of the heart is very challenging. In one of the earliest research, Fry [98] showed that WSS higher than $40 \mathrm{~Pa}$ could damage the endothelial cell layer. Later, Moore et al. [99] reported that the maximum WSS on any artery in the normal cardiovascular system is 
expected to be less than $10 \mathrm{~Pa}$. Oshinski et al. [100] applied MR phase velocity mapping to determine WSS in the aorta. They reported 5.4 Pa for the peak of wall shear stress in the aorta. Feldman et al. [101] reported that WSS of more than $7 \mathrm{~Pa}$ could produce endothelial damages in coronary arteries. Computationally predicted WSS results presented in the present study show that in most parts of the heart-liquid contact surface, WSS is lower than $2 \mathrm{~Pa}$. The maximum WSS at the pulmonary valve tip is also expected to be lower in the real case since it will open more due to the fluid pressure. Therefore, the large velocity gradient at its tip will reduce. However, one can apply a constrained optimization algorithm (Colaco and Dulikravich, [102]) to find the maximum coolant flow rate at which WSS will be kept below its safe limit value.

\subsection{Mesh Independency}

Accuracy of the computational results depends on the size of the average computational grid cells. Dependency of the simulations was studied by comparing computational results obtained on two different meshes. Figure 4.18 illustrates the heart hexahedral mesh used for simulations presented in this paper and results obtained on a finer heart mesh to examine the mesh dependency of the simulations. All meshes in this research were time independent.

The finer mesh information for each domain is presented in table 4.1. The total number of grid cells for all domains was 10,900,000. 


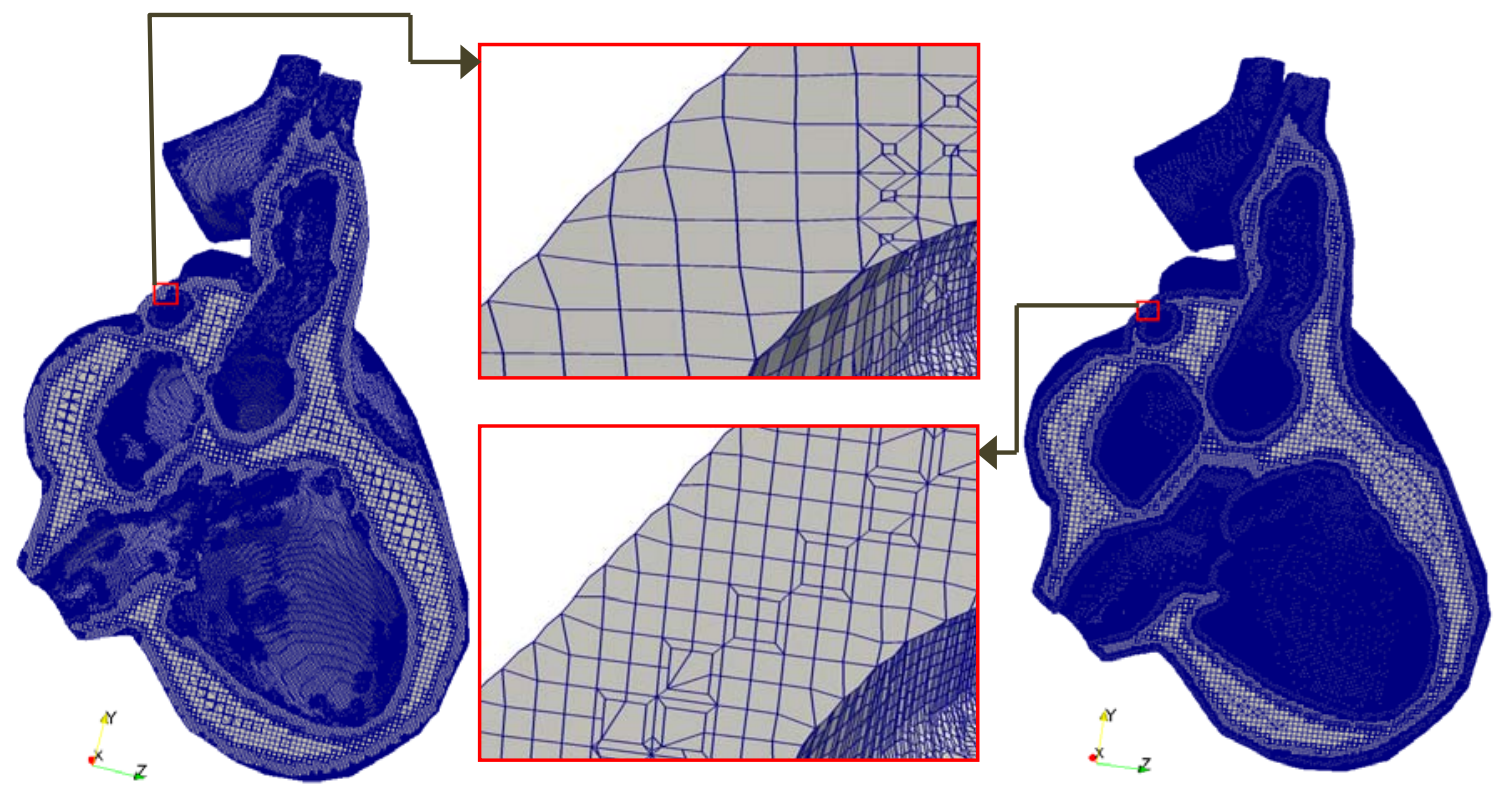

Figure 4.18. Heart hexahedral mesh; a) used for simulations presented in this research, and $b$ ) finer mesh used for simulation until $20 \mathrm{~s}$.

Table 4.1. Finer hexahedral grid cells for different computational domains

\begin{tabular}{|l|c|}
\hline Domain & Number of grid cells \\
\hline Heart pulmonary circulation & $\sim 1,200,000$ \\
\hline Heart systemic circulation & $\sim 1,200,000$ \\
\hline Heart & $\sim 5,000,000$ \\
\hline Gelatin & $\sim 3,500,000$ \\
\hline
\end{tabular}

Table 4.2 shows the simulation results (at $20 \mathrm{~s}$ ) obtained by using the first mesh having 4,200,000 grid cells. Case 4-fine in table 4.2 presents the simulation results obtained by applying the finer mesh. Variations between Case 4 and Case 4-fine results are also shown in this table. 
Table 4.2. Comparison of simulation results for Case 4 and Case 4-fine at $20 \mathrm{~s}$.

\begin{tabular}{|l|c|c|c|}
\hline Parameter & Case 4 & Case 4-fine & Variation \\
\hline Total number of cells & $\sim 4,200,000$ & $\sim 10,900,000$ & $\sim+6,700,000$ \\
\hline Minimum temperature $\left({ }^{\circ} \mathrm{C}\right)$ & 4.0 & 4.0 & 0 \\
\hline Maximum temperature $\left({ }^{\circ} \mathrm{C}\right)$ & 37 & 37 & 0 \\
\hline $\begin{array}{l}\text { Average volumetric temperature } \\
\left({ }^{\circ} \mathrm{C}\right)\end{array}$ & 32.40 & 32.46 & +0.06 \\
\hline $\begin{array}{l}\text { Maximum von Mises stress } \\
(\mathrm{kPa})\end{array}$ & 95.248 & 95.154 & -0.094 \\
\hline WSS $(\mathrm{Pa})$ & 9.243 & 9.290 & +0.047 \\
\hline Computation time $(\mathrm{s})$ & $1,496.24$ & $15,482.12$ & $+13,985.88$ \\
\hline
\end{tabular}

As these results show, results of Case 4-fine are in good agreement with results of Case 4. However, the computation time in Case 4-fine is $13,986 \mathrm{~s}$ more than the computation time in Case 4 for these 20 seconds of simulated cooling process.

\subsection{Discussion}

For a better comparison, results of semi-conjugate, conjugate and fully-conjugate cooling systems are shown in table 4.1 at $1500 \mathrm{~s}$. By comparing results of all three cases, it can be seen that the fully-conjugate cooling system had a better performance in cooling the heart within $1500 \mathrm{~s}$. The minimum temperature in Case 3 was more than other cases including Case 1 . The reason was because in Case 3 all cooling container's walls were assumed to be thermally insulated. The minimum temperature in Case 4 was the same as the one in Case 1.

Table 4.3. Results of heart cooling cases at $1500 \mathrm{~s}$. 


\begin{tabular}{|l|c|c|c|c|}
\hline Parameter & Case 1* & Case 2 & Case 3 & Case 4 $^{\text {§ }}$ \\
\hline Minimum temperature $\left({ }^{\circ} \mathrm{C}\right)$ & +2.8 & +4.0 & +6.6 & +2.8 \\
\hline Maximum temperature $\left({ }^{\circ} \mathrm{C}\right)$ & +36.8 & +32.5 & +23.8 & +18.1 \\
\hline $\begin{array}{l}\text { Average volumetric } \\
\text { temperature }\left({ }^{\circ} \mathrm{C}\right)\end{array}$ & +21.0 & +12.5 & +16.8 & +8.0 \\
\hline CV & $6.4 \mathrm{E}-05$ & $9.88 \mathrm{E}-05$ & $4.41 \mathrm{E}-05$ & $5.64 \mathrm{E}-05$ \\
\hline $\begin{array}{l}\text { Metabolic rate reduction } \\
(\%)\end{array}$ & 76.89 & 89.38 & 84.29 & 92.99 \\
\hline
\end{tabular}

* Cooling with gelatin from outside (semi-conjugate)

${ }^{\dagger}$ Cooling with UW solution from inside (conjugate)

${ }^{\ddagger}$ Cooling with gelatin from inside and outside (fully-conjugate)

${ }^{\S}$ Cooling with gelatin from ouside and UW solution from inside (fully-conjugate)

The maximum temperature in Case 4 was $+5.7^{\circ} \mathrm{C}$ less than Case $3,+14.4^{\circ} \mathrm{C}$ less than the Case 2 and $+18.7^{\circ} \mathrm{C}$ less than the Case 1. This is because of the higher heat removal capacity of the cooling Case 3 compared to the cooling Case 3, Case 2 and Case 1 . The average volumetric temperature in Case 4 was $+8.8^{\circ} \mathrm{C}(110 \%)$ less than the average volumetric temperature in Case $3,+4.5^{\circ} \mathrm{C}(56.25 \%)$ less than the one in Case 2, and $+13.0^{\circ} \mathrm{C}(162.50 \%)$ less than the one in Case 1 . The temperature uniformity $(\mathrm{CV})$ of the heart in Case 4 was smaller than those in Case 1 and Case 2, and larger than the one in Case 3. Case 3 in which gelatin was used for both internal and external cooling had the best results in terms of temperature uniformity. This was mainly because of slow conduction cooling from both sides while all containers' walls were insulated. In terms of metabolic rate reduction, it can be observed that Case 4 gave the best result. This case reduced the metabolic rate of the heart by $9.99 \%$. 


\section{CHAPTER V}

\section{FULLY-CONJUGATE COOLING WITH TURBULENT FLOWS}

In this chapter, five fully-conjugate cooling systems will be investigated numerically. In these cooling systems, the heart is cooled by the UW solution flows from the inside and outside. The main objectives of these simulations were to study effects of turbulent flows, jet flows at the heart's hot regions, and unsteady periodic inlet velocities in heart cooling process. In section 5.1, results of fully-conjugate cooling design (Case 5) in which both external and internal flows were laminar are discussed. Case 6 applies turbulent external flow and laminar internal flows for cooling. This case is presented in section 5.2. In Case 7 which is presented in section 5.3, an extra inlet was designed in such a way to create a jet impinging the hot spot within the heart. Sections 5.4 and 5.5 present two cooling cases with unsteady periodic inlet velocities. In the last section (section 5.6), results of all cooling cases are discussed.

\subsection{Case 5 - UW Cooling (Laminar Internal and External Flows)}

For cooling systems in this chapter, the same cooling container as the one in previous cooling systems was used for the heart preservation (figure 3.4a). Figure 1b shows the designed connections and caps for pumping coolant through the pulmonic and systemic vessels which were the same as previous cooling cases (figure 3.4b). For circulating the coolant outside of the heart, two inlets with $15 \mathrm{~mm}$ diameter and two outlets with $20 \mathrm{~mm}$ diameter were designed on the cooling container's walls. Inlets and 
outlets were designed in such a manner to create fluid vortices around the heart and enhance the heat transfer.

a)

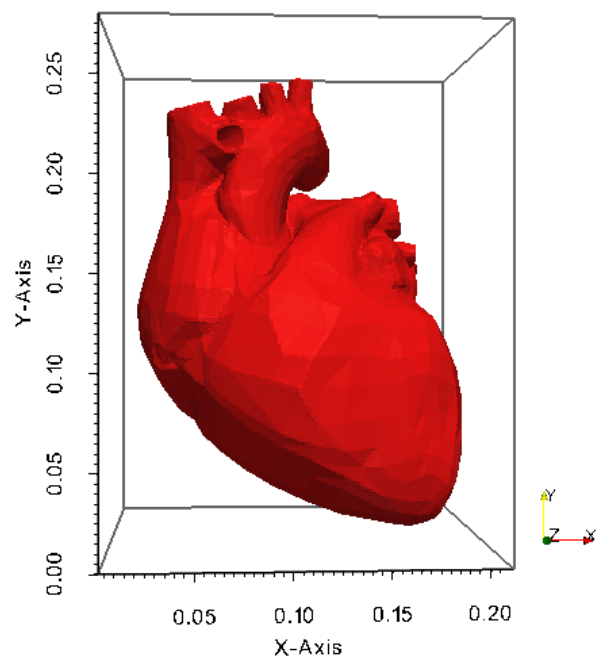

c)

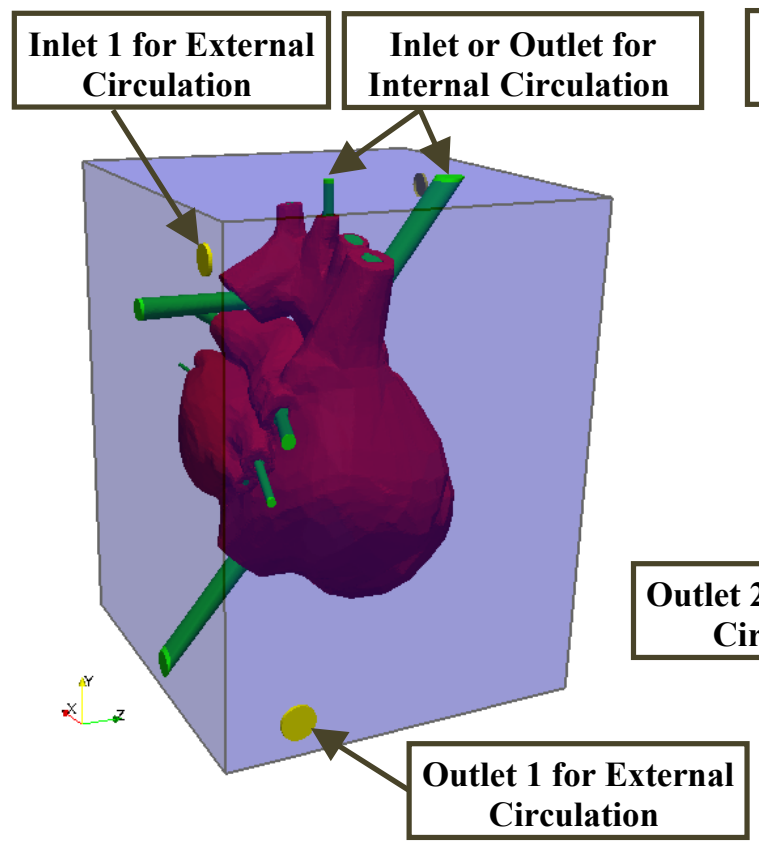

b)

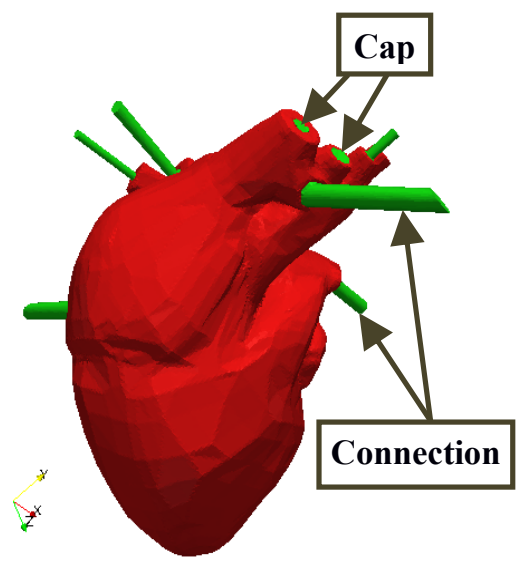

d)

Inlet 2 and 3 for External Circulation

Figure 5.1. Cooling system: a) cooling container, b) connections and caps, c) inlet 1 and outlet 1 for external cooling, d) inlet 2 and outlet 2 for external cooling coolant. 
As figures 5.1c and 5.1d illustrate, inlets were located on the top corner of the cooling container and on the opposite walls. Outlets were located on the bottom corner and on the opposite walls. The distance between each inlet (or outlet) center and its closest walls, was $20 \mathrm{~mm}$. For each of the two heart internal circulation systems, two inlets and two outlets were incorporated to pump the coolant through the heart chambers which were the same as previous cooling designs (figures $3.4 \mathrm{c}$ and $3.4 \mathrm{~d}$ ).

In the first fully-conjugate cooling case in this chapter (Case 5), inlet velocities were chosen in such manner to have the laminar flow regime in both internal and external coolant circulations. The same inlet velocities as previous cases (table 3.3), were also applied in this cooling system. Therefore, the inlet velocity of the UW solution for the pulmonary circulation was set to $0.4 \mathrm{~m} / \mathrm{s}$ and for the systemic circulation was set to $1 \mathrm{~m} / \mathrm{s}$. The inlet temperature of the UW solution was also the same as the one in previous cases which was $+4^{\circ} \mathrm{C}$. The outlet pressure values were assumed to be constant and the same as the one applied in previous $(101 \mathrm{kPa})$.

Table 5.1 demonstrates boundary conditions for the UW solution outside of the heart. In order to have laminar flow outside the heart, the UW solution was pumped with a very low velocity, $0.4 \mathrm{~m} / \mathrm{s}$. The inlet Reynolds number for the external circulation system was 1,662 . Therefore, the flow around the heart was assumed to be laminar.

Table 5.1. Boundary conditions for external fluid domain.

\begin{tabular}{|l|c|}
\hline Boundary Condition & External Circulation \\
\hline Inlet velocity magnitude & $0.4 \mathrm{~m} / \mathrm{s}$ \\
\hline Outlet pressure & $101 \mathrm{kPa}$ \\
\hline Inlet coolant temperature & $+4^{\circ} \mathrm{C}$ \\
\hline
\end{tabular}


This case was simulated for a period of $3600 \mathrm{~s}$ of the cooling process. For simulations in this chapter, the same computer cluster was used. The thermo fluid simulation of Case 5 was run on 14 Intel (Xeon E5-2680 2.7GHz) based cores with 128 GB memory. Total computing time for this case was 580,471 s.

Figure 5.2a illustrates the UW solution streamlines around the heart with temperature distribution at $300 \mathrm{~s}$. As this figure shows the maximum velocity of coolant was at the inlets. The minimum velocity occurred at fluid-solid interfaces due to viscous boundary layer of fluid. Therefore, lower velocity can be observed adjacent to the heart's outermost surfaces and container walls. Heart model and its connections were added to this figure in red color to better demonstrate UW solution streamlines around the heart. Thus, its red color is not an indication for the velocity or temperature.

a)

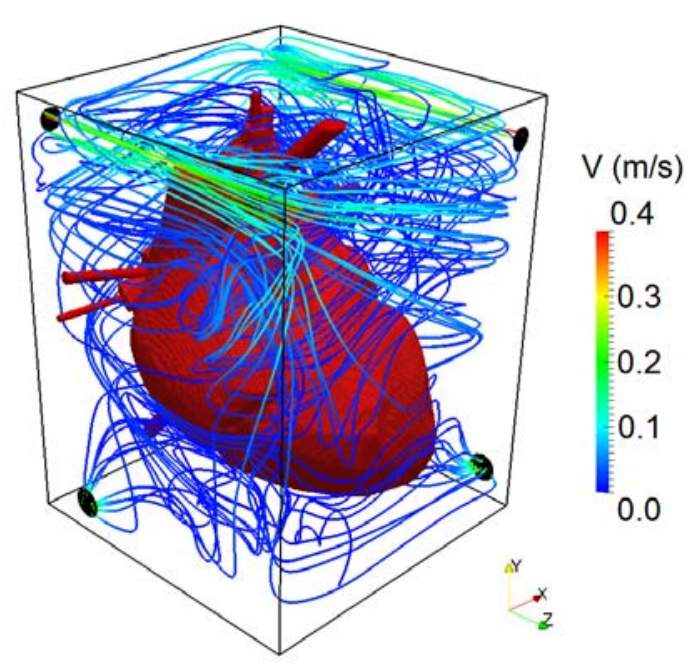

b)

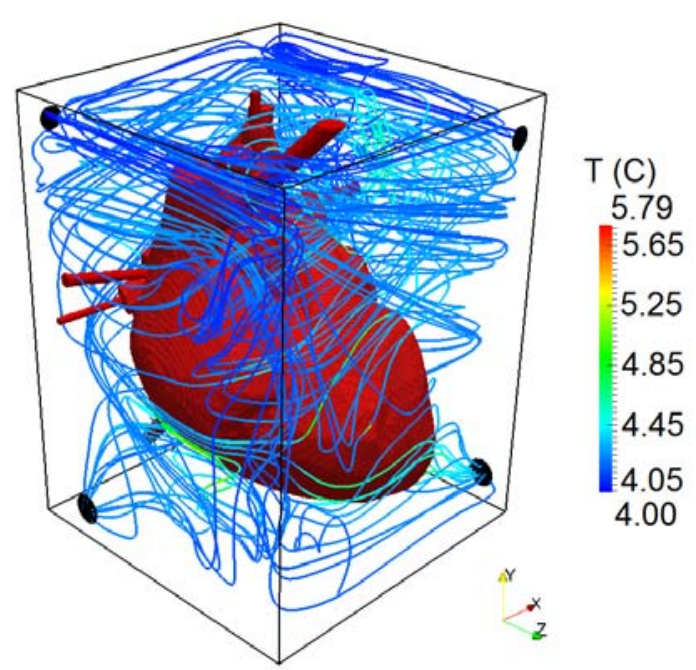

Figure 5.2. UW solution streamlines (external circulation), a) temperature distribution, and b) velocity distribution at $300 \mathrm{~s}$. 
Figure $5.2 \mathrm{~b}$ shows the temperature distribution of the UW solution around the heart at $300 \mathrm{~s}$. As this figure illustrates, the maximum temperature which was $+5.79^{\circ} \mathrm{C}$ occurred at the place where the fluid was in touch with the surface of the heart. It can also be observed that the inlet temperature $\left(+4^{\circ} \mathrm{C}\right)$ was the minimum temperature of the coolant.

Velocity and temperature distributions of the UW solution streamlines inside the heart pulmonary and systemic circulatory domains are shown in figure 5.3. Figure 5.3a illustrates that maximum velocity which was $2.24 \mathrm{~m} / \mathrm{s}$ occurred in the pulmonary circulatory domain, right after pulmonary valve. Figure $5.3 \mathrm{~b}$ shows that, the maximum temperature variation of the UW solution was $+3.19^{\circ} \mathrm{C}$.

a)

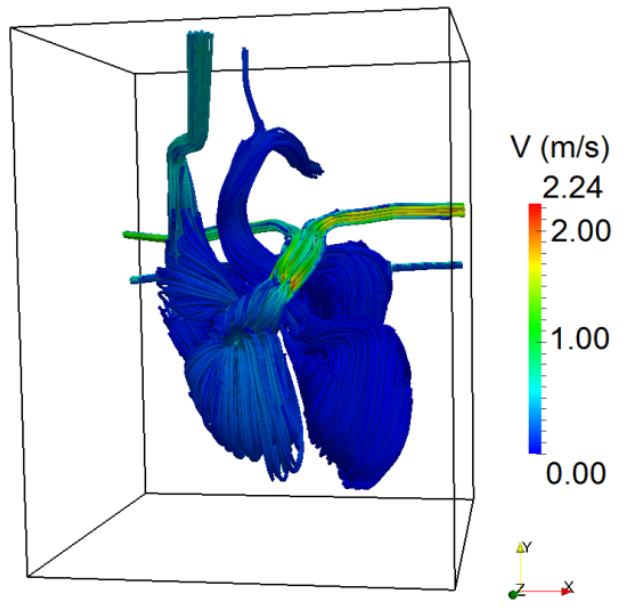

b)

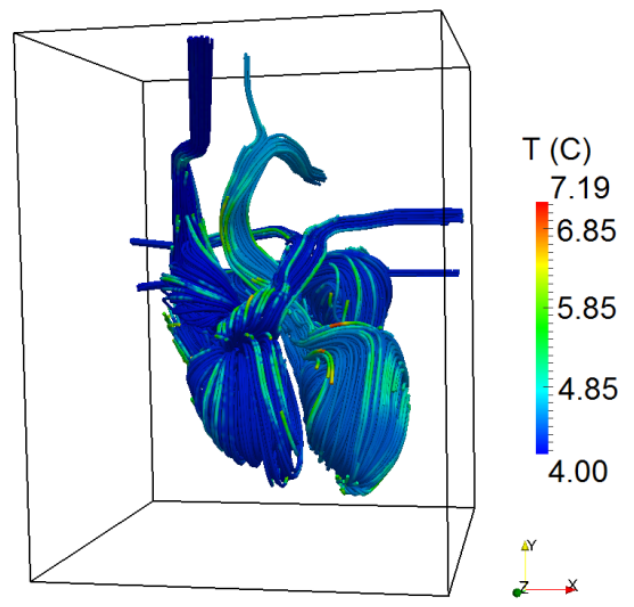

Figure 5.3. UW solution streamlines (internal circulations), a) temperature distribution, and b) velocity distribution.

The coolant temperature in the systemic circulatory domain was higher than the coolant temperature in the pulmonary circulatory domain. This was because of the lower 
velocity of the UW solution in the systemic circulatory domain than the pulmonary circulatory domain which can be observed in figure 5.3a. The lower coolant velocity will increase the heat transfer interval between the coolant and the heart. Therefore, it will increase the coolant temperature. This can enhance the heat transfer process. However, having a lower velocity will decrease the rate of heat removed by the coolant. In this chapter, effects of inlet velocity on heat transfer from the heart were investigated for the external and internal coolant flows.

Figure 5.4 shows the volumetric temperature distribution inside the heart at $0 \mathrm{~s}$, $300 \mathrm{~s}, 600 \mathrm{~s}, 900 \mathrm{~s}, 1500 \mathrm{~s}$ and $3600 \mathrm{~s}$ of cooling time. Figure 5.4a illustrates that the heart tissue's temperature distribution at the very beginning of the cooling process when the heart temperature was $+37^{\circ} \mathrm{C}$. Figures $5.4 \mathrm{~b}$ to figure $5.4 \mathrm{f}$ demonstrate the heart cooling process. A constant color legend from $+1^{\circ} \mathrm{C}$ to $+37^{\circ} \mathrm{C}$ was used to better illustrate the temperature variation of the heart tissue, and at the same time to be consistent with figures shown in previous cases. Also, this will help to better compare results of this cooling case with previous cooling cases. Therefore, the minimum and maximum temperatures of the heart are not necessarily equal to the minimal to maximal range of the color legend. The red color in figure 5.4 signifies the hot spots within the heart tissue. Figure $5.4 \mathrm{e}$ shows that after $1500 \mathrm{~s}$ of cooling, the temperature of almost all parts of the heart tissue was reduced to around $+4^{\circ} \mathrm{C}$, and only two spots within the heart had the temperature slightly higher than $+4^{\circ} \mathrm{C}$. 
a)

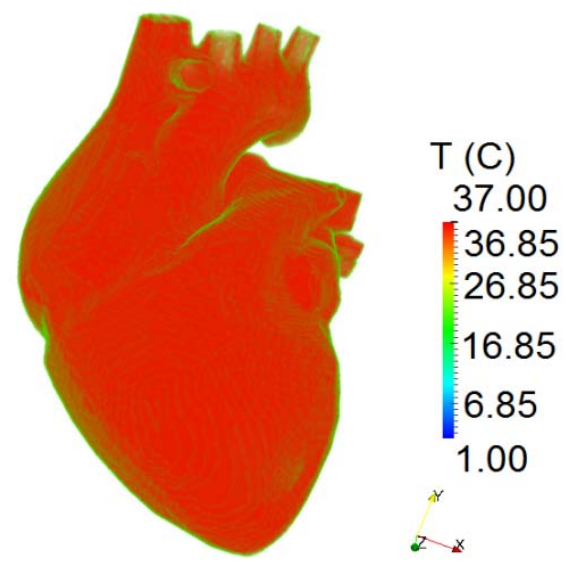

c)

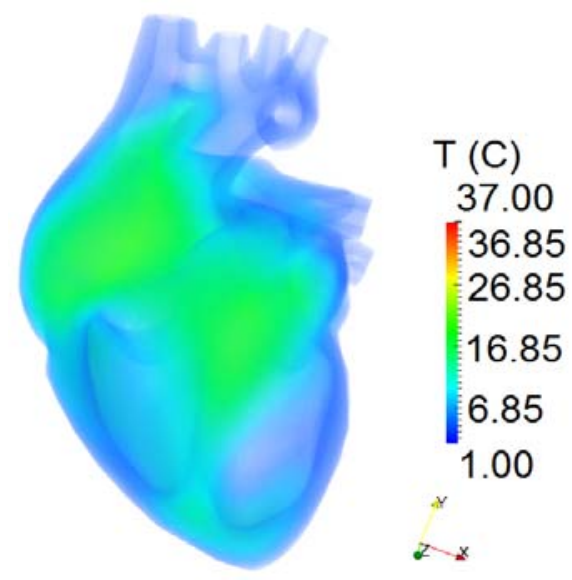

e)

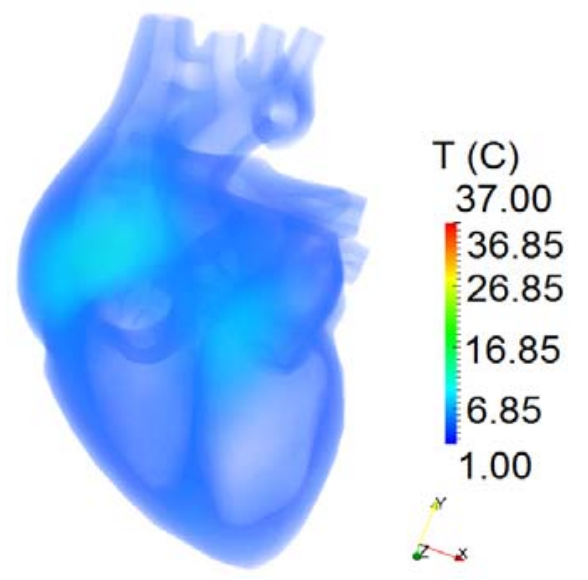

b)

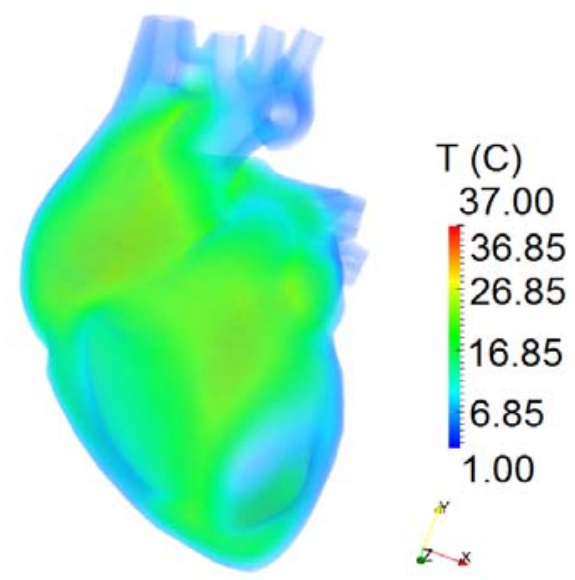

d)

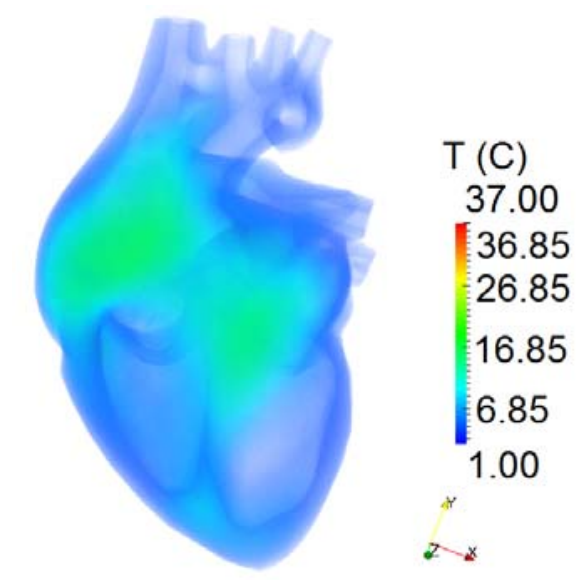

f)

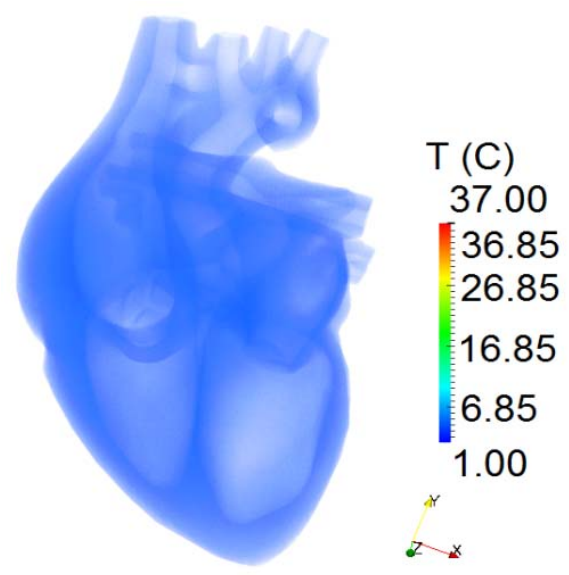

Figure 5.4. Temperature distribution of the heart tissue with constant color legend: a) $0 \mathrm{~s}$, b) $300 \mathrm{~s}$, c) $600 \mathrm{~s}$, d) $900 \mathrm{~s}$, e) $1500 \mathrm{~s}$, and f) $3600 \mathrm{~s}$. 
Since this cooling design showed a higher heat removal capacity compared to other cases, therefore, the cooling time was increased to $3600 \mathrm{~s}$ for further investigations. After $3600 \mathrm{~s}$ of cooling, the heart had the average temperature of $+4^{\circ} \mathrm{C}$. The minimum, maximum and average temperatures of the heart tissue are discussed separately in this section.

To better illustrate the locations of the heart tissue's hot spots, the heart was sliced at different planes and at different angles using ParaView visualizer software. Figure 5.5a and $5.5 \mathrm{~b}$ demonstrate the distribution of heart tissue's temperature at $300 \mathrm{~s}$ for two different cut-away views. Figure 5.5a illustrates a large hot spot located above the right ventricle, and on the right side of the right atrium.

a)

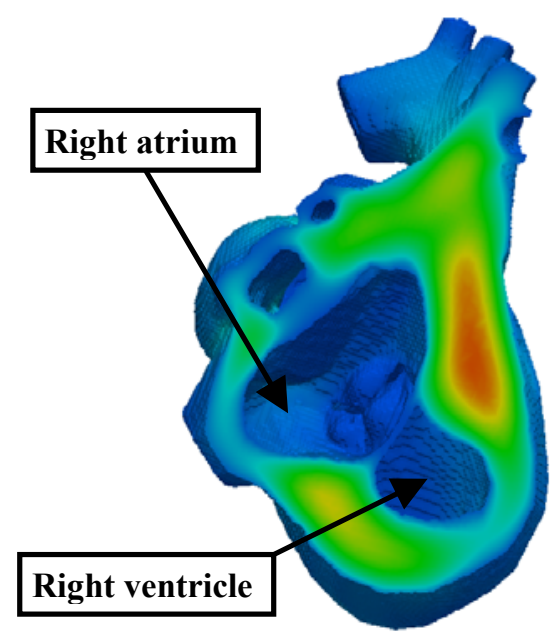

b)

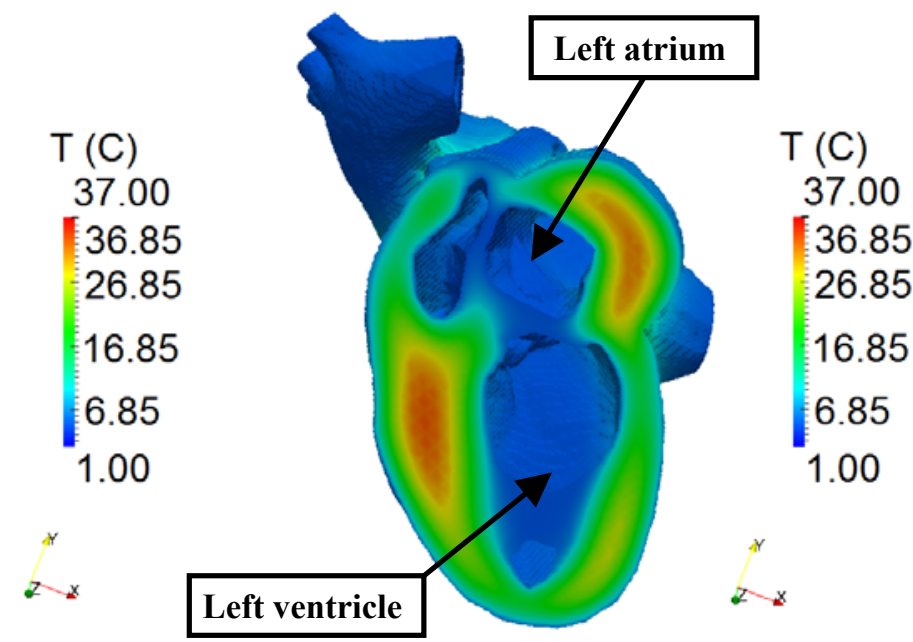

Figure 5.5. Temperature distribution at $300 \mathrm{~s}$ : a) 1st cut-away view, b) 2nd cut-away view.

The cut-away view shown in Figure 5.5b, discloses two more hot spots; one is located on the left side of the left ventricle, and the other is located on the right side of the 
left atrium. Thus, these three hot spots will take longer to cool compared to the rest of the heart tissue. The same hot spots were observed in Case 4 (figure 4.8).

To further reveal the temperature variations inside the heart during the cooling process, the maximum, minimum and average volumetric temperatures of heart tissue are shown in figure 5.6. As this figure shows, variation of the minimum temperature is not significant. The heart temperature will begin to decrease as soon as the coolant begins to touch the inner and outer heart surfaces. Since the UW solution inlet temperature is constant $\left(+4^{\circ} \mathrm{C}\right)$ and has its minimum temperature at the beginning of cooling, the minimum temperature of the heart will not change noticeably over time. The minimum temperature of the heart was $+4^{\circ} \mathrm{C}$ after $1500 \mathrm{~s}$ of cooling and $+3.9^{\circ} \mathrm{C}$ after $3600 \mathrm{~s}$. These minimum temperatures indicate that the suggested cooling system was successful in avoiding possible tissue damages due to a temperature less than $+4^{\circ} \mathrm{C}$.

The maximum temperature was decreased by $+25.0^{\circ} \mathrm{C}$, i.e., from $+37.0^{\circ} \mathrm{C}$ to $+12.0^{\circ} \mathrm{C}$ after $1500 \mathrm{~s}$. The maximum temperature reached to $4.5^{\circ} \mathrm{C}$ after $3600 \mathrm{~s}$. The average volumetric temperature of the whole heart was calculated and is also shown in figure 5.6. The average volumetric temperature was reduced by $+32.0^{\circ} \mathrm{C}$, i.e., from $+37.0^{\circ} \mathrm{C}$ to $+5.0^{\circ} \mathrm{C}$ after $1500 \mathrm{~s}$. The average volumetric temperature was $+4^{\circ} \mathrm{C}$ after $3600 \mathrm{~s}$. 


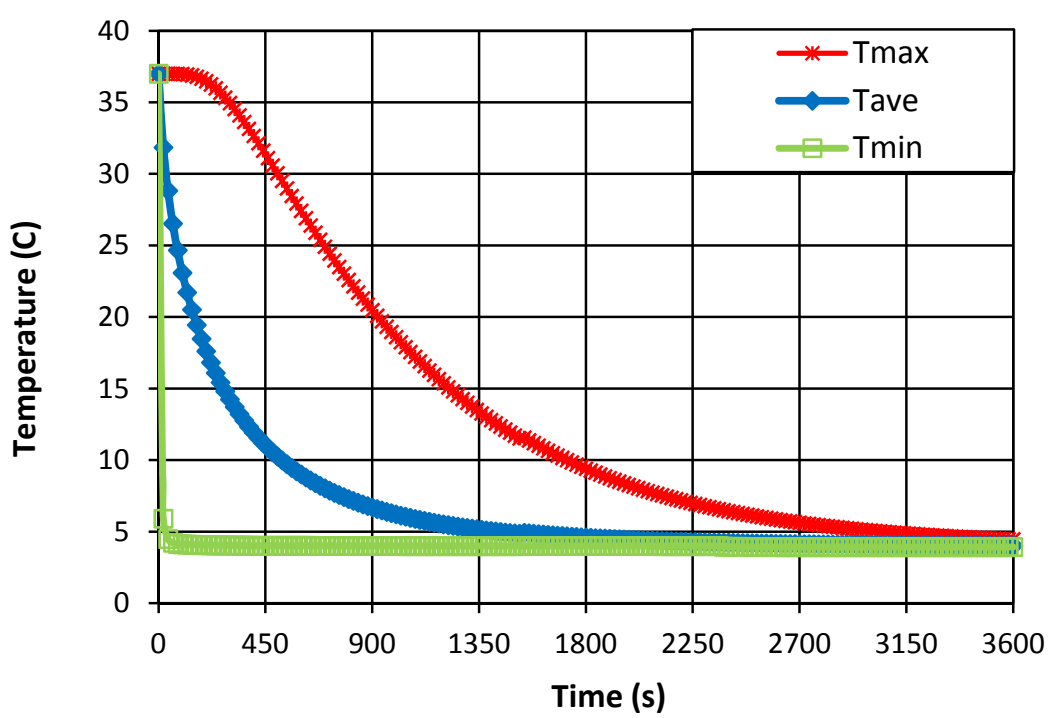

Figure 5.6. Temperature variations (maximum, minimum and average volumetric temperatures of the heart $v s$. time).

Figure 5.7 shows variations of cooling rates by time for the maximum, minimum and the average volumetric temperatures of heart on a logarithmic scale.

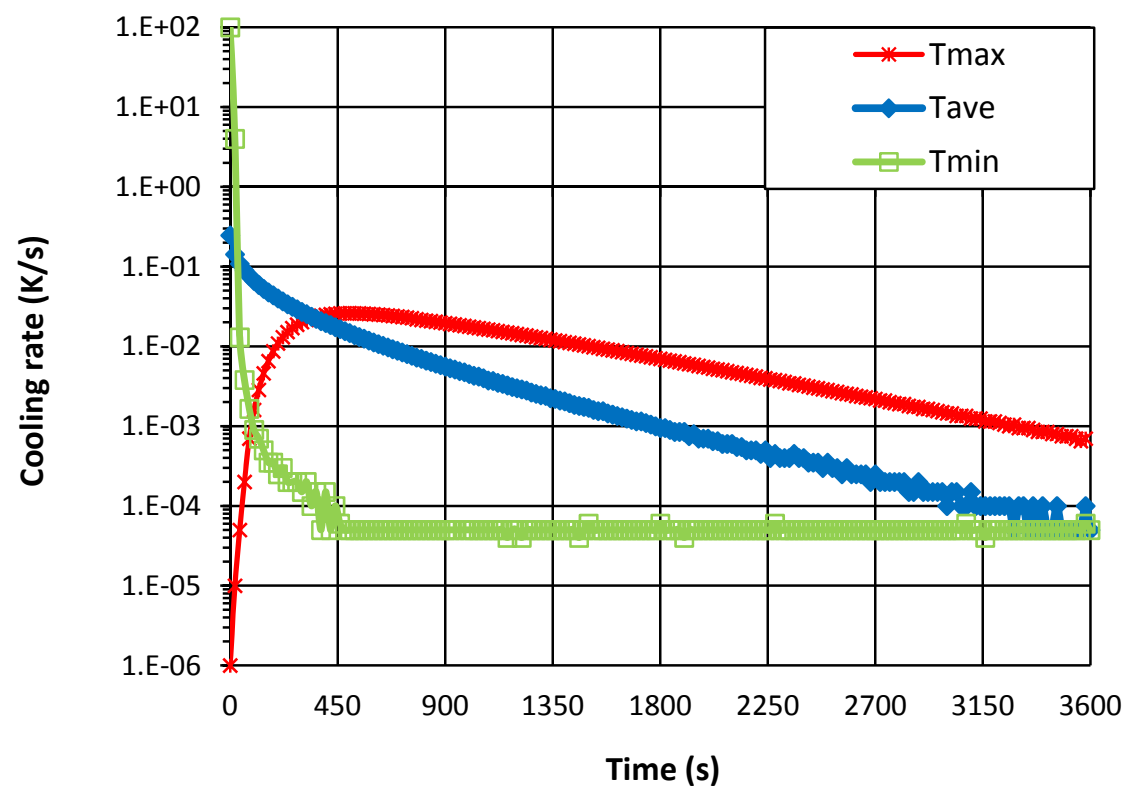

Figure 5.7. Cooling rate vs. time (logarithmic scale). 
As this figure shows, the cooling rate for average volume temperature starts at $0.247^{\circ} \mathrm{C} / \mathrm{s}$ and gradually decreases to $0.0017^{\circ} \mathrm{C} / \mathrm{s}$ at $1500 \mathrm{~s}$ and to $5.0 \mathrm{E}-5^{\circ} \mathrm{C} / \mathrm{s}$ at $3600 \mathrm{~s}$. The cooling rate of the minimum temperature was very high initially $\left(31.1^{\circ} \mathrm{C} / \mathrm{s}\right)$, but decreased rapidly after a few seconds and became less than $0.001{ }^{\circ} \mathrm{C} / \mathrm{s}$ after $100 \mathrm{~s}$. The maximum temperature started to decrease with an almost zero cooling rate, i.e., it did not cool at the beginning. Then, the cooling rate of the maximum temperature started to increase gradually and reached to its maximum value of $0.0261^{\circ} \mathrm{C} / \mathrm{s}$ at $480 \mathrm{~s}$.

The coefficient of variation of volumetric temperature (equation. 3.1) is shown in figure 5.8. The maximal value of $\mathrm{CV}$ was $1.45 \mathrm{E}-04$, which occurred at $240 \mathrm{~s}$. As this figure demonstrates, the non-uniformity of the average volumetric temperature increased until $240 \mathrm{~s}$ and then started to decrease gradually to $3.41 \mathrm{E}-5$ at $1500 \mathrm{~s}$ and to $1.77 \mathrm{E}-6$ at $3600 \mathrm{~s}$. Therefore, the non-uniformity was decreased 4.25 times at $1500 \mathrm{~s}$ compared to its maximum at $240 \mathrm{~s}$. At $3600 \mathrm{~s}, \mathrm{CV}$ was decreased 81.92 times compared to the maximum.

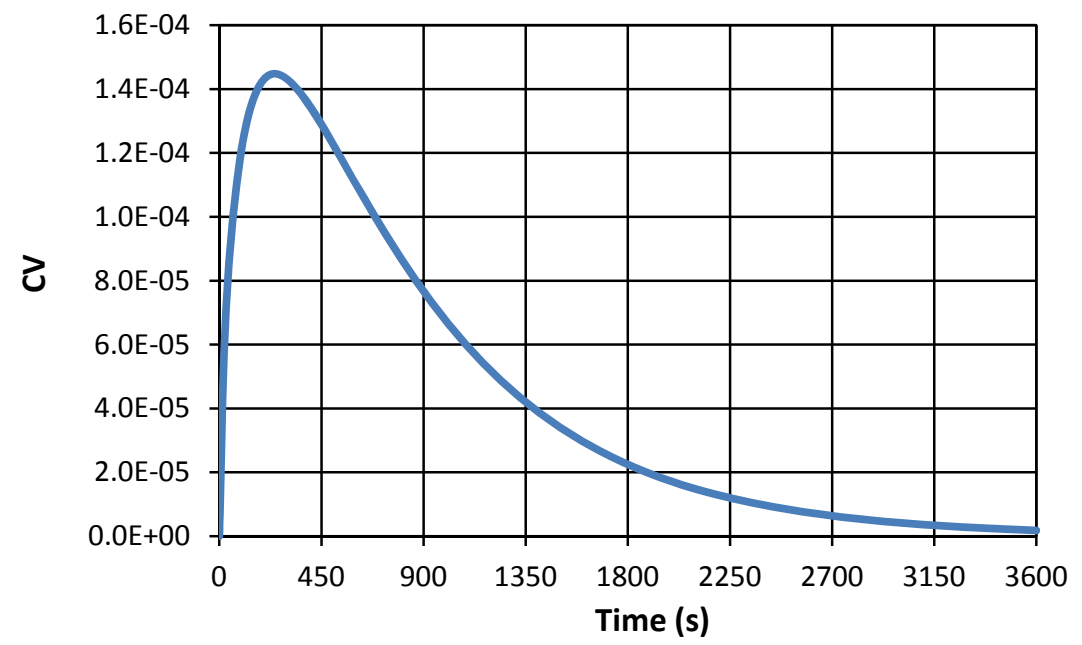

Figure 5.8. Coefficient of variation of volumetric temperature $v s$. time. 
Rate of metabolic rate reduction was calculated by using equation 1.1. The percentage of this metabolic rate reduction was shown in figure 5.9. As this figure demonstrates, after $450 \mathrm{~s}$ of cooling, metabolic rate was reduced by $90 \%$. Then, the reduction rate of metabolic rate slowed down rapidly. The metabolic rate reduction at $1040 \mathrm{~s}$ was $94.02 \%$. Variations of metabolic rate reduction after $1040 \mathrm{~s}$ were almost negligible. The reduction of metabolic rate at $1500 \mathrm{~s}$ was $94.68 \%$ and at $3600 \mathrm{~s}$ was $95.13 \%$.

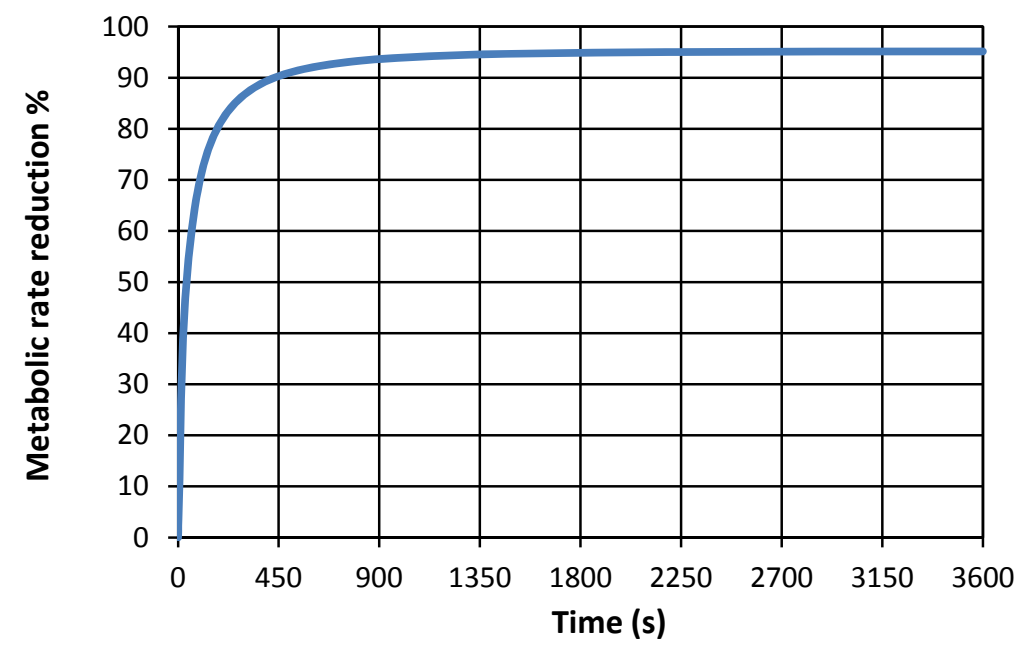

Figure 5.9. Percentage of metabolic rate reduction $v s$. time.

The stress analysis was performed by using the data obtained by the thermo fluid analysis results. However, since the same boundary and initial boundary condition were used for fluid flow inside the heart, the same results were obtained for the maximum von Mises and WSS inside the heart as those presented in chapter IV, section 4.2.2. 


\subsection{Case 6 - UW Cooling (Laminar Internal and Turbulent External Flows)}

The main objective of simulating the fully-conjugate cooling Case 6, was to study effects of coolant flow rate and turbulent flow regime in enhancing heat transfer from the heart. Except internal velocities for external circulation, all parameters and boundary conditions were kept the same as those in the previous case. In this case, the inlet velocity of the UW solution for the external circulation was increased to $1 \mathrm{~m} / \mathrm{s}$. Therefore, the value of the Reynolds number at inlets of the external circulation increased to $4,155.35$. This value indicates that the flow regime around the heart was turbulent. Thus, the $k-\varepsilon$ turbulent model explained in section 2.1.1.2 was applied to simulate turbulence effects.

This simulation was also run on 16 Intel (Xeon E5-2680 2.7GHz) based cores with 128 GB memory. Total computing time was $601,230 \mathrm{~s}$ for $3600 \mathrm{~s}$ of cooling simulation. It should be noticed that, in this case governing equations included two additional equations for the $k-\varepsilon$ turbulent model. This increased the computing time.

Figure 5.10 shows external circulations streamlines with velocity and temperature distributions at $300 \mathrm{~s}$. As figure 5.10a illustrates the maximum velocity of coolant was 1 $\mathrm{m} / \mathrm{s}$, which was located at the inlet. This figure also illustrates more vortices around the heart compared to the first case (figure 5.2). Figure 5.10b shows that the maximum temperature of the UW solution around the heart was $+5.92^{\circ} \mathrm{C}$, which is slightly higher than the one in Case $5\left(+5.79^{\circ} \mathrm{C}\right)$. However, as this figure shows, the distribution of temperature in this case was different than in Case 5 (figure 5.2b). 
a)

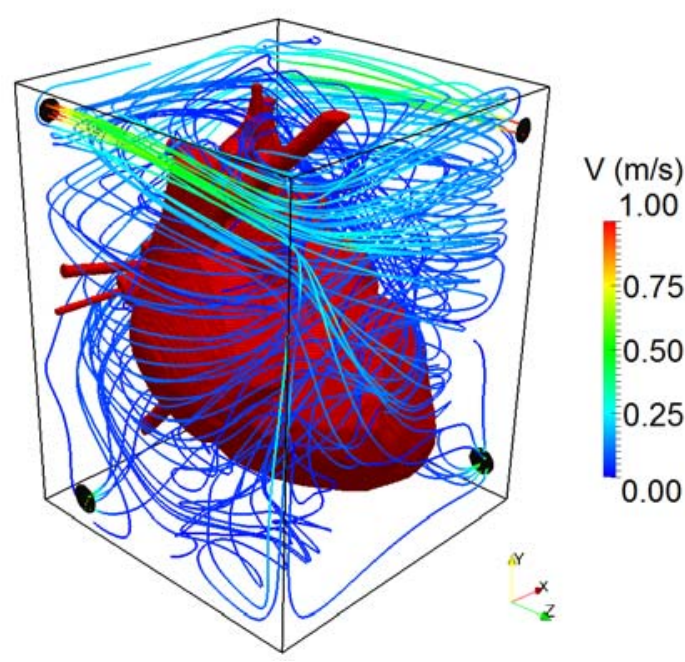

b)

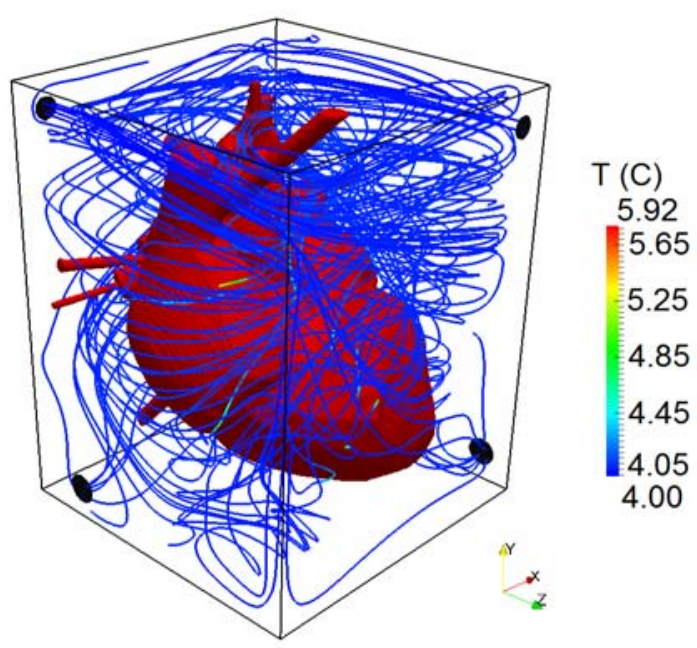

Figure 5.10. UW solution streamlines (external circulation), a) temperature distribution, and b) velocity distribution at $300 \mathrm{~s}$.

Figure 5.11 demonstrates coolant streamlines for internal circulation systems. Since the boundary conditions of internal flows were not changed, almost the same results were obtained compared to Case 5 (figure 5.3).

a)

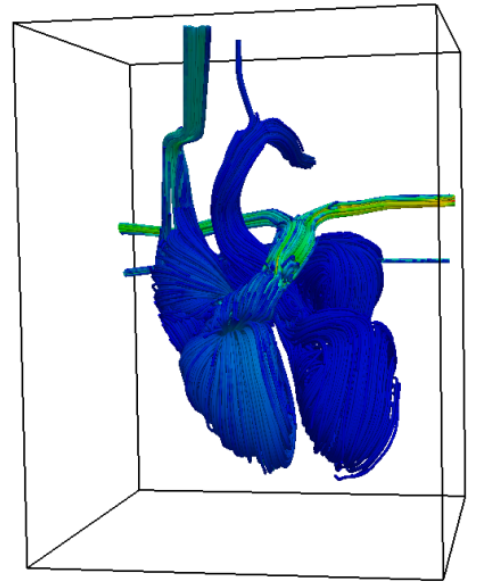

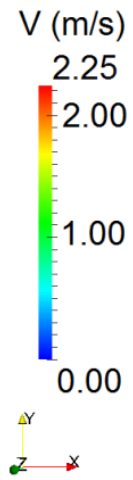

b)

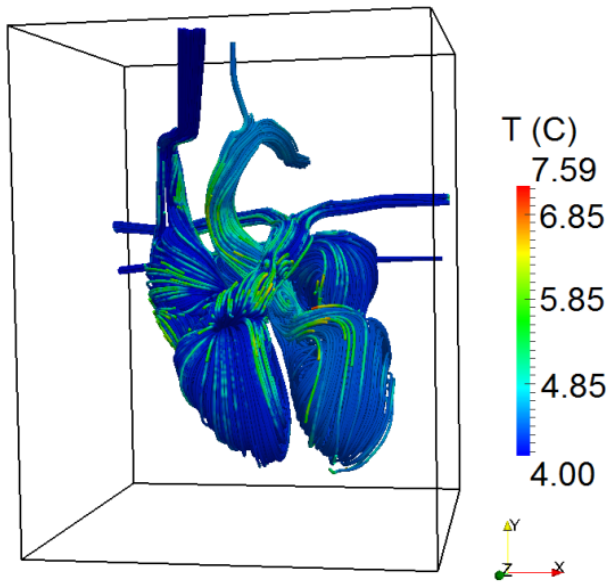

Figure 5.11. UW solution streamlines (internal circulations), a) temperature distribution, and b) velocity distribution. 


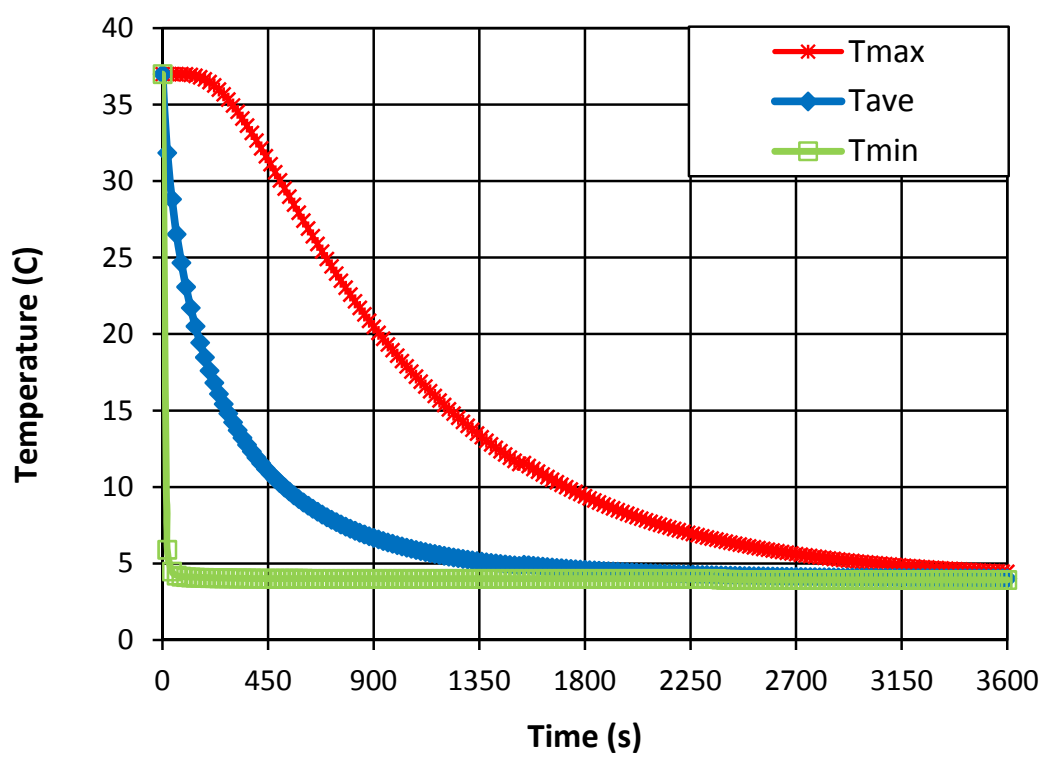

Figure 5.12. Temperature variations (maximum, minimum and average volumetric temperatures of the heart $v s$. time).

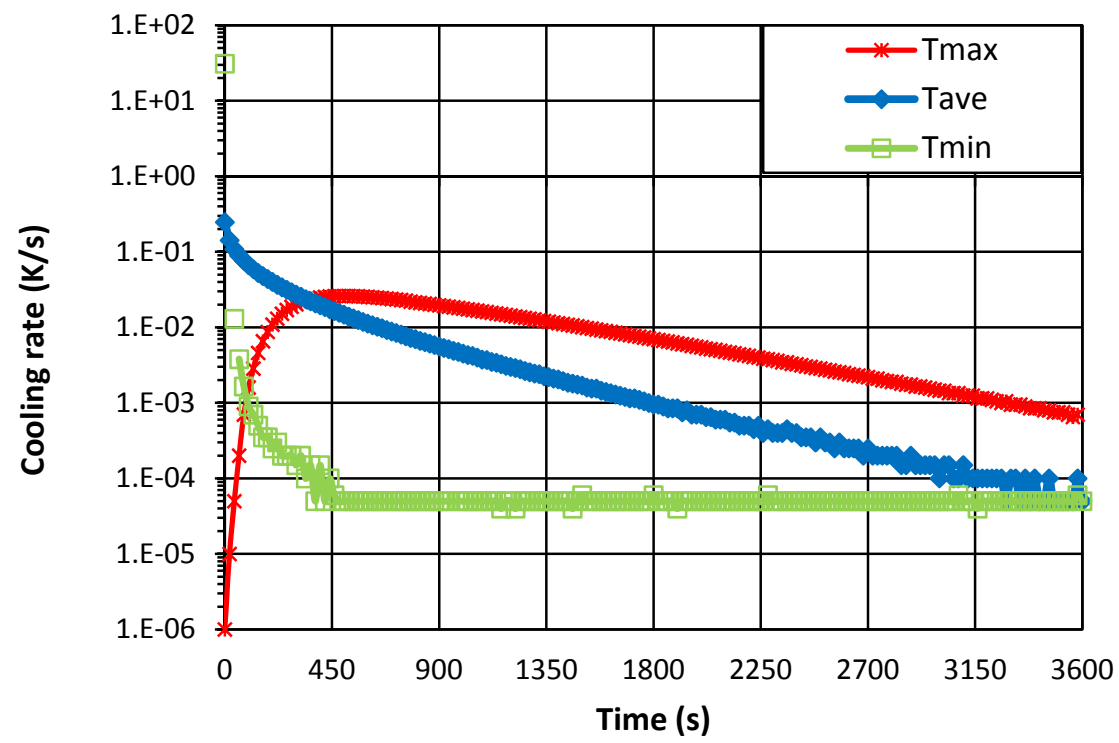

Figure 5.13. Cooling rate $v s$. time (logarithmic scale).

Variations of the maximum, minimum and average volumetric temperatures of the heart tissue are shown in figure 5.12. By comparing these results with the results of full-conjugate Case 5 (figure 5.6), it can be concluded that differences between these two 
cases are almost negligible. Cooling rates of the maximum, minimum and average volumetric temperatures are shown in figure 5.13. By comparing these results with those shown in figure 5.7, negligible differences can be detected.

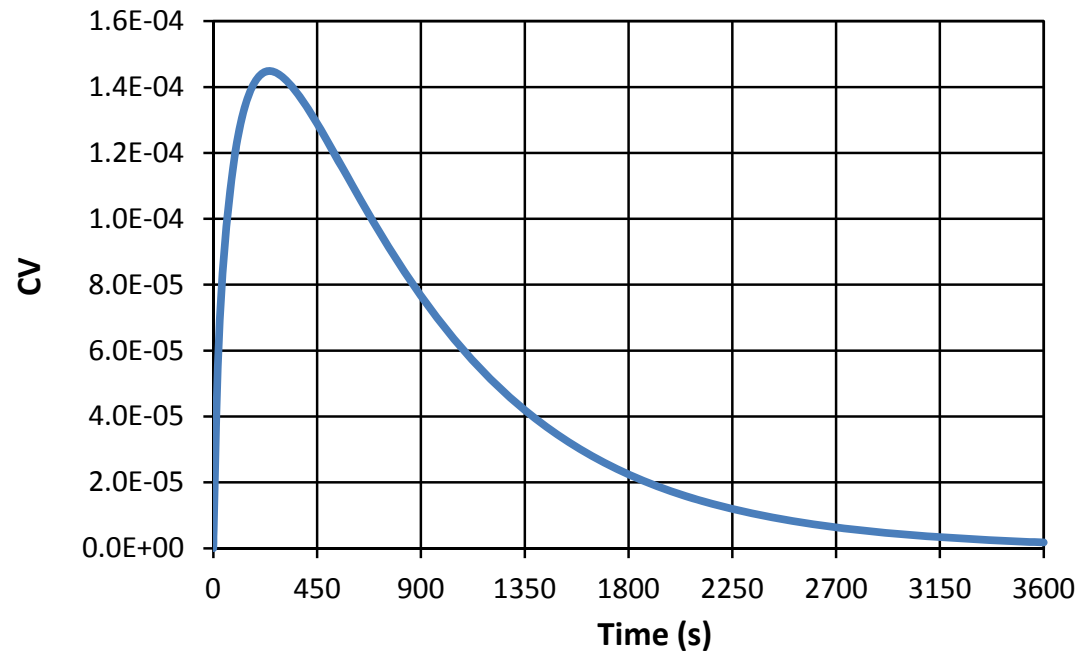

Figure 5.14. Coefficient of variation of volumetric temperature $v s$. time.

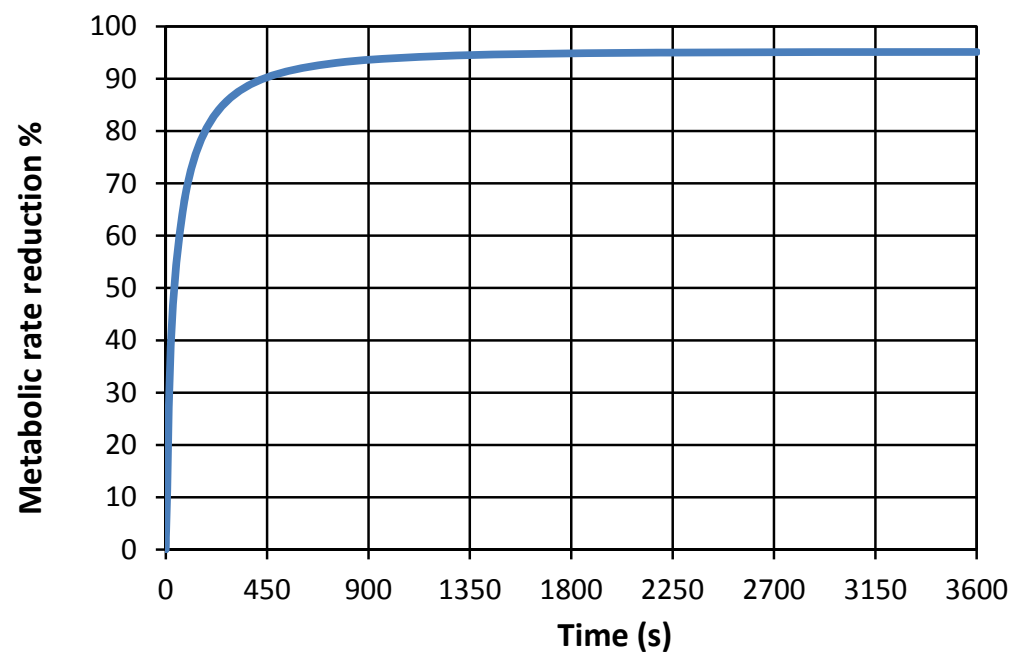

Figure 5.15. Percentage of metabolic rate reduction $v s$. time. 
The coefficient of variation of temperature is shown in figure 5.14. Again, negligible variations between these results and the results of Case 5 (figure 5.8) can be observed. The percentage of metabolic rate reduction in this case, which is shown in figure 5.15, also demonstrates almost the same result as the first case (figure 5.9).

\subsection{Case 7 - UW Cooling (Laminar Internal and Turbulent External Flows)}

The main objective of the simulation in this section was to create a UW solution jet flow right on the external surface of one of the hot spots (figure 5.5a), and study its effects in cooling the hot spot of the heart tissue. A jet flow will increase the convection heat transfer coefficient of the UW solution flow around the heart, and it can enhance the heat transfer from the heart.

Figure 5.16 shows the new cooling container with all inlets and outlets for external circulation system. Inlet 2 shown in figure 5.16b, was designed in such manner to create a jet on the external surface of the hot spot located above the right ventricle and on the right side of the right atrium (figure 5.5a). Total computing time for this case was $602,012 \mathrm{~s}$ for cooling simulation of $3600 \mathrm{~s}$.

UW solution streamlines with velocity and temperature distributions are shown in figure 5.17. Figure 5.17a shows three jet flows in the cooling container. The maximum velocity of $1.04 \mathrm{~m} / \mathrm{s}$ occurs at the outlets which was more than the inlet velocity $(1 \mathrm{~m} / \mathrm{s})$. This was because of the extra inlet (inlet 3) which increases the total flow rate and velocity of the coolant at outlets to satisfy the conservation of mass law. 
a)

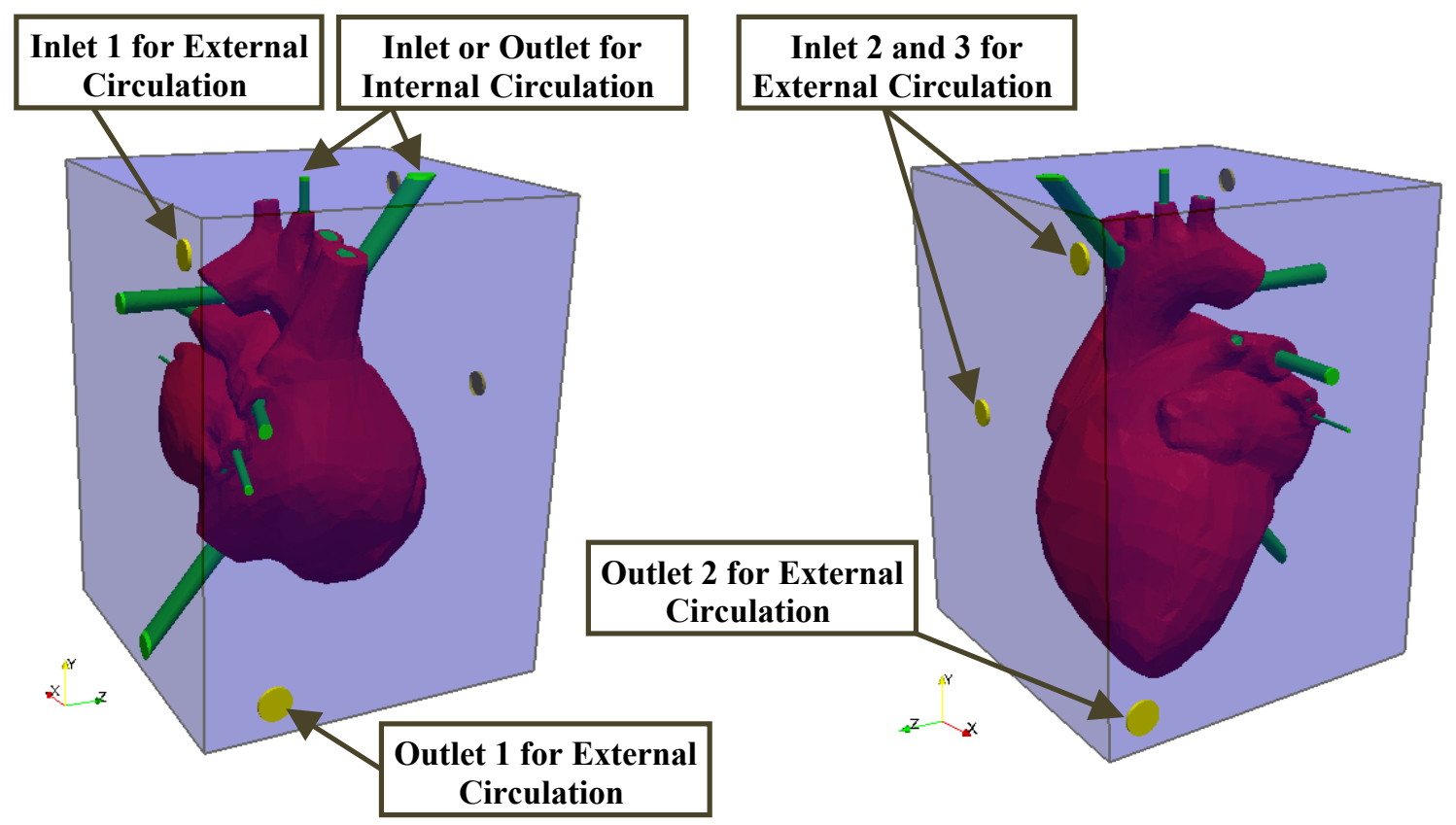

Figure 5.16. Cooling system: a) inlet 1 and outlet 1, b) inlet 2, inlet 3 and outlet 2 for the external cooling circulation.

To better illustrate the jet flow on the hot spot, the heart and UW solution streamlines were cut at the hot spot. Color of heart in figure $5.17 \mathrm{c}$ and $5.17 \mathrm{~d}$ indicates the temperature field inside the heart at $300 \mathrm{~s}$. Figure $5.17 \mathrm{c}$ clearly shows the jet flow on the external surface of the hot spot. In figure $5.17 \mathrm{~d}$, streamlines on the external surface of the hot spot are not distinguishable due do negligible temperature difference between the heart external surface and UW solution streamlines.

Streamlines of internal flows inside the heart pulmonary and systemic circulatory domains are shown in figure 5.18. Boundary conditions for internal flow were not changed. Therefore, results obtained for velocity and temperature distributions of the UW solution within the heart were almost the same as those in Case 5 and Case 6. 
a)

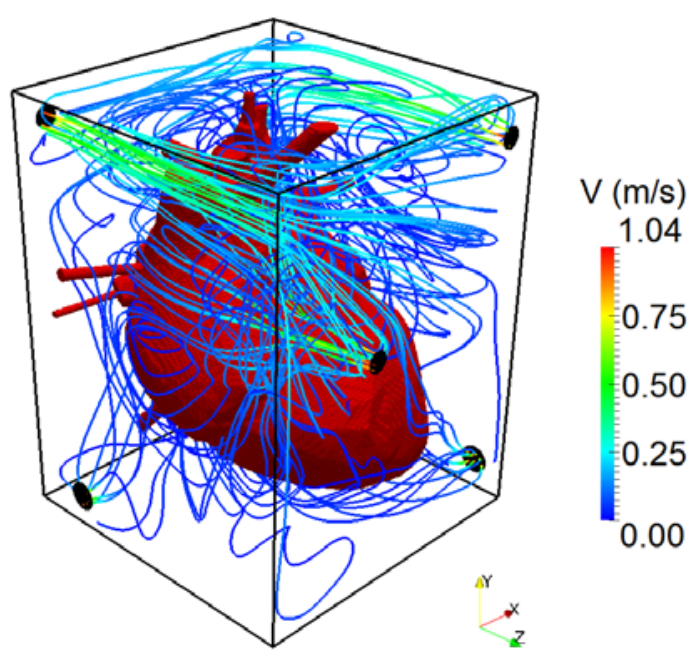

c)

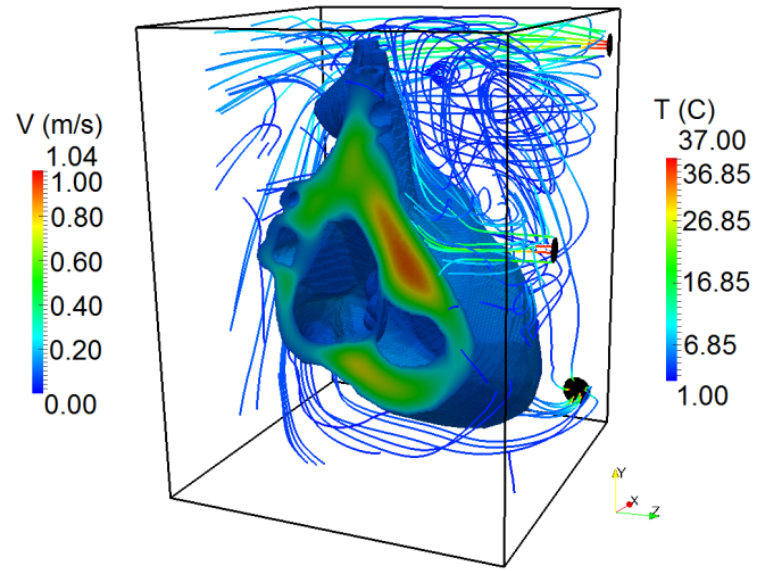

b)

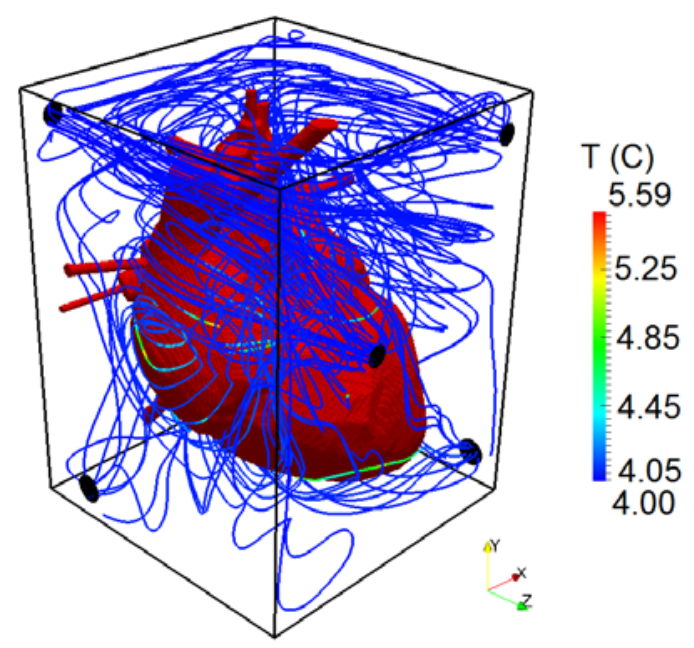

d)

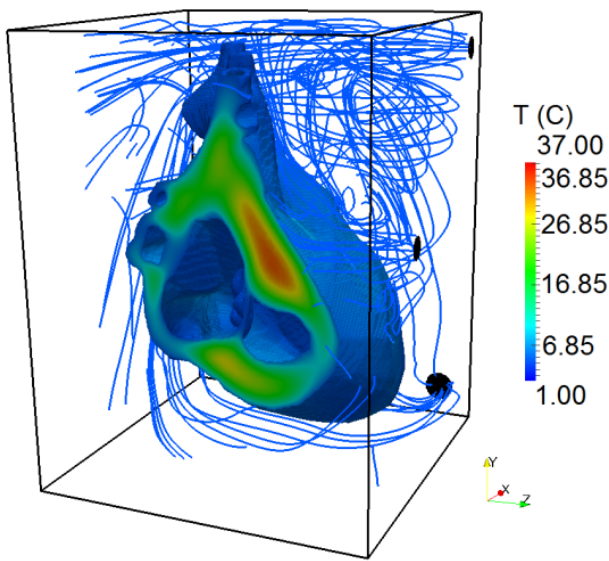

Figure 5.17. UW solution streamlines (external circulation), a) temperature distribution, and b) velocity distribution, c) cut-way view of temperature field, and d) cut-way view of velocity field at $300 \mathrm{~s}$. 
a)

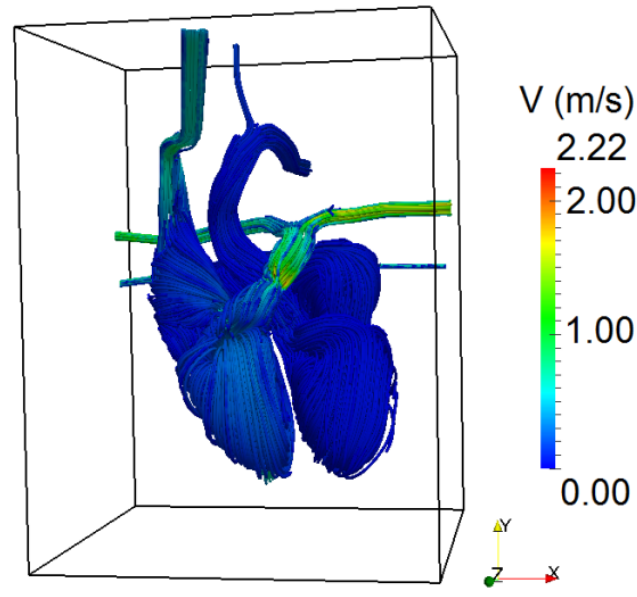

b)

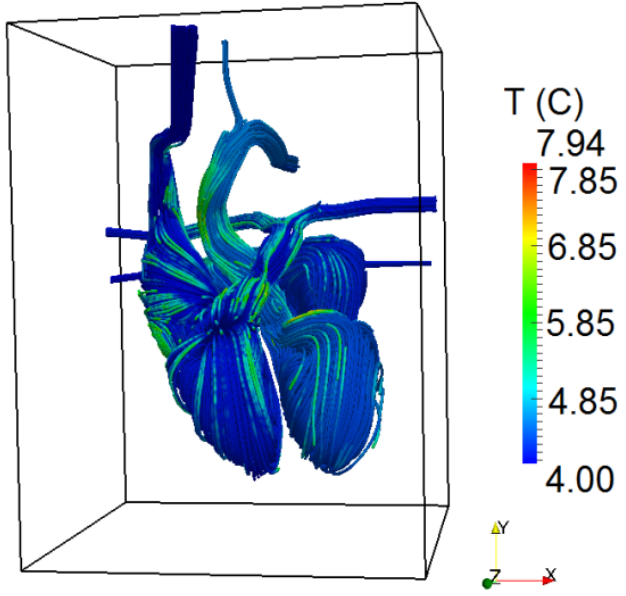

Figure 5.18. UW solution streamlines (internal circulations), a) temperature distribution, and b) velocity distribution.

Figure 5.19 demonstrates the maximum, minimum, average volumetric temperature and their cooling rates during $3600 \mathrm{~s}$ of cooling. As this figure shows, there was no significant enhancement in cooling of the heart using the fully-conjugate cooling Case 7. Figures 19, 20, 21 and 22 show temperature variations, cooling rate variations, $\mathrm{CV}$ of the average volumetric temperature, and metabolic rate reduction, respectively. As these figures illustrate results of temperature non-uniformity, metabolic reduction rate and maximum von Mises stress were almost the same as those in fully-conjugate Case 5 and Case 6. 


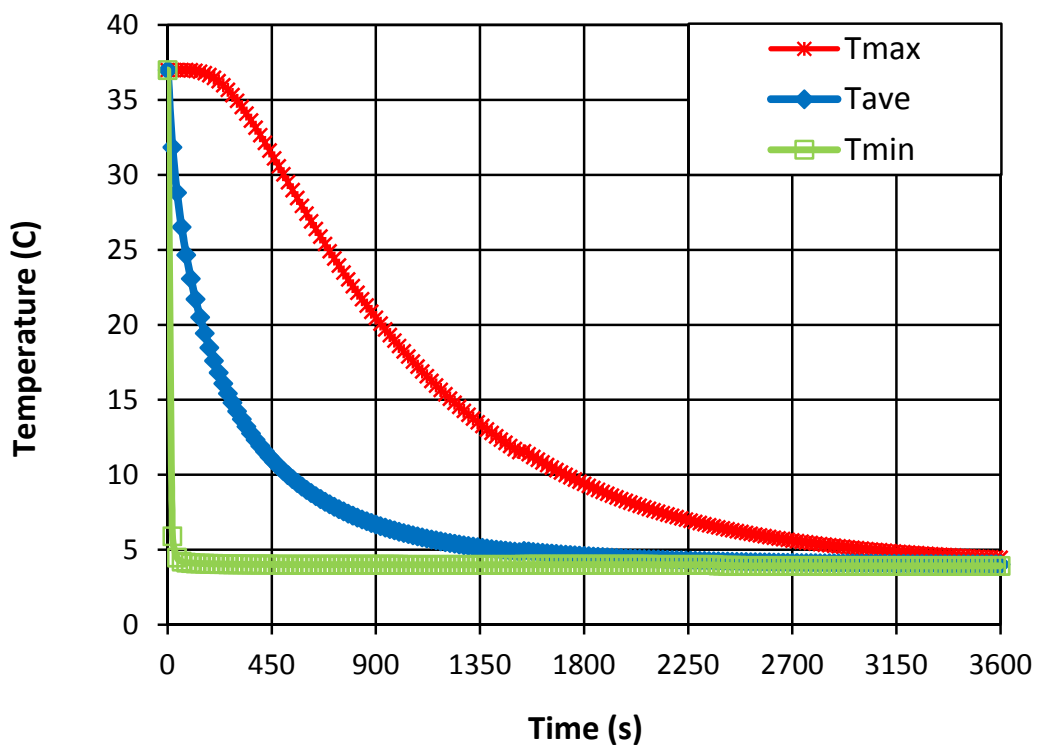

Figure 5.19. Temperature variations (maximum, minimum and average volumetric temperatures of the heart $v s$. time).

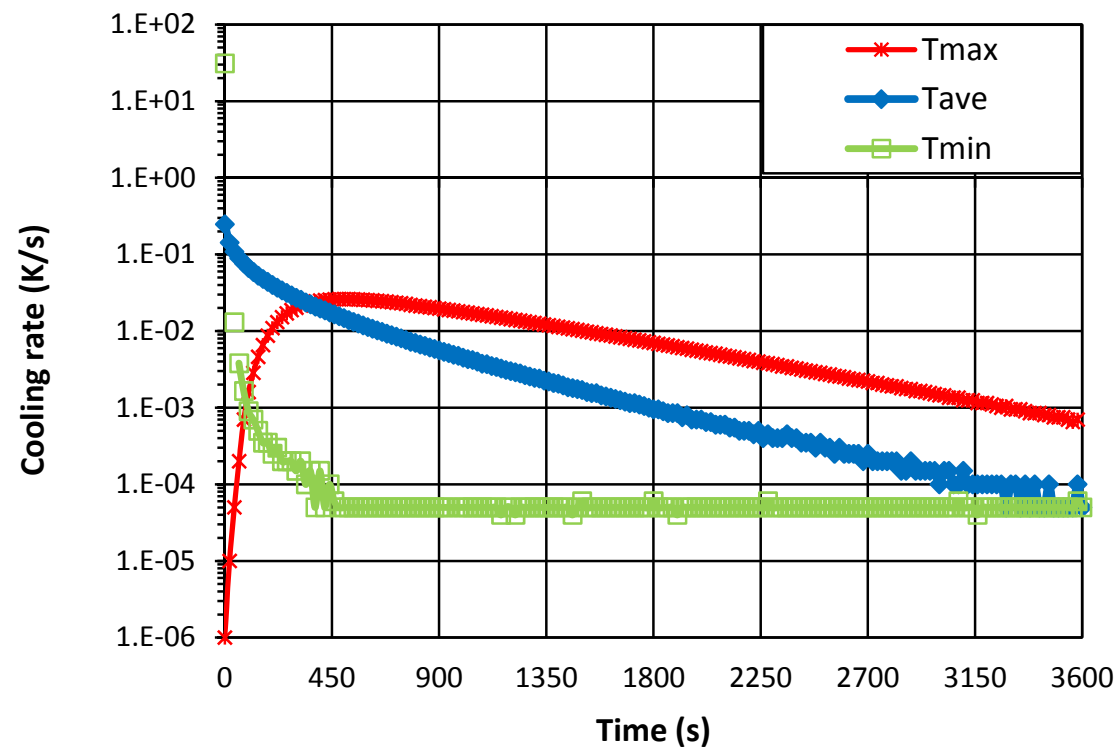

Figure 5.20. Cooling rate $v s$. time (logarithmic scale). 


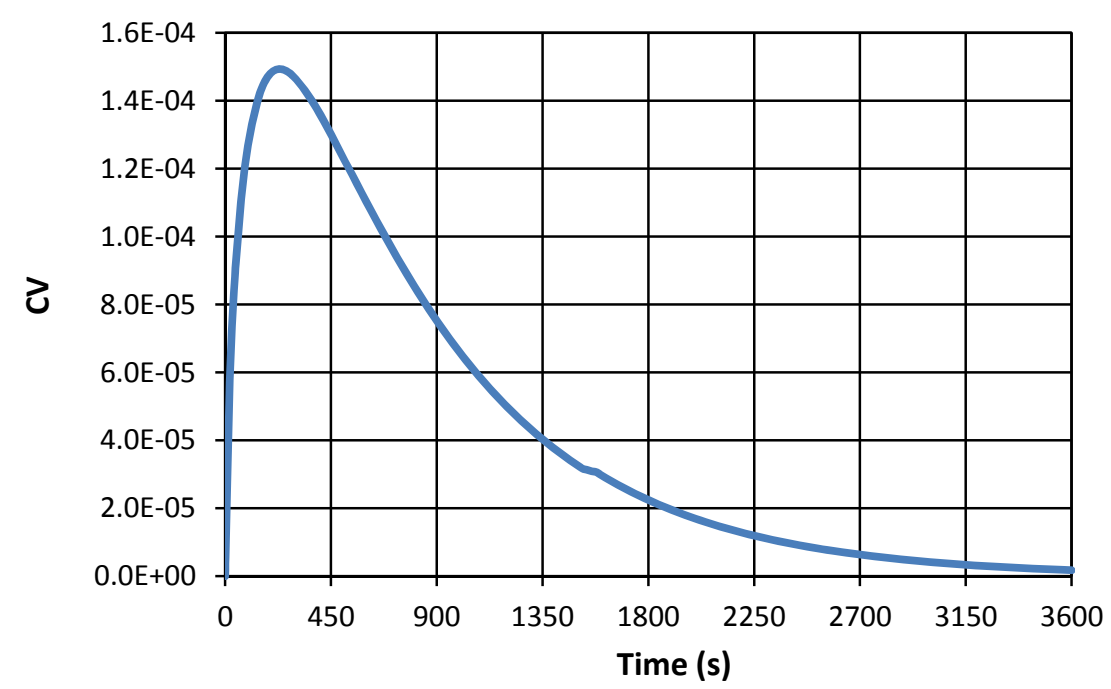

Figure 5.21. Coefficient of variation of volumetric temperature $v s$. time.

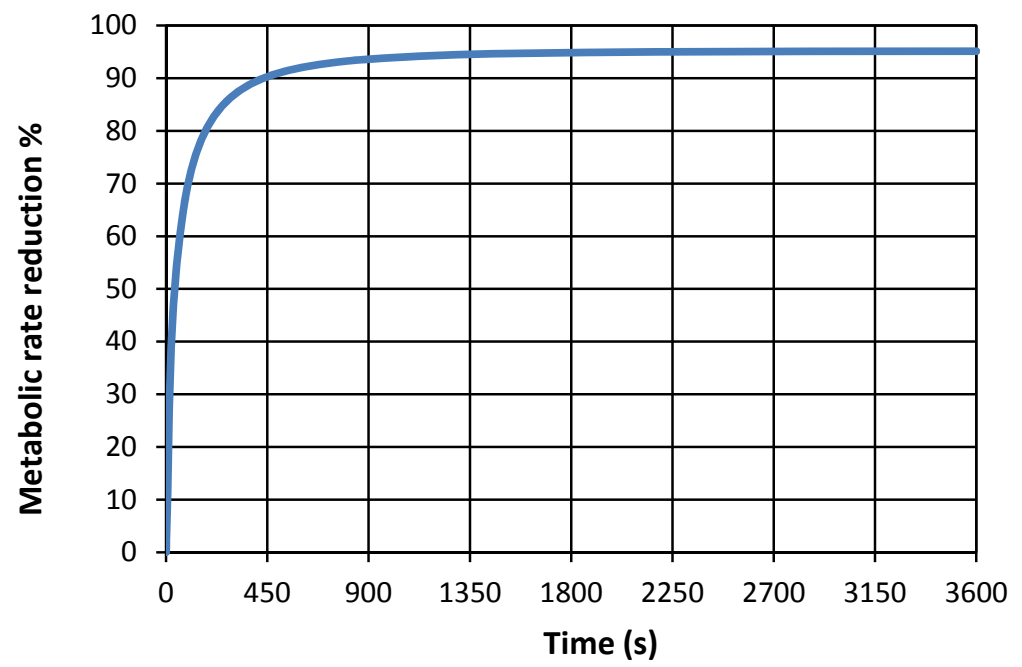

Figure 5.22. Percentage of metabolic rate reduction $v s$. time.

\subsection{Unsteady Periodic Boundary Condition}

The aim of this section was to study effects of unsteady periodic inlet velocities on cooling of the heart. A cooling container with four inlets and four outlets was designed 
for simulations presented in this section. Each of the four side walls had one inlet at its top right corner and one outlet at its bottom left corner. Figure 5.23 shows positions of inlets and outlets. Diameters of inlets and outlets were kept the same as in the previous cooling designs.

a)

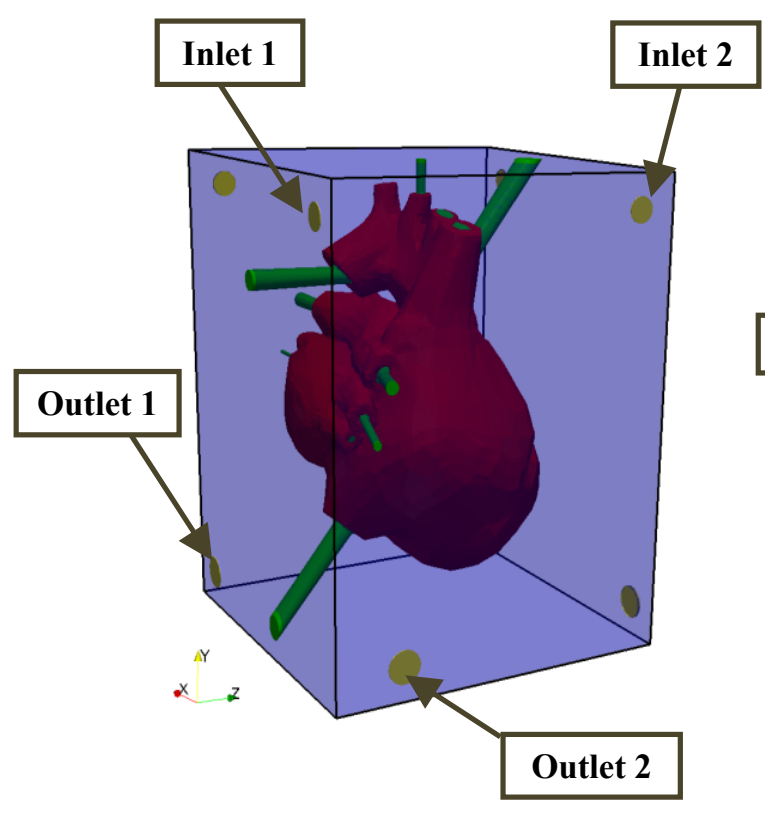

b)

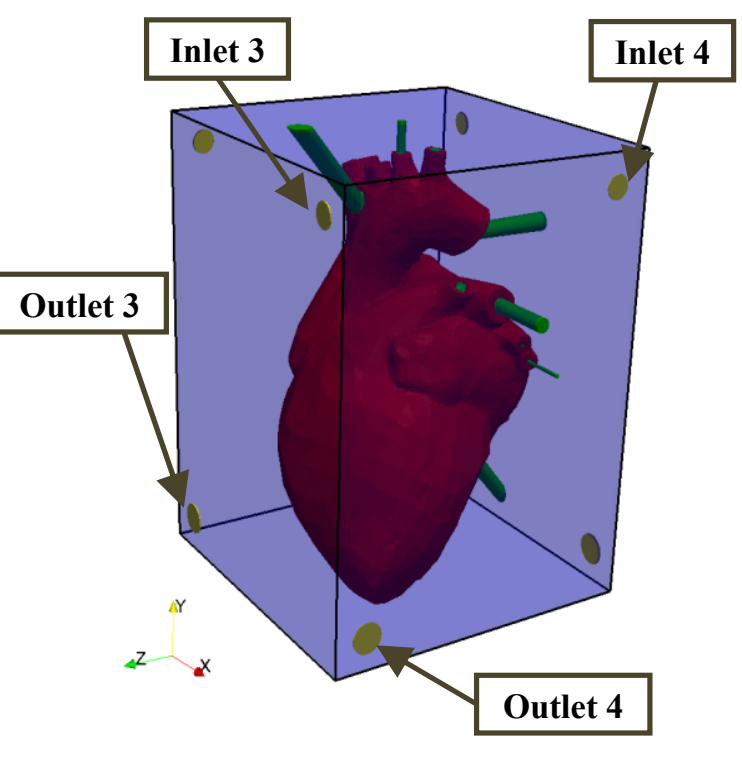

Figure 5.23. External cooling system: a) inlet $1 \& 2$ and outlet $1 \& 2$, b) inlet $3 \& 4$ and outlet $3 \& 4$ for external cooling.

For unsteady periodic inlet velocities a sine function was used as follow

$$
\mathrm{V}_{\text {in }}=\mathrm{V}_{0}+\mathrm{V}_{0} \sin (2 \pi f t)
$$

where, $f$ is the frequency and $\mathrm{V}_{0}$ is the magnitude of inlet velocity. The average magnitudes of inlet velocities for the internal and external circulations were kept the same as those in previous cases. Two relatively high frequencies $(1 \mathrm{~Hz}$ and $2 \mathrm{~Hz})$ were chosen to study the flow frequency effect on the heart cooling. Figure 5.24 shows inlet 
velocity profile for the two unsteady cooling cases, where inlet velocity magnitude was 1 $\mathrm{m} / \mathrm{s}\left(\mathrm{V}_{0}=1 \mathrm{~m} / \mathrm{s}\right)$. For such inlets, the maximum and minimum velocities were $2 \mathrm{~m} / \mathrm{s}$ and $0 \mathrm{~m} / \mathrm{s}$, respectively. As this figure illustrates, during a time period of $1 \mathrm{~s}$, the inlet velocity in Case 8 had one complete cycle. For Case 9, inlet velocity had two complete cycles per $1 \mathrm{~s}$ period.

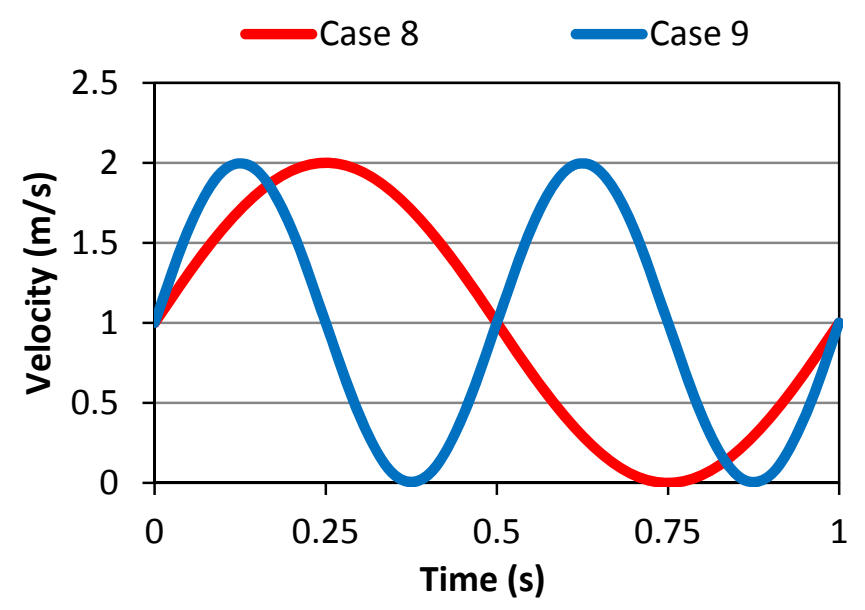

Figure 5.24. Inlet velocity profile for Case 8 and Case $9 v s$. time $\left(V_{0}=1 \mathrm{~m} / \mathrm{s}\right)$.

The maximum inlet Re numbers in Case 8 and Case 9 were double those in previous cases. Thus, the flow pattern for both internal and external circulations was assumed to be turbulent. Simulation results of unsteady Case 8 and Case 9 are presented separately in the following two sections. Based on the results of previous cases, it can be concluded that the major reduction in the average volumetric temperature of the heart occurred within $1500 \mathrm{~s}$ of cooling time. For this reason, unsteady Case 8 and Case 9 were simulated for 1500 s. Case 8 and Case 9 required smaller time steps due to their unsteady inlet velocities. Also, for these two cases more iterations were needed at each time steps. 
Total computing time for Case 8 was 346,924, and for case 9 was 411,145 for $1500 \mathrm{~s}$ of simulation.

\subsection{Case 8 - UW Cooling (Turbulent Internal and External Flows)}

Figure 5.25 shows the thermo-fluid simulation results for the unsteady external flow circulation at $300 \mathrm{~s}$. More flow vortices around the heart can be observed compared to the steady cases. Temperature variation in external flow streamlines is slightly different than in previous cases.

a)

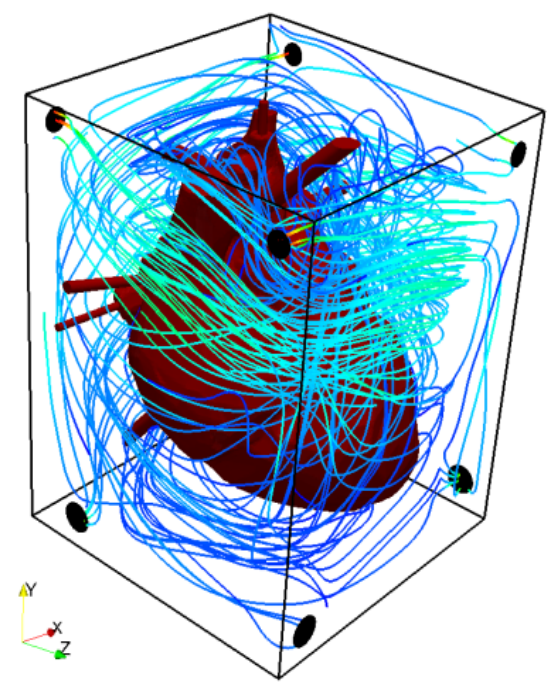

b)

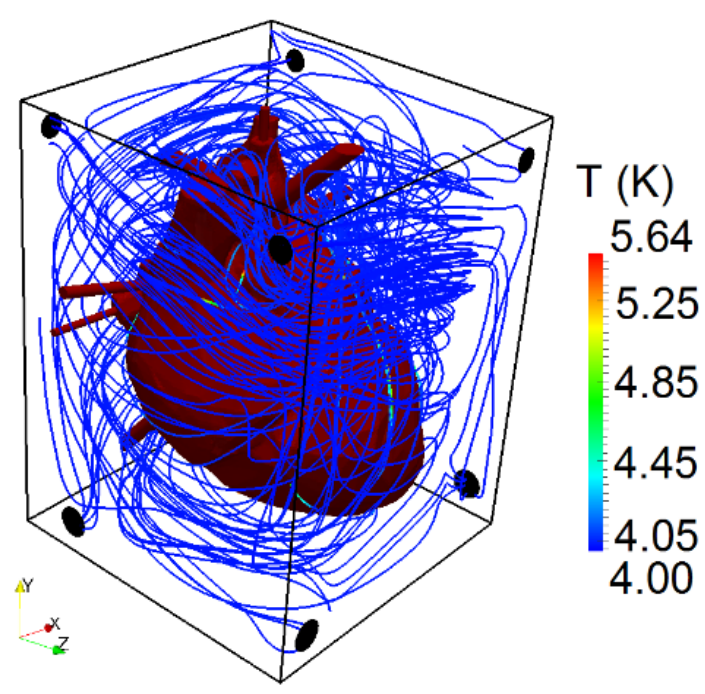

Figure 5.25. UW solution streamlines (external circulation), a) temperature distribution, and b) velocity distribution at $300 \mathrm{~s}$.

The temperature distributions of internal flow circulations are shown in figure 5.26a. The maximum temperature in this cooling design was $+0.15^{\circ} \mathrm{C}$ less than in Case 5 , 
$+1.12^{\circ} \mathrm{C}$ and $+0.77^{\circ} \mathrm{C}$ higher than in cooling Case 6 and Case 7, respectively. The maximum velocity of the internal flow was $2.3 \mathrm{~m} / \mathrm{s}$ (figure $5.26 \mathrm{~b}$ ) which was very close to the values in the previous cases.

a)

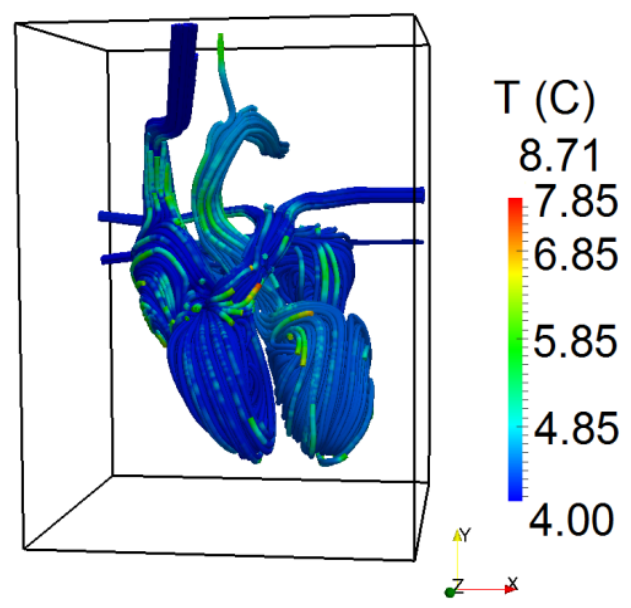

b)

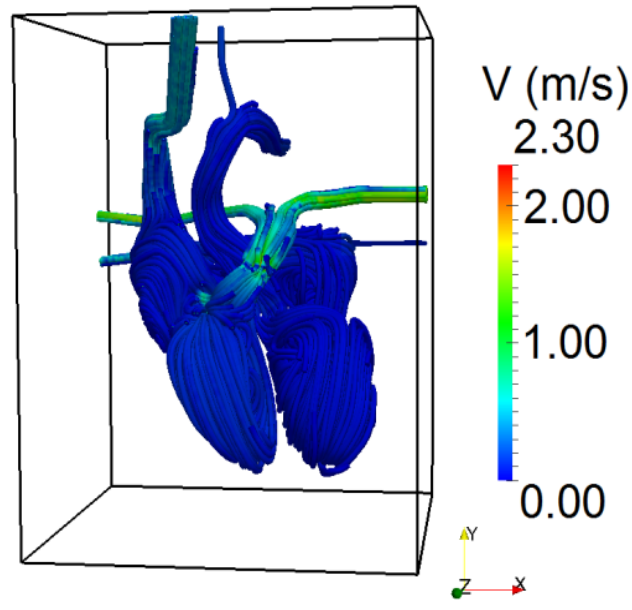

Figure 5.26. UW solution streamlines (internal circulations), a) temperature distribution, and b) velocity distribution.

Figure 5.27 shows temperature and cooling rate variations during 25 min of cooling. The average temperature at $180 \mathrm{~s}$ was around $0.8^{\circ} \mathrm{C}$ less than in Case 5, Case 6 and Case 7. After $180 \mathrm{~s}$, these values started to decrease and reached only $0.1^{\circ} \mathrm{C}$ after $1500 \mathrm{~s}$. Figure 5.28 illustrates the cooling rate for the maximum, minimum and average volume temperatures. Variations between these results and those from previous (steady) cases were negligible. The maximum value of von Mises stress was $100.49 \mathrm{kPa}$ at $80 \mathrm{~s}$ which was less than in previous cases. Then, it decreased to $100.4 \mathrm{kPa}$ at $100 \mathrm{~s}$ and remained almost constant throughout the cooling time. 


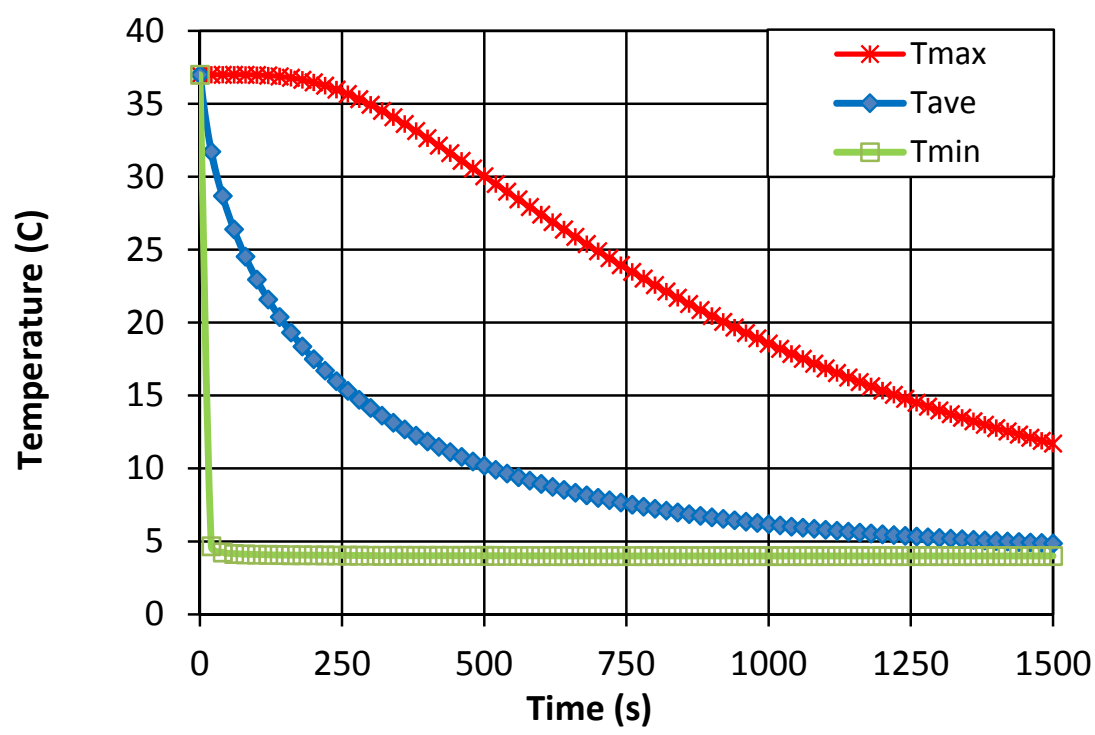

Figure 5.27. Temperature variations (maximum, minimum and average volumetric temperatures of the heart $v s$. time).

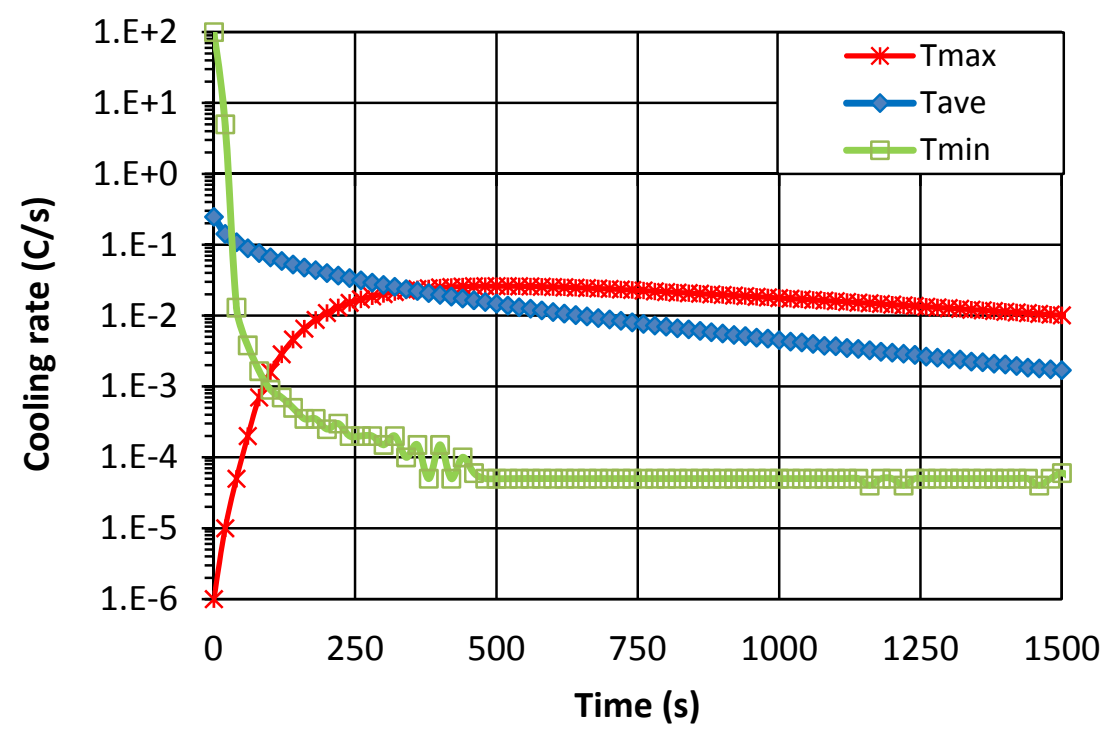

Figure 5.28. Cooling rate $v s$. time (logarithmic scale). 


\subsection{Case 9 - UW Cooling (Turbulent Internal and External Flows)}

The simulation results of the unsteady Case 9 in which the frequency of inlet velocity was $2 \mathrm{~Hz}$ are shown in this section. The velocity distribution shown in figure 5.29a reveals higher velocities near the top surface of the cooling container. Temperature variation shows almost the same values as in the previous cases.

a)

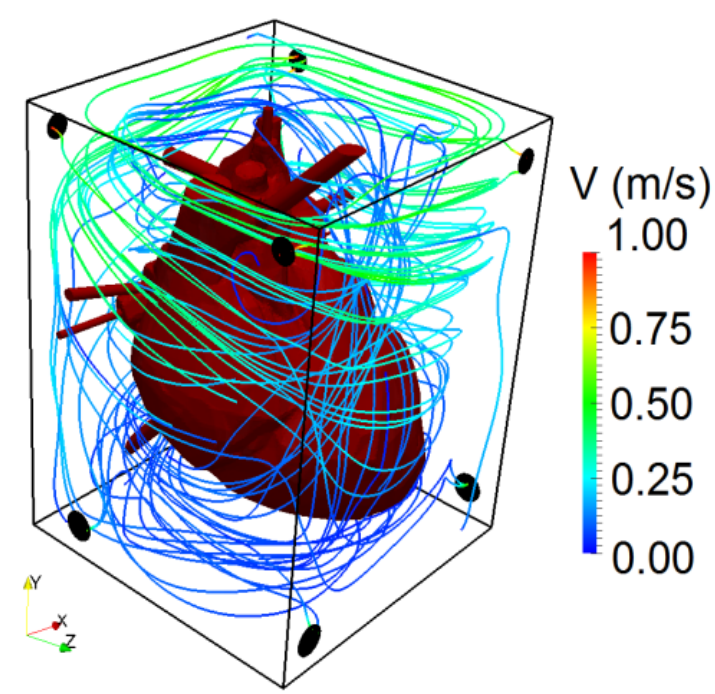

b)

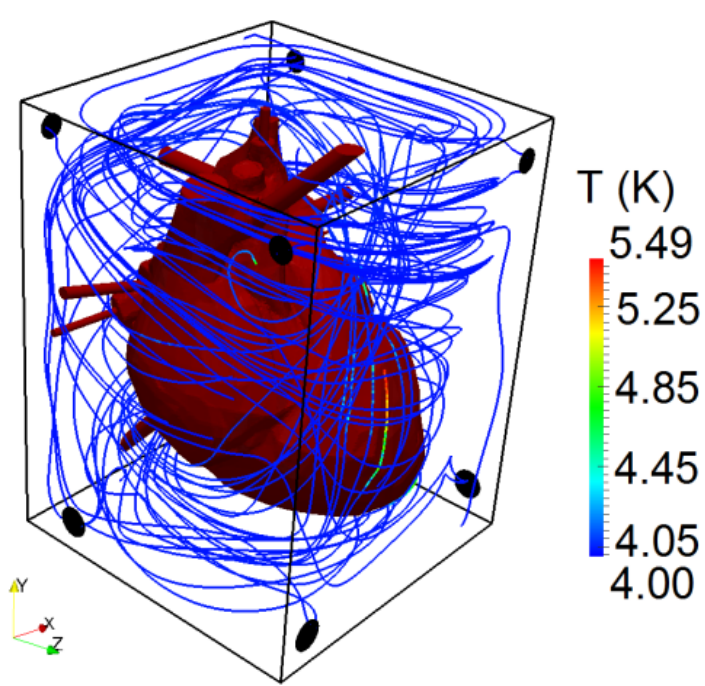

Figure 5.29. UW solution streamlines (external circulation), a) temperature distribution, and b) velocity distribution at $300 \mathrm{~s}$.

Figure 5.30 shows the temperature and velocity distributions for the internal flow circulations for Case 9. The maximum temperature was $+0.37^{\circ} \mathrm{C}$ less than in Case 8 . However, larger temperatures can be observed in most regions compared to figure 5.26a. The maximum internal flow velocity was slightly lower than in Case 8 . The velocity distribution was almost the same as in the unsteady Case 8 . 
a)

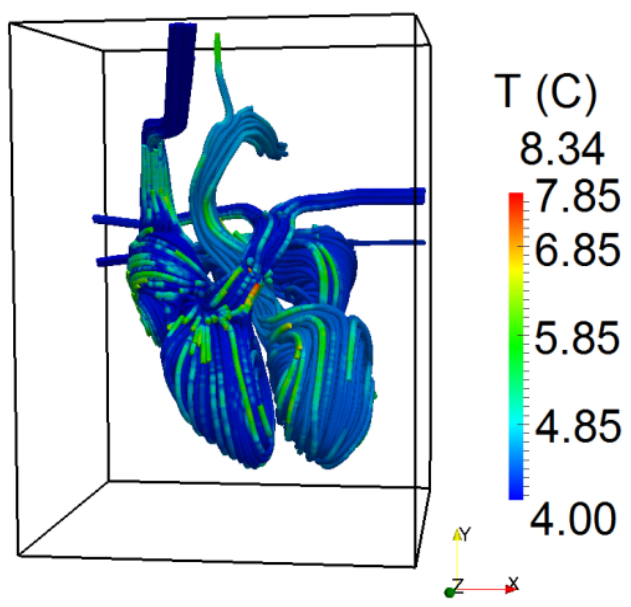

b)

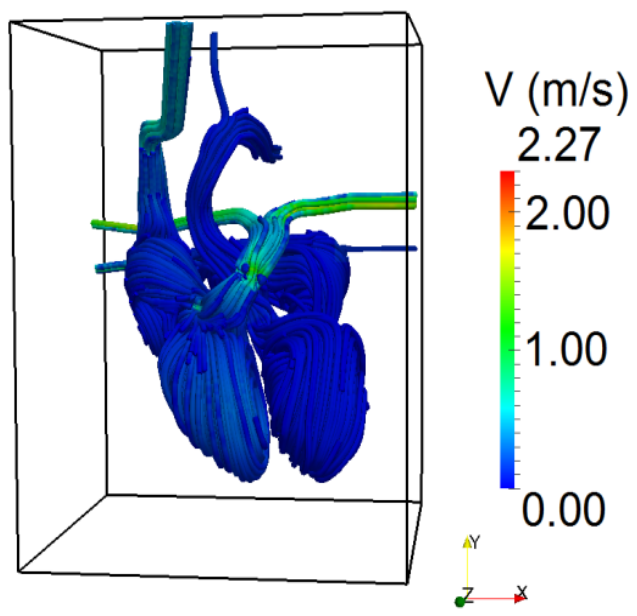

Figure 5.30. UW solution streamlines (internal circulations), a) temperature distribution, and b) velocity distribution.

Temperature and cooling rate variations versus time are shown in figure 31 . The average volumetric temperature in this case was $+0.04^{\circ} \mathrm{C}$ less than in Case 8 at $1500 \mathrm{~s}$. This difference started to decrease as cooling process proceeded. At $180 \mathrm{~s}, \mathrm{~T}_{\mathrm{ave}}$ of this case was only $0.001{ }^{\circ} \mathrm{C}$ less than in Case 5. From figure 32, very similar cooling rates can be observed compared to figure $18 \mathrm{~b}$. The maximum von Mises stress in this case was $101.45 \mathrm{kPa}$ at $20 \mathrm{~s}$. Then, it decreased to $101.3 \mathrm{kPa}$ at $320 \mathrm{~s}$ and remained almost constant for the rest of the cooling period. 


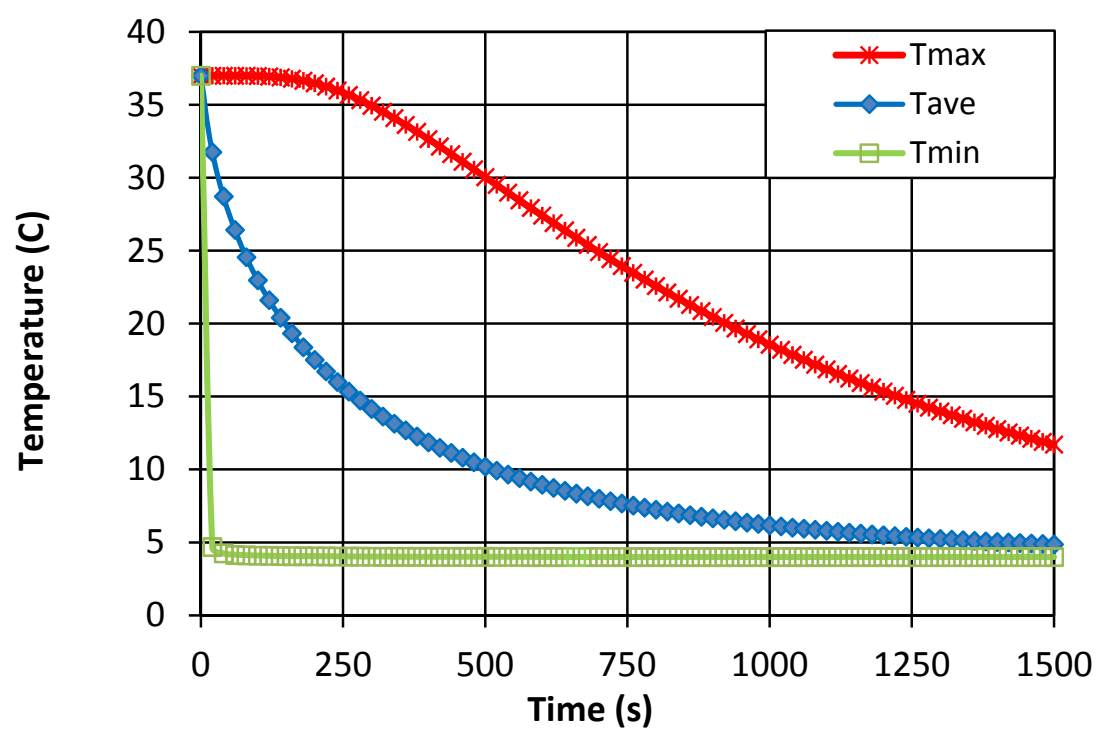

Figure 5.31. Temperature variations (maximum, minimum and average volumetric temperatures of the heart $v s$. time).

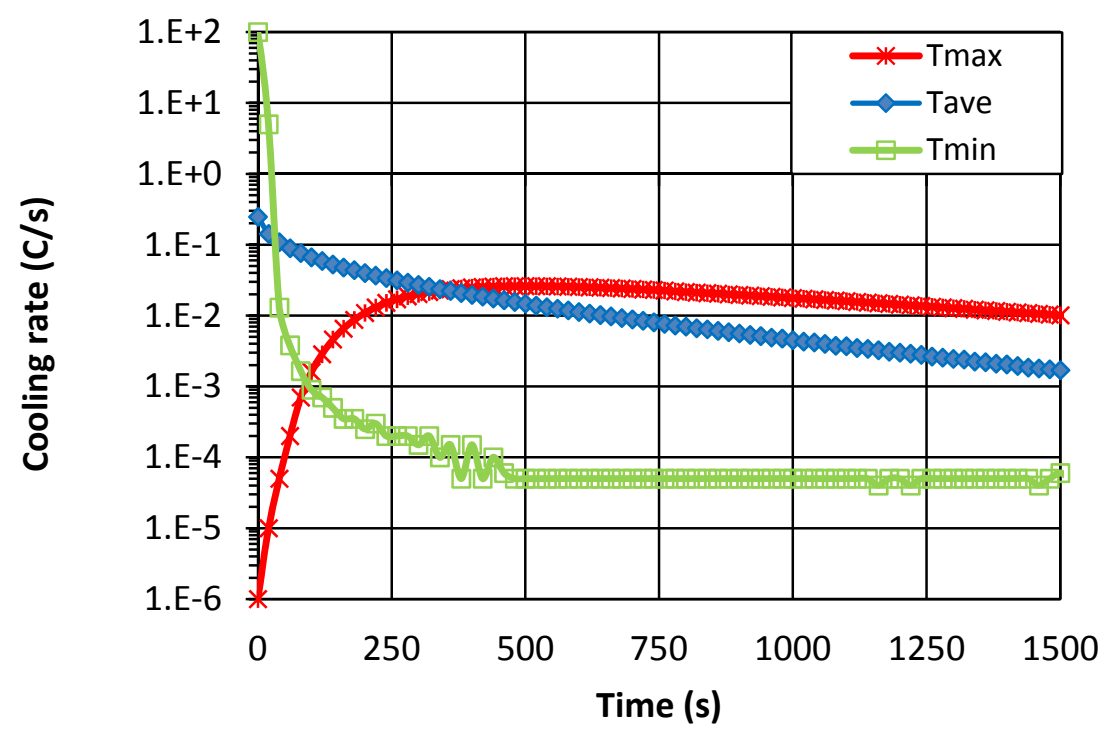

Figure 5.32. Cooling rate $v s$. time (logarithmic scale). 


\subsection{Discussions}

Table 5.2 shows results of all fully-conjugate cooling cases presented in this chapter at $1500 \mathrm{~s}$. By comparing results of fully-conjugate Case 5 (table 5.2) with results of the fully-conjugate Case 4 (table 4.1) in which gelatin was used for external cooling and UW was used for internal cooling, a significant enhancement can be observed in terms of temperature reduction of the heart.

Table 5.2. Results of all heart cooling cases at $1500 \mathrm{~s}$.

\begin{tabular}{|l|c|c|c|c|c|}
\hline Parameter & Case 5 & Case 6 & Case 7 & Case 8 & Case 9 \\
\hline Minimum temperature $\left({ }^{\circ} \mathrm{C}\right)$ & 4.0 & 4.0 & 4.0 & 4.0 & 4.0 \\
\hline Maximum temperature $\left({ }^{\circ} \mathrm{C}\right)$ & 12.1 & 12.0 & 11.9 & 11.7 & 11.7 \\
\hline $\begin{array}{l}\text { Average volumetric } \\
\text { temperature }\left({ }^{\circ} \mathrm{C}\right)\end{array}$ & 5.0 & 5.0 & 4.9 & 4.9 & 4.9 \\
\hline $\mathrm{CV}$ & $6.38 \mathrm{E}-05$ & $6.51 \mathrm{E}-05$ & $6.22 \mathrm{E}-05$ & $6.31 \mathrm{E}-05$ & $6.25 \mathrm{E}-05$ \\
\hline Metabolic rate reduction $(\%)$ & 94.67 & 94.67 & 94.72 & 94.72 & 94.72 \\
\hline $\begin{array}{l}\text { Average flow rate for } \\
\text { external circulation }(\mathrm{L} / \mathrm{min})\end{array}$ & 8.48 & 21.21 & 31.82 & 42.42 & 42.42 \\
\hline
\end{tabular}

Minimum temperatures in all five cases presented in this chapter were desirably the same as the minimum allowable temperature $\left(+4^{\circ} \mathrm{C}\right)$. In terms of temperature uniformity, all five cases had very small coefficient of variations (CV) with the same order of magnitude. Fully-conjugate Case 5 showed 1.68\% more reduction in metabolic rate compared to the conjugate Case 4 (table 4.1) at $1500 \mathrm{~s}$. By comparing results of the five cooling cases in table 5.1, it can be observed that no major enhancements were obtained by using Case 6 , Case 7, Case 8 or Case 9 instead of Case 5 . The total UW inlet 
flow rates for external flow circulation are also shown in this table. It can be seen that the required average inlet flow rate in Case 8 and 9 were 5 times more than in Case 5, 2 times more than in Case 6 and 1.3 time more than in Case 7. This will increase the required pumping power as well as the size of the entire cooling package.

Base on the convection heat transfer equation (equation 4.1), by increasing $h_{c o n v}$, convection heat transfer, $q_{\text {conv }}$, will increase in cases where $A, T_{s}$ and $T_{f}$ remain constant. By adding the third inlet in Case $6, h_{\text {conv }}$ was enhanced in the region above the hot spot. This helped removing the heat faster from the heart at the beginning of the cooling when $T_{s}-T_{f}$ was larger. As cooling proceeded, the value of $T_{s}-T_{f}$ decreased rapidly. Thus, effect of $h_{\text {conv }}$ was decreased drastically, and conduction heat transfer within the heart tissue became the major limiting factor in the cooling process. In such cases, the cooling systems are able to keep the entire boundary surfaces of the heart in the desired minimum temperature. This will be the optimal cooling design with the objective of cooling the heart as fast as possible. The cooling time in such cases will only depend on the thermal diffusivity of the heart tissue. In the next chapter, multi-objective optimizations are performed in order to find the optimal cooling system with the minimum coolant flow rate, maximum cooling capacity and minimum stresses. 


\section{CHAPTER VI \\ OPTIMIZATION}

In this chapter a multi-objective optimization will be performed for the fullyconjugate cooling Case 5. Optimization methodology, design variables and objectives are presented in section 6.1. Results and discussion are presented in section 6.2.

\subsection{Optimization Methodology}

Optimization of heart cooling design was carried out using modeFRONTIER optimization software [103]. Cooling Case 5 was used as the basic design for the optimization study. Therefore, each circulation domain (pulmonary circulation, systemic circulation and external circulation) had two inlets and two outlets. From the results presented in chapter 3,4 and 5 it can be concluded that the major reduction in heart's temperature and metabolic rate occurred within $1040 \mathrm{~s}$ of cooling. Therefore, $1040 \mathrm{~s}$ was chosen as the time interval for optimization. In other words, the goal is to find the optimal cooling design within 1040 s. Since results of Case 8 and Case 9 showed negligible enhancements, thus, all inlet velocities were assumed to be constant. Inlet velocities were chosen as design variables for optimization. The following are the three design variables

1) Inlet velocity of UW for pulmonary circulation system

2) Inlet velocity of UW for systemic circulation system

3) Inlet velocity of UW for external circulation system 
These design variables are randomly varied to generate unique cooling cases. Based on inlet Reynolds numbers, the flow pattern could be laminar or turbulent. Then, these unique random cases were imported to modeFRONTIER to generate multidimensional response surfaces to interpolate multivariate scattered data and decrease the computing time significantly. Response Surface Methodology (RSM) was implemented using Gaussian Radial Basis Function (GRBF) [103] (see Appendix 1 for more information about GRBF's parameters in modeFRONTIER).

Multi-objective Genetic Algorithm II (NSGA-II) developed by Deb et al. [104, 105], was chosen to perform optimization. The three simultaneous objectives of the optimization study were

1) Minimize the average volumetric temperature of the heart

2) Minimize WSS

2) Minimize total amount of the required volumetric flow rate of UW

By minimizing the required volumetric flow rate of $\mathrm{UW}$, the required pumping power as well as the size of the entire cooling package will be minimized. The only constraint in this study was to keep all stresses, including von Mises stresses, below the ultimate tensile stress of the heart tissue.

Abdoli and Dulikravich [106, 107] demonstrated that Gaussian Radial Basis Function (GRBF) method gives more accurate results in comparison to other response surface methods. Then, this GRBF was coupled to NSGA-II multi-objective optimization algorithm in modeFRONTIER software in order to perform the optimization. 


\subsection{Results and Discussion}

Table 6.1 shows the range of design variables. Based on the results shown in Chapter V, additional inlets for external flow circulation did not enhance the cooling process. Thus, the maximum velocity for inlet external circulation was set $1 \mathrm{~m} / \mathrm{s}$. In previous cases, the inlet velocities magnitudes for internal circulations were constant. Therefore, for optimization study the maximum values for the heart pulmonary and systemic circulations were set to $1.2 \mathrm{~m} / \mathrm{s}$ and $2 \mathrm{~m} / \mathrm{s}$, respectively. This way, effects of larger velocities in internal cooling will be examined. It should be mentioned that inlet velocities higher than those shown in table 6.1 resulted in very large velocities, especially near the heart's valves.

Table 6.1 Design variable ranges.

\begin{tabular}{|l|c|c|c|}
\hline Design Variables & $\begin{array}{c}\text { Heart Pulmonary } \\
\text { Circulation }\end{array}$ & $\begin{array}{c}\text { Heart Systemic } \\
\text { Circulation }\end{array}$ & $\begin{array}{c}\text { External } \\
\text { Circulation }\end{array}$ \\
\hline $\begin{array}{l}\text { Inlet velocity } \\
\text { magnitude }(\mathrm{m} / \mathrm{s})\end{array}$ & $0.1-1.2$ & $0.1-2$ & $0.1-1$ \\
\hline
\end{tabular}

Thirty random unique cases were generated and simulated using the same numerical package as the one in previous cases. Then, these thirty cases were imported to modeFRONTIER software to construct a 7-dimentional response surface. This multidimensional response surface will be used by the optimizer algorithm to evaluate new virtual design candidates. Response surfaces are mainly used in studies where evaluations of new designs are expensive. This applies for both computational and experimental studies. Since simulations in this research are costly, response surfaces was adopted for 
evaluating new cooling cases. Therefore, these new cases are called "virtual". In the next step, optimizer will search for the best virtual designs so called virtual "Pareto" optimal designs. For better understanding of the overall logic of the software system created, figure 6.1 depicts connections and information flow in the design system used in this research. As this figure shows, virtual Pareto designs will be validated by using the analysis package. The validated virtual Pareto designs then called "real" Pareto designs.

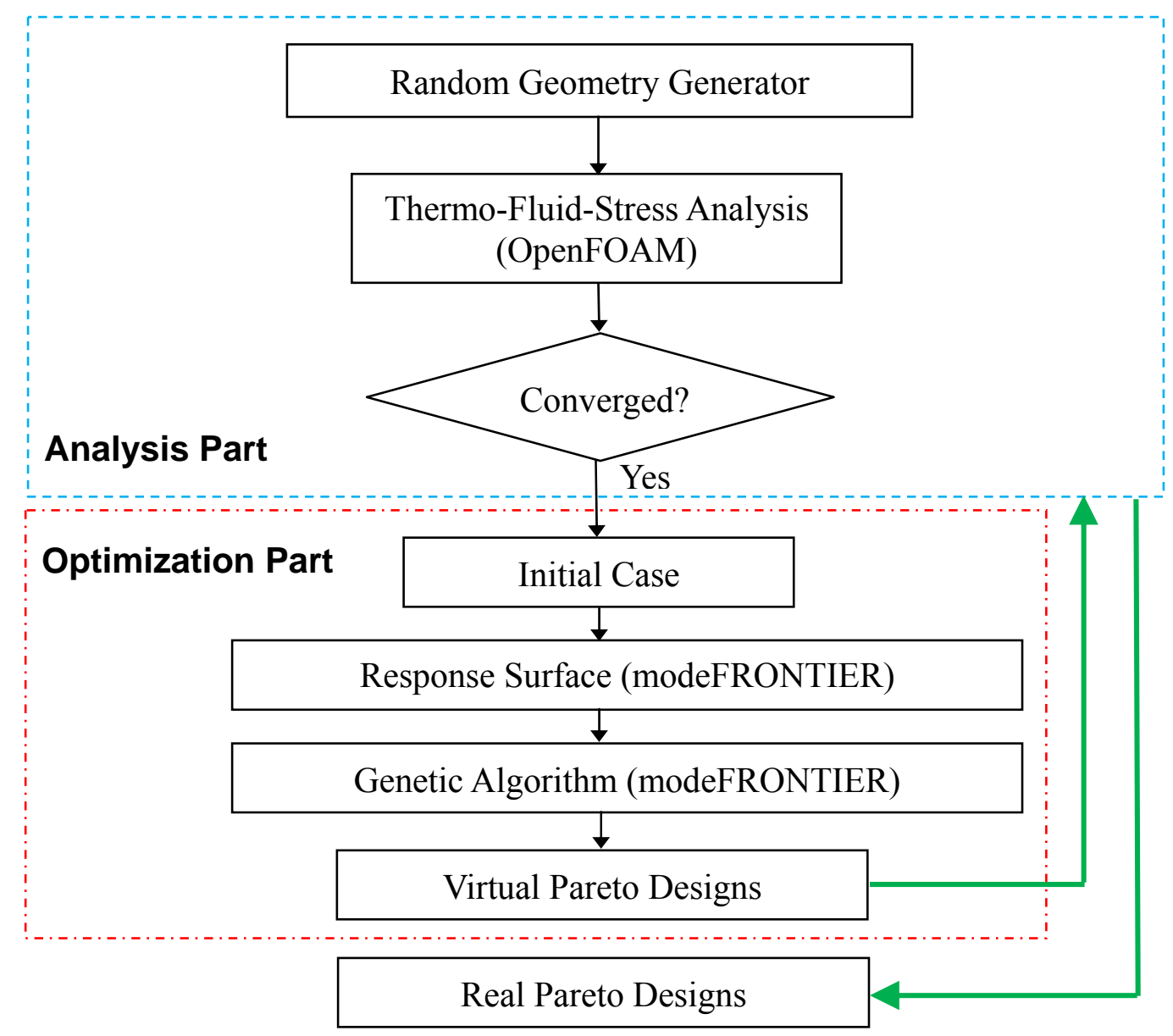

Figure 6.1. Flow chart showing how different software modules were linked together to generate virtual and real Pareto frontiers. 
Figure 6.2 shows the optimization work flow designed in modeFROTIER. As it can be seen, three inlet velocities; "V_External", "V_Pulmonary" and "V_Systemic" are the three input design variables in this work flow. Outputs are; total volumetric flow rate (Q), Stress, $\mathrm{T}_{\mathrm{ave}}$ and WSS. It can be observed that total volumetric flow rate, $\mathrm{T}_{\mathrm{ave}}$ and WSS were set to be minimized by the optimizer. A constraint was applied on stress output. As it was mentioned in the previous section, NSGA-II was used as the optimization method. Design of experiment (DOE) will enable the user to add virtual initial designs in cases where the number of initial designs are not enough or not uniformly distributed.

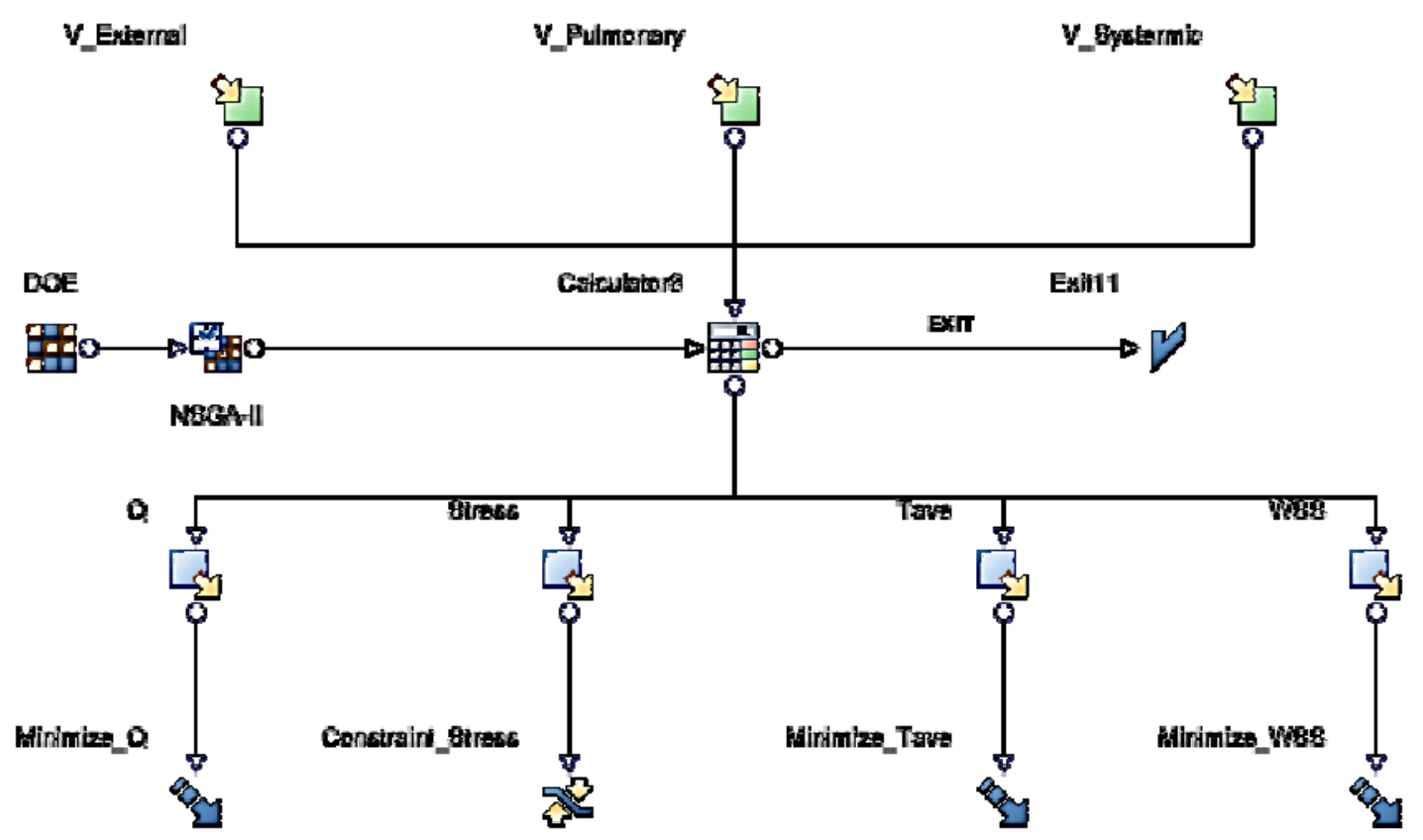

Figure 6.2. Optimization work flow in modeFRONTIER. 
Figure 6.3 illustrates the variations of two objectives; $\mathrm{T}_{\text {ave }}$ versus WSS. Initial cooling cases (initial population), virtual Pareto and real Pareto design are shown in this figure. Initial cases are shown in blue diamonds. It can be seen that by cooling cases with $\mathrm{T}_{\text {ave }}$ less than close to $+6^{\circ} \mathrm{C}$ had larger WSS. This was because of higher UW flow rates in these cases. The virtual Pareto designs obtained from optimization are illustrated by green circles. Six of these virtual Pareto were chosen (shown in red deltas) to be validated by analysis package and named "Real Pareto". As this figure shows these real Pareto designs are in good agreement with the selected virtual Pareto designs. One can choose one of these real Pareto optimal cooling designs based on their interest and design limitations. In this research, Pareto \#4 was chosen as the best optimal cooling design. One can chose any of these Pareto designs based on their interest.

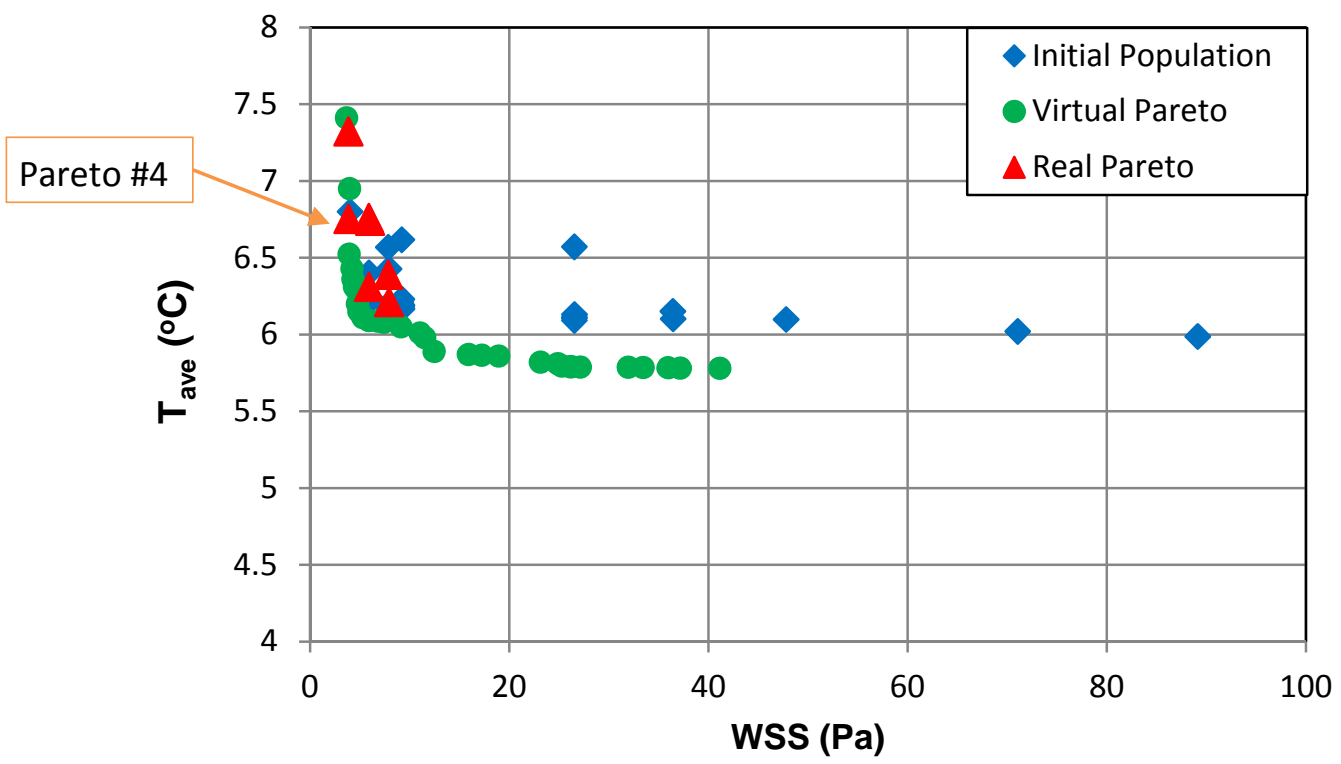

Figure 6.3. Average temperature $v s$. WSS for initial population, virtual Pareto, and real Pareto optimal designs. 
Pareto \#4 was selected in this research, mainly due to its lower requirement for the total volumetric flow rate. This would also reduce the required pumping power and the size of cooling package as well. Figure 6.4 shows $\mathrm{T}_{\text {ave }}$ versus total volumetric flow rate. Again, real Pareto designs were in good agreement with virtual Pareto designs.

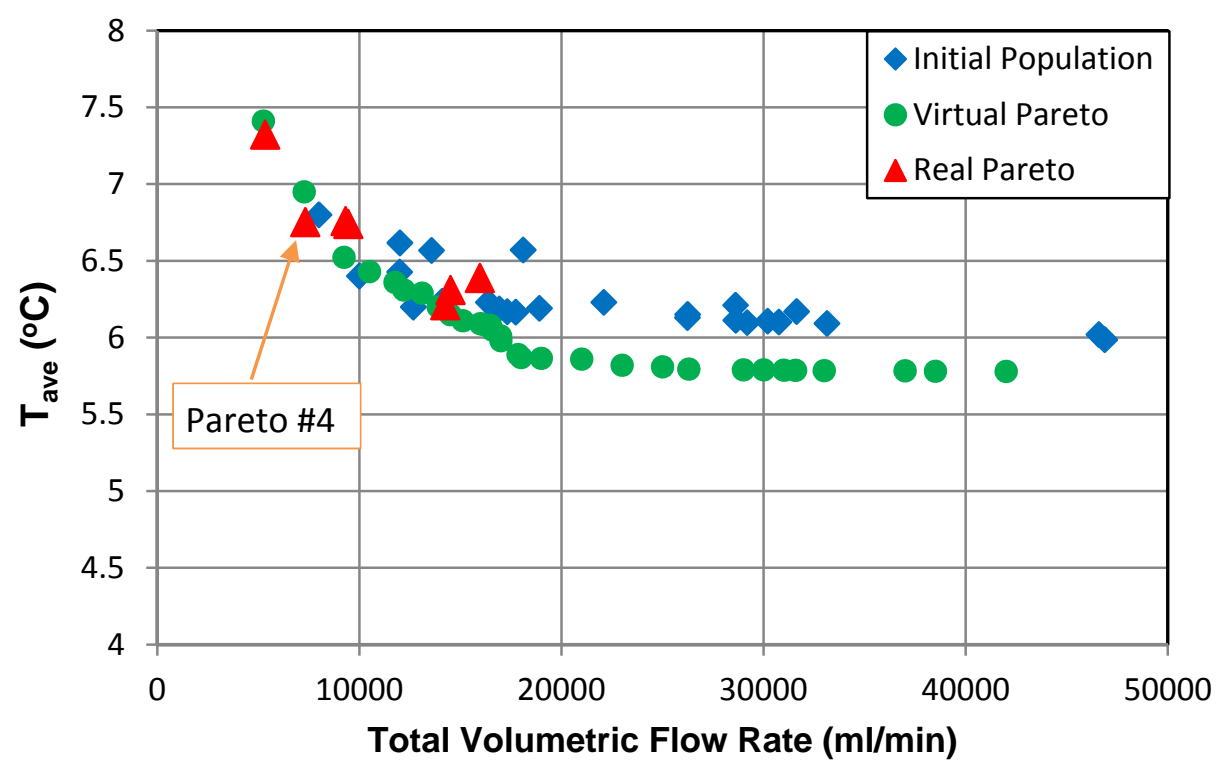

Figure 6.4. Average temperature vs. total volumetric flow rate for initial population, virtual Pareto, and real Pareto optimal designs.

Variations of WSS versus total volumetric flow rate are shown in figure 6.5. It can be observed that by increasing the total volumetric flow rate WSS increases. However, there are cases that have higher total flow rates and lower WSS. This was because in these cases external circulation had higher flow rate than internal circulations. For better illustration, $\mathrm{T}_{\text {ave }}$ versus WSS versus total volumetric flow rate is shown in figure 6.6. 


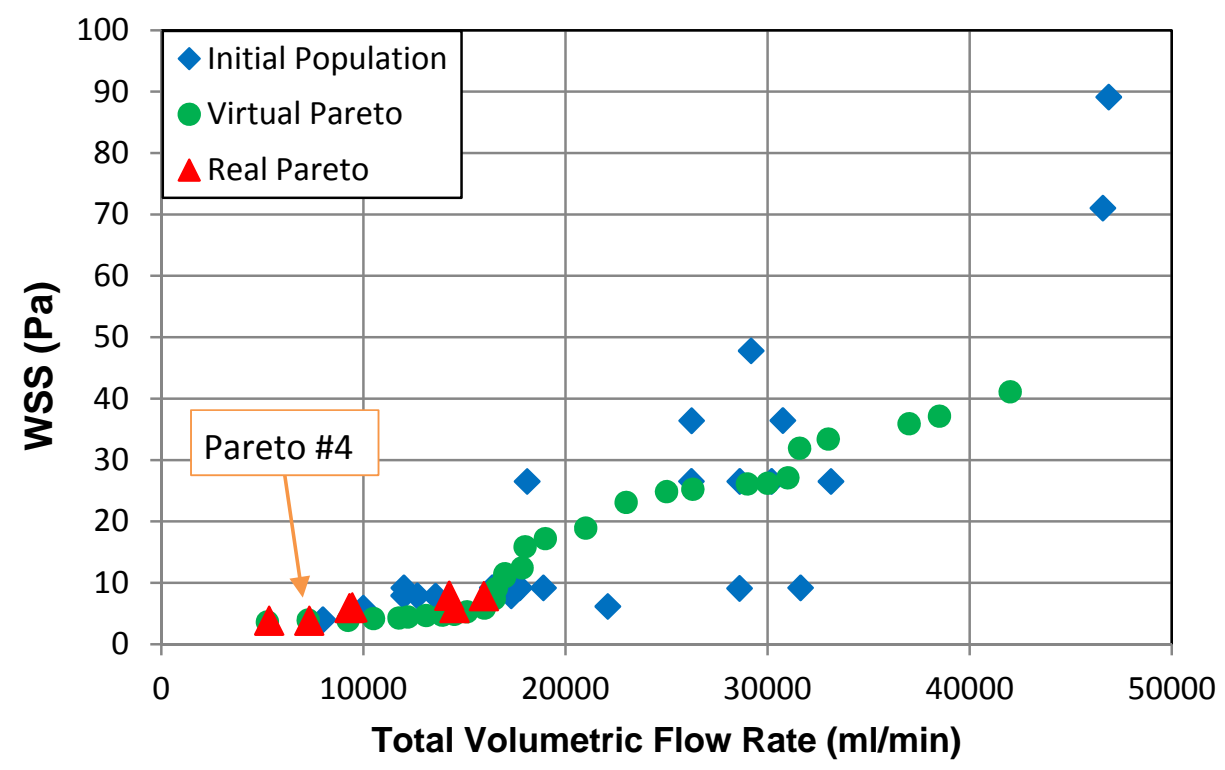

Figure 6.5. WSS vs. volumetric flow rate for initial population, virtual Pareto, and real Pareto optimal designs.

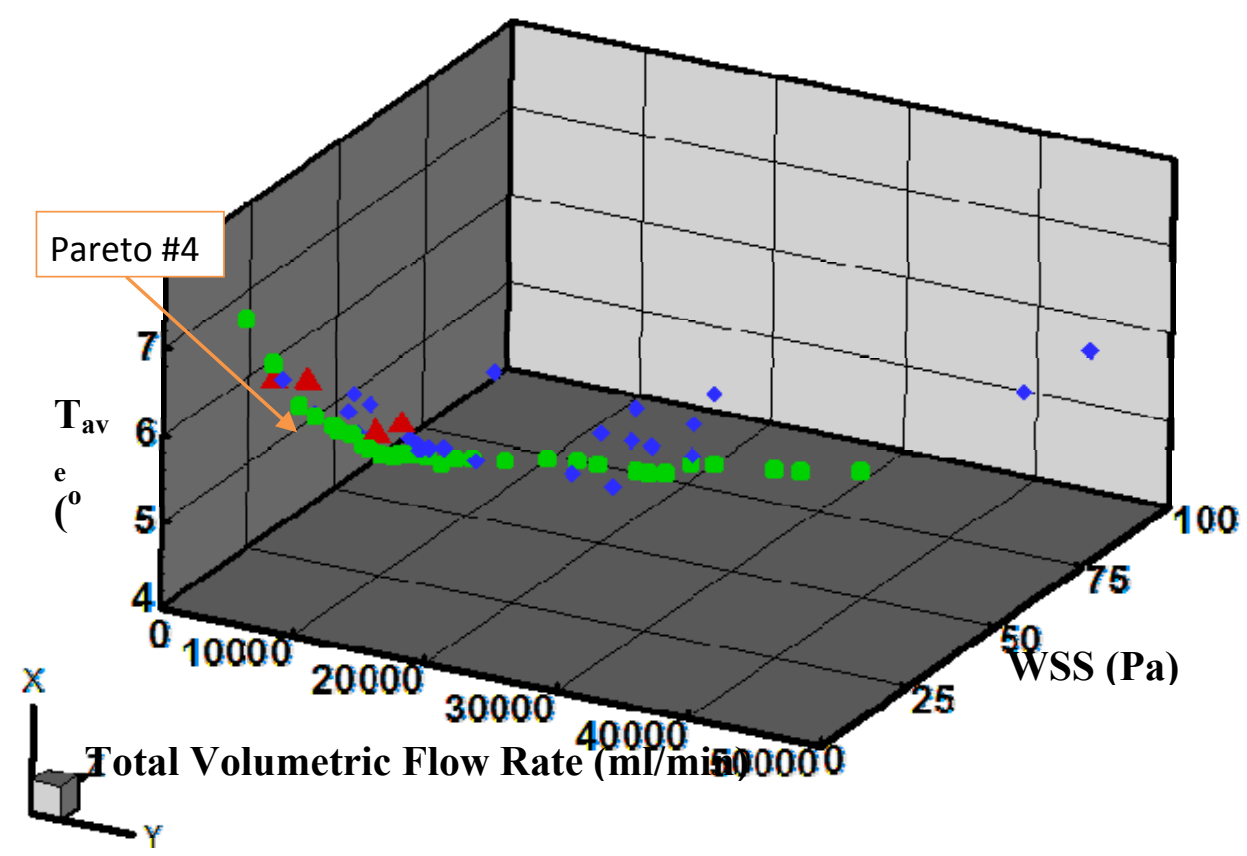

Figure 6.6. Average temperature vs.WSS vs. volumetric flow rate for initial population, virtual Pareto, and real Pareto optimal designs. 
Specifications of Pareto design \#4 is demonstrated in table 3. It can be seen that inlet velocity magnitude in heart systemic circulation was 6 times more than pulmonary circulation and 3 times more than the external circulation. Table 6.3 demonstrates the output parameters for Pareto \#4. The average temperature of the heart in this case was $+6.8^{\circ} \mathrm{C}$ at $1040 \mathrm{~s}$. WSS has a very desirable value of $3.85 \mathrm{~Pa}$. Table 6.4 shows the average error between selected virtual Pareto and real Pareto designs. The average error for $\mathrm{T}_{\text {ave }}$ was $4.5 \%$, for WSS was $6.2 \%$ and for the total volumetric flow rate was $3.9 \%$.

Table 6.2. Specifications of Pareto \#4.

\begin{tabular}{|l|c|c|c|}
\hline Design Variables & $\begin{array}{c}\text { Heart Pulmonary } \\
\text { Circulation }\end{array}$ & $\begin{array}{c}\text { Heart Systemic } \\
\text { Circulation }\end{array}$ & $\begin{array}{c}\text { External } \\
\text { Circulation }\end{array}$ \\
\hline $\begin{array}{l}\text { Inlet velocity } \\
\text { magnitude }(\mathrm{m} / \mathrm{s})\end{array}$ & 0.1 & 0.6 & 0.2 \\
\hline
\end{tabular}

Table 6.3. Output parameters for Pareto \#4.

\begin{tabular}{|l|c|c|c|}
\hline Objectives & $\mathbf{T}_{\text {ave }}\left({ }^{\mathbf{0}} \mathbf{C}\right)$ & WSS (Pa) & $\begin{array}{c}\text { Total Volumetric Flow Rate } \\
(\mathbf{m l} / \mathbf{m i n})\end{array}$ \\
\hline Values & 6.8 & 3.85 & $7,322.1$ \\
\hline
\end{tabular}

Table 6.4. Average error.

\begin{tabular}{|l|c|c|c|}
\hline Objectives & $\mathbf{T}_{\text {ave }}$ & WSS & Total Volumetric Flow Rate \\
\hline Error (\%) & 4.5 & 6.2 & 3.9 \\
\hline
\end{tabular}




\section{CHAPTER VII}

\section{CONCLUSION}

In section 7.1 , a summary of dissertation is presented. In the last section, suggestions for future studies are presented.

\subsection{Summary of Dissertation}

In this dissertation a cooling container was numerically designed for human heart preservation destined for transplantation. The objectives of this research were to cool the heart as fast and uniformly as possible, while keeping all thermal and shear stresses below their maximum allowable values. Thus, several conceptually different cooling methods were implemented to compare their capacity in achieving the objectives of this study. This research was a computational study in which a high resolution 3-D heart geometry obtained from CT-angio data was used for all simulations. Multi-domain unsteady conjugate heat transfer analysis was performed to simulate the variation of the temperature field within the heart's tissue during different cooling processes. Also, a linear stress analysis was performed simultaneously to calculate the stresses applied on the heart via different cooling systems. All simulations were carried out using OpenFOAM software platform. Four computational domains in this study were: the heart domain, the right pulmonary circulation domain, the left systemic circulation and the external domain for the region between the heart and the cooling container. 
Nine different cooling cases were proposed for cooling of the heart. The UW solution and gelatin gel were used as the two cooling medium in this research. In the first cooling design (Case 1), the heart was submerged in the cold gelatin. Thus, only external surfaces of the heart were in touch with the cold medium. In this case, the average temperature of the heart was $+21.0^{\circ} \mathrm{C}$ after $1500 \mathrm{~s}$ of cooling time. This design was named "semi-conjugate" case, since the heart was cooled via one computational domain (the external domain). Cooling Case 2 uses the UW solution for internal cooling. The UW solution was pumped inside the heart through its major veins. Two inlets and two outlets were designed for each of the right pulmonary and the left systemic circulations. Flow pattern was laminar in this case. The average temperature of the heart in this cooling design was $+12.5^{\circ} \mathrm{C}$ at $1500 \mathrm{~s}$. This showed that internal liquid cooling was $40.5 \%$ better than external gelatin cooling. This design was named "conjugate" case, since it used two internal domains for the heart cooling. The next cooling design (Case 3) applied cold gelatin for both internal and external cooling. The average temperature of the heart in Case 3 was $+16.8^{\circ} \mathrm{C} 1500 \mathrm{~s}$. Cooling Case 4 was a combination of Case 1 and Case 2. In this case the heart was cooled via gelatin from the outside and the UW solution from the inside. This cooling case decreased the average temperature of the heart from $+37^{\circ} \mathrm{C}$ to $+8.0^{\circ} \mathrm{C}$ after $1500 \mathrm{~s}$. This design was named "fully-conjugate" case, since it used all three internal and external domains for cooling of the heart.

Based on the previous cases results, cold gelatin was not as effective as the UW solution in removing the heat. In other words, conduction heat transfer was not as effective as convection heat transfer. This was mainly due to the very low thermal diffusivity of the gelatin. In the next cooling design (Case 5), the UW solution was used 
for both internal and external cooling. This cooling case was able to reduce the average temperature of the heart from $+37^{\circ} \mathrm{C}$ to $+5.0^{\circ} \mathrm{C}$ after $1500 \mathrm{~s}$. In the next cooling design (Case 6), effects of external turbulent flow on cooling process were simulated. An additional inlet was designed in Case 7. The objective was to examine the effect of the UW jet impinging the heart's hot spot to enhance heat transfer. The last two cases (Case 8 and Case 9), were applied unsteady periodic inlet velocities for internal and external cooling. The frequencies for the sinusoidal inlet velocities in Case 8 and Case 9 were 1 $\mathrm{Hz}$ and $2 \mathrm{~Hz}$, respectively. Results of the last four cases showed that the effects of turbulence flow, the UW jet flow and periodic inlet velocities were insignificant in enhancing the heat transfer from the heart.

In the last part of this research, a multi-objective constrained optimization was performed for cooling Case 5. The inlet velocities of three domains were the three design variables. The flow pattern could be laminar or turbulent based on the inlet Reynolds numbers. Minimizing the average temperature of the heart within $1500 \mathrm{~s}$, minimizing the total volumetric flow rate of the UW solution and minimizing the wall shear stresses were the three objectives of optimization. The only constraint was to keep all other stresses including von Mises stress below the ultimate tensile stress of the heart's tissue. One of the optimal designs, Pareto \#4, was able to reduce the average temperature of the heart from $+37^{\circ} \mathrm{C}$ to $+6.8^{\circ} \mathrm{C}$ within $1040 \mathrm{~s}$, while creating the WSS of $3.85 \mathrm{~Pa}$. Total flow rate of the UW solution in this design was 7,322.1 $\mathrm{ml} / \mathrm{min}$. 


\subsection{Future Work}

The following items are the suggestions for the future work in this field:

1) Researchers should use a more detailed human heart geometry which includes coronary arteries and cardiac veins. This way the coolant can be perfused within these veins and help to cool the heat walls faster. Also, the use of a model which differentiates between heart tissues such as: vascular muscle and fat tissues.

2) For the cooling container, the number of inlets and outlets can be increased from two to three or four to enhance the heat transfer. The optimal number of inlets and outlets can be determined by an optimization study.

3) Non-linear stress analysis can be performed to get a better understanding of stress distribution within the anisotropic heart's tissue. Buoyancy force can also be included into the conjugate heat transfer governing equations.

4) Electrophysiology system of the heart can also be studied during the cooling process. It would be interesting to investigate the effect of temperature variation on the heart's electrophysiology system.

5) As the heart rate decreases the diastolic $\mathrm{Ca}^{2}+$ continues to rise so relaxation is markedly reduced. Moreover, emission of ROS/RNS increases as a function of cooling. The high $\mathrm{Ca}^{2}+$ and the ROS/RNS have negative effect on the heart, even though protection against IR injury is improved by hypothermia [22]. One can incorporate the $\mathrm{Ca}^{2}+$ and ROS/RNS temperature 
based equations into the thermo-fluid equation to monitor their variation based on temperature.

6) Rewarming process of the cooled heart can also be simulated to find the best method to increase the average temperature of the heart safely.

7) This numerical package can simply be applied for normothermic preservation of the heart and for the re-warming of the heart. It can also be applied for simulating the cooling process of different organs.

8) Pareto \#4 design parameters can be used to perform an experimental study for the human heart cooling. 


\section{LIST OF REFERENCES}

[1] Silbergleit, A., "Norman E. Shumway and the Early Heart Transplants," Tex Heart Inst J, p. 33(2): 274-275, 2006.

[2] Borel, J. F., Kis, L. Z., and Beveridge, T., "The History of the Discovery and Development of Cyclosporine (Sandimmune ${ }^{\circledR}$ )," The Search for Anti-Inflammatory Drugs, pp 27-63,1995.

[3] The U.S. Organ Procurement and Transplantation Network, "Annual Report of the U.S. Organ Procurement and Transplantation Network and the Scientific Registry of Transplant Recipients," Transplant Data, 2010-2011.

[4] Organ Procurement and Transplantation Network (OPTN), "Organ Procurement and Transplantation Network POLICIES," http://optn.transplant.hrsa.gov/policiesAndBylaws/policies.asp, Feb. 2014.

[5] Colvin-Adams, M., Valapour, M., Hertz, M., Heubner, B., Paulson, K., Dhungel, V., Skeans, M. A., Edwards, L., Ghimire, V., Waller, C., Cherikh, W. S., Kasiske, B. L., Snyder, J. J., Israni, A. K. , "Lung and Heart Allocation in the United States," American Journal of Transplantation , 12: 3213-3234, 2012.

[6] Collins M. J., Moainie S. L., Griffith B. P., and Poston R. S., "Preserving and Evaluating Hearts with ex vivo Machine Perfusion: an Avenue to Improve Early Graft Performance and Expand the Donor," European Journal of Cardio-thoracic Surgery, 34 318-325, 2008.

[7] Fuller, B. J., and Lee, C. Y., "Hypothermic Perfusion Preservation: The Future of Organ Preservation Revisited?," Cryobiology, 54 129-145, 2007.

[8] Vogel, T., Brockmann, J. G., Coussios, C., and Friend, P. J., "The Role of Normothermic Extracorporeal Perfusion in Minimizing Ischemia Reperfusion Injury," Transplantation Reviews, 26 156-162, 2012.

[9] Cobert, M. L., West. L. M., and Jessen, M. E., "Machine Perfusion for Cardiac Allograft Preservation," Curr Opin Organ Transplant, 13:526-530, 2008.

[10] Yang, Y., Lin, H., Wen, Z., Huang, A., Huang, G., Hu, Y., Zhong, Y., and Li, B., "Keeping Donor Hearts in Completely Beating Status with Normothermic Blood Perfusion for Transplants," Ann Thorac Surg, 95(6):2028-34, 2013.

[11] Moore, E. M., Nichol, A. D., Bernard, S. A., and Bellomo, R., "Therapeutic Hypothermia: Benefits, Mechanisms and Potential Clinical Applications in Neurological, Cardiac and Kidney Injury," Injury Int J Care Injured, 42(9):843-54, 2011.

[12] Polderman, K. H., and Herold, I., "Mechanisms of Action, Physiological Effects, and Complications of Hypothermia," Crit Care Med, 37:S186-202, $2009 .$. 
[13] Reyes, A. B., Pendergast, J. S., and Yamazaki, S., "Mammalian Peripheral Circadian Oscillators Are Temperature Compensated," J Biol Rhythms, 23: 95-98, 2008.

[14] Suszynski, T. M., Rizzari, M. D., Scott, W. E., Tempelman, L. A., Taylor, M. J., and Papas, K. K., "Persufflation (or gaseous oxygen perfusion) as a method of organ preservation," Cryobiology, Volume 64, Issue 3, Pages 125-143, 2012.

[15] Taylor, M. J., and Baicu S. C., "Current State of Hypothermic Machine Perfusion Preservation of Organs: The Clinical Perspective," Cryobiology, 60(3S): S20-S35, 2010.

[16] Suszynski, T. M., Rizzari, M. D., Scott III, W. E., Eckman, P. M., Fonge, J. D., John, R., Chronos, N., Tempelman, L. A., Sutherland, D. ER., and Papas, K. K., "Persufflation (Gaseous Oxygen Perfusion) as a Method of Heart Preservation," Journal of Cardiothoracic Surgery, 8:105, 2013.

[17] Wagner, F. M. , "Donor Heart Preservation and Perfusion," Applied Cardiopulmonary Pathophysiology, 15: 198-206, 2011.

[18] Guibert, E. E., Petrenko, A. Y., Balaban, C. L., Somov, A. Y., Rodriguez, J. V., and Fuller, B. J., "Organ Preservation: Current Concepts and New Strategies for the Next Decade," Transfus Med Hemother, 38:125-142, 2011.

[19] Jahania, M. S., Sanchez, J. A., Narayan, P., Lasley, R. D., and Mentzer, R. M., "Heart Preservation for Transplantation: Principles and Strategies," Ann Thorac Surg, 68:1983-1987, 1999.

[20] Collins, M. J., Ozeki, T., Gu, J., Gullapalli, R., Pierson, R. N., Griffith, B. P., and Poston, R. S., "Resuscitating and Evaluating non Beating Donor Hearts Using Continuous ex vivo Perfusion: Animal Studies with Clinical Validation," Presented at the American Association of Transplant Surgeons Winter Symposium, Marco Beach, FL, 2007.

[21] Stowe, D. F., Heisner, J. S., An, J. Z., Camara, A. K. S., Varadarajan, S. G., Novalija, E., Chen, Q., and Schelling, P., "Inhibition of $\mathrm{Na}+\mathrm{H}+$ Exchange-1 Isoform Protects Hearts Reperfused After Six Hour Cardioplegic Cold Storage," $J$. Heart Lung Transpl, 21:374-382, 2002.

[22] Stowe, D. F., and Camara, A. K., "Review Mitochondrial Reactive Oxygen Species Production in Excitable Cells: Modulators of Mitochondrial and Cell Function," Antioxid Redox Signal, 11(6):1373-414 , 2009.

[23] Stowe, D. F., Gadicherla, A. K., Zhou, Y., Aldakkak, M., Cheng, Q., Kwok, W. M., Jiang, M. T., Heisner, J. S., Yang, M., and Camara, A. K., "Protection Against Cardiac Injury by Small $\mathrm{Ca}(2+)$-Sensitive $\mathrm{K}(+)$ Channels Identified in Guinea Pig Cardiac Inner Mitochondrial Membrane," Biochim Biophys Acta, 1828(2):427-42, 2013 
[24] Aldakkak, M., Stowe, D. F., Dash, R. K., and Camara, A. K., "Mitochondrial Handling of Excess $\mathrm{Ca} 2+$ is Substrate-Dependent with Implications forReactive Oxygen Species Generation," Radic Biol Med, 11(6):1373-414, 2009.

[25] Blomeyer, C. A., Bazil, J. N., Stowe, D. F., Pradhan, R. K., Dash, R. K., and Camara, A. K., "Dynamic Buffering of Mitochondrial Ca2+ during Ca2+ Uptake and Na+-Induced Ca2+ Release," J Bioenerg Biomembr, 45(3):189-202, 2013.

[26] Boelens AD, Pradhan RK, Blomeyer CA, Camara AK, Dash RK, and Stowe DF., "Extra-Matrix Mg2+ Limits $\mathrm{Ca} 2+$ Uptake and Modulates $\mathrm{Ca} 2+$ UptakeIndependent Respiration and Redox State in Cardiac Isolated Mitochondria," $J$ Bioenerg Biomembr, 45(3):203-18, 2013.

[27] White, C. W., Ali, A., Hasanally, D., Xiang, B., Li, Y., Mundt, P., Lytwyn, M., Colah, S., Klein, J., Ravandi, A., Arora, R. C., Lee, T. W., Hryshko, L., Large S., Tian, G., and Freed, D. H., "A Cardioprotective Preservation Strategy Employing ex vivo Heart Perfusion Facilitates Successful Transplant of Donor Hearts after Cardiocirculatory Death," J Heart Lung Transplant, 32(7):734-43, 2013.

[28] Southard, J. H., and Belze, F. O. , "Organ Preservation," Annual Review of Medicine, Vol. 46: 235-247, 1995.

[29] Den Toom, R, De Jong M., Krenning E. P., Van Der Hoek, H. J., Ten Kate Fiebo, J. W., Hennemann, G., and Terpstra, O. T., "Euro-Collins Solution Versus UwSolution for Long-Term Liver Preservation in the Isolated Rat-Liver Perfusion Model," HPB Surg , 4(4): 313-320, 1991.

[30] Ploeg R. J., "Kidney Preservation with the UW and Euro-Collins Solutions. A Preliminary Report of a Clinical Comparison," Transplantation, 49(2):281-4, 1990.

[31] Demmy, T. L., Biddle, J. S., Bennett, L. E., Walls, J. T., Schmaltz, R. A., and Curtis, J. J., "Organ preservation Solutions in Heart Transplantation--Patterns of Usage and Related Survival," Transplantation, 63(2):262-9, 1997.

[32] Voigt, M. R., and Delario, G. T., "Perspectives on Abdominal Organ Preservation Solutions: a Comparative Literature Review," Prog Transplant, 23(4):383-91, 2013.

[33] Hermes, O., "Histidine-Tryptophan-Ketoglutarate," Publisher: Bellum Publishing, 2011.

[34] Li, L. B., Ma, L., Su, C., Zhang, T., and Gao, C. Q., "Low-Flow Perfusion Preservation versus Static Preservation for Isolated Rat Heart: Effects on Recovery of Myocardial Function," Transplant Proc, 45(2):523-7, 2013.

[35] O'Callaghan, J. M., Knight, S. R., Morgan, R. D., and Morris, P. J., "Preservation Solutions for Static Cold Storage of Kidney Allografts: a Systematic Review and Meta-Analysis," Am J Transplant, 12(4):896-906, 2012. 
[36] Feng, L., Zhao, N., Yao, X., Sun, X., Du, L., Diao, X., Li, S., and Li, Y., "Histidine-Tryptophan-Ketoglutarate Solution vs. University of Wisconsin Solution for Liver Transplantation: a Systematic Review," Liver Transpl, 13(8):1125-36, 2007.

[37] Rayya, F., Harms, J., Martin, A. P., Bartels, M., Hauss, J., and Fangmann, J., "Comparison of Histidine-Tryptophan-Ketoglutarate Solution and University of Wisconsin Solution in Adult Liver Transplantation," Transplant Proc, 40(4):891-4, 2008 .

[38] Reichenspurner, H., Russ, C., Wagner, F., Uberfuhr, P., Nollert, G., Weinhold, C., and Reichart, B., "Comparison of UW versus HTK Solution for Myocardial Protection in Heart Transplantation," Transpl Int, Suppl 1:S481-4, 1994.

[39] Gao, L., Hicks, M., and MacDonald, P. S. , "Improved Preservation of the Rat Heart with Celsior Solution Supplemented with Cariporide Plus Glyceryl Trinitrate," American Journal of Transplantation, 5: 1820-1826, 2005.

[40] Mühlbachera, F., Langera, F., and Mittermayera, C., "Preservation Solutions for Transplantation," Transplantation Proceedings, 31, 2069-2070, 1999.

[41] Southard, J. H., and Belzer, F. O., "Organ Preservation," Annual Rev Med, 46:23547, 1995.

[42] Dulikravich, G. S., "Inverse Design and Active Control Concepts in Strong Unsteady Heat Conduction," Applied Mechanics Reviews, Vol. 41, No. 6, pp. 270$277,1988$.

[43] Dulikravich, G. S., and Hayes, L. J. , "Control of Surface Temperatures to Optimize Survival in Cryopreservation," ASME Winter Annual Meeting, Chicago, Illinois, Proceedings of the Symposium on Computational Methods in Bioenginee, Nov. 27 - Dec.2, 1988.

[44] Dennis, B. H., and Dulikravich, G. S,, "Determination of Unsteady Container Temperatures During Freezing of Three-dimensional Organs With Constrained Thermal Stresses," International Symposium on Inverse Problems in Engineering Mechanics, ISIP'2k, , Elsevier (eds: M. Tanaka and G. S. Dulikravich), Nagano, Japan, March 7-10, 2000.

[45] Dennis, B. H., Eberhart, R. C., Dulikravich, G. S., and Radons, S. W., "FiniteElement Simulation of Cooling of Realistic 3-D Human Head and Neck," Journal of Biomechanical Engineering, 125(6):832-40, 2003.

[46] Neimark, M. A., Konstas, AA., Choi, J. H., Laine, A. F., and Pile-Spellman, J. , " Brain Cooling Maintenance with Cooling Cap Following Induction with Intracarotid Cold Saline Infusion: A Quantitative Model," Journal of Theoretical Biology, 253, 2008 . 
[47] Trunk, P., Gersak, B., and Trobec, R., "Topical Cardiac Cooling-Computer Simulation of Myocardial Temperature Changes," Computers in Biology and Medicine, 33 203-214, 2003.

[48] Trobec, R., Pipan, G., Gersak, B., "Parallel Simulation of Topical Heart Cooling," Parallel and Distributed Processing Symposium., Proceedings 15th International, 1530-2075, 23-27 April, 2000..

[49] National Library of Medicine, "Visible Human Data," National Library of Medicine, Bethesda,1997.

[50] Sterk, M., and Trobec, R., "Biomedical Simulation of Heat Transfer in a Human Heart," J Chem Inf Model , 45, 1558-1563, 2005.

[51] Trayanova, N. A., "Whole-Heart Modeling: Applications to Cardiac Electrophysiology and Electromechanics," Circ Res, 108:113-128, 2011.

[52] Prassl, A. J., Kickinger, F., Ahammer, H., Grau, V., Schneider, J. E., Hofer, E., Vigmond, E. J., Trayanova, N. A., Plank, G., "Automatically Generated, Anatomically Accurate Meshes for Cardiac Electrophysiology Problems," IEEE TRANSACTIONS ON BIOMEDICAL ENGINEERING, VOL. 56, NO. 5, 2009.

[53] Carson, J. P., Kuprat, A. P., Jiao, X., Dyedov, V., Del Pin, F., Johnson, G. A., Guccione, J. M., Ratcliffe, M. B., Einstein, D. R., "Adaptive Generation of Multimaterial Grids from Imaging Data for Biomedical Lagrangian Fluid-Structure Simulations," Biomech Model Mechanobiol, 9(2): 187-201, 2010.

[54] Einstein, D. R., Del Pin, F. Jiao, X., Kuprat, A. P., Carson, J. P., Kunzelman, K. S., Cochran, R. P., Guccione, J. M., and Ratcliffe, M. B., "Fluid-Structure Interactions of the Mitral Valve and Left Heart: Comprehensive Strategies, Past, Present and Future," Int J Numer Methods Eng, 26(3-4): 348-380, 2010.

[55] Zhang, Y., and Bajaj, C., "Finite Element Meshing for Cardiac Analysis," ICES Technical Report 04-26, University of Texas at Austin, 2004.

[56] Bajaj, C., Goswami, S., Yu, Z., Zhang,Y., Bazilevs,Y., and Hughes, T., "Patient Specific Heart Models from High Resolution CT," CompIMAGE. Coimbra, Portugal, October 20-21, 2006.

[57] Bajaj, C., and Goswami, S., "Modeling Cardiovascular Anatomy from PatientSpecific Imaging," Advances in Computational Vision and Medical Image Processing, ed. by J. Tavares and R. Jorge, Springer, 2008, Chapter 1, pgs 1-28, NIHMS155076.

[58] Bajaj, C., and Goswami, S., "Multi-Component Heart Reconstruction from Volumetric Imaging," Proceedings of the ACM Solid and Physical Modeling Symposium, Stony Brook, NY, pp. 193-202, 1364928, 2008. 
[59] Kisslo, J. A., and Adams, B. D., "Principles of Doppler Echocardiography and the Doppler Examination \#1," London: Ciba-geigy, 1987.

[60] Stein, P. D., and Sabbah, H. N., "Turbulent Blood Flow in the Ascending Aorta of Humans with Normal and Diseased Aortic Valves," Circulation Research, 1976; 39: 58-65.

[61] Pope, S. B., "Turbulent Flows," Cambridge University Press, 2000.

[62] Arunachalam, B. K., Millard, R. W., Kazmierczak, M. J., Rodriguez-Rilo, H. L., and Banerjee P. K., "Evaluation of Thermal Efficacy of Hypothermic Tissue Preservation Methods," Cell Preservation Technology, Vol. 4, 97-116, 2006.

[63] Ohayon, J. and Chadwick RS., "Effects of Collagen Microstructure on the Mechanics of the Left Ventricle," Biophys J, 54(6):1077-88, 1988.

[64] Hetnarski, R. B., and Eslami, M. R., "Thermal Stresses - Advanced Theory and Applications," Publisher Springer Netherlands, ISBN 978-1-4020-9246-6, 2009.

[65] Yamada, H., "Strength of Biological Materials," Williams \& Wilkins, ISBN-13: 978-0683093230, 1970.

[66] Park, J., and Lakes, R. S., "Biomaterials: An Introduction," Springer; 3rd edition, ISBN-13: 978-0387378794, 2007.

[67] Amini, A. A., and Prince J. L., "Measurement of Cardiac Deformations from MRI: Physical and Mathematical Models," Springer, 1st edition, ISBN-13: 9781402002229, 2001.

[68] Palmeri, M. L., and Nightingale, K. R., "On the Thermal Effects Associated with Radiation Force Imaging of Soft Tissue," IEEE Transactions on Ultrasonics, Ferroelectrics, and Frequency Control, vol. 51, no. 5, 2004.

[69] Hou, G., Wang, J., and Layton, A., "Numerical Methods for Fluid-Structure Interaction-A Review," Commun Comput Phys, pp. 337-377, 2012.

[70] Cambell, R. L., "Fluid-Structure Interaction and Inverse Design Simulations for Flexible Turbomachinery," Ph.D. Thesis, The Pennsylvania State University, 2010.

[71] Heil, M., "Stokes Flow in an Elastic Tube-a large-Displacement Fluid-Structure Interaction Problem," International J for Numerical Methods in Fluids, 28:243$265,1998$.

[72] Ishihara, D., and Yoshimura, S., "A Monolithic Approach for Interaction of Incompressible Viscous Fluid and an Elastic Body Based on Fluid Pressure Poisson Equation," International J for Numerical Methods in Engineering, 64:167-203, 2005. 
[73] Hübner, B., Walhorn, E., and Dinkler, D., "A Monolithic Approach to FluidStructure Interaction Using Space-Time Finite Elements," Computer Methods in Applied Mechanics and Engineering, 193(23-26):2087-2104, 2004.

[74] Slone, A., Pericleous, K., Bailey, C., Cross, M., and Bennett, C., "A Finite Volume Unstructured Mesh Approach to Dynamic Fluid-Structure Interaction: an Assessment of the Challenge of Predicting the Onset of Flutte," Applied Mathematical Modelling, 28(2):211-239, 2004.

[75] Farhat, C., Geuzaine, P., and Brown, G., "Application of a Three-Field Nonlinear Fluid-Structure Formulation to the Prediction of the Aeroelastic Parameters of an F-16 Fighter," Computers and Fluids, 32(1):3-29, 2003.

[76] Piperno, S., and Farhat, C., "Partitioned Procedures for the Transient Solution of Coupled Aeroelastic Problems-Part II: Energy Transfer Analysis and ThreeDimensional Applications," Computer Methods in Applied Mechanics and Engineering, 190(24-25):3147-3170, 2001.

[77] Peltola, J., Pättikangas, T., Brockmann, T., Siikonen, T.,Toppila, T., and Brandt T., "Adaptation and Validation of OpenFOAM ${ }^{\circ C F D-S o l v e r s ~ f o r ~ N u c l e a r ~ S a f e t y ~}$ Related Flow Simulations," SAFIR2010, 17.5.2011, CSC, Espoo, Finland, 2011.

[78] OpenCFD Ltd., "OpenFOAM," <http://www.opencfd.co.uk /openfoam/>, 20002013.

[79] Hinze, J.O., "Turbulence," McGraw-Hill, 1975.

[80] Muzaferija, S., "Adaptive Finite Volume Method for Flow Prediction Using Unstructured Meshes and Multigrid Approach," Ph.D. Thesis, Imperial College, University of London, 1994. .

[81] Jasak, H., "Error Analysis and Estimation for the Finite Volume Method with Applications to Fluid Flows," Ph.D. Thesis, Imperial College, University of London, 1996.

[82] Caretto, L., Curr, R. M., and Spalding, D. B., "Two Numerical Methods for ThreeDimensional Boundary Layers," Comp Methods Appl Mech Eng, 1:39, 1972..

[83] Vanka, S.P., "Block-Implicit Multigrid Solution of Navier-Stokes Equations in Primitive Variables," J Comp Physics, 65:138\{158, 1986.

[84] Patankar, S. V., and Baliga, B. R., "A New Finite-Difference Scheme for Parabolic Differential Equations," Numerical Heat Transfer, 1:27, 1978.

[85] Issa, R. I., "Solution of the Implicitly Discretized Fluid Flow Equations by Operator-Splitting," J Comp Physics, 62:40\{65, 1986.

[86] Ferziger, J. H., and Peric, M., "Computational Methods for Fluid Dynamics," Springer, 3rd Ed., 2001. 
[87] The Open Source CFD Toolbox, "Programmer's Guide," Version 2.2.2, 2013.

[88] Weller, H. G., Tabor, G., Jasak, H., and Fureby C. , "A Tensorial Approach to Computational Continuum Mechanics Using Object-Oriented Techniques," Computers in Physics, vol. 12, no. 6, pp. 620-631, 1998.

[89] AlOnazi, A. , "Design and Optimization of OpenFOAM-based CFD Applications for Modern Hybrid and Heterogeneous HPC Platforms," Uniersity College Dublin, M.Sc., 2013.

[90] Ferziger, J. H., and Peric, M. , "Computational Methods for Fluid Dynamics," Springer Berlin, vol. 3.,1996.

[91] Gropp, W. D., and Keyes, D. E. , "Domain Decomposition on Parallel Computers," Impact Comput Sci Eng, vol. 1, pp. 421-439, 1989.

[92] Jasak, H., "Handling Parallelisation in OpenFOAM," Cyprus Advanced HPC Workshop , Tracking: FH6190763 Feb, 2012.

[93] Karypis, G., and Kumar, V., "MeTis: Unstructured Graph Partitioning and Sparse Matrix Ordering System, Version 5.0," http://www.cs.umn.edu/ metis, University of Minnesota, Minneapolis, MN, 2013.

[94] Chevalier, C., and Pellegrini, F. , Parallel Comput, vol. 34, no. 6-8, pp. 318-331, 2008.

[95] Peura, R. A., "Medical Instrumentation," Wiley, Chapter 7, ISBN-10: 0471676004, 2009.

[96] Gisvold, S. E., and Brubakk, A. O., "Measurement of Instantaneous Blood-Flow Velocity in the Human Aorta Using Pulsed Doppler Ultrasound," Cardiovasc Res, 16 (1): 26-33, 1982.

[97] Wexler, L., Bergel, D. H., Gabe, I. T., Makin, G. S., and Mills, C. J., "Velocity of Blood Flow in Normal Human Venae Cavae," Cardiovasc Res, Circulation Research, Vol. XXIII, September 1968.

[98] Fry, D. L., "Acute Vascular Endothelial Changes Associated with Increased Blood Velocity Gradients," Circulation Research, 22: 165-197, 1968.

[99] Moore, J. E. Jr., Xu, C., Glagov, S., Zarins, C. K., Ku, D. N., "Fluid Wall Shear Stress Measurements in a Model of the Human Abdominal Aorta: Oscillatory Behavior and Relationship to Atherosclerosis," Atherosclerosis, 110(2):225-40, 1994.

[100] Oshinski, J. N., Ku, D. N., Mukundan, S. Jr., Loth, F., Pettigrew, R. I., "Determination of Wall Shear Stress in the Aorta with the Use of MR Phase Velocity Mapping," J Magn Reson Imaging , (6):640-71995, 1995. 
[101] Feldman, C. L., Ilegbusi, O. J., Hu, Z., Nesto, R., Waxman, S., Stone, P. H., "Determination of in Vivo Velocity and Endothelial Shear Stress Patterns with Phasic Flow in Human Coronary Arteries: A Methodology to Predict Progression of Coronary Atherosclerosis," American Heart Journal, Volume 143, Issue 6, Pages 931-939, 2002.

[102] Colaço, J. M., Dulikravich, G. S., "A Survey of Basic Deterministic, Heuristic and Hybrid Methods for Single-Objective Optimization and Response Surface Generation," Taylor \& Francis, Chapter 10 in Thermal Measurements and Inverse Techniques, (eds: Orlande, H. R. B., Fudym, O., Maillet, D. and Cotta, R.), Pages 355-405, 2011.

[103] ESTECO, "modeFRONTIER optimization software," http://www.esteco.com/modefrontier, 1999-2014.

[104] Deb, K., and Agrawal, R.B., "Simulated Binary Crossover for Continuous Search Space," Complex Systems, pp. 9, pp. 115, 1999.

[105] Deb, K., Pratap, A., Agarwal, S., and Meyarivan, T., "A Fast and Elitist MultiObjective Genetic Algorithm-NSGA-II," KanGAL Report Number 2000001, 2000.

[106] Abdoli, A. and Dulikravich, G. S., "Multi-Objective Design Optimization of Branching, Multifloor, Counterflow Microheat Exchangers," Journal of Heat Transfer, 136(10):101801-10.2014, DOI: 10.1115/1.4027911, 2014.

[107] Abdoli, A. and Dulikravich, G. S., "Optimized Multi-Floor Throughflow Micro Heat Exchangers," International Journal of Thermal Sciences, 78 (2014) 111e123, 2014. 
APPENDICES 
Appendix 1 - Gaussian Radial Basis Function's parameters in modeFRONTIER 
Some parameters must be defined for this algorithm [103]:

Training set: the designs set for Radial Basis Functions training. It is possible to choose between All Designs database and Only Marked Designs.

Exclude Error Designs: if selected, the algorithm discards those designs which present errors in one or more unselected variables (whether input or output). Designs which present errors in one or more selected variables are already automatically excluded from training.

Radial Functions: five different radial functions are available: Gaussians $(\mathrm{G})$, Duchon's Polyharmonic Splines (PS), Hardy's MultiQuadrics (MQ), Inverse MultiQuadrics (IMQ), and Wendland's Compactly Supported (W2).

Scaling Policy: the Automatic selection will let the algorithm to choose the proper scaling parameter value by means of minimization of the rms leave-one-out error (which costs -at most- ten repeated training of the RSM). On the contrary, if the User Defined choice is selected, the user has to define manually the value of the scaling parameter.

Maximum number of optimization steps: this field is significant if and only if the Automatic choice is selected, and defines the maximum number of attempts allowed for automatically tuning the scaling parameter. Whenever the optimization cannot start due to an ill-conditioned database, the algorithm will switch to a random search for a 
successful scaling value. This routine will be allowed to try at most a number of values equal to 10 times the number specified in this field.

Scaling Parameter: this field is significant if and only if the User Defined choice is selected, and defines the value of the scaling parameter.

Compute Leave-One-Out Errors: if this parameter is not selected, the computation of LOO errors will be skipped. Although this computation does not involve new linear system solutions, the time it may require increases more than linearly with respect to the training database size. If the Automatic Scaling Policy is selected, LOO errors are always computed.

Disable the robust Fail-Safe mode: if this parameter is selected, the training will not be done in the robust (but time consuming) fail-safe mode whenever the algorithm cannot finish the run in the regular way (for example, when the linear system is ill-conditioned). If the user-defined Scaling Policy is selected, the training will be interrupted in case of failures. Otherwise, if the automatic policy is running, the algorithm will sample new scaling values according to different criteria depending on the step in which the failure occurs. In case of problems occurring at the first attempt, the optimization cannot start and the algorithm will randomly try to generate at least one feasible scaling parameter. In case of problems occurring when the optimization is already under way, then the unfeasible value will be penalized and the routine will continue. In any case, the 
maximum number of sampled scaling parameters is controlled by the "Maximum number of optimization steps" parameter, as described above.

Variables Normalization: if Enabled (suggested default choice), input and output variables are normalized within the unitary interval. In this way the algorithm can deal also with different scaled variables. The Disabled option should be reserved only for cases in which variables have the same nature and the same scale.

Multi-threading Policy: it is possible to choose between two different policies: Use Maximum Number of Available Processors or User Defined. In fact the resolution of the linear systems involved in the training be carried out in parallel: in this way it is possible to take advantage of multi-core systems, reducing the total training time of the algorithm.

Number of Threads: this field is active only when the Multi-threading Policy is User Defined. This parameter determines the number of threads that will be used in multithreading training. The upper limit is automatically fixed to the number of processors/cores available on the local machine.

Save Leave-One-Out Errors File to Directory: it is possible to save the leave-one-out errors and values to a file, either in xls or in txt format. By pressing the File icon it is possible to choose the destination directory where the file will be created, and the file type. 
File Name Prefix: if the leave-one-out errors are saved to a file, with this field it is possible to choose a prefix for the file name. A progressive number will be set automatically as the suffix of the file name. 
VITA

\section{ABAS ABDOLI}

March 2008- Apr 2010

Oct 2005- March 2008

Oct 2001- July 2005

Karaj, Tehran, Iran
Research Assistant in Department of Physics Sharif University of Technology

Tehran, Iran

M.Sc. in Mechanical Engineering

Urmia University

Urmia, Iran

B.Sc. in Mechanical Engineering

Azad University, Karaj Beranch,

Karaj, Tehran, Iran

Diploma, Mathematics and Physics

Mirehee High School

Karaj, Tehran, Iran

\section{PUBLICATIONS AND PRESENTATIONS (SINCE 2013)}

Abdoli, A., Dulikravich, G. S., Bajaj, C., Stowe, D. F., and Jahania, M. S. (2014). Human Heart Conjugate Cooling Simulation: Unsteady Thermo-Fluid-Stress Analysis. International Journal of Numerical Methods in Biomedical Engineering, DOI: 10.1002/cnm.2662.

Abdoli, A., Dulikravich, G. S., Bajaj, C., Stowe, D. F., and Jahania, M. S. (2014). Simulation of Conjugate Cooling Preservation System for Human Hearts Destined for Transplantation. Submitted to the Journal of Heart and Lung Transplantation.

Abdoli, A., Dulikravich, G. S., Bajaj, C., Stowe, D. F., and Jahania, M. S. (2014). Thermo-Fluid Analysis of a Deceased a Human Heart during a Preservation Process Using Simultaneous Internal and External Liquid Cooling. Submitted to the International Journal of Numerical Methods in Heat and Fluid Flow (invited paper).

Abdoli, A., Dulikravich, G. S., Bajaj, C., Stowe, D. F., and Jahania, M. S. (2014). Simulation of Fully Conjugate Cooling Preservation System for Systems for Human Hearts Destined for Transplantation. BMES Annual Meeting, San Antonio, Texas, October 22-25.

Abdoli, A., Dulikravich, G. S., Bajaj, C., Stowe, D. F., and Jahania, M. S. (2014). Human Heart Cooling Simulations to Extend Its Useful Life for Transportation and Transplantation. CONEM2014, Uberlandia, Brazil, August 10-15. 
Abdoli, A., Dulikravich, G. S., Bajaj, C., Stowe, D. F., and Jahania, M. S. (2014). MultiDisciplinary Analysis of Cooling Protocols for Human Heart Destined for Transplantation", ThermaComp2014, Bled, Slovenia, June 2-4.

Abdoli, A., Dulikravich, G. S. (2014). Multi-Objective Design Optimization of Branching, Multifloor, Counterflow Microheat Exchangers. ASME Journal of Heat Transfer, 136(10):101801-10.2014, DOI: 10.1115/1.4027911.

Abdoli, A., Dulikravich, G. S. (2014). Optimized Multi-Floor Throughflow Micro Heat Exchangers. International Journal of Thermal Sciences, Volume 78, Pages 111-123.

Abdoli, A., Dulikravich, G. S., Vasquez, G., Rastkar, S. (2014). Thermo-Fluid-Stress Analysis in Microchannels Cooling of Electronics with Hot Spots. ThermaComp2014, Bled, Slovenia, June 2-4.

Abdoli, A., Dulikravich, G. S. (2013). Optimized Multi-Floor Throughflow Micro Heat Exchangers. paper IMECE2013-63590, ASME International Mechanical Engineering Congress and Exposition, San Diego, CA, November 15-20.

Abdoli, A., Dulikravich, G. S. (2013). Multi-Objective Design Optimization of MultiFloor, Counter Flow Micro Heat Exchangers. paper HT2013-17738, ASME Heat Transfer Conference, Minneapolis, MN, July 14-19.

Abdoli, A., Jimenez, G., and Dulikravich, G.S. (2014). Simulation of Influence of Cooling Fluid on Electric and Magnetic Fields in Microelectronic Systems with Integrated Through-Silicon Vias (TSVS). Submitted to the IEEE Transactions on Components, Packaging and Manufacturing Technology.

Abdoli, A., Jimenez, G., and Dulikravich, G.S. (2014). Thermo-Fluid Analysis of Single and Double Floor Integrated Through-Silicon Vias (TSVs) Cooling Configurations for High Heat Fluxes with a Hot Spot. Submitted to the International Journal of Thermal Sciences.

A. Abdoli, G. S. Dulikravich, G. Vasquez and Rastkar, S. (2014). Thermo-Fluid-Stress Analysis in Microchannels Cooling of Electronics with Hot Spots. Submitted to the ASME Journal of Electronic Packaging.

Reddy, S., Sobieczky, H., Dulikravich, G. S., and Abdoli A. (2014). Winglets Multiobjective Optimization of Aerodynamic Shapes. 11th World Congress of Computational Mechanics - WCCM XI, Barcelona, Spain, July 20-25.

Reddy, S., Dulikravich, G. S., Abdoli A., and Sobieczky, H. (2015). Multi-Winglets: Multiobjective Optimization of Aerodynamic Shapes. 53rd AIAA Aerospace Sciences Meeting, Kissimmee, Florida, 5 - 9 January. 